\title{
Antiplasmodial, antimalarial activities and toxicity of African medicinal plants: a systematic review of literature
}

Elahe Tajbakhsh' ${ }^{1}$, Tebit Emmanuel Kwenti ${ }^{2,3,4}$, Parya Kheyri ${ }^{5}$, Saeed Nezaratizade ${ }^{5}$, David S. Lindsay ${ }^{6}$ and Faham Khamesipour ${ }^{7,8^{*}}$ (1)

\begin{abstract}
Background: Malaria still constitutes a major public health menace, especially in tropical and subtropical countries. Close to half a million people mainly children in Africa, die every year from the disease. With the rising resistance to frontline drugs (artemisinin-based combinations), there is a need to accelerate the discovery and development of newer anti-malarial drugs. A systematic review was conducted to identify the African medicinal plants with significant antiplasmodial and/or anti-malarial activity, toxicity, as wells as assessing the variation in their activity between study designs (in vitro and in vivo).
\end{abstract}

Methods: Key health-related databases including Google Scholar, PubMed, PubMed Central, and Science Direct were searched for relevant literature on the antiplasmodial and anti-malarial activities of African medicinal plants.

Results: In total, 200 research articles were identified, a majority of which were studies conducted in Nigeria. The selected research articles constituted 722 independent experiments evaluating 502 plant species. Of the 722 studies, $81.9 \%, 12.4 \%$, and $5.5 \%$ were in vitro, in vivo, and combined in vitro and in vivo, respectively. The most frequently investigated plant species were Azadirachta indica, Zanthoxylum chalybeum, Picrilima nitida, and Nauclea latifolia meanwhile Fabaceae, Euphorbiaceae, Annonaceae, Rubiaceae, Rutaceae, Meliaceae, and Lamiaceae were the most frequently investigated plant families. Overall, 248 (34.3\%), 241 (33.4\%), and 233 (32.3\%) of the studies reported very good, good, and moderate activity, respectively. Alchornea cordifolia, Flueggea virosa, Cryptolepis sanguinolenta, Zanthoxylum chalybeum, and Maytenus senegalensis gave consistently very good activity across the different studies. In all, only $31(4.3 \%)$ of studies involved pure compounds and these had significantly $(p=0.044)$ higher antiplasmodial activity relative to crude extracts. Out of the 198 plant species tested for toxicity, 52 (26.3\%) demonstrated some degree of toxicity, with toxicity most frequently reported with Azadirachta indica and Vernonia amygdalina. These species were equally the most frequently inactive plants reported. The leaves were the most frequently reported toxic part of plants used. Furthermore, toxicity was observed to decrease with increasing antiplasmodial activity.

Conclusions: Although there are many indigenous plants with considerable antiplasmodial and anti-malarial activity, the progress in the development of new anti-malarial drugs from African medicinal plants is still slothful, with only one clinical trial with Cochlospermum planchonii (Bixaceae) conducted to date. There is, therefore, the need to scale up anti-malarial drug discovery in the African region.

Keywords: Malaria, Medicinal plants, Antiplasmodial activity, Antimalarial activity

\footnotetext{
*Correspondence: faham.khamesipour@yahoo.com

${ }^{7}$ Shahrekord Branch, Islamic Azad University, Shahrekord, Iran

Full list of author information is available at the end of the article
} original author(s) and the source, provide a link to the Creative Commons licence, and indicate if changes were made. The images or other third party material in this article are included in the article's Creative Commons licence, unless indicated otherwise in a credit line to the material. If material is not included in the article's Creative Commons licence and your intended use is not permitted by statutory regulation or exceeds the permitted use, you will need to obtain permission directly from the copyright holder. To view a copy of this licence, visit http://creativecommons.org/licenses/by/4.0/. The Creative Commons Public Domain Dedication waiver (http://creativeco mmons.org/publicdomain/zero/1.0/) applies to the data made available in this article, unless otherwise stated in a credit line to the data. 


\section{Background}

Malaria still constitutes a major public health menace, especially in tropical and subtropical countries. Various species of Plasmodium, transmitted through the bite of an infected female Anopheles mosquito, cause malaria, including Plasmodium falciparum, Plasmodium malariae, Plasmodium ovale, Plasmodium vivax, and Plasmodium knowlesi. Among these species, P. falciparum is the most virulent, responsible for the highest morbidity and mortality. It is also the predominant species in sub-Saharan Africa (SSA), a region with the highest number of malaria cases and deaths in the world. According to the World Health Organization (WHO), there were 228 million cases, and 405,000 malaria attributed deaths in 2018 [1]. In SSA, children and pregnant women are the most at-risk groups [1-3].

Malaria can be treated using chemotherapy but there is widespread resistance to many of the drugs. The first case of resistance to artemisinins was reported in Cambodia in 2006 and has then spread to most of SouthEast Asia [4, 5]. The safety of chemoprophylaxis is also a major concern; for instance, primaquine, atovaquone, and doxycycline are contraindicated in pregnant women and children [6]. All these shortcomings necessitate the discovery and production of new drugs to treat malaria.

In the past 50 years, natural compounds including plant products, have played a major role in drug discovery and have provided value to the pharmaceutical industry [7]. For instance, therapeutics for various infectious diseases, cancer, and other debilitation diseases caused by metabolic disorders have all benefitted from many drug classes that were initially developed based on active compounds from plant sources [8]. Furthermore, quinine and artemisinin, and their synthetic derivatives which are the mainstay of anti-malarial chemotherapy, were also derived from plant sources. In malaria-endemic areas, especially in Africa, many people rely on herbal medicines as the first line of treatment [9]. The common reasons for their preference vary from the cost of standard drugs, availability and accessibility, perceived effectiveness, low side effect, and faith in traditional medicines [10].

Reviews of the antiplasmodial and anti-malarial activities of medicinal plants are needed to drive research into the discovery and production of new anti-malarial drugs. Only a few reviews of the antiplasmodial or anti-malarial activity of medicinal plants have been published in the scientific literature [11-16]. These reviews focused only on studies with high antiplasmodial or anti-malarial activity and hardly report on their toxicity. The purpose of this study was to review medicinal plants with moderate to very good antiplasmodial and anti-malarial activities, as well as assess the variation in the activities between different methods. Furthermore, the toxicity of plant species is highlighted.

\section{Methods}

The literature was reviewed in search of scientific articles reporting antiplasmodial activities $\left(\mathrm{IC}_{50}, \mathrm{ED}_{50}, \mathrm{LD}_{50}\right.$, and parasite suppression rate) of medicinal plants used in Africa to treat malaria. The current study conforms to the Preferred Reporting Items for Systematic Reviews and Meta-analysis (PRISMA) guidelines [17].

\section{Search strategy and selection criteria}

Relevant articles were searched in health-related electronic databases including PubMed, PubMed Central, Google Scholar, and ScienceDirect using the keywords: Traditional herbs or Medicinal plants or Antiplasmodial activity or Antimalarial activity or Herbal medicine or Plasmodium.

The search was limited to studies published in English or containing at least an abstract written in English until May 2020. The titles and abstracts were subsequently examined by two reviewers, independently (parallel method) to identify articles reporting the antiplasmodial activity of medicinal plants. In the case of any discrepancy in their reports, a third reviewer was brought in to resolve the issue. Relevant papers were equally manually cross-checked to identify further references. The following data were extracted from the selected articles by the reviewers: plant species, plant family, place of collection of plant, parts of the plant used, type of study (whether in vitro, in vivo, or human), the extraction solvent used, $\mathrm{IC}_{50}$ or $\mathrm{ED}_{50}$ values, parasite suppression rate, isolated compounds, interaction with known malarial drugs (whether synergistic or antagonistic), and toxicity. Articles that did not report antiplasmodial or anti-malarial activity of medicinal plants as well as review articles were excluded. The entire selection process is presented in Fig. 1.

In this study, antiplasmodial activity pertains to studies performed in vitro using different strains of Plasmodium falciparum, meanwhile, anti-malarial activity is reserved for in vivo studies performed using mice and various parasite models (including Plasmodium berghei, Plasmodium yoelii, and Plasmodium chabaudi) and reporting parasite suppression rate.

\section{Categorization of antiplasmodial and anti-malarial activities}

For in vitro studies, the antiplasmodial activity of an extract was considered very good if $\mathrm{IC}_{50}<5 \mu \mathrm{g} / \mathrm{ml}$, good $5 \mu \mathrm{g} / \mathrm{ml} \leq \mathrm{IC}_{50}<10 \mu \mathrm{g} / \mathrm{ml}$, and moderate $10 \mu \mathrm{g} /$ $\mathrm{ml} \leq \mathrm{IC}_{50}<20 \mu \mathrm{g} / \mathrm{ml}[18]$. For in vivo studies, the antimalarial activity of an extract is considered very good if the suppression is $\geq 50 \%$ at $100 \mathrm{mg} / \mathrm{kg}$ body weight/ day, good if the suppression is $\geq 50 \%$ at $250 \mathrm{mg} / \mathrm{kg}$ body weight/day, and moderate if the suppression is $\geq 50 \%$ at $500 \mathrm{mg} / \mathrm{kg}$ body weight/day [18]. Antiplasmodial activities of $20 \mu \mathrm{g} / \mathrm{ml}$ and above for in vitro studies and 


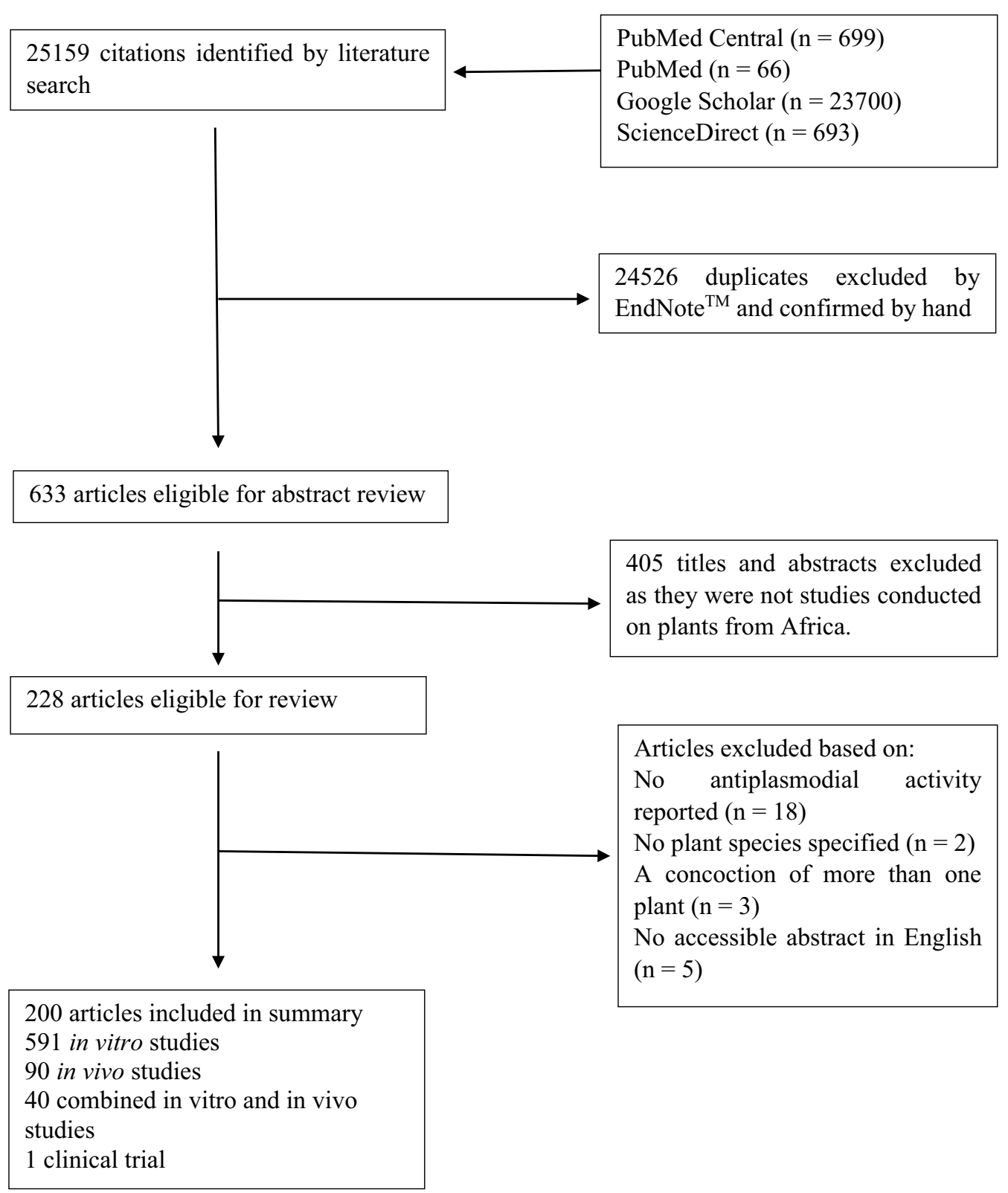

Fig. 1 Flowchart of the selection process for publications included in this review

anti-malarial $\geq 50 \%$ at $>500 \mathrm{mg} / \mathrm{kg}$ body weight/day for in vivo studies, were considered inactive.

\section{Risk of bias in individual studies}

The level of risk of bias for the study was likely to be high mainly because of differences in the studies and the methods used to determine the antiplasmodial or anti-malarial activity. The stains of Plasmodium used to assess the antiplasmodial or anti-malarial activity of the medicinal plants equally varied between studies. Furthermore, the extraction solvent, as well as the extraction yield of the plants in the different studies, was not the same, which may have accounted for the variation in the antiplasmodial and anti-malarial activities for the same plants but in the different studies.

\section{Results}

The PRISMA flowchart (Fig. 1) presents a four-phase study selection process in the present systematic review study. A total of 25,159 titles were identified in the initial search. After the title and abstract screening, 228 full-text 
articles were retrieved. Of these, a final 200 articles were identified for the review.

For this review, the evaluation of the individual plant species was considered as an independent study, so it is common for one article to have more than one study depending on the number of plant species evaluated. In all, there were 722 independent studies. Five hundred and ninety-on (81.9\%) of the independent studies were in vitro (Table 1), 90 (12.4\%) were in vivo (Table 2) and $40(5.5 \%)$ were both in vitro and in vivo (Table 3$)$. There was only one human study (clinical trial) conducted so far (Table 4). The selected research articles were from 31 African countries. Out of the 200 research articles reviewed, most of them were from Nigeria 58 (29.0\%), Kenya 24 (12.0\%), Ethiopia 13 (6.5\%), Cameroon 12 (6.0\%), Ivory Coast 11 (5.5\%), D.R. Congo 10 (5.0\%), and Burkina Faso 7 (3.5\%) (Fig. 2). The studies cover the period from 1989 to 2020 .

\section{Family and species distribution of plants evaluated}

From 722 studies, the most frequent plant families studied included Fabaceae 47 (6.5\%), Euphorbiaceae 45 (6.2\%), Annonaceae 37 (5.1\%), Rubiaceae 37 (5.1\%), Rutaceae 37 (5.1\%), Meliaceae 30 (4.2\%), and Lamiaceae 12 (1.7\%). Five hundred and two (502) plant species were investigated in this study. Of them, the most investigated were: Azadirachta indica, Zanthoxylum chalybeum, Picrilima nitida, and Nauclea latifolia. The most frequent parts of the plants tested were the leaves, roots, root barkss, stems, and the whole plant. A majority of the studies used the crude extracts of the plants compared to pure compounds ( $95.7 \%$ vs. $4.3 \%)$. In descending order, methanol 322 (44.7\%), dichloromethane 207 (28.7\%), ethanol 103 (14.3\%), water 85 (11.7\%) and ethyl acetate $62(8.6 \%)$ were the most frequent extraction solvent used.

\section{In vitro and in vivo activities of the plants evaluated}

Overall, 248 (34.3\%) of the studies reported activity that was very good $\left(\mathrm{IC}_{50}\right.$ values $<5 \mu \mathrm{g} / \mathrm{ml}$ or suppression rate of $\geq 50 \%$ at $100 \mathrm{mg} / \mathrm{kg}$ body weight/day), 241 (33.4\%) reported good activity and $233(32.3 \%)$ reported moderate activity. For the in vitro studies, a majority 228 (38.6\%) reported very good activity; 206 (34.9\%) reported good activity and 187 (31.6\%) reported moderate activity. Meanwhile for the in vivo studies, a majority 19 (21.1\%) reported moderate activity, $16(17.8 \%)$ reported very good activity and 13 (14.4\%) reported good activity. For studies reporting both the in vitro and in vivo activity, a majority of 17 (42.5\%) reported only moderate activity, 13 (32.5\%) studies reported very good activity and 10 (25.0\%) reported good activity. Among the plants with very good activity, only one species demonstrated very good activity both in vitro and in vivo (Table 3 ).

Among the studies, the most frequent plant species demonstrating very good antiplasmodial activity were: Alchornea cordifolia [3/3, 100\%], Flueggea virosa [3/3, $100 \%]$, Cryptolepis sanguinolenta [3/4,75\%], Zanthoxylum chalbeum [4/5, 80\%] and Maytenus senegalensis [3/6, 50\%]. Plant families with the most active species include Rutaceae [13/25, 52.0\%], Apocynaceae [13/26, 50\%], Celastraceae [7/15, 46.7\%], Annonaceae [17/37, 45.9\%], Euphorbiaceae [21/48, 43.8], Combretaceae [7/16, 43.8\%], Fabaceae [18/47, 38.3\%], Lamiaceae [8/23, 34.8\%], Asteraceae $[23 / 69,33.3 \%]$, and Rubiaceae [8/37, 21.6\%]. The fractions are derived from the count of studies reporting very good antiplasmodial activity (numerator) divided by the total number of studies that assessed the activity of that plant species (denominator).

Azadirachta indica and Vernonia amygdalina were the most frequently reported inactive species (Additional file 1: Table S1). Furthermore, Fabaceae, Rubiaceae, Euphorbiaceae, and Asteraceae were the plant families containing the most frequently reported inactive plants. A majority of $95.7 \%(691 / 722)$ of the studies used the crude extract of the plants. The antiplasmodial and/or anti-malarial activity was significantly higher $(\mathrm{p}=0.044)$ in studies using pure compounds compared to those using crude preparations.

\section{Toxicity of plants evaluated for their antiplasmodial and anti-malarial activity}

Out of the 198 plants evaluated in toxicity assays, 52 (26.3\%) were found to demonstrate some degree of toxicity. The most frequently reported plants with toxicity were Azadirachta indica and Vernonia amygdalina. Plant families harboring the most toxic species were Lamiaceae, Anacardiaceae, Moraceae, Meliaceae, Asteraceae, and Fabaceae. Approximately $33 \%$ of the plants tested demonstrated some toxicity in vitro and $26.7 \%$ had some degree of toxicity in vivo. Among plants with very good, good, and moderate antiplasmodial activity, 17.8\%, 28.3\%, and $35.4 \%$ had some degree of toxicity, respectively. The leaf was the plant part with the most frequently reported toxicity. Albino mice and Vero E6 cells were the most commonly used assays for the assessment of the toxicity of the plants.

\section{Discussion}

Resistance to the frontline anti-malarial drugs is increasing and is now a global concern. With this rising rate of resistance, there is a need to accelerate research into the discovery and development of new anti-malarial drugs. Unfortunately, from this study, it is evident that the progress into the discovery of a new anti-malarial drug in 
Table 1 In vitro antiplasmodial activity of African medicinal plants

\begin{tabular}{|c|c|c|c|c|c|c|c|c|c|}
\hline Plant species & Plant family & Source & $\begin{array}{l}\text { Country } \\
\text { of study }\end{array}$ & $\begin{array}{l}\text { Part of } \\
\text { plant } \\
\text { used }\end{array}$ & $\begin{array}{l}\text { Extraction } \\
\text { solvent }\end{array}$ & $\begin{array}{l}\text { Antiplas- } \\
\text { modial } \\
\text { Activity }\end{array}$ & $\begin{array}{l}\mathrm{IC}_{50} \text { or } \mathrm{ED}_{50} \\
\text { or } \mathrm{LD}_{50}\end{array}$ & $\begin{array}{l}\text { Strain of } \\
\text { Plasmodium } \\
\text { Tested }\end{array}$ & $\begin{array}{l}\text { Toxicity (value; } \\
\text { assay) }\end{array}$ \\
\hline $\begin{array}{l}\text { Dicoma anomala } \\
\text { subsp. Gerrardii }\end{array}$ & Compositae & [19] & $\begin{array}{l}\text { South } \\
\text { Africa }\end{array}$ & $\begin{array}{l}\text { Whole } \\
\text { plant }\end{array}$ & $\begin{array}{l}\text { Methanol, Water, } \\
\text { Hexane, Dichlo- } \\
\text { romethane }\end{array}$ & $\begin{array}{l}\text { Very } \\
\text { good }^{a}\end{array}$ & $1.865 \mu \mathrm{M} I \mathrm{C}_{50}$ & $\begin{array}{l}\text { Plasmodium falcipa- } \\
\text { rum 3D7, D10 }\end{array}$ & $\mathrm{Nd}$ \\
\hline $\begin{array}{l}\text { Abutilon grandi- } \\
\text { florum }\end{array}$ & Malvaceae & [20] & Tanzania & Roots & Ethyl Acetate & Moderate & $10 \mu \mathrm{g} / \mathrm{ml} \mathrm{IC}_{50}$ & $\begin{array}{l}\text { Plasmodium falcipa- } \\
\quad \text { rum K1 }\end{array}$ & $\mathrm{Nd}$ \\
\hline Acacia mellifera & Fabaceae & [21] & Kenya & $\begin{array}{l}\text { Inner } \\
\text { Barks }\end{array}$ & Methanol & Very Good & $\begin{array}{l}4.48 \mu \mathrm{g} / \mathrm{ml} \\
\mathrm{IC}_{50}\end{array}$ & $\begin{array}{l}\text { Plasmodium falcipa- } \\
\text { rum D6 }\end{array}$ & No \\
\hline \multirow[t]{2}{*}{ Acacia nilotica } & \multirow[t]{2}{*}{ Fabaceae } & [22] & $\begin{array}{l}\text { South } \\
\text { Africa }\end{array}$ & Twigs & $\begin{array}{l}\text { Dichlorometh- } \\
\text { ane/Methanol }\end{array}$ & Moderate & $13 \mu \mathrm{g} / \mathrm{ml} \mathrm{IC_{50 }}$ & $\begin{array}{l}\text { Plasmodium falcipa- } \\
\text { rum D10 }\end{array}$ & $\mathrm{Nd}$ \\
\hline & & [23] & Sudan & Seeds & Methanol & Very Good & $\begin{array}{l}0.9-4.1 \mu \mathrm{g} / \mathrm{ml} \\
\mid \mathrm{C}_{50}\end{array}$ & $\begin{array}{l}\text { Plasmodium falcipa- } \\
\text { rum 3D7, Dd2 }\end{array}$ & No \\
\hline $\begin{array}{l}\text { Acacia polya- } \\
\text { cantha }\end{array}$ & Fabaceae & {$[20]$} & Tanzania & $\begin{array}{l}\text { Root } \\
\text { Barkss }\end{array}$ & Ethyl Acetate & Moderate & $13 \mu \mathrm{g} / \mathrm{ml} / \mathrm{C}_{50}$ & $\begin{array}{l}\text { Plasmodium falcipa- } \\
\text { rum K1 }\end{array}$ & $\mathrm{Nd}$ \\
\hline \multirow[t]{2}{*}{ Acacia tortilis } & \multirow[t]{2}{*}{ Fabaceae } & [24] & Kenya & $\begin{array}{l}\text { Stem } \\
\text { Barks }\end{array}$ & Methanol & Moderate & $\begin{array}{l}13.4 \mu \mathrm{g} / \mathrm{ml} \\
\mathrm{IC}_{50}\end{array}$ & $\begin{array}{l}\text { Plasmodium falcipa- } \\
\text { rum D6, W2 }\end{array}$ & $\mathrm{Nd}$ \\
\hline & & [22] & $\begin{array}{l}\text { South } \\
\text { Africa }\end{array}$ & $\begin{array}{l}\text { Whole } \\
\text { Plant }\end{array}$ & $\begin{array}{l}\text { Dichlorometh- } \\
\text { ane/Methanol }\end{array}$ & Very Good & $4.8 \mu \mathrm{g} / \mathrm{ml} \mathrm{I} \mathrm{C}_{50}$ & $\begin{array}{l}\text { Plasmodium falcipa- } \\
\text { rum D10 }\end{array}$ & $\mathrm{Nd}$ \\
\hline \multirow[t]{2}{*}{$\begin{array}{l}\text { Acacia xanthop- } \\
\text { loea }\end{array}$} & \multirow[t]{2}{*}{ Fabaceae } & [25] & $\begin{array}{l}\text { South } \\
\text { Africa }\end{array}$ & $\begin{array}{l}\text { Stem } \\
\text { Barks }\end{array}$ & Acetone & Moderate & $\begin{array}{l}10.1 \mu \mathrm{g} / \mathrm{ml} \\
\mathrm{I}_{50}\end{array}$ & $\begin{array}{l}\text { Plasmodium falcipa- } \\
\text { rum UP1 (CQ-R) }\end{array}$ & $\mathrm{Nd}$ \\
\hline & & [24] & Kenya & $\begin{array}{l}\text { Stem } \\
\text { Barks }\end{array}$ & Methanol & Moderate & $\begin{array}{l}17.3 \mu \mathrm{g} / \mathrm{ml} \\
\mathrm{I}_{50}\end{array}$ & $\begin{array}{l}\text { Plasmodium falcipa- } \\
\text { rum D6, W2 }\end{array}$ & $\mathrm{Nd}$ \\
\hline Acacia mellifera & Fabaceae & [24] & Kenya & $\begin{array}{l}\text { Stem } \\
\text { Barks }\end{array}$ & Methanol & Moderate & $\begin{array}{l}12.3 \mu \mathrm{g} / \mathrm{ml} \\
\mathrm{I}_{50}\end{array}$ & $\begin{array}{l}\text { Plasmodium falcipa- } \\
\text { rum D6, W2 }\end{array}$ & $\mathrm{Nd}$ \\
\hline $\begin{array}{l}\text { Amorpha fruti- } \\
\text { cosa }\end{array}$ & Euphorbiaceae & [26] & Kenya & Leaves & Methanol & Moderate & $\begin{array}{l}13.8 \mu \mathrm{g} / \mathrm{ml} \\
\mathrm{IC}_{50}\end{array}$ & $\begin{array}{l}\text { Plasmodium falcipa- } \\
\text { rum D6, W2 }\end{array}$ & $\mathrm{Nd}$ \\
\hline $\begin{array}{l}\text { Acampe pachy- } \\
\text { glossa }\end{array}$ & Orchidaceae & [20] & Kenya & Leaves & Ethyl Acetate & Moderate & $11 \mu \mathrm{g} / \mathrm{ml} \mathrm{IC}_{50}$ & $\begin{array}{l}\text { Plasmodium falcipa- } \\
\text { rum K1 }\end{array}$ & $\mathrm{Nd}$ \\
\hline \multirow{3}{*}{$\begin{array}{l}\text { Acanthosper- } \\
\text { mum hispidum } \\
\text { DC }\end{array}$} & \multirow{3}{*}{ Compositae } & [27] & $\begin{array}{l}\text { Burkina } \\
\text { Faso }\end{array}$ & $\begin{array}{l}\text { Stems, } \\
\text { Leaves }\end{array}$ & Crude Alkaloid & Good & $\begin{array}{l}4-10 \mu \mathrm{g} / \mathrm{ml} \\
\mid \mathrm{C}_{50}\end{array}$ & $\begin{array}{l}\text { Plasmodium falcipa- } \\
\text { rum W2 }\end{array}$ & $\mathrm{Nd}$ \\
\hline & & {$[28]$} & Ivory Coast & $\begin{array}{l}\text { Stems } \\
\text { and } \\
\text { Leaves }\end{array}$ & Ethanol & Moderate & $\begin{array}{l}13.7 \mu \mathrm{g} / \mathrm{ml} \\
\mathrm{IC}_{50}\end{array}$ & $\begin{array}{l}\text { Plasmodium } \\
\text { falciparum Fcb1/ } \\
\text { Colombia Strain }\end{array}$ & $\mathrm{Nd}$ \\
\hline & & [29] & $\begin{array}{l}\text { Republic of } \\
\text { Congo }\end{array}$ & Leaves & $\begin{array}{l}\text { Methanolic, } \\
\text { Ethanol }\end{array}$ & Very Good & $2.8 \mu \mathrm{g} / \mathrm{ml} \mathrm{IC_{50 }}$ & $\begin{array}{l}\text { Plasmodium falci- } \\
\text { parum }\end{array}$ & No \\
\hline $\begin{array}{l}\text { Achyranthes } \\
\text { aspera }\end{array}$ & Amaranthaceae & [22] & $\begin{array}{l}\text { South } \\
\text { Africa }\end{array}$ & $\begin{array}{l}\text { Whole } \\
\text { plant }\end{array}$ & $\begin{array}{l}\text { Dichlorometh- } \\
\text { ane/Methanol }\end{array}$ & Good & $9.9 \mu \mathrm{g} / \mathrm{ml} \mathrm{IC_{50 }}$ & $\begin{array}{l}\text { Plasmodium falcipa- } \\
\text { rum D10 }\end{array}$ & $\mathrm{Nd}$ \\
\hline $\begin{array}{l}\text { Acmella cau- } \\
\text { lirhiza }\end{array}$ & Compositae & [30] & Kenya & $\begin{array}{l}\text { Whole } \\
\text { plant }\end{array}$ & Dichloromethane & Good & $\begin{array}{l}\text { 5.201- } \\
\quad 9.939 \mu \mathrm{g} / \mathrm{ml} \\
\mathrm{IC}_{50}\end{array}$ & $\begin{array}{l}\text { Plasmodium falcipa- } \\
\text { rum W2, D6 }\end{array}$ & $\mathrm{Nd}$ \\
\hline $\begin{array}{l}\text { Acridocarpus } \\
\text { chloropterus }\end{array}$ & Malpighiaceae & [31] & Tanzania & Roots & Dichloromethane & Good & $\begin{array}{l}5.06 \mu \mathrm{g} / \mathrm{ml} \\
\mathrm{IC}_{50}\end{array}$ & $\begin{array}{l}\text { Plasmodium falcipa- } \\
\text { rum K1 }\end{array}$ & No \\
\hline $\begin{array}{l}\text { Achyranthes } \\
\text { aspera }\end{array}$ & Amaranthaceae & [20] & Tanzania & $\begin{array}{l}\text { Root } \\
\text { barks }\end{array}$ & Ethyl Acetate & Very Good & $3 \mu \mathrm{g} / \mathrm{ml} \mathrm{IC} \mathrm{C}_{50}$ & $\begin{array}{l}\text { Plasmodium falcipa- } \\
\text { rum K1 }\end{array}$ & $\mathrm{Nd}$ \\
\hline $\begin{array}{c}\text { Adansonia } \\
\text { digitata }\end{array}$ & Malvaceae & [20] & Kenya & $\begin{array}{l}\text { Stem } \\
\text { barks }\end{array}$ & Ethyl Acetate & Good & $8.2 \mu \mathrm{g} / \mathrm{ml} \mathrm{IC_{50 }}$ & $\begin{array}{l}\text { Plasmodium falcipa- } \\
\quad \text { rum K1 }\end{array}$ & $\mathrm{Nd}$ \\
\hline $\begin{array}{l}\text { Adenia cissampe- } \\
\text { loides }\end{array}$ & - Passifloraceae & [32] & Ghana & $\begin{array}{l}\text { Whole } \\
\text { plant }\end{array}$ & Ethanol & Good & $\begin{array}{l}8.521 \mu \mathrm{g} / \mathrm{ml} \\
\mathrm{IC}_{50}\end{array}$ & $\begin{array}{l}\text { Plasmodium falcipa- } \\
\text { rum 3D7 }\end{array}$ & $\mathrm{Nd}$ \\
\hline $\begin{array}{l}\text { Adhatoda lati- } \\
\text { bracteata }\end{array}$ & Acanthaceae & {$[33]$} & Gabon & Stems & Dichloromethane & Very Good & $\begin{array}{l}0.7-1.6 \mu \mathrm{g} / \mathrm{ml} \\
\mid \mathrm{C}_{50}\end{array}$ & $\begin{array}{l}\text { Plasmodium falcipa- } \\
\text { rum Fcbm W2 }\end{array}$ & No \\
\hline Aervajavanica & Amaranthaceae & [34] & Sudan & $\begin{array}{l}\text { Whole } \\
\text { plant }\end{array}$ & $\begin{array}{l}\text { Petroleum Ether/ } \\
\text { Chloroform }\end{array}$ & Very Good & $<5 \mu \mathrm{g} / \mathrm{ml} \mathrm{IC} C_{50}$ & $\begin{array}{l}\text { Plasmodium falci- } \\
\text { parum }\end{array}$ & $\mathrm{Nd}$ \\
\hline Aerva lanata & Amaranthaceae & [20] & Tanzania & $\begin{array}{l}\text { Whole } \\
\text { plant }\end{array}$ & Ethyl Acetate & Good & $8.6 \mu \mathrm{g} / \mathrm{ml} \mathrm{IC} 50$ & $\begin{array}{l}\text { Plasmodium falcipa- } \\
\text { rum K1 }\end{array}$ & $\mathrm{Nd}$ \\
\hline $\begin{array}{l}\text { Aframomum } \\
\text { giganteum }\end{array}$ & Zingiberaceae & [33] & Gabon & Stems & Dichloromethane & Moderate & $\begin{array}{l}8.3-13.5 \mu \mathrm{g} / \\
\mathrm{ml} \mathrm{IC_{50 }}\end{array}$ & $\begin{array}{l}\text { Plasmodium falcipa- } \\
\text { rum Fcbm W2 }\end{array}$ & No \\
\hline
\end{tabular}


Table 1 (continued)

\begin{tabular}{|c|c|c|c|c|c|c|c|c|c|}
\hline Plant species & Plant family & Source & $\begin{array}{l}\text { Country } \\
\text { of study }\end{array}$ & $\begin{array}{l}\text { Part of } \\
\text { plant } \\
\text { used }\end{array}$ & $\begin{array}{l}\text { Extraction } \\
\text { solvent }\end{array}$ & $\begin{array}{l}\text { Antiplas- } \\
\text { modial } \\
\text { Activity }\end{array}$ & $\begin{array}{l}\mathrm{IC}_{50} \text { or } \mathrm{ED}_{50} \\
\text { or } \mathrm{LD}_{50}\end{array}$ & $\begin{array}{l}\text { Strain of } \\
\text { Plasmodium } \\
\text { Tested }\end{array}$ & $\begin{array}{l}\text { Toxicity (value; } \\
\text { assay) }\end{array}$ \\
\hline $\begin{array}{r}\text { Agathosma } \\
\text { apiculata }\end{array}$ & Rutaceae & [22] & $\begin{array}{l}\text { South } \\
\text { Africa }\end{array}$ & $\begin{array}{l}\text { Whole } \\
\text { plant }\end{array}$ & $\begin{array}{l}\text { Dichlorometh- } \\
\text { ane/Methanol }\end{array}$ & Good & $5.2 \mu \mathrm{g} / \mathrm{ml} \mathrm{IC}{ }_{50}$ & $\begin{array}{l}\text { Plasmodium falcipa- } \\
\text { rum D10 }\end{array}$ & $\mathrm{Nd}$ \\
\hline \multirow[t]{2}{*}{$\begin{array}{l}\text { Ageratum cony- } \\
\text { zoides }\end{array}$} & Compositae & [24] & Kenya & $\begin{array}{l}\text { Whole } \\
\text { plant }\end{array}$ & Methanol & Moderate & $\begin{array}{l}11.5-12.1 \mu \mathrm{g} / \\
\mathrm{ml} \mathrm{IC}_{50}\end{array}$ & $\begin{array}{l}\text { Plasmodium falcipa- } \\
\text { rum D6, W2 }\end{array}$ & $\mathrm{Nd}$ \\
\hline & & [30] & Kenya & $\begin{array}{l}\text { Whole } \\
\text { plant }\end{array}$ & Dichloromethane & Very Good & 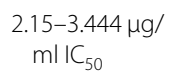 & $\begin{array}{l}\text { Plasmodium falcipa- } \\
\text { rum W2, D6 }\end{array}$ & $\mathrm{Nd}$ \\
\hline \multirow[t]{2}{*}{ Ajuga remota } & Lamiaceae & {$[35]$} & Kenya & Ns & Ns & Good $^{\mathrm{a}}$ & $8.2 \mu \mathrm{M} I \mathrm{C}_{50}$ & $\begin{array}{l}\text { Plasmodium falcipa- } \\
\text { rum FCA 20/GHA }\end{array}$ & No \\
\hline & & [35] & Kenya & $\begin{array}{l}\text { Aerial } \\
\text { parts }\end{array}$ & Chloroform & Good & $8.2 \mu \mathrm{g} / \mathrm{ml} \mathrm{IC_{50 }}$ & $\begin{array}{l}\text { Plasmodium falcipa- } \\
\text { rum FCA 20/GHA }\end{array}$ & No \\
\hline Alafia barteri & Apocynaceae & {$[36]$} & Nigeria & Leaves & Water & Very Good & $1.5 \mu \mathrm{g} / \mathrm{ml} \mathrm{IC_{50 }}$ & $\begin{array}{l}\text { Plasmodium falci- } \\
\text { parum }\end{array}$ & $\mathrm{Nd}$ \\
\hline \multirow[t]{2}{*}{ Albizia coriaria } & Fabaceae & [30] & Kenya & $\begin{array}{l}\text { Stem } \\
\text { barks }\end{array}$ & Dichloromethane & Good & 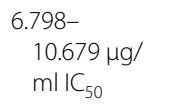 & $\begin{array}{l}\text { Plasmodium falcipa- } \\
\text { rum W2, D6 }\end{array}$ & $\mathrm{Nd}$ \\
\hline & & [24] & Kenya & $\begin{array}{l}\text { Stem } \\
\text { barks }\end{array}$ & Methanol & Moderate & $\begin{array}{l}15.2-16.8 \mu \mathrm{g} / \\
\mathrm{ml} \mathrm{C}_{50}\end{array}$ & $\begin{array}{l}\text { Plasmodium falcipa- } \\
\text { rum D6, W2 }\end{array}$ & $\mathrm{Nd}$ \\
\hline \multirow[t]{2}{*}{$\begin{array}{l}\text { Albizia gum- } \\
\text { mifera }\end{array}$} & Fabaceae & [24] & Kenya & $\begin{array}{l}\text { Stem } \\
\text { barks }\end{array}$ & Methanol & Good & $6.7 \mu \mathrm{g} / \mathrm{ml} \mathrm{I} \mathrm{C}_{50}$ & $\begin{array}{l}\text { Plasmodium falcipa- } \\
\text { rum D6, W2 }\end{array}$ & $\mathrm{Nd}$ \\
\hline & & {$[20]$} & Tanzania & $\begin{array}{l}\text { Stem } \\
\text { barks }\end{array}$ & Ethyl Acetate & Moderate & $15 \mu \mathrm{g} / \mathrm{ml} / \mathrm{I}_{50}$ & $\begin{array}{l}\text { Plasmodium falcipa- } \\
\text { rum K1 }\end{array}$ & $\mathrm{Nd}$ \\
\hline $\begin{array}{l}\text { Albizia versicolor } \\
\text { Welw.ex Oliv }\end{array}$ & Fabaceae & {$[37]$} & $\begin{array}{l}\text { South } \\
\text { Africa }\end{array}$ & Roots & Dichloromethane & Very Good & $\begin{array}{l}2.12 \mu \mathrm{g} / \mathrm{ml} \\
\mathrm{IC}_{50}\end{array}$ & $\begin{array}{l}\text { Plasmodium falcipa- } \\
\text { rum NF54 }\end{array}$ & $\mathrm{Nd}$ \\
\hline \multirow[t]{3}{*}{$\begin{array}{l}\text { Alchornea } \\
\text { cordifolia }\end{array}$} & Euphorbiaceae & {$[38]$} & Ivory Coast & Leaves & Ethanol & $\begin{array}{l}\text { Very } \\
\text { Good }^{a}\end{array}$ & $\begin{array}{l}0.2-0.5 \mu \mathrm{M} \\
\mathrm{IC}_{50}\end{array}$ & $\begin{array}{l}\text { Plasmodium } \\
\text { falciparum Fcm29 } \\
\text { Cameroon And } \\
\text { Nigerian Strain }\end{array}$ & No \\
\hline & & [39] & Ivory Coast & $\begin{array}{l}\text { Stems, } \\
\text { leaves }\end{array}$ & $\begin{array}{l}\text { Water, Ethanol, } \\
\text { Pentane }\end{array}$ & Very Good & $\begin{array}{l}2.43-4.56 \mu \mathrm{g} / \\
\mathrm{ml} \mathrm{IC} \mathrm{C}_{50}\end{array}$ & $\begin{array}{l}\text { Plasmodium } \\
\text { falciparum Fcm29, } \\
\text { Fcb1, Plasmodium } \\
\text { falciparum CQ-S } \\
\text { (Nigerian) }\end{array}$ & No \\
\hline & & {$[40]$} & D.R.Congo & Leaves & Water & Very Good & $\begin{array}{l}4.84 \mu \mathrm{g} / \mathrm{ml} \\
\mid \mathrm{C}_{50}\end{array}$ & $\begin{array}{l}\text { Plasmodium falcipa- } \\
\text { rum K1 }\end{array}$ & No \\
\hline $\begin{array}{l}\text { Alepidea amat- } \\
\text { ymbica }\end{array}$ & Apiaceae & [22] & $\begin{array}{l}\text { South } \\
\text { Africa }\end{array}$ & $\begin{array}{l}\text { Whole } \\
\text { plant }\end{array}$ & $\begin{array}{l}\text { Dichlorometh- } \\
\text { ane/Methanol }\end{array}$ & Moderate & $\begin{array}{l}12.5 \mu \mathrm{g} / \mathrm{ml} \\
\mathrm{I}_{50}\end{array}$ & $\begin{array}{l}\text { Plasmodium falcipa- } \\
\text { rum D10 }\end{array}$ & $\mathrm{Nd}$ \\
\hline Aloe marlothii & $\begin{array}{l}\text { Xanthor- } \\
\text { rhoeaceae }\end{array}$ & [22] & $\begin{array}{l}\text { South } \\
\quad \text { Africa }\end{array}$ & $\begin{array}{l}\text { Whole } \\
\text { plant }\end{array}$ & Dichloromethane & Very Good & $3.5 \mu \mathrm{g} / \mathrm{ml} \mathrm{I} C_{50}$ & $\begin{array}{l}\text { Plasmodium falcipa- } \\
\text { rum D10 }\end{array}$ & $\mathrm{Nd}$ \\
\hline Aloe ferox & $\begin{array}{l}\text { Xanthor- } \\
\text { rhoeaceae }\end{array}$ & [22] & $\begin{array}{l}\text { South } \\
\text { Africa }\end{array}$ & $\begin{array}{l}\text { Whole } \\
\text { plant }\end{array}$ & $\begin{array}{l}\text { Dichlorometh- } \\
\text { ane/Methanol }\end{array}$ & Good & $8 \mu \mathrm{g} / \mathrm{ml} \mathrm{I} C_{50}$ & $\begin{array}{l}\text { Plasmodium falcipa- } \\
\text { rum D10 }\end{array}$ & $\mathrm{Nd}$ \\
\hline Aloe maculata & $\begin{array}{l}\text { Xanthor- } \\
\text { rhoeaceae }\end{array}$ & [22] & $\begin{array}{l}\text { South } \\
\quad \text { Africa }\end{array}$ & $\begin{array}{l}\text { Whole } \\
\text { plant }\end{array}$ & $\begin{array}{l}\text { Dichlorometh- } \\
\text { ane/Methanol }\end{array}$ & Moderate & $\begin{array}{l}12.4 \mu \mathrm{g} / \mathrm{ml} \\
\mid \mathrm{C}_{50}\end{array}$ & $\begin{array}{l}\text { Plasmodium falcipa- } \\
\text { rum D10 }\end{array}$ & $\mathrm{Nd}$ \\
\hline Aloe pulcherrima & $\begin{array}{l}\text { Xanthor- } \\
\text { rhoeaceae }\end{array}$ & [41] & Ethiopia & Roots & $\begin{array}{l}\text { N-Hexane, } \\
\text { Chloroform, } \\
\text { Acetone Ans } \\
\text { Methanol }\end{array}$ & Moderate $^{a}$ & $\begin{array}{l}18.6 \mu \mathrm{g} / \mathrm{ml} \\
\mathrm{IC}_{50}\end{array}$ & $\begin{array}{l}\text { Plasmodiumfalci- } \\
\text { parum }\end{array}$ & $\mathrm{Nd}$ \\
\hline Aloe secundiflora & $\begin{array}{l}\text { Xanthor- } \\
\text { rhoeaceae }\end{array}$ & [24] & Kenya & Leaves & Methanol & Moderate & $\begin{array}{l}15.4 \mu \mathrm{g} / \mathrm{ml} \\
\mathrm{IC}_{50}\end{array}$ & $\begin{array}{l}\text { Plasmodium falcipa- } \\
\text { rum D6, W2 }\end{array}$ & $\mathrm{Nd}$ \\
\hline \multirow[t]{2}{*}{ Alstonia boonei } & Apocynaceae & {$[42]$} & Nigeria & $\begin{array}{l}\text { Stem } \\
\text { barks }\end{array}$ & Ethanol & $\mathrm{Nd}$ & nd & $\begin{array}{l}\text { Plasmodium beghei } \\
\text { NK-65 }\end{array}$ & No \\
\hline & & [43] & Ivory Coast & $\begin{array}{l}\text { Stem } \\
\text { barks }\end{array}$ & Ethanol & Moderate & $\begin{array}{l}12.3 \mu \mathrm{g} / \mathrm{ml} \\
\mid \mathrm{C}_{50}\end{array}$ & $\begin{array}{l}\text { Plasmodium falcipa- } \\
\text { rum FCB1 }\end{array}$ & $\mathrm{Nd}$ \\
\hline $\begin{array}{l}\text { Alstonia con- } \\
\text { gensis }\end{array}$ & Apocynaceae & [44] & D.R. Congo & $\begin{array}{l}\text { Leaves, } \\
\text { Root } \\
\text { Barks, } \\
\text { Stem } \\
\text { Barks }\end{array}$ & Water, Methanol & Very Good & $\begin{array}{l}2-5 \mu \mathrm{g} / \mathrm{ml} \\
\mathrm{IC}_{50}\end{array}$ & $\begin{array}{l}\text { Plasmodium falcipa- } \\
\text { rum K1 }\end{array}$ & $\mathrm{Nd}$ \\
\hline
\end{tabular}


Table 1 (continued)

\begin{tabular}{|c|c|c|c|c|c|c|c|c|c|}
\hline Plant species & Plant family & Source & $\begin{array}{l}\text { Country } \\
\text { of study }\end{array}$ & $\begin{array}{l}\text { Part of } \\
\text { plant } \\
\text { used }\end{array}$ & $\begin{array}{l}\text { Extraction } \\
\text { solvent }\end{array}$ & $\begin{array}{l}\text { Antiplas- } \\
\text { modial } \\
\text { Activity }\end{array}$ & $\begin{array}{l}\mathrm{IC}_{50} \text { or } \mathrm{ED}_{50} \\
\text { or } \mathrm{LD}_{50}\end{array}$ & $\begin{array}{l}\text { Strain of } \\
\text { Plasmodium } \\
\text { Tested }\end{array}$ & $\begin{array}{l}\text { Toxicity (value; } \\
\text { assay) }\end{array}$ \\
\hline $\begin{array}{l}\text { Ampelocissus } \\
\text { africana }\end{array}$ & Vitaceae & [20] & Kenya & $\begin{array}{l}\text { Whole } \\
\text { plant }\end{array}$ & Ethyl Acetate & Good & $9.0 \mu \mathrm{g} / \mathrm{ml} \mathrm{I} \mathrm{C}_{50}$ & $\begin{array}{l}\text { Plasmodium falcipa- } \\
\text { rum K1 }\end{array}$ & $\mathrm{Nd}$ \\
\hline $\begin{array}{c}\text { Andrographis } \\
\text { peniculata }\end{array}$ & Acanthaceae & {$[45]$} & Cambodia & $\begin{array}{l}\text { Whole } \\
\text { plant }\end{array}$ & Dichloromethane & Moderate & $\begin{array}{l}12.7 \mu \mathrm{g} / \mathrm{ml} \\
\mathrm{IC}_{50}\end{array}$ & $\begin{array}{l}\text { Plasmodium falcipa- } \\
\text { rum W2 }\end{array}$ & $\mathrm{Nd}$ \\
\hline $\begin{array}{l}\text { Annickia kum- } \\
\text { meriae }\end{array}$ & Annonaceae & [31] & Tanzania & Leaves & Methanol & Very Good & $\begin{array}{l}0.12 \mu \mathrm{g} / \mathrm{ml} \\
\mid \mathrm{C}_{50}\end{array}$ & $\begin{array}{l}\text { Plasmodium falcipa- } \\
\text { rum K1 }\end{array}$ & No \\
\hline $\begin{array}{l}\text { Anisopappus } \\
\text { chinensis }\end{array}$ & Compositae & {$[46]$} & D.R. Congo & $\begin{array}{l}\text { Whole } \\
\text { plant }\end{array}$ & $\begin{array}{l}\text { Methanolic and } \\
\text { dichlorometh- } \\
\text { ane }\end{array}$ & Good & $\begin{array}{l}6.53 \mu \mathrm{g} / \mathrm{ml} \\
\mid \mathrm{C}_{50}\end{array}$ & $\begin{array}{l}\text { Plasmodium } \\
\text { falciparum (3D7, } \\
\text { W2), Plasmodium } \\
\text { berghei berghei }\end{array}$ & No \\
\hline $\begin{array}{l}\text { Annona reticu- } \\
\text { lata }\end{array}$ & Annonaceae & {$[47]$} & Cameroon & Roots & Ethanol & Very good & $\begin{array}{l}1.90 \mu \mathrm{g} / \mathrm{ml} \\
\mathrm{IC}_{50}\end{array}$ & $\begin{array}{l}\text { Plasmodium falcipa- } \\
\text { rum W2 }\end{array}$ & No \\
\hline \multirow[t]{3}{*}{$\begin{array}{l}\text { Annona muri- } \\
\text { cata }\end{array}$} & Annonaceae & {$[48]$} & Ivory Coast & Leaves & Pentane & Moderate & $\begin{array}{l}8-18 \mu \mathrm{g} / \mathrm{ml} \\
\mid \mathrm{C}_{50}\end{array}$ & $\begin{array}{l}\text { Plasmodium falci- } \\
\text { parum FCM29, } \\
\text { Plasmodium } \\
\text { falciparum CQ-S } \\
\text { (Nigerian) }\end{array}$ & $\mathrm{Nd}$ \\
\hline & & [49] & Cameroon & Leaves & Hexane & Very Good & $\begin{array}{l}2.03 \mu \mathrm{g} / \mathrm{ml} \\
\mathrm{IC}_{50}\end{array}$ & $\begin{array}{l}\text { Plasmodium falcipa- } \\
\text { rum W2 }\end{array}$ & $\mathrm{Nd}$ \\
\hline & & [47] & Cameroon & $\begin{array}{l}\text { Stem } \\
\text { barks }\end{array}$ & Ethanol & Very Good & $\begin{array}{l}1.45 \mu \mathrm{g} / \mathrm{ml} \\
\mathrm{IC}_{50}\end{array}$ & $\begin{array}{l}\text { Plasmodium falcipa- } \\
\text { rum W2 }\end{array}$ & No \\
\hline \multirow[t]{2}{*}{$\begin{array}{l}\text { Anogeissus } \\
\text { leiocarpus }\end{array}$} & Combretaceae & [50] & Nigeria & Ns & $\begin{array}{l}\text { Methanol, Water, } \\
\text { Butanol, Ethyl } \\
\text { Acetate }\end{array}$ & Moderate & $\begin{array}{l}10.94- \\
13.77 \mu \mathrm{g} / \mathrm{ml} \\
\mid \mathrm{C}_{50}\end{array}$ & $\begin{array}{l}\text { Plasmodium falcipa- } \\
\text { rum 3D7, K1 }\end{array}$ & $\begin{array}{l}\text { Yes }(\mathrm{SI}=121 ; \\
\quad \text { mouse }[\mathrm{NBMH}])\end{array}$ \\
\hline & & [51] & Ivory Coast & Leaves & $\begin{array}{c}\text { Methylene } \\
\text { Chloride }\end{array}$ & Very Good & $3.8 \mu \mathrm{g} / \mathrm{ml} \mathrm{I} \mathrm{C}_{50}$ & $\begin{array}{l}\text { Plasmodium falcipa- } \\
\quad \text { rum K1 }\end{array}$ & No \\
\hline $\begin{array}{l}\text { Anonidium } \\
\text { mannii }\end{array}$ & Annonaceae & [49] & Cameroon & Twigs & Methanol & Very Good & $\begin{array}{l}2.04 \mu \mathrm{g} / \mathrm{ml} \\
\mathrm{I}_{50}\end{array}$ & $\begin{array}{l}\text { Plasmodium falcipa- } \\
\text { rum W2 }\end{array}$ & $\mathrm{Nd}$ \\
\hline Ansellia africana & Orchidaceae & [20] & Tanzania & Leaves & Ethyl Acetate & Moderate & $10 \mu \mathrm{g} / \mathrm{ml} \mathrm{IC_{50 }}$ & $\begin{array}{l}\text { Plasmodium falcipa- } \\
\quad \text { rum K1 }\end{array}$ & $\mathrm{Nd}$ \\
\hline $\begin{array}{l}\text { Anthocleista } \\
\text { grandiflora } \\
\text { Gilg }\end{array}$ & Gentianaceae & [37] & $\begin{array}{l}\text { South } \\
\text { Africa }\end{array}$ & $\begin{array}{l}\text { Stem } \\
\text { barks }\end{array}$ & Dichloromethane & Good & $\begin{array}{l}8.69 \mu \mathrm{g} / \mathrm{ml} \\
\mid \mathrm{C}_{50}\end{array}$ & $\begin{array}{l}\text { Plasmodium falcipa- } \\
\text { rum NF54 }\end{array}$ & $\mathrm{Nd}$ \\
\hline $\begin{array}{l}\text { Anthocleista } \\
\text { nobilis }\end{array}$ & Gentianaceae & {$[52]$} & $\begin{array}{l}\text { Burkina } \\
\text { Faso }\end{array}$ & Leaves & Dichloromethane & Moderate & $10 \mu \mathrm{g} / \mathrm{ml}$ & $\begin{array}{l}\text { Plasmodium falci- } \\
\text { parum }\end{array}$ & $\mathrm{Nd}$ \\
\hline $\begin{array}{c}\text { Anthocleista } \\
\text { vogelii }\end{array}$ & Gentianaceae & [53] & Nigeria & Roots & Petroleum Ether & Good & $\begin{array}{l}9.50 \mu \mathrm{g} / \mathrm{ml} \\
\mathrm{IC}_{50}\end{array}$ & $\begin{array}{l}\text { Plasmodium falcipa- } \\
\text { rum D10 }\end{array}$ & $\mathrm{Nd}$ \\
\hline Arenga engleri & Arecaceae & [25] & $\begin{array}{l}\text { South } \\
\text { Africa }\end{array}$ & $\begin{array}{l}\text { Stem } \\
\text { barks }\end{array}$ & Dichloromethane & Very Good & $1.7 \mu \mathrm{g} / \mathrm{ml} \mathrm{IC_{50 }}$ & $\begin{array}{l}\text { Plasmodium falcipa- } \\
\text { rum UP1 (CQ-R) }\end{array}$ & $\begin{array}{l}\text { Yes }\left(\mathrm{ID}_{50}=35 \mu \mathrm{g} /\right. \\
\text { ml; Monkey } \\
\text { kidney cells })\end{array}$ \\
\hline $\begin{array}{l}\text { Artabotrys } \\
\text { monteiroae }\end{array}$ & Annonaceae & {$[22]$} & $\begin{array}{l}\text { South } \\
\text { Africa }\end{array}$ & Twigs & $\begin{array}{l}\text { Dichlorometh- } \\
\text { ane/Methanol }\end{array}$ & Good & $8.7 \mu \mathrm{g} / \mathrm{ml} \mathrm{I} \mathrm{C}_{50}$ & $\begin{array}{l}\text { Plasmodium falcipa- } \\
\text { rum D10 }\end{array}$ & $\mathrm{Nd}$ \\
\hline \multirow[t]{3}{*}{ Artemisia afra } & Asteraceae & [54] & Zimbabwe & Leaves & $\begin{array}{l}\text { Petrolether/Ethyl- } \\
\text { acetate }\end{array}$ & Moderate & 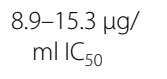 & $\begin{array}{l}\text { Plasmodium falcipa- } \\
\text { rum Pow, Dd2 }\end{array}$ & $\mathrm{Nd}$ \\
\hline & & {$[22]$} & $\begin{array}{l}\text { South } \\
\text { Africa }\end{array}$ & Leaves & Dichloromethane & Good & $5 \mu \mathrm{g} / \mathrm{ml} \mathrm{IC} \mathrm{C}_{50}$ & $\begin{array}{l}\text { Plasmodium falcipa- } \\
\text { rum D10 }\end{array}$ & $\mathrm{Nd}$ \\
\hline & & [24] & Kenya & Leaves & Methanol & Good & $\begin{array}{l}3.9-9.1 \mu \mathrm{g} / \\
\mathrm{ml} \mathrm{C}_{50}\end{array}$ & $\begin{array}{l}\text { Plasmodium falcipa- } \\
\text { rum D6, W2 }\end{array}$ & $\mathrm{Nd}$ \\
\hline $\begin{array}{l}\text { Artemisia } \\
\text { annua L }\end{array}$ & Asteraceae & [24] & Kenya & Leaves & Methanol & Good & $\begin{array}{l}4.7-5.5 \mu \mathrm{g} / \\
\mathrm{ml} \mathrm{C}_{50}\end{array}$ & $\begin{array}{l}\text { Plasmodium falcipa- } \\
\text { rum D6, W2 }\end{array}$ & $\mathrm{Nd}$ \\
\hline $\begin{array}{l}\text { Artocarpus com- } \\
\text { munis }\end{array}$ & Moraceae & {$[55]$} & Cameroon & $\begin{array}{l}\text { Stems, } \\
\text { Leaves }\end{array}$ & $\begin{array}{l}\text { Ethanol, Water, } \\
\text { Dichlorometh- } \\
\text { ane, Methanol, } \\
\text { Hexane }\end{array}$ & Very Good & 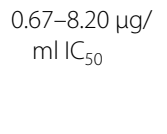 & $\begin{array}{l}\text { Plasmodium falcipa- } \\
\text { rum W2 }\end{array}$ & $\mathrm{Nd}$ \\
\hline $\begin{array}{l}\text { Asparagus } \\
\text { virgatus }\end{array}$ & Asparagaceae & [22] & $\begin{array}{l}\text { South } \\
\text { Africa }\end{array}$ & $\begin{array}{l}\text { Whole } \\
\text { plant }\end{array}$ & $\begin{array}{l}\text { Dichlorometh- } \\
\text { ane/Methanol }\end{array}$ & Good & $8 \mu \mathrm{g} / \mathrm{ml} \mathrm{IC} C_{50}$ & $\begin{array}{l}\text { Plasmodium falcipa- } \\
\text { rum D10 }\end{array}$ & $\mathrm{Nd}$ \\
\hline Aspilia africana & Asteraceae & {$[56]$} & Uganda & Shoots & Ethyl Acetate & Moderate & $\begin{array}{l}9.3-11.5 \mu \mathrm{g} / \\
\mathrm{ml} \mathrm{IC_{50 }}\end{array}$ & $\begin{array}{l}\text { Plasmodium falcipa- } \\
\text { rum D10, K1 }\end{array}$ & $\mathrm{Nd}$ \\
\hline
\end{tabular}


Table 1 (continued)

\begin{tabular}{|c|c|c|c|c|c|c|c|c|c|}
\hline Plant species & Plant family & Source & $\begin{array}{l}\text { Country } \\
\text { of study }\end{array}$ & $\begin{array}{l}\text { Part of } \\
\text { plant } \\
\text { used }\end{array}$ & $\begin{array}{l}\text { Extraction } \\
\text { solvent }\end{array}$ & $\begin{array}{l}\text { Antiplas- } \\
\text { modial } \\
\text { Activity }\end{array}$ & $\begin{array}{l}I C_{50} \text { or } E D_{50} \\
\text { or } L_{50}\end{array}$ & $\begin{array}{l}\text { Strain of } \\
\text { Plasmodium } \\
\text { Tested }\end{array}$ & $\begin{array}{l}\text { Toxicity (value; } \\
\text { assay) }\end{array}$ \\
\hline Aspilia pruliseta & Compositae & {$[24]$} & Kenya & $\begin{array}{l}\text { Root } \\
\text { BARKS }\end{array}$ & Methanol & Good & $\begin{array}{c}6.8-9.7 \mu \mathrm{g} / \\
\mathrm{ml} \mathrm{C}_{50}\end{array}$ & $\begin{array}{l}\text { Plasmodium falcipa- } \\
\text { rum D6, W2 }\end{array}$ & $\mathrm{Nd}$ \\
\hline $\begin{array}{l}\text { Asystasia } \\
\text { gangetica }\end{array}$ & Acanthaceae & {$[22]$} & $\begin{array}{l}\text { South } \\
\text { Africa }\end{array}$ & Twigs & $\begin{array}{l}\text { Dichlorometh- } \\
\text { ane/Methanol }\end{array}$ & Moderate & $16 \mu \mathrm{g} / \mathrm{ml} I C_{50}$ & $\begin{array}{l}\text { Plasmodium falcipa- } \\
\text { rum D10 }\end{array}$ & $\mathrm{Nd}$ \\
\hline \multirow[t]{4}{*}{$\begin{array}{l}\text { Azadirachta } \\
\text { indica }\end{array}$} & Meliaceae & {$[57]$} & Ivory Coast & $\begin{array}{l}\text { Stems, } \\
\text { leaves }\end{array}$ & Water & Very Good & $\begin{array}{l}2.35-6.8 \mu \mathrm{g} / \\
\mathrm{ml} \mathrm{IC}_{50}\end{array}$ & $\begin{array}{l}\text { Plasmodium falcipa- } \\
\quad \text { rum Fcb1 \& F32 }\end{array}$ & $\mathrm{Nd}$ \\
\hline & & {$[45]$} & Cambodia & Barks & Dichloromethane & Very Good & $4.7 \mu \mathrm{g} / \mathrm{ml} \mathrm{IC}_{50}$ & $\begin{array}{l}\text { Plasmodium falcipa- } \\
\text { rum W2 }\end{array}$ & $\mathrm{Nd}$ \\
\hline & & {$[58]$} & Sudan & Leaves & Methanol & Very Good & $\begin{array}{l}1.7-5.8 \mu \mathrm{g} / \mathrm{ml} \\
\mid \mathrm{C}_{50}\end{array}$ & $\begin{array}{l}\text { Plasmodium falcipa- } \\
\text { rum 3D7, Dd5 }\end{array}$ & $\mathrm{Nd}$ \\
\hline & & {$[59]$} & Togo & Leaves & Ethanol & Very Good & $\begin{array}{l}2.48-2.5 \mu \mathrm{g} / \\
\mathrm{ml} \mathrm{IC}_{50}\end{array}$ & $\begin{array}{l}\text { Plasmodium falcipa- } \\
\text { rum W2, D6 }\end{array}$ & $\mathrm{Nd}$ \\
\hline $\begin{array}{l}\text { Azanza garck- } \\
\text { eana }\end{array}$ & Malvaceae & {$[60]$} & Malawi & Leaves & Dichloromethane & Moderate & $\begin{array}{l}11.79 \mu \mathrm{g} / \mathrm{ml} \\
\mathrm{IC}_{50}\end{array}$ & $\begin{array}{l}\text { Plasmodium falcipa- } \\
\text { rum, VI/S }\end{array}$ & $\mathrm{Nd}$ \\
\hline \multirow[t]{2}{*}{$\begin{array}{l}\text { Balanites aegyp- } \\
\quad \text { tiaca }\end{array}$} & Zygophyllaceae & {$[24]$} & Kenya & $\begin{array}{l}\text { Root } \\
\text { barks }\end{array}$ & Methanol & Good & $8.9 \mu \mathrm{g} / \mathrm{ml} \mathrm{C}_{50}$ & $\begin{array}{l}\text { Plasmodium falcipa- } \\
\quad \text { rum D6, W2 }\end{array}$ & $\mathrm{Nd}$ \\
\hline & & {$[21]$} & Kenya & $\begin{array}{l}\text { Root } \\
\text { barks }\end{array}$ & Methanol & Very good & $\begin{array}{l}3.49 \mu \mathrm{g} / \mathrm{ml} \\
\mid \mathrm{C}_{50}\end{array}$ & $\begin{array}{l}\text { Plasmodium falcipa- } \\
\text { rum D6 }\end{array}$ & No \\
\hline $\begin{array}{l}\text { Balanites } \\
\quad \text { maughamii }\end{array}$ & Zygophyllaceae & {$[25]$} & $\begin{array}{l}\text { South } \\
\text { Africa }\end{array}$ & $\begin{array}{l}\text { Stem } \\
\text { barks }\end{array}$ & Dichloromethane & Very good & $\begin{array}{l}1.94 \mu \mathrm{g} / \mathrm{ml} \\
\mathrm{IC}_{50}\end{array}$ & $\begin{array}{l}\text { Plasmodium falcipa- } \\
\text { rum UP1 (CQ-R) }\end{array}$ & $\mathrm{Nd}$ \\
\hline $\begin{array}{c}\text { Barringtonia } \\
\text { racemosa }\end{array}$ & Lecythidaceae & {$[22]$} & $\begin{array}{l}\text { South } \\
\text { Africa }\end{array}$ & Twigs & $\begin{array}{l}\text { Dichlorometh- } \\
\text { ane/Methanol }\end{array}$ & Good & $5.7 \mu \mathrm{g} / \mathrm{ml} \mathrm{IC} 50$ & $\begin{array}{l}\text { Plasmodium falcipa- } \\
\text { rum D10 }\end{array}$ & $\mathrm{Nd}$ \\
\hline \multirow[t]{2}{*}{ Berberis holstii } & Berberidaceae & {$[61]$} & Malawi & Roots & $\begin{array}{l}\text { Dichlorometh- } \\
\text { ane/Methanol }\end{array}$ & Very good & $\begin{array}{l}0.17 \mu \mathrm{g} / \mathrm{ml} \\
\mid \mathrm{C}_{50}\end{array}$ & $\begin{array}{l}\text { Plasmodium falcipa- } \\
\text { rum 3D7 }\end{array}$ & $\mathrm{Nd}$ \\
\hline & & {$[24]$} & Kenya & $\begin{array}{l}\text { Root } \\
\text { barks }\end{array}$ & Methanol & Very Good & $<5 \mu \mathrm{g} / \mathrm{ml} \mathrm{C}_{50}$ & $\begin{array}{l}\text { Plasmodium falcipa- } \\
\text { rum D6, W2 }\end{array}$ & $\mathrm{Nd}$ \\
\hline $\begin{array}{l}\text { Bergia suffruti- } \\
\text { cosa }\end{array}$ & Elatinaceae & {$[62]$} & $\begin{array}{l}\text { Burkina } \\
\text { Faso }\end{array}$ & $\begin{array}{l}\text { Whole } \\
\text { plant }\end{array}$ & Dichloromethane & Moderate & $\begin{array}{l}19.53 \mu \mathrm{g} / \mathrm{ml} \\
\mathrm{IC}_{50}\end{array}$ & $\begin{array}{l}\text { Plasmodium falcipa- } \\
\text { rum 3D7 \&W2 }\end{array}$ & $\mathrm{Nd}$ \\
\hline \multirow[t]{3}{*}{ Berula erecta } & Apiaceae & {$[22]$} & $\begin{array}{l}\text { South } \\
\text { Africa }\end{array}$ & $\begin{array}{l}\text { Whole } \\
\text { plant }\end{array}$ & $\begin{array}{l}\text { Dichlorometh- } \\
\text { ane/Methanol }\end{array}$ & Good & $6.6 \mu \mathrm{g} / \mathrm{ml} \mathrm{IC}_{50}$ & $\begin{array}{l}\text { Plasmodium falcipa- } \\
\text { rum D10 }\end{array}$ & $\mathrm{Nd}$ \\
\hline & & {$[24]$} & Kenya & Leaves & Methanol & Good & $9.9 \mu \mathrm{g} / \mathrm{ml} \mathrm{C}_{50}$ & $\begin{array}{l}\text { Plasmodium falcipa- } \\
\text { rum D6, W2 }\end{array}$ & $\mathrm{Nd}$ \\
\hline & & {$[22]$} & $\begin{array}{l}\text { South } \\
\text { Africa }\end{array}$ & Leaves & Methanol & Good & $5 \mu \mathrm{g} / \mathrm{ml} \mathrm{IC} C_{50}$ & $\begin{array}{l}\text { Plasmodium falcipa- } \\
\text { rum D10 }\end{array}$ & $\mathrm{Nd}$ \\
\hline Bidens engleri & Compositae & {$[63]$} & Senegal & Leaves & Petroleum ether & Moderate & $\begin{array}{l}9-18 \mu \mathrm{g} / \mathrm{ml} \\
\mid \mathrm{C}_{50}\end{array}$ & $\begin{array}{l}\text { Plasmodium } \\
\text { falciparum FcM29, } \\
\text { FcB1, Plasmodium } \\
\text { vinckei petteri }\end{array}$ & $\begin{array}{c}\text { Yes }\left(\mathrm{IC}_{50}=10 \mu \mathrm{g} /\right. \\
\mathrm{ml} \text {; Vero cells })\end{array}$ \\
\hline Bixa orellana & Bixaceae & {$[45]$} & Cambodia & Leaves & Water & Good & $9.3 \mu \mathrm{g} / \mathrm{ml} \mathrm{IC}_{50}$ & $\begin{array}{l}\text { Plasmodium falcipa- } \\
\text { rum W2 }\end{array}$ & $\mathrm{Nd}$ \\
\hline $\begin{array}{l}\text { Boscia angusti- } \\
\quad \text { folia }\end{array}$ & Capparaceae & {$[24]$} & Kenya & $\begin{array}{l}\text { Stem } \\
\text { barks }\end{array}$ & Water & Very good & $\begin{array}{l}1.4-4.7 \mu \mathrm{g} / \\
\mathrm{ml} \mathrm{C}_{50}\end{array}$ & $\begin{array}{l}\text { Plasmodium falcipa- } \\
\text { rum D6, W2 }\end{array}$ & $\mathrm{Nd}$ \\
\hline Boscia salicifolia & Capparaceae & {$[26]$} & Kenya & $\begin{array}{l}\text { Stem } \\
\text { barks }\end{array}$ & Methanol & good & $\begin{array}{l}1.1-8.8 \mu \mathrm{g} / \mathrm{ml} \\
\mid \mathrm{C}_{50}\end{array}$ & $\begin{array}{l}\text { Plasmodium falcipa- } \\
\text { rum D6, W2 }\end{array}$ & $\mathrm{Nd}$ \\
\hline \multirow[t]{2}{*}{ Boswellia dalzielii } & Burseraceae & {$[50]$} & Nigeria & Ns & $\begin{array}{l}\text { Methanol, Water, } \\
\text { Butanol, Ethyl } \\
\text { Acetate }\end{array}$ & Moderate & $\begin{array}{l}14.59-15.1 \mu \mathrm{g} / \\
\mathrm{ml} \mathrm{IC}_{50}\end{array}$ & $\begin{array}{l}\text { Plasmodium falcipa- } \\
\text { rum 3D7, K1 }\end{array}$ & $\begin{array}{l}\text { Yes }(\mathrm{SI} \geq 101 ; \\
\quad \text { Mouse }[\mathrm{NBMH}]\end{array}$ \\
\hline & & {$[62]$} & $\begin{array}{l}\text { Burkina } \\
\text { Faso }\end{array}$ & Leaves & Methanol & Moderate & $\begin{array}{l}18.85 \mu \mathrm{g} / \mathrm{ml} \\
\mathrm{IC}_{50}\end{array}$ & $\begin{array}{l}\text { Plasmodium falcipa- } \\
\text { rum 3D7 \&W2 }\end{array}$ & $\mathrm{Nd}$ \\
\hline $\begin{array}{l}\text { Bridelia micran- } \\
\text { tha }\end{array}$ & Phyllanthaceae & {$[26]$} & Kenya & $\begin{array}{l}\text { Stem } \\
\text { Barks }\end{array}$ & Methanol & Moderate & $\begin{array}{l}14.2-19.4 \mu \mathrm{g} / \\
\mathrm{ml} \mathrm{IC}_{50}\end{array}$ & $\begin{array}{l}\text { Plasmodium falcipa- } \\
\text { rum D6, W2 }\end{array}$ & $\mathrm{Nd}$ \\
\hline $\begin{array}{l}\text { Bridelia mollis } \\
\text { Hutch }\end{array}$ & Phyllanthaceae & {$[37]$} & $\begin{array}{l}\text { South } \\
\text { Africa }\end{array}$ & Roots & Dichloromethane & Very good & $\begin{array}{l}3.06 \mu \mathrm{g} / \mathrm{ml} \\
I_{50}\end{array}$ & $\begin{array}{l}\text { Plasmodium falcipa- } \\
\text { rumNF54 }\end{array}$ & $\mathrm{Nd}$ \\
\hline Brucea javanica & Simaroubaceae & {$[45]$} & Cambodia & Roots & Dichloromethane & Very good & $1.0 \mu \mathrm{g} / \mathrm{ml} \mathrm{IC_{50 }}$ & $\begin{array}{l}\text { Plasmodium falcipa- } \\
\text { rum W2 }\end{array}$ & $\mathrm{Nd}$ \\
\hline $\begin{array}{l}\text { Bruguiera gym- } \\
\text { norhiza }\end{array}$ & Rhizophoraceae & {$[22]$} & $\begin{array}{l}\text { South } \\
\text { Africa }\end{array}$ & Twigs & $\begin{array}{l}\text { Dichlorometh- } \\
\text { ane/Methanol }\end{array}$ & Moderate & $\begin{array}{c}11.7 \mu \mathrm{g} / \mathrm{ml} \\
\mid \mathrm{C}_{50}\end{array}$ & $\begin{array}{l}\text { Plasmodium falcipa- } \\
\quad \text { rum D10 }\end{array}$ & $\mathrm{Nd}$ \\
\hline
\end{tabular}


Table 1 (continued)

\begin{tabular}{|c|c|c|c|c|c|c|c|c|c|}
\hline Plant species & Plant family & Source & $\begin{array}{l}\text { Country } \\
\text { of study }\end{array}$ & $\begin{array}{l}\text { Part of } \\
\text { plant } \\
\text { used }\end{array}$ & $\begin{array}{l}\text { Extraction } \\
\text { solvent }\end{array}$ & $\begin{array}{l}\text { Antiplas- } \\
\text { modial } \\
\text { Activity }\end{array}$ & $\begin{array}{l}\mathrm{IC}_{50} \text { or } \mathrm{ED}_{50} \\
\text { or } \mathrm{LD}_{50}\end{array}$ & $\begin{array}{l}\text { Strain of } \\
\text { Plasmodium } \\
\text { Tested }\end{array}$ & $\begin{array}{l}\text { Toxicity (value; } \\
\text { assay) }\end{array}$ \\
\hline $\begin{array}{l}\text { Burchellia } \\
\text { bubalina }\end{array}$ & Rubiaceae & [22] & $\begin{array}{l}\text { South } \\
\text { Africa }\end{array}$ & Twigs & $\begin{array}{l}\text { Dichlorometh- } \\
\text { ane/Methanol }\end{array}$ & Moderate & $18 \mu \mathrm{g} / \mathrm{ml} / \mathrm{C}_{50}$ & $\begin{array}{l}\text { Plasmodium falcipa- } \\
\text { rum D10 }\end{array}$ & $\mathrm{Nd}$ \\
\hline $\begin{array}{l}\text { Caesalpinia } \\
\text { bonducella }\end{array}$ & Fabaceae & {$[64]$} & Nigeria & $\begin{array}{l}\text { Aerial } \\
\text { Parts }\end{array}$ & Ethyl Acetate & Moderate & $16 \mu \mathrm{g} / \mathrm{ml} \mathrm{EC} 50$ & $\begin{array}{l}\text { Plasmodium falci- } \\
\text { parum }\end{array}$ & $\begin{array}{l}\text { Yes }(\mathrm{SI}=0.29-0.69 ; \\
\text { mouse mam- } \\
\text { mary tumour } \\
[\mathrm{FM} 3 \mathrm{~A}])\end{array}$ \\
\hline $\begin{array}{l}\text { Canthium } \\
\text { setosum }\end{array}$ & Rubiaceae & {$[65]$} & Benin & $\begin{array}{l}\text { Aerial } \\
\text { Parts }\end{array}$ & $\begin{array}{c}\text { Methylene } \\
\text { Chloride }\end{array}$ & Very good & $\begin{array}{l}2.77-4.80 \mu \mathrm{g} / \\
\mathrm{ml} \mathrm{IC}_{50}\end{array}$ & $\begin{array}{l}\text { Plasmodium falcipa- } \\
\text { rum 3D7 \& K1 }\end{array}$ & $\mathrm{Nd}$ \\
\hline $\begin{array}{l}\text { Capparis tomen- } \\
\text { tosa Lam }\end{array}$ & Capparaceae & {$[37]$} & $\begin{array}{l}\text { South } \\
\text { Africa }\end{array}$ & Roots & Dichloromethane & Very good & $\begin{array}{l}2.19 \mu \mathrm{g} / \mathrm{ml} \\
\mid \mathrm{C}_{50}\end{array}$ & $\begin{array}{l}\text { Plasmodium falcipa- } \\
\text { rum NF54 }\end{array}$ & $\mathrm{Nd}$ \\
\hline $\begin{array}{l}\text { Cardiospermum } \\
\text { halicacabum }\end{array}$ & Sapindaceae & [22] & $\begin{array}{l}\text { South } \\
\text { Africa }\end{array}$ & $\begin{array}{l}\text { Whole } \\
\text { Plant }\end{array}$ & $\begin{array}{l}\text { Dichlorometh- } \\
\text { ane/Methanol }\end{array}$ & Moderate & $20 \mu \mathrm{g} / \mathrm{ml} \mathrm{IC_{50 }}$ & $\begin{array}{l}\text { Plasmodium falcipa- } \\
\text { rum D10 }\end{array}$ & $\mathrm{Nd}$ \\
\hline Carica papaya & Caricaceae & {$[66]$} & Nigeria & Leaves & Ethyl Acetate & Very good & $\begin{array}{l}2.96 \mu \mathrm{g} / \mathrm{ml} \\
\mathrm{IC}_{50}\end{array}$ & $\begin{array}{l}\text { Plasmodium falcipa- } \\
\text { rum D10, DD2 }\end{array}$ & No \\
\hline Carissa edulis & Apocynaceae & [21] & Kenya & $\begin{array}{l}\text { Root } \\
\text { barks }\end{array}$ & Methanol & Good & $\begin{array}{l}6.41 \mu \mathrm{g} / \mathrm{ml} \\
\mathrm{IC}_{50}\end{array}$ & $\begin{array}{l}\text { Plasmodium falcipa- } \\
\text { rum D6 }\end{array}$ & No \\
\hline Carpolobia alba & Polygalaceae & {$[53]$} & Nigeria & Roots & Dichloromethane & Good & $\begin{array}{l}7.10 \mu \mathrm{g} / \mathrm{ml} \\
\mid \mathrm{C}_{50}\end{array}$ & $\begin{array}{l}\text { Plasmodium falcipa- } \\
\text { rum D10 }\end{array}$ & $\mathrm{Nd}$ \\
\hline $\begin{array}{l}\text { Cassia abbre- } \\
\text { viata }\end{array}$ & Fabaceae & {$[60]$} & Malawi & Roots & Dichloromethane & Very Good & $\begin{array}{l}2 \cdot 88 \mu \mathrm{g} / \mathrm{ml} \\
\mathrm{IC}_{50}\end{array}$ & $\begin{array}{l}\text { Plasmodium falcipa- } \\
\text { rum VI/S }\end{array}$ & $\mathrm{Nd}$ \\
\hline Cassia alata & Fabaceae & {$[67]$} & D.R.Congo & Leaves & $\begin{array}{l}\text { Ethanol, Metha- } \\
\text { nol, Petroleum } \\
\text { Ether, Chloro- } \\
\text { form }\end{array}$ & Very Good & $\begin{array}{l}<0.1-5.4 \mu \mathrm{g} / \\
\mathrm{ml} \mathrm{IC}\end{array}$ & $\begin{array}{l}\text { Plasmodium Falci- } \\
\text { parum }\end{array}$ & $\mathrm{Nd}$ \\
\hline \multirow[t]{4}{*}{$\begin{array}{l}\text { Senna occiden- } \\
\text { talis } L\end{array}$} & Fabaceae & {$[68]$} & $\begin{array}{l}\text { Mozam- } \\
\text { bique } \\
\text { And } \\
\text { Portugal }\end{array}$ & Roots & N-Hexane & Moderate & $\begin{array}{l}19.3 \mu \mathrm{g} / \mathrm{ml} \\
\mathrm{IC}_{50}\end{array}$ & $\begin{array}{l}\text { Plasmodium falcipa- } \\
\text { rum 3D7 }\end{array}$ & $\mathrm{Nd}$ \\
\hline & & {$[26]$} & Kenya & $\begin{array}{l}\text { Root } \\
\text { Barks }\end{array}$ & Methanol & Moderate & $\begin{array}{l}18.8 \mu \mathrm{g} / \mathrm{ml} \\
\mathrm{IC}_{50}\end{array}$ & $\begin{array}{l}\text { Plasmodium falcipa- } \\
\text { rum D6, W2 }\end{array}$ & $\mathrm{Nd}$ \\
\hline & & [69] & D.R. Congo & Leaves & Petroleum Ether & Very Good & $1.5 \mu \mathrm{g} / \mathrm{ml} \mathrm{IC_{50 }}$ & $\begin{array}{l}\text { Plasmodium falci- } \\
\text { parum }\end{array}$ & $\mathrm{Nd}$ \\
\hline & & {$[67]$} & D.R. Congo & Leaves & $\begin{array}{l}\text { Ethanol, Metha- } \\
\text { nol, Petroleum } \\
\text { Ether, Chloro- } \\
\text { form }\end{array}$ & Very Good & $\begin{array}{l}<0.1- \\
0.25 \mu \mathrm{g} / \mathrm{ml} \\
\mid C_{50}\end{array}$ & $\begin{array}{l}\text { Plasmodium falci- } \\
\text { parum }\end{array}$ & $\mathrm{Nd}$ \\
\hline \multirow[t]{2}{*}{ Cassia siamea } & Fabaceae & {$[70]$} & Togo & Leaves & Water & Good & $<7 \mu \mathrm{g} / \mathrm{ml} \mathrm{IC} 50$ & $\begin{array}{l}\text { Plasmodium falci- } \\
\text { parum }\end{array}$ & $\mathrm{Nd}$ \\
\hline & & {$[27]$} & $\begin{array}{l}\text { Burkina } \\
\text { Faso }\end{array}$ & Leaves & Crude Alkaloid & Good & $\begin{array}{l}4-10 \mu \mathrm{g} / \mathrm{ml} \\
\mid \mathrm{C}_{50}\end{array}$ & $\begin{array}{l}\text { Plasmodium falcipa- } \\
\text { rum W2 }\end{array}$ & $\mathrm{Nd}$ \\
\hline Cassia tora & Fabaceae & {$[23]$} & Sudan & $\begin{array}{l}\text { Aerial } \\
\text { parts }\end{array}$ & Methanol & Good & $\begin{array}{l}3.3-5.2 \mu \mathrm{m} / \mathrm{ml} \\
\mid \mathrm{C}_{50}\end{array}$ & $\begin{array}{l}\text { Plasmodium falcipa- } \\
\text { rum 3D7, Dd2 }\end{array}$ & No \\
\hline Catha edulis & Celastraceae & [22] & $\begin{array}{l}\text { South } \\
\text { Africa }\end{array}$ & Roots & Dichloromethane & Very Good & $\begin{array}{l}0.68 \mu \mathrm{g} / \mathrm{ml} \\
\mathrm{IC}_{50}\end{array}$ & $\begin{array}{l}\text { Plasmodium falcipa- } \\
\text { rum D10 }\end{array}$ & $\mathrm{Nd}$ \\
\hline Cedrelopsis grevei & i Rutaceae & [71] & $\begin{array}{l}\text { Madagas- } \\
\text { car }\end{array}$ & Leaves & Water & Moderate & $17.5 \mathrm{mg} / \mathrm{L} I \mathrm{C}_{50}$ & $\begin{array}{l}\text { Plasmodium falci- } \\
\text { parum }\end{array}$ & $\mathrm{Nd}$ \\
\hline Celtis integrifolia & Cannabaceae & {$[52]$} & $\begin{array}{l}\text { Burkina } \\
\text { Faso }\end{array}$ & Leaves & Dichloromethane & Very Good & $3.7 \mu \mathrm{g} / \mathrm{ml} \mathrm{IC_{50 }}$ & $\begin{array}{l}\text { Plasmodiumfalci- } \\
\text { parum }\end{array}$ & $\begin{array}{l}\text { Yes }(\mathrm{SI} \geq 0.5 ; \text { HepG2 } \\
\text { cells) }\end{array}$ \\
\hline \multirow[t]{2}{*}{ Centella asiatica } & Apiaceae & {$[22]$} & $\begin{array}{l}\text { South } \\
\quad \text { Africa }\end{array}$ & Leaves & $\begin{array}{l}\text { Dichlorometh- } \\
\text { ane/Methanol }\end{array}$ & Good & $8.3 \mu \mathrm{g} / \mathrm{ml} \mathrm{I} C_{50}$ & $\begin{array}{l}\text { Plasmodium falcipa- } \\
\text { rum D10 }\end{array}$ & $\mathrm{Nd}$ \\
\hline & & [72] & Kenya & $\begin{array}{l}\text { Root } \\
\text { Barks }\end{array}$ & Dichloromethane & Moderate & 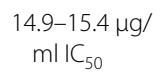 & $\begin{array}{l}\text { Plasmodium falcipa- } \\
\text { rum K1, NF54 }\end{array}$ & $\mathrm{Nd}$ \\
\hline $\begin{array}{l}\text { Cephalanthus } \\
\text { natalensis }\end{array}$ & Rubiaceae & [22] & $\begin{array}{l}\text { South } \\
\text { Africa }\end{array}$ & Twigs & $\begin{array}{l}\text { Dichlorometh- } \\
\text { ane/Methanol }\end{array}$ & Moderate & $\begin{array}{l}16.5 \mu \mathrm{g} / \mathrm{ml} \\
\mathrm{IC}_{50}\end{array}$ & $\begin{array}{l}\text { Plasmodium falcipa- } \\
\text { rum D10 }\end{array}$ & $\mathrm{Nd}$ \\
\hline $\begin{array}{l}\text { Ceratotheca } \\
\text { sesamoides }\end{array}$ & Pedaliaceae & [63] & Senegal & Leaves & Petroleum ether & Moderate & $\begin{array}{l}15-23 \mu \mathrm{g} / \mathrm{ml} \\
\mid \mathrm{C}_{50}\end{array}$ & $\begin{array}{l}\text { Plasmodium } \\
\text { falciparum FcM29, } \\
\text { FcB1, Plasmodium } \\
\text { vinckei petteri }\end{array}$ & $\begin{array}{l}\text { Yes }\left(I C_{50}=50 \mu \mathrm{g} /\right. \\
\quad \mathrm{ml} \text {; Vero cells })\end{array}$ \\
\hline
\end{tabular}


Table 1 (continued)

\begin{tabular}{|c|c|c|c|c|c|c|c|c|c|}
\hline Plant species & Plant family & Source & $\begin{array}{l}\text { Country } \\
\text { of study }\end{array}$ & $\begin{array}{l}\text { Part of } \\
\text { plant } \\
\text { used }\end{array}$ & $\begin{array}{l}\text { Extraction } \\
\text { solvent }\end{array}$ & $\begin{array}{l}\text { Antiplas- } \\
\text { modial } \\
\text { Activity }\end{array}$ & $\begin{array}{l}\mathrm{IC}_{50} \text { or } \mathrm{ED}_{50} \\
\text { or } \mathrm{LD}_{50}\end{array}$ & $\begin{array}{l}\text { Strain of } \\
\text { Plasmodium } \\
\text { Tested }\end{array}$ & $\begin{array}{l}\text { Toxicity (value; } \\
\text { assay) }\end{array}$ \\
\hline $\begin{array}{l}\text { Chrysophyllum } \\
\text { perpulchrum }\end{array}$ & Sapotaceae & [43] & Ivory Coast & $\begin{array}{l}\text { Stem } \\
\text { Barks }\end{array}$ & Ethanol & Moderate & $\begin{array}{l}12.8 \mu \mathrm{g} / \mathrm{ml} \\
\mid \mathrm{C}_{50}\end{array}$ & $\begin{array}{l}\text { Plasmodium falcipa- } \\
\text { rumFCB1 }\end{array}$ & $\mathrm{Nd}$ \\
\hline $\begin{array}{l}\text { Cinchona suc- } \\
\text { cirubra }\end{array}$ & Rubiaceae & [73] & $\begin{array}{l}\text { S. Tome' } \\
\text { And Prı } \\
\text { 'Ncipe }\end{array}$ & Barks & $\begin{array}{l}\text { Petroleum Ether, } \\
\text { Dichlorometh- } \\
\text { ane, Ethyl } \\
\text { Acetate, Metha- } \\
\text { nol }\end{array}$ & Good & $\begin{array}{l}<10 \mu \mathrm{g} / \mathrm{ml} \\
\mid \mathrm{C}_{50}\end{array}$ & $\begin{array}{l}\text { Plasmodium falcipa- } \\
\text { rum3D7 And Dd2 }\end{array}$ & $\mathrm{Nd}$ \\
\hline $\begin{array}{l}\text { Cinnamonum } \\
\text { camphora }\end{array}$ & Lauraceae & [57] & Ivory Coast & Cortex & Water & Moderate & $\begin{array}{l}9.37-16.6 \mu \mathrm{g} / \\
\mathrm{ml} \mathrm{II}_{50}\end{array}$ & $\begin{array}{l}\text { Plasmodium falcipa- } \\
\text { rumFcb1 \& F32 }\end{array}$ & $\mathrm{Nd}$ \\
\hline \multirow[t]{2}{*}{$\begin{array}{l}\text { Cissampelos } \\
\text { mucronata }\end{array}$} & $\begin{array}{l}\text { Menisper- } \\
\text { maceae }\end{array}$ & [20] & Tanzania & Roots & Ethyl Acetate & Very Good & $\begin{array}{l}0.38 \mu \mathrm{g} / \mathrm{ml} \\
\mathrm{IC} 50\end{array}$ & $\begin{array}{l}\text { Plasmodium falcipa- } \\
\text { rumK1 }\end{array}$ & $\mathrm{Nd}$ \\
\hline & & {$[26]$} & Kenya & Leaves & Methanol & Very Good & $4.4 \mu \mathrm{g} / \mathrm{ml} \mathrm{I} \mathrm{C}_{50}$ & $\begin{array}{l}\text { Plasmodium falcipa- } \\
\text { rumD6, W2 }\end{array}$ & $\mathrm{Nd}$ \\
\hline \multirow[t]{2}{*}{$\begin{array}{l}\text { Cissampelos } \\
\text { pareira }\end{array}$} & $\begin{array}{l}\text { Menisper- } \\
\text { maceae }\end{array}$ & [24] & Kenya & $\begin{array}{l}\text { Root } \\
\text { Barks }\end{array}$ & Methanol & Good & $\begin{array}{l}5.2-6.5 \mu \mathrm{g} / \\
\mathrm{ml}_{50}\end{array}$ & $\begin{array}{l}\text { Plasmodium falcipa- } \\
\text { rumD6, W2 }\end{array}$ & $\mathrm{Nd}$ \\
\hline & & [74] & Kenya & Root & Methanol & Good & 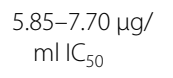 & $\begin{array}{l}\text { Plasmodium falcipa- } \\
\text { rumNF54, ENT30 }\end{array}$ & $\mathrm{Nd}$ \\
\hline Cissus populnea & Vitaceae & {$[50]$} & Nigeria & Ns & $\begin{array}{l}\text { Methanol, Water, } \\
\text { Butanol, Ethyl } \\
\text { Acetate }\end{array}$ & Moderate & $\begin{array}{l}15.81- \\
19.91 \mu \mathrm{g} / \mathrm{ml} \\
\mathrm{IC}_{50}\end{array}$ & $\begin{array}{l}\text { Plasmodium falcipa- } \\
\text { rum3D7, K1 }\end{array}$ & $\begin{array}{l}\text { Yes }(\mathrm{SI} \geq 84 \text {, Mouse } \\
[\mathrm{NBMH}])\end{array}$ \\
\hline $\begin{array}{l}\text { Citropsis articu- } \\
\text { lata }\end{array}$ & Rutaceae & [75] & Uganda & $\begin{array}{l}\text { Root } \\
\text { Barks }\end{array}$ & Ethyl Acetate & $\mathrm{Nd}$ & nd & $\begin{array}{l}\text { Plasmodium falcipa- } \\
\text { rumFcb1 }\end{array}$ & $\mathrm{Nd}$ \\
\hline \multirow[t]{2}{*}{ Clausena anisota } & Rutaceae & [24] & Kenya & $\begin{array}{l}\text { Stem } \\
\text { Barks }\end{array}$ & Methanol & Good & $\begin{array}{l}8.4-9.2 \mu \mathrm{g} / \\
\mathrm{ml} \mathrm{C}_{50}\end{array}$ & $\begin{array}{l}\text { Plasmodium falcipa- } \\
\text { rumD6, W2 }\end{array}$ & $\mathrm{Nd}$ \\
\hline & & [22] & $\begin{array}{l}\text { South } \\
\text { Africa }\end{array}$ & Twigs & $\begin{array}{l}\text { Dichlorometh- } \\
\text { ane/Methanol }\end{array}$ & Moderate & $18 \mu \mathrm{g} / \mathrm{ml} I \mathrm{C}_{50}$ & $\begin{array}{l}\text { Plasmodium falcipa- } \\
\text { rumD10 }\end{array}$ & $\mathrm{Nd}$ \\
\hline \multirow[t]{2}{*}{$\begin{array}{l}\text { Clematis bra- } \\
\text { chiata Thunb }\end{array}$} & Ranunculaceae & [37] & $\begin{array}{l}\text { South } \\
\text { Africa }\end{array}$ & Roots & Dichloromethane & Good & $\begin{array}{l}5.36 \mu \mathrm{g} / \mathrm{ml} \\
\mathrm{IC}_{50}\end{array}$ & $\begin{array}{l}\text { Plasmodium falcipa- } \\
\text { rumNF54 }\end{array}$ & $\mathrm{Nd}$ \\
\hline & & [21] & Kenya & $\begin{array}{l}\text { Root } \\
\text { Barks }\end{array}$ & Methanol & Very Good & $\begin{array}{l}4.15 \mu \mathrm{g} / \mathrm{ml} \\
\mathrm{IC}_{50}\end{array}$ & $\begin{array}{l}\text { Plasmodium falcipa- } \\
\text { rumD6 }\end{array}$ & No \\
\hline \multirow[t]{2}{*}{$\begin{array}{l}\text { Clerodendrum } \\
\text { eriophyllum }\end{array}$} & Lamiaceae & {$[72]$} & Kenya & $\begin{array}{l}\text { Root } \\
\text { Barks }\end{array}$ & Dichloromethane & Very Good & $\begin{array}{l}2.7-5.3 \mu \mathrm{g} / \mathrm{ml} \\
\mathrm{IC}_{50}\end{array}$ & $\begin{array}{l}\text { Plasmodium falcipa- } \\
\text { rumK1, NF54 }\end{array}$ & $\mathrm{Nd}$ \\
\hline & & [24] & Kenya & Leaves & Methanol & Very Good & $\begin{array}{l}<1.8-3.9 \mu \mathrm{g} / \\
\mathrm{ml} \mathrm{C}_{50}\end{array}$ & $\begin{array}{l}\text { Plasmodium falcipa- } \\
\text { rumD6, W2 }\end{array}$ & $\mathrm{Nd}$ \\
\hline $\begin{array}{l}\text { Clerodendrum } \\
\text { glabrum E. } \\
\text { Mey }\end{array}$ & Lamiaceae & {$[37]$} & $\begin{array}{l}\text { South } \\
\text { Africa }\end{array}$ & Leaves & Dicloromethane & Good & $\begin{array}{l}8.89 \mu \mathrm{g} / \mathrm{ml} \\
\mathrm{IC}_{50}\end{array}$ & $\begin{array}{l}\text { Plasmodium falcipa- } \\
\text { rumNF54 }\end{array}$ & $\mathrm{Nd}$ \\
\hline $\begin{array}{l}\text { Clerodendrum } \\
\text { glabrum var. } \\
\text { glabrum }\end{array}$ & Lamiaceae & [22] & $\begin{array}{l}\text { South } \\
\text { Africa }\end{array}$ & Twigs & $\begin{array}{l}\text { Dichlorometh- } \\
\text { ane/Methanol }\end{array}$ & Moderate & $19 \mu \mathrm{g} / \mathrm{ml} \mathrm{IC}_{50}$ & $\begin{array}{l}\text { Plasmodium falcipa- } \\
\text { rumD10 }\end{array}$ & $\mathrm{Nd}$ \\
\hline $\begin{array}{l}\text { Clerodendrum } \\
\text { johnstonii }\end{array}$ & Lamiaceae & [24] & Kenya & $\begin{array}{l}\text { Root } \\
\text { Barks }\end{array}$ & Methanol & Good & $8.5 \mu \mathrm{g} / \mathrm{ml} \mathrm{C}_{50}$ & $\begin{array}{l}\text { Plasmodium falcipa- } \\
\text { rumD6, W2 }\end{array}$ & $\mathrm{Nd}$ \\
\hline \multirow[t]{4}{*}{$\begin{array}{l}\text { Rotheca myri- } \\
\text { coides }\end{array}$} & Lamiaceae & {$[76]$} & Kenya & $\begin{array}{l}\text { Root } \\
\text { Barks }\end{array}$ & Methanol & Good & $\begin{array}{l}4.0-8.4 \mu \mathrm{g} / \\
\mathrm{ml} \mathrm{IC} \mathrm{C}_{50}\end{array}$ & $\begin{array}{l}\text { Plasmodium } \\
\text { falciparum(K39, } \\
\text { ENT30, NF54, V1/S) }\end{array}$ & $\mathrm{Nd}$ \\
\hline & & [26] & Kenya & $\begin{array}{l}\text { Root } \\
\text { Barks }\end{array}$ & Methanol & Good & $\begin{array}{l}4.7-8.3 \mu \mathrm{g} / \mathrm{ml} \\
\mid \mathrm{C}_{50}\end{array}$ & $\begin{array}{l}\text { Plasmodium falcipa- } \\
\text { rumD6, W2 }\end{array}$ & $\mathrm{Nd}$ \\
\hline & & [20] & Tanzania & $\begin{array}{l}\text { Root } \\
\text { Barks }\end{array}$ & Ethyl Acetate & Moderate & $11 \mu \mathrm{g} / \mathrm{ml} / \mathrm{C}_{50}$ & $\begin{array}{l}\text { Plasmodium falcipa- } \\
\text { rumK1 }\end{array}$ & $\mathrm{Nd}$ \\
\hline & & [72] & Kenya & $\begin{array}{l}\text { Root } \\
\text { Barks }\end{array}$ & Dichloromethane & Moderate & 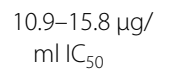 & $\begin{array}{l}\text { Plasmodium falcipa- } \\
\text { rumK1, NF54 }\end{array}$ & $\mathrm{Nd}$ \\
\hline \multirow[t]{2}{*}{$\begin{array}{l}\text { Clerodendrum } \\
\text { rotundifolium }\end{array}$} & Lamiaceae & [24] & Kenya & Leaves & Dichloromethane & Good & $\begin{array}{l}<3.9-15.7 \mu \mathrm{g} / \\
\mathrm{ml} \mathrm{C}_{50}\end{array}$ & $\begin{array}{l}\text { Plasmodium falcipa- } \\
\text { rumD6, W2 }\end{array}$ & $\mathrm{Nd}$ \\
\hline & & [77] & Uganda & Leaves & Ethyl Acetate & Very Good & 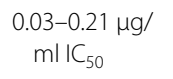 & $\begin{array}{l}\text { Plasmodium falcipa- } \\
\text { rumNF54 \& FCR3 }\end{array}$ & $\mathrm{Nd}$ \\
\hline Clutia abyssinica & Peraceae & [24] & Kenya & Leaves & Methanol & Moderate & 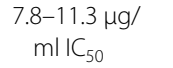 & $\begin{array}{l}\text { Plasmodium falcipa- } \\
\text { rum D6, W2 }\end{array}$ & $\mathrm{Nd}$ \\
\hline
\end{tabular}


Table 1 (continued)

\begin{tabular}{|c|c|c|c|c|c|c|c|c|c|}
\hline Plant species & Plant family & Source & $\begin{array}{l}\text { Country } \\
\text { of study }\end{array}$ & $\begin{array}{l}\text { Part of } \\
\text { plant } \\
\text { used }\end{array}$ & $\begin{array}{l}\text { Extraction } \\
\text { solvent }\end{array}$ & $\begin{array}{l}\text { Antiplas- } \\
\text { modial } \\
\text { Activity }\end{array}$ & $\begin{array}{l}\mathrm{IC}_{50} \text { or } \mathrm{ED}_{50} \\
\text { or } \mathrm{LD}_{50}\end{array}$ & $\begin{array}{l}\text { Strain of } \\
\text { Plasmodium } \\
\text { Tested }\end{array}$ & $\begin{array}{l}\text { Toxicity (value; } \\
\text { assay) }\end{array}$ \\
\hline Clutia hirsuta & Peraceae & {$[22]$} & $\begin{array}{l}\text { South } \\
\text { Africa }\end{array}$ & $\begin{array}{l}\text { Whole } \\
\text { Plant }\end{array}$ & $\begin{array}{l}\text { Dichlorometh- } \\
\text { ane/Methanol }\end{array}$ & Moderate & $15 \mu \mathrm{g} / \mathrm{ml} \mathrm{IC} 50$ & $\begin{array}{l}\text { Plasmodium falcipa- } \\
\text { rum D10 }\end{array}$ & $\mathrm{Nd}$ \\
\hline Clutia robusta & Peraceae & {$[24]$} & Kenya & Leaves & Methanol & Good & $\begin{array}{l}3.4-7.5 \mu \mathrm{g} / \mathrm{ml} \\
\mid \mathrm{C}_{50}\end{array}$ & $\begin{array}{l}\text { Plasmodium falcipa- } \\
\text { rum D6, W2 }\end{array}$ & $\mathrm{Nd}$ \\
\hline \multirow[t]{2}{*}{$\begin{array}{l}\text { Cochlospermum } \\
\text { planchonii }\end{array}$} & Bixaceae & {$[78]$} & $\begin{array}{l}\text { Burkina } \\
\text { Faso }\end{array}$ & $\begin{array}{l}\text { Rhi- } \\
\text { zomes }\end{array}$ & $\begin{array}{l}\text { Methanol, Dichlo- } \\
\text { romethane }\end{array}$ & Good $^{a}$ & $\begin{array}{l}2.4-11.5 \mu \mathrm{g} / \\
\mathrm{ml} \mathrm{IC}_{50}\end{array}$ & $\begin{array}{l}\text { Plasmodium falcipa- } \\
\text { rum 3D7 }\end{array}$ & $\mathrm{Nd}$ \\
\hline & & {$[51]$} & Ivory Coast & Roots & $\begin{array}{c}\text { Methylene } \\
\text { Chloride }\end{array}$ & Very Good & $4.4 \mu \mathrm{g} / \mathrm{ml} \mathrm{I} C_{50}$ & $\begin{array}{l}\text { Plasmodium falcipa- } \\
\text { rum K1 }\end{array}$ & No \\
\hline \multirow[t]{2}{*}{$\begin{array}{l}\text { Cochlospermum } \\
\text { tinctorium }\end{array}$} & Bixaceae & {$[79]$} & $\begin{array}{l}\text { Burkina } \\
\text { Faso }\end{array}$ & Tubecles & Ns & Very Good & $1-2 \mu \mathrm{g} / \mathrm{ml} \mathrm{IC} C_{50}$ & $\begin{array}{l}\text { Plasmodium falci- } \\
\text { parum }\end{array}$ & $\mathrm{Nd}$ \\
\hline & & {$[79]$} & $\begin{array}{l}\text { Burkina } \\
\text { Faso }\end{array}$ & $\begin{array}{c}\text { Tuber- } \\
\text { cles }\end{array}$ & Water & Very Good & $\begin{array}{c}0.4-1.56 \mu \mathrm{g} / \\
\mathrm{ml} \mathrm{IC}_{50}\end{array}$ & $\begin{array}{l}\text { Plasmodium falcipa- } \\
\text { rum Fcbl And F32 }\end{array}$ & $\mathrm{Nd}$ \\
\hline Cola caricaefolia & Malvaceae & {$[48]$} & Ivory Coast & Leaves & Pentane & Moderate & $\begin{array}{l}11-16 \mu \mathrm{g} / \mathrm{ml} \\
\mid C_{50}\end{array}$ & $\begin{array}{l}\text { Plasmodium falcipa- } \\
\text { rum FCM29, CQ-S } \\
\text { (Nigerian) }\end{array}$ & No \\
\hline $\begin{array}{l}\text { Combretum col- } \\
\text { linum }\end{array}$ & Combretaceae & {$[52]$} & $\begin{array}{l}\text { Burkina } \\
\text { Faso }\end{array}$ & Leaves & Dichloromethane & Very Good & $0.2 \mu \mathrm{g} / \mathrm{ml} \mathrm{I} \mathrm{C}_{50}$ & $\begin{array}{l}\text { Plasmodiumfalci- } \\
\text { parum }\end{array}$ & $\mathrm{Nd}$ \\
\hline $\begin{array}{l}\text { Combretum } \\
\text { micranthum }\end{array}$ & Combretaceae & {$[57]$} & Ivory Coast & $\begin{array}{l}\text { Stem, } \\
\text { Leaves }\end{array}$ & Water & Very Good & $\begin{array}{l}0.88-1.7 \mu \mathrm{g} / \\
\mathrm{ml} \mathrm{IC}_{50}\end{array}$ & $\begin{array}{l}\text { Plasmodium falcipa- } \\
\text { rum Fcb1 \& F32 }\end{array}$ & $\mathrm{Nd}$ \\
\hline $\begin{array}{l}\text { Combretum psid- } \\
\text { ioides subsp. } \\
\text { Psilophyllum }\end{array}$ & Combretaceae & {$[20]$} & Tanzania & $\begin{array}{l}\text { Root } \\
\text { Barks }\end{array}$ & Ethyl Acetate & Good & $6.5 \mu \mathrm{g} / \mathrm{ml} \mathrm{IC} 50$ & $\begin{array}{l}\text { Plasmodium falcipa- } \\
\text { rum K1 }\end{array}$ & $\mathrm{Nd}$ \\
\hline $\begin{array}{c}\text { Combretum } \\
\text { zeyheri }\end{array}$ & Combretaceae & {$[22]$} & $\begin{array}{l}\text { South } \\
\text { Africa }\end{array}$ & Twigs & $\begin{array}{l}\text { Dichlorometh- } \\
\text { ane/Methanol }\end{array}$ & Moderate & $15 \mu \mathrm{g} / \mathrm{ml} / \mathrm{C}_{50}$ & $\begin{array}{l}\text { Plasmodium falcipa- } \\
\quad \text { rum D10 }\end{array}$ & $\mathrm{Nd}$ \\
\hline $\begin{array}{l}\text { Commiphora } \\
\text { africana }\end{array}$ & Burseraceae & {$[24]$} & Kenya & $\begin{array}{l}\text { Stem } \\
\text { Barks }\end{array}$ & Methanol & Good & $\begin{array}{c}9.6-10.2 \mu \mathrm{g} / \\
\mathrm{ml} \mathrm{IC}_{50}\end{array}$ & $\begin{array}{l}\text { Plasmodium falcipa- } \\
\text { rum D6, W2 }\end{array}$ & $\mathrm{Nd}$ \\
\hline \multirow[t]{2}{*}{$\begin{array}{l}\text { Commiphora } \\
\text { schimperi }\end{array}$} & Burseraceae & {$[26]$} & Kenya & $\begin{array}{l}\text { Stem } \\
\text { Barks }\end{array}$ & Methanol & Very Good & $\begin{array}{l}3.9-5.2 \mu \mathrm{g} / \mathrm{ml} \\
\mid \mathrm{C}_{50}\end{array}$ & $\begin{array}{l}\text { Plasmodium falcipa- } \\
\text { rum D6, W2 }\end{array}$ & $\mathrm{Nd}$ \\
\hline & & {$[21]$} & Kenya & $\begin{array}{l}\text { Inner } \\
\text { Barks }\end{array}$ & Methanol & Very Good & $\begin{array}{l}4.63 \mu \mathrm{g} / \mathrm{ml} \\
\mid C_{50}\end{array}$ & $\begin{array}{l}\text { Plasmodium falcipa- } \\
\text { rum D6 }\end{array}$ & No \\
\hline Conyza albida & Asteraceae & {$[22]$} & $\begin{array}{l}\text { South } \\
\text { Africa }\end{array}$ & $\begin{array}{l}\text { Whole } \\
\text { Plant }\end{array}$ & $\begin{array}{l}\text { Dichlorometh- } \\
\text { ane/Methanol }\end{array}$ & Very Good & $2 \mu \mathrm{g} / \mathrm{ml} \mathrm{IC_{50 }}$ & $\begin{array}{l}\text { Plasmodium falcipa- } \\
\text { rum D10 }\end{array}$ & $\mathrm{Nd}$ \\
\hline $\begin{array}{l}\text { Conyza podo- } \\
\text { cephala }\end{array}$ & Asteraceae & {$[22]$} & $\begin{array}{l}\text { South } \\
\text { Africa }\end{array}$ & $\begin{array}{l}\text { Whole } \\
\text { Plant }\end{array}$ & $\begin{array}{l}\text { Dichlorometh- } \\
\text { ane/Methanol }\end{array}$ & Good & $6.8 \mu \mathrm{g} / \mathrm{ml} \mathrm{IC} 50$ & $\begin{array}{l}\text { Plasmodium falcipa- } \\
\text { rum D10 }\end{array}$ & $\mathrm{Nd}$ \\
\hline Conyza scabrida & Asteraceae & {$[22]$} & $\begin{array}{l}\text { South } \\
\text { Africa }\end{array}$ & Flower & $\begin{array}{l}\text { Dichlorometh- } \\
\text { ane/Methanol }\end{array}$ & Good & $7.8 \mu \mathrm{g} / \mathrm{ml} \mathrm{IC} 50$ & $\begin{array}{l}\text { Plasmodium falcipa- } \\
\quad \text { rum D10 }\end{array}$ & $\mathrm{Nd}$ \\
\hline $\begin{array}{l}\text { Copaifera } \\
\text { religiosa }\end{array}$ & Fabaceae & [33] & Gabon & Leaves & Dichloromethane & Moderate & $\begin{array}{l}8.5-13.4 \mu \mathrm{g} / \\
\mathrm{ml} \mathrm{IC}_{50}\end{array}$ & $\begin{array}{l}\text { Plasmodium falcipa- } \\
\quad \text { rum FCB, 3D7 }\end{array}$ & $\begin{array}{l}\text { Yes } \\
\qquad\left(\mathrm{CC}_{50}=4.87 \mu \mathrm{g} /\right. \\
\text { ml; human } \\
\text { embryonic lung } \\
\text { cells [MRC-5]) }\end{array}$ \\
\hline Cordia myxa & Boraginaceae & {$[52]$} & $\begin{array}{l}\text { Burkina } \\
\text { Faso }\end{array}$ & Leaves & Dichloromethane & Good & $6.2 \mu \mathrm{g} / \mathrm{ml} \mathrm{I} \mathrm{C}_{50}$ & $\begin{array}{l}\text { Plasmodiumfalci- } \\
\text { parum }\end{array}$ & $\begin{array}{l}\text { Yes (SI }=0.5-0.9 \\
\text { HrpG2 cells) }\end{array}$ \\
\hline Coula edulis & Olacaceae & {$[80]$} & Cameroon & $\begin{array}{l}\text { Stem } \\
\text { Barks }\end{array}$ & Methanol & Good & $\begin{array}{l}5.79-13.8 \mu \mathrm{g} / \\
\quad \mathrm{ml} \mathrm{IC}_{50}\end{array}$ & $\begin{array}{l}\text { Plasmodium falcipa- } \\
\text { rum 3D7, DD2 }\end{array}$ & No \\
\hline $\begin{array}{l}\text { Crossopteryx } \\
\text { febrifuga }\end{array}$ & Rubiaceae & {$[27]$} & $\begin{array}{l}\text { Burkina } \\
\text { Faso }\end{array}$ & Leaves & Crude Alkaloid & Good & $\begin{array}{l}4-10 \mu \mathrm{g} / \mathrm{ml} \\
\mid \mathrm{C}_{50}\end{array}$ & $\begin{array}{l}\text { Plasmodium falcipa- } \\
\text { rum W2 }\end{array}$ & $\mathrm{Nd}$ \\
\hline $\begin{array}{l}\text { Crotalaria } \\
\text { burkeana }\end{array}$ & Fabaceae & {$[22]$} & $\begin{array}{l}\text { South } \\
\text { Africa }\end{array}$ & Roots & Dichloromethane & Good & $9.5 \mu \mathrm{g} / \mathrm{ml} \mathrm{IC} 50$ & $\begin{array}{l}\text { Plasmodium falcipa- } \\
\text { rum D10 }\end{array}$ & $\mathrm{Nd}$ \\
\hline $\begin{array}{l}\text { Croton gratis- } \\
\text { simus var. } \\
\text { subgratissimus }\end{array}$ & Euphorbiaceae & {$[22]$} & $\begin{array}{l}\text { South } \\
\text { Africa }\end{array}$ & Leaves & Dichloromethane & Very Good & $3.5 \mu \mathrm{g} / \mathrm{ml} \mathrm{I} C_{50}$ & $\begin{array}{l}\text { Plasmodium falcipa- } \\
\text { rum D10 }\end{array}$ & $\mathrm{Nd}$ \\
\hline Croton lobatus & Euphorbiaceae & {$[65]$} & Benin & Roots & Methanol & Good & $\begin{array}{l}2.80-6.56 \mu \mathrm{g} / \\
\mathrm{ml} \mathrm{IC}_{50}\end{array}$ & $\begin{array}{l}\text { Plasmodium falcipa- } \\
\text { rum 3D7 \& K1 }\end{array}$ & $\mathrm{Nd}$ \\
\hline $\begin{array}{l}\text { Croton macros- } \\
\text { tachyus }\end{array}$ & Euphorbiaceae & {$[30]$} & Kenya & $\begin{array}{l}\text { Leaves, } \\
\text { Stems }\end{array}$ & Dichloromethane & Very Good & $\begin{array}{l}2.72 \mu \mathrm{g} / \mathrm{ml} \\
\mid \mathrm{C}_{50}\end{array}$ & $\begin{array}{l}\text { Plasmodium falcipa- } \\
\text { rum W2, D6 }\end{array}$ & $\mathrm{Nd}$ \\
\hline
\end{tabular}


Table 1 (continued)

\begin{tabular}{|c|c|c|c|c|c|c|c|c|c|}
\hline Plant species & Plant family & Source & $\begin{array}{l}\text { Country } \\
\text { of study }\end{array}$ & $\begin{array}{l}\text { Part of } \\
\text { plant } \\
\text { used }\end{array}$ & $\begin{array}{l}\text { Extraction } \\
\text { solvent }\end{array}$ & $\begin{array}{l}\text { Antiplas- } \\
\text { modial } \\
\text { Activity }\end{array}$ & $\begin{array}{l}\mathrm{IC}_{50} \text { or } \mathrm{ED}_{50} \\
\text { or } \mathrm{LD}_{50}\end{array}$ & $\begin{array}{l}\text { Strain of } \\
\text { Plasmodium } \\
\text { Tested }\end{array}$ & $\begin{array}{l}\text { Toxicity (value; } \\
\text { assay) }\end{array}$ \\
\hline $\begin{array}{l}\text { Croton meng- } \\
\text { hartii }\end{array}$ & Euphorbiaceae & [22] & $\begin{array}{l}\text { South } \\
\text { Africa }\end{array}$ & Leaves & $\begin{array}{l}\text { Dichlorometh- } \\
\text { ane/Methanol }\end{array}$ & Very Good & $1.7 \mu \mathrm{g} / \mathrm{ml} / \mathrm{C}_{50}$ & $\begin{array}{l}\text { Plasmodium falcipa- } \\
\text { rum D10 }\end{array}$ & $\mathrm{Nd}$ \\
\hline $\begin{array}{l}\text { Croton pseudop- } \\
\text { ulchellus }\end{array}$ & Euphorbiaceae & [25] & $\begin{array}{l}\text { South } \\
\text { Africa }\end{array}$ & $\begin{array}{l}\text { Stem } \\
\text { Barks }\end{array}$ & Chloroform & Very Good & $\begin{array}{l}3.45 \mu \mathrm{g} / \mathrm{ml} \\
\mathrm{I}_{50}\end{array}$ & $\begin{array}{l}\text { Plasmodium falcipa- } \\
\text { rum UP1 (CQ-R) }\end{array}$ & $\mathrm{Nd}$ \\
\hline \multirow[t]{2}{*}{$\begin{array}{l}\text { Croton zambe- } \\
\text { sicus }\end{array}$} & Euphorbiaceae & {$[55]$} & Cameroon & $\begin{array}{l}\text { Stem } \\
\text { Barks }\end{array}$ & $\begin{array}{l}\text { Ethanol, Water, } \\
\text { Dichlorometh- } \\
\text { ane, Methanol, } \\
\text { Hexane }\end{array}$ & Good & $\begin{array}{l}0.88-9.14 \mu \mathrm{g} / \\
\mathrm{ml} / \mathrm{IC}_{50}\end{array}$ & $\begin{array}{l}\text { Plasmodium falcipa- } \\
\text { rum W2 }\end{array}$ & $\mathrm{Nd}$ \\
\hline & & [34] & Sudan & Fruits & $\begin{array}{l}\text { Petroleum Ether/ } \\
\text { Chloroform }\end{array}$ & Very Good & $<5 \mu \mathrm{g} / \mathrm{ml} \mathrm{IC_{50 }}$ & $\begin{array}{l}\text { Plasmodium falci- } \\
\text { parum }\end{array}$ & $\mathrm{Nd}$ \\
\hline \multirow[t]{4}{*}{$\begin{array}{l}\text { Cryptolepis san- } \\
\text { guinolenta }\end{array}$} & Apocynaceae & [81] & $\begin{array}{l}\text { Guinea- } \\
\text { Bissau }\end{array}$ & $\begin{array}{l}\text { Leaves, } \\
\text { Roots }\end{array}$ & $\begin{array}{c}\text { Ethanol, Chcl3, } \\
\text { Chloroform }\end{array}$ & Very Good & $\begin{array}{l}1.79 \mu \mathrm{g} / \mathrm{ml} \\
\mid \mathrm{C}_{50}\end{array}$ & $\begin{array}{l}\text { Plasmodium falcipa- } \\
\text { rum K1,T996 }\end{array}$ & $\mathrm{Nd}$ \\
\hline & & [82] & Ghana & Roots & Ethanol & $\begin{array}{l}\text { Very } \\
\text { good }^{\mathrm{a}}\end{array}$ & $\begin{array}{l}0.031 \mu \mathrm{g} / \mathrm{ml} \\
\mid \mathrm{C}_{50}\end{array}$ & $\begin{array}{l}\text { Plasmodium falcipa- } \\
\text { rum K1, Plasmo- } \\
\text { dium berghei }\end{array}$ & $\mathrm{Nd}$ \\
\hline & & [83] & D.R. Congo & $\begin{array}{l}\text { Root } \\
\text { barks }\end{array}$ & $\begin{array}{l}\text { Water, ethanol, } \\
\text { chloroform }\end{array}$ & Very good & $\begin{array}{l}27-41 \mathrm{ng} / \mathrm{ml} \\
\mid \mathrm{C}_{50}\end{array}$ & $\begin{array}{l}\text { Plasmodium } \\
\text { falciparum D6, K1, } \\
\text { W2, Plasmodium } \\
\text { berghei yoelii, Plas- } \\
\text { modium berghei } \\
\text { berghei }\end{array}$ & $\mathrm{Nd}$ \\
\hline & & [84] & Ghana & Roots & $\begin{array}{l}\text { Hexane, ethanol, } \\
\text { dichlorometh- } \\
\text { ane }\end{array}$ & $\begin{array}{l}\text { Very } \\
\text { good }^{\mathrm{a}}\end{array}$ & $\begin{array}{l}0.2-0.6 \mu \mathrm{M} \\
\mathrm{IC}_{50}\end{array}$ & $\begin{array}{l}\text { Plasmodium vinckei } \\
\text { petteri, Plasmo- } \\
\text { dium berghei } \\
\text { ANKA }\end{array}$ & $\mathrm{Nd}$ \\
\hline \multirow[t]{2}{*}{$\begin{array}{l}\text { Cussonia spicata } \\
\text { Thunb }\end{array}$} & Araliaceae & [22] & $\begin{array}{l}\text { South } \\
\text { Africa }\end{array}$ & Fruits & $\begin{array}{l}\text { Dichlorometh- } \\
\text { ane/Methanol }\end{array}$ & Moderate & $14 \mu \mathrm{g} / \mathrm{ml} / \mathrm{C}_{50}$ & $\begin{array}{l}\text { Plasmodium falcipa- } \\
\text { rum D10 }\end{array}$ & $\mathrm{Nd}$ \\
\hline & & {$[37]$} & $\begin{array}{l}\text { South } \\
\text { Africa }\end{array}$ & $\begin{array}{l}\text { Root } \\
\text { Barks }\end{array}$ & Dichloromethane & Very Good & $\begin{array}{l}3.25 \mu \mathrm{g} / \mathrm{ml} \\
\mathrm{C}_{50}\end{array}$ & $\begin{array}{l}\text { Plasmodium falcipa- } \\
\text { rum NF54 }\end{array}$ & $\mathrm{Nd}$ \\
\hline $\begin{array}{l}\text { Cussonia zim- } \\
\text { mermannii }\end{array}$ & Araliaceae & [20] & Tanzania & $\begin{array}{l}\text { Root } \\
\text { Barks }\end{array}$ & Petroleum Ether & Very Good & $3.3 \mu \mathrm{g} / \mathrm{ml} \mathrm{I} C_{50}$ & $\begin{array}{l}\text { Plasmodium falcipa- } \\
\text { rum K1 }\end{array}$ & $\mathrm{Nd}$ \\
\hline Cuviera longiflora & Rubiaceae & [80] & Cameroon & Leaves & $\begin{array}{l}\text { Dichlorometh- } \\
\text { ane/Methanol }\end{array}$ & Moderate & $\begin{array}{l}13.91- \\
20.24 \mu \mathrm{g} / \mathrm{ml} \\
\mid C_{50}\end{array}$ & $\begin{array}{l}\text { Plasmodium falcipa- } \\
\text { rum 3D7, DD2 }\end{array}$ & No \\
\hline $\begin{array}{l}\text { Cyathala pros- } \\
\text { tate }\end{array}$ & Amaranthaceae & [43] & Ivory Coast & $\begin{array}{l}\text { Whole } \\
\text { Plant }\end{array}$ & Ethanol & Moderate & $\begin{array}{l}12.4 \mu \mathrm{g} / \mathrm{ml} \\
\mid \mathrm{C}_{50}\end{array}$ & $\begin{array}{l}\text { Plasmodium falcipa- } \\
\text { rum FCB1 }\end{array}$ & $\mathrm{Nd}$ \\
\hline $\begin{array}{l}\text { Cyathula schim- } \\
\text { periana }\end{array}$ & Amaranthaceae & [24] & Kenya & $\begin{array}{l}\text { Root } \\
\text { Barks }\end{array}$ & Methanol & Moderate & $\begin{array}{l}5-17.6 \mu \mathrm{g} / \mathrm{ml} \\
\mathrm{C}_{50}\end{array}$ & $\begin{array}{l}\text { Plasmodium falcipa- } \\
\text { rum D6, W2 }\end{array}$ & $\mathrm{Nd}$ \\
\hline $\begin{array}{l}\text { Cymbopogon } \\
\text { validus }\end{array}$ & Poaceae & [22] & $\begin{array}{l}\text { South } \\
\text { Africa }\end{array}$ & $\begin{array}{l}\text { Whole } \\
\text { Plant }\end{array}$ & $\begin{array}{l}\text { Dichlorometh- } \\
\text { ane/Methanol }\end{array}$ & Good & $5.8 \mu \mathrm{g} / \mathrm{ml} \mathrm{IC_{50 }}$ & $\begin{array}{l}\text { Plasmodium falcipa- } \\
\text { rum D10 }\end{array}$ & $\mathrm{Nd}$ \\
\hline \multirow[t]{2}{*}{$\begin{array}{l}\text { Cyperus articu- } \\
\text { latus }\end{array}$} & Cyperaceae & [24] & Kenya & Tubers & Methanol & Good & $\begin{array}{l}4.8-8.7 \mu \mathrm{g} / \\
\mathrm{ml} \mathrm{C}_{50}\end{array}$ & $\begin{array}{l}\text { Plasmodium falcipa- } \\
\text { rum D6, W2 }\end{array}$ & $\mathrm{Nd}$ \\
\hline & & [74] & Kenya & $\begin{array}{l}\text { Rhi- } \\
\text { zomes }\end{array}$ & Methanol & Good & 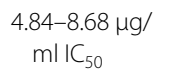 & $\begin{array}{l}\text { Plasmodium falcipa- } \\
\text { rum NF54, ENT30 }\end{array}$ & $\mathrm{Nd}$ \\
\hline $\begin{array}{l}\text { Cyphostemma } \\
\text { spp }\end{array}$ & Vitaceae & [86] & Namibia & $\begin{array}{l}\text { Whole } \\
\text { Plant }\end{array}$ & Methanol & Very Good & $\begin{array}{l}3.276 \mu \mathrm{g} / \mathrm{ml} \\
\mathrm{IC}_{50}\end{array}$ & $\begin{array}{l}\text { Plasmodium falcipa- } \\
\text { rum 3D7 }\end{array}$ & $\mathrm{Nd}$ \\
\hline \multirow[t]{2}{*}{ Dacryodes edulis } & Burseraceae & {$[80]$} & Cameroon & Leaves & $\begin{array}{l}\text { Dichlorometh- } \\
\text { ane/Methanol }\end{array}$ & Good & 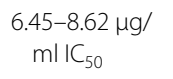 & $\begin{array}{l}\text { Plasmodium falcipa- } \\
\text { rum 3D7, DD2 }\end{array}$ & No \\
\hline & & [85] & Cameroon & $\begin{array}{l}\text { Root } \\
\text { Barks }\end{array}$ & $\begin{array}{l}\text { Methylene Chlo- } \\
\text { ride/Methanol }\end{array}$ & Very Good & $\begin{array}{l}0.37 \mu \mathrm{g} / \mathrm{ml} \\
\mathrm{I}_{50}\end{array}$ & $\begin{array}{l}\text { Plasmodiumfalci- } \\
\text { parum }\end{array}$ & No \\
\hline $\begin{array}{l}\text { Dichapetalum } \\
\text { guineense }\end{array}$ & $\begin{array}{l}\text { Dichapetal- } \\
\text { aceae }\end{array}$ & {$[65]$} & Benin & Leaves & Methanol & Moderate & 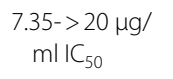 & $\begin{array}{l}\text { Plasmodium falcipa- } \\
\text { rum 3D7 \& K1 }\end{array}$ & $\mathrm{Nd}$ \\
\hline $\begin{array}{l}\text { Dichrostachys } \\
\text { cinerea Wight } \\
\text { et Arn }\end{array}$ & Fabaceae & [37] & $\begin{array}{l}\text { South } \\
\text { Africa }\end{array}$ & Roots & Dichloromethane & Very Good & $2.1 \mu \mathrm{g} / \mathrm{ml} \mathrm{IC} \mathrm{C}_{50}$ & $\begin{array}{l}\text { Plasmodium falcipa- } \\
\text { rum NF54 }\end{array}$ & $\mathrm{Nd}$ \\
\hline
\end{tabular}


Table 1 (continued)

\begin{tabular}{|c|c|c|c|c|c|c|c|c|c|}
\hline Plant species & Plant family & Source & $\begin{array}{l}\text { Country } \\
\text { of study }\end{array}$ & $\begin{array}{l}\text { Part of } \\
\text { plant } \\
\text { used }\end{array}$ & $\begin{array}{l}\text { Extraction } \\
\text { solvent }\end{array}$ & $\begin{array}{l}\text { Antiplas- } \\
\text { modial } \\
\text { Activity }\end{array}$ & $\begin{array}{l}I C_{50} \text { or } E D_{50} \\
\text { or } L D_{50}\end{array}$ & $\begin{array}{l}\text { Strain of } \\
\text { Plasmodium } \\
\text { Tested }\end{array}$ & $\begin{array}{l}\text { Toxicity (value; } \\
\text { assay) }\end{array}$ \\
\hline \multirow[t]{2}{*}{$\begin{array}{l}\text { Dicoma tomen- } \\
\text { tosa }\end{array}$} & Asteraceae & {$[62]$} & $\begin{array}{l}\text { Burkina } \\
\text { Faso }\end{array}$ & $\begin{array}{l}\text { Whole } \\
\text { Plant }\end{array}$ & $\begin{array}{l}\text { Dichlorometh- } \\
\text { ane, Methanol }\end{array}$ & Good & $\begin{array}{l}7.04-7.90 \mu \mathrm{g} / \\
\mathrm{ml} \mathrm{IC_{50 }}\end{array}$ & $\begin{array}{l}\text { Plasmodium falcipa- } \\
\text { rum 3D7 \&W2 }\end{array}$ & $\mathrm{Nd}$ \\
\hline & & {$[87]$} & $\begin{array}{l}\text { Burkina } \\
\text { Faso }\end{array}$ & $\begin{array}{l}\text { Whole } \\
\text { plant }\end{array}$ & Dichloromethane & Very Good & $\begin{array}{l}1.9-3.4 \mu \mathrm{g} / \mathrm{ml} \\
\mid \mathrm{C}_{50}\end{array}$ & $\begin{array}{l}\text { Plasmodium } \\
\text { Falcipârum 3D7, } \\
\text { W2, Plasmodium } \\
\text { berghei }\end{array}$ & $\mathrm{Nd}$ \\
\hline $\begin{array}{l}\text { Diospyros abysi- } \\
\text { nica }\end{array}$ & Ebenaceae & {$[75]$} & Uganda & Leaves & Ethyl Acetate & $\mathrm{Nd}$ & nd & $\begin{array}{l}\text { Plasmodium falcipa- } \\
\text { rum Fcb2 }\end{array}$ & $\mathrm{Nd}$ \\
\hline \multirow[t]{2}{*}{$\begin{array}{l}\text { Diospyros } \\
\text { mespiliformis }\end{array}$} & Ebeneceae & {$[86]$} & Namibia & $\begin{array}{l}\text { Leaves, } \\
\text { Roots }\end{array}$ & Methanol & Very Good & $\begin{array}{l}3.179- \\
\quad 3.523 \mu \mathrm{g} / \mathrm{ml} \\
\mathrm{IC}_{50}\end{array}$ & $\begin{array}{l}\text { Plasmodium falcipa- } \\
\text { rum 3D7 }\end{array}$ & $\mathrm{Nd}$ \\
\hline & & [37] & $\begin{array}{l}\text { South } \\
\text { Africa }\end{array}$ & Roots & Dichloromethane & Very Good & $\begin{array}{l}4.40 \mu \mathrm{g} / \mathrm{ml} \\
\mid \mathrm{C}_{50}\end{array}$ & $\begin{array}{l}\text { Plasmodium falcipa- } \\
\text { rum NF54 }\end{array}$ & $\mathrm{Nd}$ \\
\hline $\begin{array}{l}\text { Diospyros mon- } \\
\text { buttensis }\end{array}$ & Ebenaceae & {$[88]$} & Nigeria & Leaves & Methanol & Very Good & $3.2 \mathrm{nM}$ & $\begin{array}{l}\text { Plasmodium falci- } \\
\text { parum }\end{array}$ & $\mathrm{Nd}$ \\
\hline $\begin{array}{l}\text { Dombeyashu- } \\
\text { pangae }\end{array}$ & Malvaceae & {$[20]$} & Tanzania & $\begin{array}{l}\text { Root } \\
\text { Barks }\end{array}$ & Ethyl Acetate & Good & $7.5 \mu \mathrm{g} / \mathrm{ml} \mathrm{I} \mathrm{C}_{50}$ & $\begin{array}{l}\text { Plasmodium falcipa- } \\
\text { rum K1 }\end{array}$ & $\mathrm{Nd}$ \\
\hline $\begin{array}{l}\text { Dorstenia } \\
\text { convexa }\end{array}$ & Moraceae & {$[56]$} & Cameroon & Twigs & $\begin{array}{l}\text { Ethanol, Water, } \\
\text { Dichlorometh- } \\
\text { ane, Methanol, } \\
\text { Hexane }\end{array}$ & Good & $\begin{array}{l}0.28-8.95 \mu \mathrm{g} / \\
\mathrm{ml} \mathrm{IC}_{50}\end{array}$ & $\begin{array}{l}\text { Plasmodium falcipa- } \\
\text { rum W2 }\end{array}$ & $\mathrm{Nd}$ \\
\hline $\begin{array}{l}\text { Dorstenia } \\
\text { klaineana }\end{array}$ & Moraceae & [33] & Gabon & Stems & Methanol & Moderate & $\begin{array}{l}16.7-17.0 \mu \mathrm{g} / \\
\mathrm{ml} \mathrm{IC}_{50}\end{array}$ & $\begin{array}{l}\text { Plasmodium falcipa- } \\
\text { rum Fcbm, W2 }\end{array}$ & $\begin{array}{l}\text { Yes (SI=16.2- } \\
28.89 ; \text { human } \\
\text { embryonic lung } \\
\text { cells [MRC-5]) }\end{array}$ \\
\hline $\begin{array}{l}\text { Dracaena cam- } \\
\text { bodiana }\end{array}$ & Asparagaceae & {$[45]$} & Cambodia & Stems & Dichloromethane & Good & $8.7 \mu \mathrm{g} / \mathrm{ml} \mathrm{IC} 50$ & $\begin{array}{l}\text { Plasmodium falcipa- } \\
\text { rum W2 }\end{array}$ & $\mathrm{Nd}$ \\
\hline $\begin{array}{l}\text { Drypetes natal- } \\
\text { ensis }\end{array}$ & Putranjivaceae & {$[31]$} & Tanzania & Roots & Ethanol & Very Good & $\begin{array}{l}1.06 \mu \mathrm{g} / \mathrm{ml} \\
\mathrm{IC}_{50}\end{array}$ & $\begin{array}{l}\text { Plasmodium falcipa- } \\
\text { rum K1 }\end{array}$ & No \\
\hline \multirow[t]{4}{*}{$\begin{array}{l}\text { Ekebergia } \\
\text { capensis }\end{array}$} & Meliaceae & {$[22]$} & $\begin{array}{l}\text { South } \\
\text { Africa }\end{array}$ & Fruits & $\begin{array}{l}\text { Dichlorometh- } \\
\text { ane/Methanol }\end{array}$ & Moderate & $10 \mu \mathrm{g} / \mathrm{ml} \mathrm{IC} 50$ & $\begin{array}{l}\text { Plasmodium falcipa- } \\
\text { rum D10 }\end{array}$ & $\mathrm{Nd}$ \\
\hline & & {$[76]$} & Kenya & $\begin{array}{l}\text { Stem } \\
\text { Barks }\end{array}$ & Chloroform & Good & $\begin{array}{l}3.9-13.4 \mu \mathrm{g} / \\
\mathrm{ml} \mathrm{IC}_{50}\end{array}$ & $\begin{array}{l}\text { Plasmodium falcipa- } \\
\text { rum K39, ENT30, } \\
\text { NF54, V1/S }\end{array}$ & $\mathrm{Nd}$ \\
\hline & & {$[21]$} & Kenya & $\begin{array}{l}\text { Inner } \\
\text { Barks }\end{array}$ & Methanol & Very Good & $\begin{array}{l}3.97 \mu \mathrm{g} / \mathrm{ml} \\
\mathrm{IC}_{50}\end{array}$ & $\begin{array}{l}\text { Plasmodium falcipa- } \\
\text { rum D6 }\end{array}$ & No \\
\hline & & {$[24]$} & Kenya & $\begin{array}{l}\text { Stem } \\
\text { Barks }\end{array}$ & Methanol & Moderate & $\begin{array}{l}10.5 \mu \mathrm{g} / \mathrm{ml} \\
\mid \mathrm{C}_{50}\end{array}$ & $\begin{array}{l}\text { Plasmodium falcipa- } \\
\text { rum D6, W2 }\end{array}$ & $\mathrm{Nd}$ \\
\hline Elaeis guineensis & Arecaceae & {$[32]$} & Ghana & Leaves & Ethanol & Very Good & $\begin{array}{l}1.195 \mu \mathrm{g} / \mathrm{ml} \\
I_{50}\end{array}$ & $\begin{array}{l}\text { Plasmodium falcipa- } \\
\text { rum 3D7 }\end{array}$ & $\mathrm{Nd}$ \\
\hline $\begin{array}{l}\text { Elaeodendron } \\
\text { buchananii }\end{array}$ & Celastraceae & {$[24]$} & Kenya & $\begin{array}{l}\text { Stem } \\
\text { Barks }\end{array}$ & Methanol & Moderate & $\begin{array}{l}17.1 \mu \mathrm{g} / \mathrm{ml} \\
\mid \mathrm{C}_{50}\end{array}$ & $\begin{array}{l}\text { Plasmodium falcipa- } \\
\text { rum D6, W2 }\end{array}$ & $\mathrm{Nd}$ \\
\hline \multirow[t]{2}{*}{$\begin{array}{l}\text { Enantia chlor- } \\
\text { antha }\end{array}$} & Annonaceae & {$[55]$} & Cameroon & $\begin{array}{l}\text { Stem } \\
\text { Barks }\end{array}$ & $\begin{array}{l}\text { Ethanol, Water, } \\
\text { Dichlorometh- } \\
\text { ane, Methanol, } \\
\text { Hexane }\end{array}$ & Good & $\begin{array}{l}0.68-14.72 \mu \mathrm{g} / \\
\mathrm{ml} \mathrm{IC}_{50}\end{array}$ & $\begin{array}{l}\text { Plasmodium falcipa- } \\
\text { rum W2 }\end{array}$ & $\mathrm{Nd}$ \\
\hline & & {$[40]$} & DR Congo & $\begin{array}{l}\text { Stem } \\
\text { Barks }\end{array}$ & Water & Good & $\begin{array}{l}7.77 \mu \mathrm{g} / \mathrm{ml} \\
\mid \mathrm{C}_{50}\end{array}$ & $\begin{array}{l}\text { Plasmodium falcipa- } \\
\text { rum K1 }\end{array}$ & $\begin{array}{l}\text { Yes }\left(\mathrm{CC}_{50}=3.0 \mu \mathrm{g} /\right. \\
\text { ml; human } \\
\text { embryonic lung } \\
\text { cells [MRC-5]) }\end{array}$ \\
\hline $\begin{array}{l}\text { Entandro- } \\
\text { phragma } \\
\text { angolense }\end{array}$ & Meliaceae & [89] & Cameroon & $\begin{array}{l}\text { Stem } \\
\text { Barks }\end{array}$ & $\begin{array}{l}\text { Dichlorometh- } \\
\text { ane/Methanol }\end{array}$ & Moderate & $\begin{array}{l}18.4 \mu \mathrm{g} / \mathrm{ml} \\
\mathrm{IC}_{50}\end{array}$ & $\begin{array}{l}\text { Plasmodium falcipa- } \\
\text { rum W2 }\end{array}$ & $\mathrm{Nd}$ \\
\hline $\begin{array}{l}\text { Entandro- } \\
\text { phragma } \\
\text { caudatum }\end{array}$ & Meliaceae & {$[25]$} & $\begin{array}{l}\text { South } \\
\text { Africa }\end{array}$ & $\begin{array}{l}\text { Stem } \\
\text { Barks }\end{array}$ & Dichloromethane & Very Good & $2.9 \mu \mathrm{g} / \mathrm{ml} \mathrm{I} C_{50}$ & $\begin{array}{l}\text { Plasmodium falcipa- } \\
\text { rum UP1 (CQ-R) }\end{array}$ & No \\
\hline
\end{tabular}


Table 1 (continued)

\begin{tabular}{|c|c|c|c|c|c|c|c|c|c|}
\hline Plant species & Plant family & Source & $\begin{array}{l}\text { Country } \\
\text { of study }\end{array}$ & $\begin{array}{l}\text { Part of } \\
\text { plant } \\
\text { used }\end{array}$ & $\begin{array}{l}\text { Extraction } \\
\text { solvent }\end{array}$ & $\begin{array}{l}\text { Antiplas- } \\
\text { modial } \\
\text { Activity }\end{array}$ & $\begin{array}{l}\mathrm{IC}_{50} \text { or } \mathrm{ED}_{50} \\
\text { or } \mathrm{LD}_{50}\end{array}$ & $\begin{array}{l}\text { Strain of } \\
\text { Plasmodium } \\
\text { Tested }\end{array}$ & $\begin{array}{l}\text { Toxicity (value; } \\
\text { assay) }\end{array}$ \\
\hline $\begin{array}{l}\text { Entandro- } \\
\text { phragma } \\
\text { palustre }\end{array}$ & Meliaceae & [46] & D.R. Congo & $\begin{array}{l}\text { Stem } \\
\text { barks }\end{array}$ & Methanol & Moderate & $\begin{array}{l}15.84 \mu \mathrm{g} / \mathrm{ml} \\
\mathrm{IC}_{50}\end{array}$ & $\begin{array}{l}\text { Plasmodium } \\
\text { falciparum 3D7, } \\
\text { W2, Plasmodium } \\
\text { berghei berghei }\end{array}$ & $\mathrm{Nd}$ \\
\hline $\begin{array}{l}\text { Erigeron floribun- } \\
\text { dus }\end{array}$ & Asteraceae & {$[48]$} & Ivory Coast & Leaves & Pentane & Good & $\begin{array}{l}4.3-10 \mu \mathrm{g} / \mathrm{ml} \\
\mid \mathrm{C}_{50}\end{array}$ & $\begin{array}{l}\text { Plasmodium falci- } \\
\text { parum FCM29, } \\
\text { Plasmodium } \\
\text { falciparum CQ-S } \\
\text { (Nigerian) }\end{array}$ & $\mathrm{Nd}$ \\
\hline $\begin{array}{l}\text { Erioglossum } \\
\text { edule }\end{array}$ & Sapindaceae & {$[45]$} & Cambodia & Barks & Dichloromethane & Very Good & $1.7 \mu \mathrm{g} / \mathrm{ml} \mathrm{I} \mathrm{C}_{50}$ & $\begin{array}{l}\text { Plasmodium falcipa- } \\
\text { rum W2 }\end{array}$ & $\mathrm{Nd}$ \\
\hline $\begin{array}{l}\text { Erythrina abys- } \\
\text { sinica }\end{array}$ & Fabaceae & {$[75]$} & Uganda & Barks & Ethyl Acetate & $\mathrm{Nd}$ & nd & $\begin{array}{l}\text { Plasmodium falcipa- } \\
\text { rum Fcb3 }\end{array}$ & $\mathrm{Nd}$ \\
\hline $\begin{array}{l}\text { Erythrina lysiste- } \\
\text { mon }\end{array}$ & Fabaceae & {$[25]$} & $\begin{array}{l}\text { South } \\
\text { Africa }\end{array}$ & $\begin{array}{l}\text { Stem } \\
\text { Barks }\end{array}$ & Acetone & Very Good & $4.8 \mu \mathrm{g} / \mathrm{ml} \mathrm{I} \mathrm{C}_{50}$ & $\begin{array}{l}\text { Plasmodium falcipa- } \\
\text { rum UP1 (CQ-R) }\end{array}$ & $\mathrm{Nd}$ \\
\hline $\begin{array}{l}\text { Erythrina } \\
\text { sacleuxii }\end{array}$ & Fabaceae & [20] & Tanzania & $\begin{array}{l}\text { Root } \\
\text { Barks }\end{array}$ & Ethyl Acetate & Very Good & $3.0 \mu \mathrm{g} / \mathrm{ml} \mathrm{I} \mathrm{C}_{50}$ & $\begin{array}{l}\text { Plasmodium falcipa- } \\
\text { rum K1 }\end{array}$ & $\mathrm{Nd}$ \\
\hline $\begin{array}{c}\text { Erythrococca } \\
\text { anomala }\end{array}$ & Euphorbiaceae & {$[43]$} & Ivory Coast & Leaves & Ethanol & Moderate & $13.1 \mu \mathrm{g} / \mathrm{dl} I C_{50}$ & $\begin{array}{l}\text { Plasmodium falcipa- } \\
\text { rum FCB1 }\end{array}$ & $\mathrm{Nd}$ \\
\hline Euclea divinorum & Ebenaceae & [24] & Kenya & $\begin{array}{l}\text { Root } \\
\text { Barks }\end{array}$ & Methanol & Good & 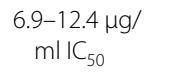 & $\begin{array}{l}\text { Plasmodium falcipa- } \\
\text { rum D6, W2 }\end{array}$ & $\mathrm{Nd}$ \\
\hline Euclea natalensis & Ebenaceae & [22] & $\begin{array}{l}\text { South } \\
\text { Africa }\end{array}$ & Twigs & $\begin{array}{l}\text { Dichlorometh- } \\
\text { ane/Methanol }\end{array}$ & Very Good & $4.6 \mu \mathrm{g} / \mathrm{ml} \mathrm{IC} C_{50}$ & $\begin{array}{l}\text { Plasmodium falcipa- } \\
\text { rum D10 }\end{array}$ & $\mathrm{Nd}$ \\
\hline $\begin{array}{l}\text { Eucomis autum- } \\
\text { nalis }\end{array}$ & Asparagaceae & [22] & $\begin{array}{l}\text { South } \\
\text { Africa }\end{array}$ & Bulbs & $\begin{array}{l}\text { Dichlorometh- } \\
\text { ane/Methanol }\end{array}$ & Good & $9.5 \mu \mathrm{g} / \mathrm{ml} \mathrm{I} C_{50}$ & $\begin{array}{l}\text { Plasmodium falcipa- } \\
\text { rum D10 }\end{array}$ & $\mathrm{Nd}$ \\
\hline \multirow[t]{2}{*}{ Euphorbia hirta } & Euphorbiaceae & {$[90]$} & D.R. Congo & $\begin{array}{l}\text { Aerial } \\
\text { Parts }\end{array}$ & $\begin{array}{l}\text { Methanol, } \\
\text { Hexane: Ethyl } \\
\text { Acetate }\end{array}$ & Good $^{a}$ & $\begin{array}{l}1.1-5.4 \mu \mathrm{g} / \\
\mathrm{ml} / \mathrm{C}_{50}\end{array}$ & $\begin{array}{l}\text { Plasmodium falci- } \\
\text { parum }\end{array}$ & No \\
\hline & & [70] & D.R. Congo & $\begin{array}{l}\text { Whole } \\
\text { Plant }\end{array}$ & Petroleum Ether & Very Good & $1.2 \mu \mathrm{g} / \mathrm{ml} \mathrm{IC}_{50}$ & $\begin{array}{l}\text { Plasmodium falci- } \\
\text { parum }\end{array}$ & $\mathrm{Nd}$ \\
\hline $\begin{array}{c}\text { Euphorbia } \\
\text { tirucalli }\end{array}$ & Euphorbiaceae & {$[22]$} & $\begin{array}{l}\text { South } \\
\text { Africa }\end{array}$ & Leaves & Dichloromethane & Moderate & $12 \mu \mathrm{g} / \mathrm{ml} \mathrm{IC_{50 }}$ & $\begin{array}{l}\text { Plasmodium falcipa- } \\
\text { rum D10 }\end{array}$ & $\mathrm{Nd}$ \\
\hline Fadogia agrestis & Rubiaceae & {$[27]$} & $\begin{array}{l}\text { Burkina } \\
\text { Faso }\end{array}$ & Leaves & Crude Alkaloid & Good & $\begin{array}{l}4-10 \mu \mathrm{g} / \mathrm{ml} \\
\mid \mathrm{C}_{50}\end{array}$ & $\begin{array}{l}\text { Plasmodium falcipa- } \\
\text { rum W2 }\end{array}$ & $\mathrm{Nd}$ \\
\hline $\begin{array}{l}\text { Fagara macro- } \\
\text { phylla }\end{array}$ & Rutaceae & {$[28]$} & Ivory Coast & $\begin{array}{l}\text { Stem } \\
\text { Barks }\end{array}$ & Ethanol & Very Good & $2.3 \mu \mathrm{g} / \mathrm{ml} \mathrm{I} C_{50}$ & $\begin{array}{l}\text { Plasmodium } \\
\text { falciparum Fcb1/ } \\
\text { Colombia Strain }\end{array}$ & No \\
\hline $\begin{array}{l}\text { Fagaropsis } \\
\text { angolensis }\end{array}$ & Rutaceae & [24] & Kenya & $\begin{array}{l}\text { Stem } \\
\text { Barks }\end{array}$ & Methanol & Good & $\begin{array}{l}4.2-6.9 \mu \mathrm{g} / \mathrm{ml} \\
\mid \mathrm{C}_{50}\end{array}$ & $\begin{array}{l}\text { Plasmodium falcipa- } \\
\text { rum D6, W2 }\end{array}$ & $\mathrm{Nd}$ \\
\hline Fagraea fragrans & Gentianaceae & {$[45]$} & Cambodia & Stems & Dichloromethane & Moderate & $\begin{array}{l}12.8 \mu \mathrm{g} / \mathrm{ml} \\
\mid \mathrm{C}_{50}\end{array}$ & $\begin{array}{l}\text { Plasmodium falcipa- } \\
\text { rum W2 }\end{array}$ & $\mathrm{Nd}$ \\
\hline Ficus capraefolia & Moraceae & {$[52]$} & $\begin{array}{l}\text { Burkina } \\
\text { Faso }\end{array}$ & Leaves & Dichloromethane & Very Good & $1.8 \mu \mathrm{g} / \mathrm{ml} \mathrm{IC}_{50}$ & $\begin{array}{l}\text { Plasmodium falci- } \\
\text { parum }\end{array}$ & $\begin{array}{l}\text { Yes }(\mathrm{SI}=0.4 ; \text { HepG2 } \\
\text { cells) }\end{array}$ \\
\hline Ficus platyhylla & Moraceae & {$[50]$} & Nigeria & Ns & $\begin{array}{l}\text { Methanol, Water, } \\
\text { Butanol, Ethyl } \\
\text { Acetate }\end{array}$ & Moderate & $\begin{array}{l}13.77- \\
15.28 \mu \mathrm{gg} / \mathrm{ml} \\
\mid \mathrm{C}_{50}\end{array}$ & $\begin{array}{l}\text { Plasmodium falcipa- } \\
\text { rum 3D7, K1 }\end{array}$ & $\begin{array}{l}\text { Yes }(S I \geq 77 \text {; mouse } \\
[\mathrm{NBMH}])\end{array}$ \\
\hline \multirow[t]{2}{*}{ Ficus sur } & Moraceae & [24] & Kenya & $\begin{array}{l}\text { Stem } \\
\text { Barks }\end{array}$ & Methanol & Moderate & $\begin{array}{l}8.5-15.9 \mu \mathrm{g} / \\
\mathrm{ml} / \mathrm{I}_{50}\end{array}$ & $\begin{array}{l}\text { Plasmodium falcipa- } \\
\text { rum D6, W2 }\end{array}$ & $\mathrm{Nd}$ \\
\hline & & {$[76]$} & Kenya & $\begin{array}{l}\text { Stem } \\
\text { Barks }\end{array}$ & $\begin{array}{l}\text { Chloroform, } \\
\text { Hexane }\end{array}$ & Moderate & $\begin{array}{l}9.0-19.2 \mu \mathrm{g} / \\
\quad \mathrm{ml} \mathrm{IC}_{50}\end{array}$ & $\begin{array}{l}\text { Plasmodium falcipa- } \\
\text { rum K39 (CQ-S), } \\
\text { ENT30, NF54, V1/S }\end{array}$ & $\mathrm{Nd}$ \\
\hline \multirow[t]{2}{*}{ Ficus thonningii } & Moraceae & [29] & $\begin{array}{l}\text { Republic } \\
\text { Of } \\
\text { Congo }\end{array}$ & Leaves & $\begin{array}{l}\text { Methanol, } \\
\text { Ethanol }\end{array}$ & Good & $\begin{array}{l}9.61 \mu \mathrm{g} / \mathrm{ml} \\
\mid \mathrm{C}_{50}\end{array}$ & $\begin{array}{l}\text { Plasmodium falci- } \\
\text { parum }\end{array}$ & No \\
\hline & & {$[50]$} & Nigeria & Ns & $\begin{array}{l}\text { Methanol, Water, } \\
\text { Butanol, Ethyl } \\
\text { Acetate }\end{array}$ & Moderate & $\begin{array}{l}14.09- \\
25.06 \mu \mathrm{g} / \mathrm{ml} \\
\mid \mathrm{C}_{50}\end{array}$ & $\begin{array}{l}\text { Plasmodium falcipa- } \\
\text { rum 3D7, K1 }\end{array}$ & $\begin{array}{l}\text { Yes }(\mathrm{SI} \geq 103 ; \\
\text { mouse }[\mathrm{NBMH}])\end{array}$ \\
\hline
\end{tabular}


Table 1 (continued)

\begin{tabular}{|c|c|c|c|c|c|c|c|c|c|}
\hline Plant species & Plant family & Source & $\begin{array}{l}\text { Country } \\
\text { of study }\end{array}$ & $\begin{array}{l}\text { Part of } \\
\text { plant } \\
\text { used }\end{array}$ & $\begin{array}{l}\text { Extraction } \\
\text { solvent }\end{array}$ & $\begin{array}{l}\text { Antiplas- } \\
\text { modial } \\
\text { Activity }\end{array}$ & $\begin{array}{l}\mathrm{IC}_{50} \text { or } \mathrm{ED}_{50} \\
\text { or } \mathrm{LD}_{50}\end{array}$ & $\begin{array}{l}\text { Strain of } \\
\text { Plasmodium } \\
\text { Tested }\end{array}$ & $\begin{array}{l}\text { Toxicity (value; } \\
\text { assay) }\end{array}$ \\
\hline Ficus sycomorus & Moraceae & [27] & $\begin{array}{c}\text { Burkina } \\
\text { Faso }\end{array}$ & Leaves & Crude Alkaloid & Good & $\begin{array}{l}4-10 \mu \mathrm{g} / \mathrm{ml} \\
\mid \mathrm{C}_{50}\end{array}$ & $\begin{array}{l}\text { Plasmodium falcipa- } \\
\text { rum W2 }\end{array}$ & $\mathrm{Nd}$ \\
\hline \multirow[t]{3}{*}{ Flueggea virosa } & Phyllanthaceae & [91] & Comoros & Leaves & Water/Methanol & Very Good & $2 \mu \mathrm{g} / \mathrm{ml} \mathrm{IC} C_{50}$ & $\begin{array}{l}\text { Plasmodium falcipa- } \\
\text { rum W2 }\end{array}$ & No \\
\hline & & [26] & Kenya & $\begin{array}{l}\text { Stem } \\
\text { Barks }\end{array}$ & Methanol & Very Good & $\begin{array}{l}2.2-3.6 \mu \mathrm{g} / \mathrm{ml} \\
\mathrm{IC}_{50}\end{array}$ & $\begin{array}{l}\text { Plasmodium falcipa- } \\
\text { rum D6, W2 }\end{array}$ & $\mathrm{Nd}$ \\
\hline & & [22] & $\begin{array}{l}\text { South } \\
\text { Africa }\end{array}$ & $\begin{array}{l}\text { Leaves, } \\
\text { Twigs }\end{array}$ & Water & Moderate & $\begin{array}{l}11.4 \mu \mathrm{g} / \mathrm{ml} \\
\mathrm{IC}_{50}\end{array}$ & $\begin{array}{l}\text { Plasmodium falcipa- } \\
\text { rum D10 }\end{array}$ & $\mathrm{Nd}$ \\
\hline \multirow[t]{3}{*}{ Fuerstia africana } & Lamiaceae & [92] & Rwanda & $\begin{array}{l}\text { Leaves, } \\
\text { Stems }\end{array}$ & Methanol & Good & $\begin{array}{l}4.1-6.9 \mu \mathrm{g} / \mathrm{ml} \\
\mathrm{IC}_{50}\end{array}$ & $\begin{array}{l}\text { Plasmodium falcipa- } \\
\text { rum 3D7, W2 }\end{array}$ & $\begin{array}{l}\text { Yes (SI=1.9; } \\
\text { human normal } \\
\text { foetal lung fibro- } \\
\text { blast [WI-38) }\end{array}$ \\
\hline & & [21] & Kenya & Leaves & Methanol & Very Good & $\begin{array}{l}3.76 \mu \mathrm{g} / \mathrm{ml} \\
\mathrm{IC}_{50}\end{array}$ & $\begin{array}{l}\text { Plasmodium falcipa- } \\
\text { rum D6 }\end{array}$ & No \\
\hline & & [24] & Kenya & $\begin{array}{l}\text { Whole } \\
\text { Plant }\end{array}$ & Methanol & Very Good & $\begin{array}{l}0.9-2.4 \mu \mathrm{g} / \mathrm{ml} \\
\mid \mathrm{C}_{50}\end{array}$ & $\begin{array}{l}\text { Plasmodium falcipa- } \\
\text { rum D6, W2 }\end{array}$ & $\mathrm{Nd}$ \\
\hline \multirow[t]{2}{*}{$\begin{array}{r}\text { Funtumia } \\
\text { elastica }\end{array}$} & Apocynaceae & [43] & Ivory Coast & $\begin{array}{l}\text { Stem } \\
\text { Barks }\end{array}$ & Ethanol & Very Good & $3.6 \mu \mathrm{g} / \mathrm{ml} \mathrm{IC} 50$ & $\begin{array}{l}\text { Plasmodium falcipa- } \\
\text { rum FCB1 }\end{array}$ & $\mathrm{Nd}$ \\
\hline & & [28] & Ivory Coast & $\begin{array}{l}\text { Stem } \\
\text { Barks }\end{array}$ & Ethanol & Very Good & $3.3 \mu \mathrm{g} / \mathrm{ml} \mathrm{I} \mathrm{C}_{50}$ & $\begin{array}{l}\text { Plasmodium } \\
\text { falciparum Fcb1/ } \\
\text { Colombia Strain }\end{array}$ & No \\
\hline $\begin{array}{r}\text { Funtumia } \\
\text { latifolia }\end{array}$ & Apocynaceae & [75] & Uganda & Leaves & Ethyl Acetate & $\mathrm{Nd}$ & nd & $\begin{array}{l}\text { Plasmodium falcipa- } \\
\text { rum Fcb4 }\end{array}$ & $\mathrm{Nd}$ \\
\hline \multirow[t]{2}{*}{ Garcinia kola } & Clusiaceae & [67] & D.R. Congo & Seeds & $\begin{array}{l}\text { Ethanol, Metha- } \\
\text { nol, Petroleum } \\
\text { Ether, Chloro- } \\
\text { form }\end{array}$ & Good & $\begin{array}{l}1.02- \\
15.75 \mu \mathrm{g} / \mathrm{ml} \\
\mathrm{IC}_{50}\end{array}$ & $\begin{array}{l}\text { Plasmodium falci- } \\
\text { parum }\end{array}$ & $\mathrm{Nd}$ \\
\hline & & [69] & D.R. Congo & $\begin{array}{l}\text { Stem } \\
\text { Barks }\end{array}$ & Petroleum Ether & Very Good & $1.6 \mu \mathrm{g} / \mathrm{ml} \mathrm{IC}_{50}$ & $\begin{array}{l}\text { Plasmodium falci- } \\
\text { parum }\end{array}$ & $\mathrm{Nd}$ \\
\hline Gardenia lutea & Rubiaceae & [23] & Sudan & Leaves & Methanol & Good & $\begin{array}{l}3.3-5.2 \mu \mathrm{g} / \mathrm{ml} \\
\mathrm{IC}_{50}\end{array}$ & $\begin{array}{l}\text { Plasmodium falcipa- } \\
\text { rum 3D7, Dd2 }\end{array}$ & No \\
\hline $\begin{array}{l}\text { Gardenia } \\
\text { sokotensis }\end{array}$ & Rubiaceae & {$[62]$} & $\begin{array}{l}\text { Burkina } \\
\text { Faso }\end{array}$ & Leaves & Dichloromethane & Moderate & $\begin{array}{l}14.01 \mu \mathrm{g} / \mathrm{ml} \\
\mathrm{IC}_{50}\end{array}$ & $\begin{array}{l}\text { Plasmodium falcipa- } \\
\text { rum 3D7 \&W2 }\end{array}$ & $\mathrm{Nd}$ \\
\hline $\begin{array}{l}\text { Glinus oppositi- } \\
\text { folius }\end{array}$ & Molluginaceae & [93] & Mali & $\begin{array}{l}\text { Aerial } \\
\text { parts }\end{array}$ & Chloroform & Moderate & $\begin{array}{l}15.52- \\
18.70 \mu \mathrm{g} / \mathrm{ml} \\
\mid \mathrm{C}_{50}\end{array}$ & $\begin{array}{l}\text { Plasmodium falcipa- } \\
\text { rum W2 \& 3D7 }\end{array}$ & No \\
\hline Gloriosa superba & Colchicaceae & [22] & $\begin{array}{l}\text { South } \\
\text { Africa }\end{array}$ & $\begin{array}{l}\text { Whole } \\
\text { plant }\end{array}$ & $\begin{array}{l}\text { Dichlorometh- } \\
\text { ane/Methanol }\end{array}$ & Moderate & $17 \mu \mathrm{g} / \mathrm{ml} \mathrm{IC_{50 }}$ & $\begin{array}{l}\text { Plasmodium falcipa- } \\
\text { rum D10 }\end{array}$ & $\mathrm{Nd}$ \\
\hline Gnidia cuneata & Thymelaeaceae & {$[22]$} & $\begin{array}{l}\text { South } \\
\text { Africa }\end{array}$ & Stems & Dichloromethane & Moderate & $\begin{array}{l}15.9 \mu \mathrm{m} / \mathrm{ml} \\
\mathrm{IC}_{50}\end{array}$ & $\begin{array}{l}\text { Plasmodium falcipa- } \\
\text { rum D10 }\end{array}$ & $\mathrm{Nd}$ \\
\hline $\begin{array}{l}\text { Gnidia kraus- } \\
\text { siana var. } \\
\text { kraussiana }\end{array}$ & Thymelaeaceae & [22] & $\begin{array}{l}\text { South } \\
\text { Africa }\end{array}$ & $\begin{array}{l}\text { Leaves, } \\
\text { Twigs }\end{array}$ & $\begin{array}{l}\text { Dichlorometh- } \\
\text { ane/Methanol }\end{array}$ & Moderate & $\begin{array}{l}10.8 \mu \mathrm{g} / \mathrm{ml} \\
\mid \mathrm{C}_{50}\end{array}$ & $\begin{array}{l}\text { Plasmodium falcipa- } \\
\text { rum D10 }\end{array}$ & $\mathrm{Nd}$ \\
\hline \multirow[t]{3}{*}{$\begin{array}{l}\text { Gomphrena } \\
\text { celosioides }\end{array}$} & Amaranthaceae & {$[65]$} & Benin & $\begin{array}{l}\text { Aerial } \\
\text { Parts }\end{array}$ & Methanol & Good & $\begin{array}{l}4.26-14.97 \mu \mathrm{g} / \\
\mathrm{ml} / \mathrm{C}_{50}\end{array}$ & $\begin{array}{l}\text { Plasmodium falcipa- } \\
\text { rum 3D7 \& K1 }\end{array}$ & $\mathrm{Nd}$ \\
\hline & & [70] & Togo & $\begin{array}{l}\text { Aerial } \\
\text { Parts }\end{array}$ & Water & Moderate & $\begin{array}{l}<15 \mu \mathrm{g} / \mathrm{ml} \\
\mid \mathrm{C}_{50}\end{array}$ & $\begin{array}{l}\text { Plasmodium falci- } \\
\text { parum }\end{array}$ & $\mathrm{Nd}$ \\
\hline & & [20] & Tanzania & $\begin{array}{l}\text { Whole } \\
\text { plant }\end{array}$ & Ethyl Acetate & Moderate & $15 \mu \mathrm{g} / \mathrm{ml} \mathrm{IC_{50 }}$ & $\begin{array}{l}\text { Plasmodium falcipa- } \\
\text { rum K1 }\end{array}$ & $\mathrm{Nd}$ \\
\hline \multirow[t]{2}{*}{$\begin{array}{l}\text { Guiera senega- } \\
\text { lensis }\end{array}$} & Combretaceae & [57] & Ivory Coast & $\begin{array}{l}\text { Stem, } \\
\text { Leave }\end{array}$ & Water & Good & $\begin{array}{l}0.79-7.03 \mu \mathrm{g} / \\
\mathrm{ml} \mathrm{IC} C_{50}\end{array}$ & $\begin{array}{l}\text { Plasmodium falcipa- } \\
\text { rum Fcb1 \& F32 }\end{array}$ & $\mathrm{Nd}$ \\
\hline & & [94] & Mali & Roots & Chloroform & $\begin{array}{l}\text { Very } \\
\text { Good }^{a}\end{array}$ & $<4 \mu \mathrm{g} / \mathrm{ml} \mathrm{I} C_{50}$ & $\begin{array}{l}\text { Plasmodium falci- } \\
\text { parum }\end{array}$ & $\mathrm{Nd}$ \\
\hline $\begin{array}{l}\text { Gutenbergia } \\
\text { cordifolia }\end{array}$ & Asteraceae & [21] & Kenya & Leaves & Methanol & Very Good & $\begin{array}{l}4.40 \mu \mathrm{g} / \mathrm{ml} \\
\mathrm{IC}_{50}\end{array}$ & $\begin{array}{l}\text { Plasmodium falcipa- } \\
\text { rum D6 }\end{array}$ & No \\
\hline $\begin{array}{l}\text { Gynandropsis } \\
\text { gynandra }\end{array}$ & Cleomaceae & [20] & Tanzania & Roots & Ethyl Acetate & Moderate & $14 \mu \mathrm{g} / \mathrm{ml} \mathrm{IC} C_{50}$ & $\begin{array}{l}\text { Plasmodium falcipa- } \\
\text { rum K1 }\end{array}$ & $\mathrm{Nd}$ \\
\hline
\end{tabular}


Table 1 (continued)

\begin{tabular}{|c|c|c|c|c|c|c|c|c|c|}
\hline Plant species & Plant family & Source & $\begin{array}{l}\text { Country } \\
\text { of study }\end{array}$ & $\begin{array}{l}\text { Part of } \\
\text { plant } \\
\text { used }\end{array}$ & $\begin{array}{l}\text { Extraction } \\
\text { solvent }\end{array}$ & $\begin{array}{l}\text { Antiplas- } \\
\text { modial } \\
\text { Activity }\end{array}$ & $\begin{array}{l}\mathrm{IC}_{50} \text { or } \mathrm{ED}_{50} \\
\text { or } \mathrm{LD}_{50}\end{array}$ & $\begin{array}{l}\text { Strain of } \\
\text { Plasmodium } \\
\text { Tested }\end{array}$ & $\begin{array}{l}\text { Toxicity (value; } \\
\text { assay) }\end{array}$ \\
\hline H. suaveolens & Lamiaceae & [53] & Nigeria & Leaves & Petroleum Ether & Very Good & $\begin{array}{l}2.54 \mu \mathrm{g} / \mathrm{ml} \\
\mid \mathrm{C}_{50}\end{array}$ & $\begin{array}{l}\text { Plasmodium falcipa- } \\
\text { rum D10 }\end{array}$ & $\mathrm{Nd}$ \\
\hline $\begin{array}{l}\text { Haplophyllum } \\
\text { tuberculatum }\end{array}$ & Rutaceae & [23] & Sudan & $\begin{array}{l}\text { Aerial } \\
\text { Parts }\end{array}$ & Methanol & Very Good & $\begin{array}{l}1.2-1.5 \mu \mathrm{g} / \mathrm{ml} \\
\mathrm{IC}_{50}\end{array}$ & $\begin{array}{l}\text { Plasmodium falcipa- } \\
\text { rum 3D7, Dd2 }\end{array}$ & No \\
\hline \multirow[t]{4}{*}{$\begin{array}{l}\text { Harrisonia abys- } \\
\text { sinica }\end{array}$} & Rutaceae & [58] & Sudan & $\begin{array}{l}\text { Stem } \\
\text { Barks }\end{array}$ & Methanol & Good & $\begin{array}{l}4.7-10 \mu \mathrm{g} / \mathrm{ml} \\
\mathrm{IC}_{50}\end{array}$ & $\begin{array}{l}\text { Plasmodium falcipa- } \\
\text { rum 3D7, Dd3 }\end{array}$ & $\mathrm{Nd}$ \\
\hline & & [72] & Kenya & $\begin{array}{l}\text { Stem } \\
\text { Barks }\end{array}$ & Dichloromethane & Good & $\begin{array}{l}4.4-5.6 \mu \mathrm{gg} / \mathrm{ml} \\
\mid \mathrm{C}_{50}\end{array}$ & $\begin{array}{l}\text { Plasmodium falcipa- } \\
\text { rum K1, NF54 }\end{array}$ & $\mathrm{Nd}$ \\
\hline & & {$[26]$} & Kenya & $\begin{array}{l}\text { Root } \\
\text { Barks }\end{array}$ & Methanol & Good & $\begin{array}{l}7.8-11.4 \mu \mathrm{g} / \\
\mathrm{ml} \mathrm{IC}\end{array}$ & $\begin{array}{l}\text { Plasmodium falcipa- } \\
\text { rum D6, W2 }\end{array}$ & $\mathrm{Nd}$ \\
\hline & & [95] & Kenya & $\begin{array}{l}\text { Barks/ } \\
\text { Roots/ } \\
\text { Stem }\end{array}$ & Water & Very Good & $1.0 \mu \mathrm{g} / \mathrm{ml} \mathrm{IC_{50 }}$ & $\begin{array}{l}\text { Plasmodium } \\
\text { Knowlesi }\end{array}$ & $\mathrm{Nd}$ \\
\hline $\begin{array}{l}\text { Harrisonia } \\
\text { perforata }\end{array}$ & Rutaceae & {$[45]$} & Cambodia & Stems & Dichloromethane & Good & $6.0 \mu \mathrm{g} / \mathrm{ml} \mathrm{IC_{50 }}$ & $\begin{array}{l}\text { Plasmodium falcipa- } \\
\text { rum W2 }\end{array}$ & $\mathrm{Nd}$ \\
\hline \multirow[t]{2}{*}{$\begin{array}{c}\text { Harunganamad- } \\
\text { agascariensis }\end{array}$} & - Hypericaceae & {$[40]$} & D.R.Congo & $\begin{array}{l}\text { Stem } \\
\text { Barks }\end{array}$ & Water & Good & $\begin{array}{l}9.64 \mu \mathrm{g} / \mathrm{ml} \\
\mid \mathrm{C}_{50}\end{array}$ & $\begin{array}{l}\text { Plasmodium falcipa- } \\
\text { rum K1 }\end{array}$ & No \\
\hline & & [20] & Tanzania & Roots & Ethyl Acetate & Very Good & $4.0 \mu \mathrm{g} / \mathrm{ml} \mathrm{I} \mathrm{C}_{50}$ & $\begin{array}{l}\text { Plasmodium falcipa- } \\
\quad \text { rum K1 }\end{array}$ & $\mathrm{Nd}$ \\
\hline $\begin{array}{l}\text { Helichrysum } \\
\text { gymnocepha- } \\
\text { lum }\end{array}$ & Asteraceae & [96] & $\begin{array}{l}\text { Madagas- } \\
\text { car }\end{array}$ & Leaves & Essential Oil & In Active & $25 \mathrm{mg} / \mathrm{l}$ & $\begin{array}{l}\text { Plasmodium falcipa- } \\
\text { rum Fcb1 }\end{array}$ & $\mathrm{Nd}$ \\
\hline $\begin{array}{l}\text { Heli- } \\
\text { chrysum cymo- } \\
\text { sum }\end{array}$ & Asteraceae & [97] & $\begin{array}{l}\text { South } \\
\text { Africa }\end{array}$ & Leaves & $\begin{array}{l}\text { Water, Essential } \\
\text { Oil }\end{array}$ & $\begin{array}{l}\text { Very } \\
\text { Good }^{\mathrm{a}}\end{array}$ & $\begin{array}{l}1.25 \mu \mathrm{g} / \mathrm{ml} \\
I_{50}\end{array}$ & $\begin{array}{l}\text { Plasmodium falcipa- } \\
\text { rum FCR-3 }\end{array}$ & Yes \\
\hline $\begin{array}{l}\text { Heli- } \\
\text { chrysum nudi- } \\
\text { folium }\end{array}$ & Asteraceae & [22] & $\begin{array}{l}\text { South } \\
\text { Africa }\end{array}$ & $\begin{array}{l}\text { Whole } \\
\text { plant }\end{array}$ & $\begin{array}{l}\text { Dichlorometh- } \\
\text { ane/Methanol }\end{array}$ & Good & $6.8 \mu \mathrm{g} / \mathrm{ml} \mathrm{I} \mathrm{C}_{50}$ & $\begin{array}{l}\text { Plasmodium falcipa- } \\
\text { rum D10 }\end{array}$ & $\mathrm{Nd}$ \\
\hline $\begin{array}{c}\text { Hermannia } \\
\text { depressa }\end{array}$ & Malvaceae & [22] & $\begin{array}{l}\text { South } \\
\text { Africa }\end{array}$ & $\begin{array}{l}\text { Whole } \\
\text { plant }\end{array}$ & $\begin{array}{l}\text { Dichlorometh- } \\
\text { ane/Methanol }\end{array}$ & Good & $6.9 \mu \mathrm{g} / \mathrm{ml} \mathrm{I} \mathrm{C}_{50}$ & $\begin{array}{l}\text { Plasmodium falcipa- } \\
\text { rum D10 }\end{array}$ & $\mathrm{Nd}$ \\
\hline $\begin{array}{l}\text { Hexalobus } \\
\text { crispiflorus }\end{array}$ & Annonaceae & [98] & Cameroon & $\begin{array}{l}\text { Stem } \\
\text { Barks }\end{array}$ & Water & $\begin{array}{l}\text { Very } \\
\text { Good }^{a}\end{array}$ & $2.0 \mu \mathrm{g} / \mathrm{ml} \mathrm{IC_{50 }}$ & $\begin{array}{l}\text { Plasmodium falcipa- } \\
\text { rum W6 }\end{array}$ & $\mathrm{Nd}$ \\
\hline $\begin{array}{c}\text { Hippobromus } \\
\text { pauciflorus }\end{array}$ & Sapindaceae & {$[22]$} & $\begin{array}{l}\text { South } \\
\text { Africa }\end{array}$ & Twigs & $\begin{array}{l}\text { Dichlorometh- } \\
\text { ane/Methanol }\end{array}$ & Good & $5.9 \mu \mathrm{g} / \mathrm{ml} \mathrm{IC_{50 }}$ & $\begin{array}{l}\text { Plasmodium falcipa- } \\
\text { rum D10 }\end{array}$ & $\mathrm{Nd}$ \\
\hline $\begin{array}{l}\text { Holarrhena flori- } \\
\text { bunda }\end{array}$ & Apocynaceae & [99] & Cameroon & $\begin{array}{l}\text { Stem } \\
\text { Barkss }\end{array}$ & Water, Ethanol & Good & $\begin{array}{l}1.02-18.53 \mu \mathrm{g} / \\
\mathrm{mL} \mathrm{IC}_{50}\end{array}$ & $\begin{array}{l}\text { Plasmodium falcipa- } \\
\text { rum W2,D6, FCR-3, } \\
\text { 3D7 }\end{array}$ & $\mathrm{Nd}$ \\
\hline \multirow[t]{3}{*}{$\begin{array}{l}\text { Hoslundia } \\
\text { opposita }\end{array}$} & Lamiaceae & [20] & Tanzania & $\begin{array}{l}\text { Root } \\
\text { Barks }\end{array}$ & Petroleum Ether & Moderate & $10 \mu \mathrm{g} / \mathrm{ml} / \mathrm{I}_{50}$ & $\begin{array}{l}\text { Plasmodium falcipa- } \\
\text { rum K1 }\end{array}$ & $\mathrm{Nd}$ \\
\hline & & [26] & Kenya & Leaves & Methanol & Moderate & $\begin{array}{l}15.2-25.6 \mu \mathrm{g} / \\
\mathrm{ml} \mathrm{IC}_{50}\end{array}$ & $\begin{array}{l}\text { Plasmodium falcipa- } \\
\text { rum D6, W2 }\end{array}$ & $\mathrm{Nd}$ \\
\hline & & [75] & Uganda & Leaves & Ethyl Acetate & $\mathrm{Nd}$ & nd & $\begin{array}{l}\text { Plasmodium falcipa- } \\
\text { rum Fcb5 }\end{array}$ & $\mathrm{Nd}$ \\
\hline Hunteria eburnea & Apocynaceae & {$[43]$} & Ivory Coast & $\begin{array}{l}\text { Stem } \\
\text { Barks }\end{array}$ & Ethanol & Very Good & $2.2 \mu \mathrm{g} / \mathrm{ml} \mathrm{IC_{50 }}$ & $\begin{array}{l}\text { Plasmodium falcipa- } \\
\text { rum FCB1 }\end{array}$ & $\mathrm{Nd}$ \\
\hline $\begin{array}{l}\text { Hybanthus } \\
\text { enneaspermus }\end{array}$ & Violaceae & {$[65]$} & Benin & $\begin{array}{l}\text { Aerial } \\
\text { Parts }\end{array}$ & Methanol & Moderate & $\begin{array}{l}2.57->20 \mu \mathrm{g} / \\
\mathrm{ml} \mathrm{IC}_{50}\end{array}$ & $\begin{array}{l}\text { Plasmodium falcipa- } \\
\text { rum 3D7 \& K1 }\end{array}$ & $\mathrm{Nd}$ \\
\hline $\begin{array}{l}\text { Hymenocardia } \\
\text { acida }\end{array}$ & Phyllanthaceae & [51] & Ivory Coast & Leaves & $\begin{array}{l}\text { Methylene } \\
\text { Chloride }\end{array}$ & Good & $6.9 \mu \mathrm{g} / \mathrm{ml} \mathrm{IC_{50 }}$ & $\begin{array}{l}\text { Plasmodium falcipa- } \\
\text { rum K1 }\end{array}$ & $\begin{array}{c}\text { Yes (SI }=6-10 ; \text { rat } \\
\text { skeletal muscle } \\
\text { myoblast [L6]) }\end{array}$ \\
\hline $\begin{array}{l}\text { Hypericum } \\
\text { aethiopicum }\end{array}$ & Hypericaceae & [22] & $\begin{array}{l}\text { South } \\
\text { Africa }\end{array}$ & $\begin{array}{l}\text { Leaves/ } \\
\text { Flow- } \\
\text { ers }\end{array}$ & $\begin{array}{l}\text { Dichlorometh- } \\
\text { ane/Methanol }\end{array}$ & Very Good & $1.4 \mu \mathrm{g} / \mathrm{ml} \mathrm{IC_{50 }}$ & $\begin{array}{l}\text { Plasmodium falcipa- } \\
\text { rum D10 }\end{array}$ & $\mathrm{Nd}$ \\
\hline $\begin{array}{l}\text { Hypericum } \\
\text { lanceolatum }\end{array}$ & Hypericaceae & {$[80]$} & Cameroon & $\begin{array}{l}\text { Stem } \\
\text { Barks }\end{array}$ & $\begin{array}{l}\text { Methanol, } \\
\text { N-Hexane, } \\
\text { Ethyl Acetate, } \\
\text { N-Butanol }\end{array}$ & Very Good & $\begin{array}{l}3.98 \mu \mathrm{g} / \mathrm{ml} \\
\mathrm{IC}_{50}\end{array}$ & $\begin{array}{l}\text { Plasmodium falcipa- } \\
\text { rum W2, SHF4 }\end{array}$ & $\mathrm{Nd}$ \\
\hline
\end{tabular}


Table 1 (continued)

\begin{tabular}{|c|c|c|c|c|c|c|c|c|c|}
\hline Plant species & Plant family & Source & $\begin{array}{l}\text { Country } \\
\text { of study }\end{array}$ & $\begin{array}{l}\text { Part of } \\
\text { plant } \\
\text { used }\end{array}$ & $\begin{array}{l}\text { Extraction } \\
\text { solvent }\end{array}$ & $\begin{array}{l}\text { Antiplas- } \\
\text { modial } \\
\text { Activity }\end{array}$ & $\begin{array}{l}I C_{50} \text { or } E D_{50} \\
\text { or } L_{50}\end{array}$ & $\begin{array}{l}\text { Strain of } \\
\text { Plasmodium } \\
\text { Tested }\end{array}$ & $\begin{array}{l}\text { Toxicity (value; } \\
\text { assay) }\end{array}$ \\
\hline $\begin{array}{l}\text { Hypoestes } \\
\text { forskaolii }\end{array}$ & Acanthaceae & {$[24]$} & Kenya & $\begin{array}{l}\text { Root } \\
\text { Barks }\end{array}$ & Methanol & Good & $\begin{array}{l}4.3-6.7 \mu \mathrm{g} / \mathrm{ml} \\
\mid \mathrm{C}_{50}\end{array}$ & $\begin{array}{l}\text { Plasmodium falcipa- } \\
\text { rum D6, W2 }\end{array}$ & $\mathrm{Nd}$ \\
\hline Hyptis pectinata & Lamiaceae & {$[22]$} & $\begin{array}{l}\text { South } \\
\text { Africa }\end{array}$ & $\begin{array}{l}\text { Leaves, } \\
\text { Stem, } \\
\text { Flower }\end{array}$ & $\begin{array}{l}\text { Dichlorometh- } \\
\text { ane/Methanol }\end{array}$ & Moderate & $\begin{array}{l}17.5 \mu \mathrm{g} / \mathrm{ml} \\
\mid \mathrm{C}_{50}\end{array}$ & $\begin{array}{l}\text { Plasmodium falcipa- } \\
\text { rum D10 }\end{array}$ & $\mathrm{Nd}$ \\
\hline $\begin{array}{l}\text { Icacina senega- } \\
\text { lensis }\end{array}$ & Icacinaceae & {$[100]$} & Senegal & Leaves & Methanol & Good & $\begin{array}{l}4.7-8 \mu \mathrm{g} / \mathrm{ml} \\
\mid \mathrm{C}_{50}\end{array}$ & $\begin{array}{l}\text { Plasmodium falcipa- } \\
\text { rum 3D7, 7G8 }\end{array}$ & No \\
\hline Isolona hexaloba & Annonaceae & {$[40]$} & D.R. Congo & $\begin{array}{l}\text { Root } \\
\text { Barks }\end{array}$ & Water & Moderate & $\begin{array}{l}15.28 \mu \mathrm{g} / \mathrm{ml} \\
\mid \mathrm{C}_{50}\end{array}$ & $\begin{array}{l}\text { Plasmodium falcipa- } \\
\text { rum K1 }\end{array}$ & No \\
\hline $\begin{array}{l}\text { Khaya grandifo- } \\
\text { liola }\end{array}$ & Meliaceae & {$[101]$} & Cameroon & $\begin{array}{l}\text { Barks, } \\
\text { Seeds }\end{array}$ & $\begin{array}{l}\text { Methanol-Meth- } \\
\text { ylene Chloride }\end{array}$ & Good $^{\mathrm{a}}$ & $\begin{array}{l}1.25- \\
9.63 \mu \mathrm{g} / \mathrm{ml} \\
\mathrm{IC}_{50}\end{array}$ & $\begin{array}{l}\text { Plasmodium falcipa- } \\
\text { rum W2 }\end{array}$ & $\mathrm{Nd}$ \\
\hline $\begin{array}{l}\text { Khaya senega- } \\
\text { lensis }\end{array}$ & Meliaceae & {$[50]$} & Nigeria & Ns & $\begin{array}{l}\text { Methanol, Water, } \\
\text { Butanol, Ethyl } \\
\text { Acetate }\end{array}$ & Moderate & $\begin{array}{l}15.46- \\
28.12 \mu \mathrm{g} / \mathrm{ml} \\
\mathrm{IC}_{50}\end{array}$ & $\begin{array}{l}\text { Plasmodium falcipa- } \\
\text { rum 3D7, K1 }\end{array}$ & $\begin{array}{l}\text { Yes }(\mathrm{SI} \geq 69 ; \text { mouse } \\
[\mathrm{NBMH}])\end{array}$ \\
\hline \multirow[t]{2}{*}{ Kigelia africana } & Bignoniaceae & {$[24]$} & Kenya & Leaves & Methanol & Moderate & $\begin{array}{l}15.9 \mu \mathrm{g} / \mathrm{ml} \\
\mathrm{IC}_{50}\end{array}$ & $\begin{array}{l}\text { Plasmodium falcipa- } \\
\text { rum D6, W2 }\end{array}$ & $\mathrm{Nd}$ \\
\hline & & {$[80]$} & Cameroon & $\begin{array}{l}\text { Stem } \\
\text { Barks }\end{array}$ & Ethyl Acetate & Moderate & $\begin{array}{l}11.15 \mu \mathrm{g} / \\
\mathrm{mLIC} \mathrm{C}_{50}\end{array}$ & $\begin{array}{l}\text { Plasmodium falcipa- } \\
\text { rum W2 }\end{array}$ & No \\
\hline Kirkia wilmsii & Kirkiaceae & {$[22]$} & $\begin{array}{l}\text { South } \\
\text { Africa }\end{array}$ & Leaves & $\begin{array}{l}\text { Dichlorometh- } \\
\text { ane/Methanol }\end{array}$ & Very Good & $3.7 \mu \mathrm{g} / \mathrm{ml} \mathrm{IC} 50$ & $\begin{array}{l}\text { Plasmodium falcipa- } \\
\text { rum D10 }\end{array}$ & $\mathrm{Nd}$ \\
\hline Kniphofia foliosa $>$ & $\begin{array}{l}\text { Xanthor- } \\
\text { rhoeaceae }\end{array}$ & [102] & Ethiopia & Roots & Dichloromethane & Very Good & $\begin{array}{l}3.8 \mu \mathrm{g} / \mathrm{mL} \\
\mathrm{ED}_{50}\end{array}$ & $\begin{array}{l}\text { Plasmodium falcipa- } \\
\text { rum 3D7 }\end{array}$ & No \\
\hline $\begin{array}{l}\text { Landolphia } \\
\text { lanceolata }\end{array}$ & Apocynaceae & {$[103]$} & $\begin{array}{l}\text { Congo } \\
\text { Brazza- } \\
\text { ville }\end{array}$ & Roots & Dichloromethane & Moderate & $11 \mu \mathrm{g} / \mathrm{ml} \mathrm{IC} 50$ & $\begin{array}{l}\text { Plasmodium falcipa- } \\
\text { rum Fcm29- } \\
\text { Cameroon }\end{array}$ & $\mathrm{Nd}$ \\
\hline Lannea edulis & Anacardiaceae & {$[20]$} & Kenya & $\begin{array}{l}\text { Whole } \\
\text { Plant }\end{array}$ & Ethyl Acetate & Moderate & $17 \mu \mathrm{g} / \mathrm{ml} \mathrm{IC_{50 }}$ & $\begin{array}{l}\text { Plasmodium falcipa- } \\
\text { rum K1 }\end{array}$ & $\mathrm{Nd}$ \\
\hline Lantana camara & Verbenaceae & {$[22]$} & $\begin{array}{l}\text { South } \\
\text { Africa }\end{array}$ & $\begin{array}{l}\text { Leaves, } \\
\text { Twigs }\end{array}$ & $\begin{array}{l}\text { Dichlorometh- } \\
\text { ane/Methanol }\end{array}$ & Moderate & $11 \mu \mathrm{g} / \mathrm{ml} \mathrm{IC} 50$ & $\begin{array}{l}\text { Plasmodium falcipa- } \\
\text { rum D10 }\end{array}$ & $\mathrm{Nd}$ \\
\hline $\begin{array}{l}\text { Leonotis mollis- } \\
\quad \text { sima }\end{array}$ & Lamiaceae & {$[20]$} & Tanzania & Leaves & Ethyl Acetate & Good & $9 \mu \mathrm{g} / \mathrm{ml} \mathrm{I} C_{50}$ & $\begin{array}{l}\text { Plasmodium falcipa- } \\
\text { rum K1 }\end{array}$ & $\mathrm{Nd}$ \\
\hline Leonotis africana & Lamiaceae & [33] & Gabon & Stems & Dichloromethane & Moderate & $\begin{array}{l}15.2-27.1 \mu \mathrm{g} / \\
\mathrm{ml} \mathrm{IC}_{50}\end{array}$ & $\begin{array}{l}\text { Plasmodium falcipa- } \\
\text { rum Fcbm W2 }\end{array}$ & $\begin{array}{l}\text { Yes (SI=6.07-6.82; } \\
\text { human embry- } \\
\text { onic lung cells } \\
\text { [MRC-5]) }\end{array}$ \\
\hline Leonotis leonurus & Lamiaceae & {$[22]$} & $\begin{array}{l}\text { South } \\
\text { Africa }\end{array}$ & $\begin{array}{l}\text { Leaves, } \\
\text { Twigs }\end{array}$ & $\begin{array}{l}\text { Dichlorometh- } \\
\text { ane/Methanol }\end{array}$ & Good & $5.4 \mu \mathrm{g} / \mathrm{ml} \mathrm{IC} C_{50}$ & $\begin{array}{l}\text { Plasmodium falcipa- } \\
\text { rum D10 }\end{array}$ & $\mathrm{Nd}$ \\
\hline $\begin{array}{l}\text { Leonotis nepeti- } \\
\quad \text { folia }\end{array}$ & Lamiaceae & {$[22]$} & $\begin{array}{l}\text { South } \\
\text { Africa }\end{array}$ & $\begin{array}{l}\text { Whole } \\
\text { Plant }\end{array}$ & $\begin{array}{l}\text { Dichlorometh- } \\
\text { ane/Methanol }\end{array}$ & Moderate & $15 \mu \mathrm{g} / \mathrm{ml} \mathrm{IC} 50$ & $\begin{array}{l}\text { Plasmodium falcipa- } \\
\text { rum D10 }\end{array}$ & $\mathrm{Nd}$ \\
\hline $\begin{array}{l}\text { Leonotis ocymi- } \\
\quad \text { folia }\end{array}$ & Lamiaceae & {$[22]$} & $\begin{array}{l}\text { South } \\
\text { Africa }\end{array}$ & Leaves & $\begin{array}{l}\text { Dichlorometh- } \\
\text { ane/Methanol }\end{array}$ & Good & $6.1 \mu \mathrm{g} / \mathrm{ml} \mathrm{I} \mathrm{C}_{50}$ & $\begin{array}{l}\text { Plasmodium falcipa- } \\
\text { rum D10 }\end{array}$ & $\mathrm{Nd}$ \\
\hline $\begin{array}{l}\text { Leptadenia } \\
\text { madagas- } \\
\text { cariensis }\end{array}$ & Apocynaceae & [91] & Comoros & Ns & Dichloromethane & Good & $9 \mu \mathrm{g} / \mathrm{ml} \mathrm{I} C_{50}$ & $\begin{array}{l}\text { Plasmodium falcipa- } \\
\text { rum W2 }\end{array}$ & No \\
\hline $\begin{array}{l}\text { Leucas calos- } \\
\text { tachys }\end{array}$ & Lamiaceae & {$[95]$} & Kenya & $\begin{array}{l}\text { Whole } \\
\text { Plant }\end{array}$ & Water & Very Good & $\begin{array}{l}0.79 \mu \mathrm{g} / \mathrm{ml} \\
\mathrm{IC}_{50}\end{array}$ & $\begin{array}{l}\text { Plasmodium } \\
\text { Knowlesi }\end{array}$ & $\mathrm{Nd}$ \\
\hline $\begin{array}{l}\text { Leucas martini- } \\
\text { censis }\end{array}$ & Lamiaceae & {$[22]$} & $\begin{array}{l}\text { South } \\
\text { Africa }\end{array}$ & $\begin{array}{l}\text { Whole } \\
\text { Plant }\end{array}$ & $\begin{array}{l}\text { Dichlorometh- } \\
\text { ane/Methanol }\end{array}$ & Moderate & $\begin{array}{l}13.3 \mu \mathrm{g} / \mathrm{ml} \\
\mathrm{IC}_{50}\end{array}$ & $\begin{array}{l}\text { Plasmodium falcipa- } \\
\text { rum D10 }\end{array}$ & $\mathrm{Nd}$ \\
\hline
\end{tabular}


Table 1 (continued)

\begin{tabular}{|c|c|c|c|c|c|c|c|c|c|}
\hline Plant species & Plant family & Source & $\begin{array}{l}\text { Country } \\
\text { of study }\end{array}$ & $\begin{array}{l}\text { Part of } \\
\text { plant } \\
\text { used }\end{array}$ & $\begin{array}{l}\text { Extraction } \\
\text { solvent }\end{array}$ & $\begin{array}{l}\text { Antiplas- } \\
\text { modial } \\
\text { Activity }\end{array}$ & $\begin{array}{l}\mathrm{IC}_{50} \text { or } \mathrm{ED}_{50} \\
\text { or } \mathrm{LD}_{50}\end{array}$ & $\begin{array}{l}\text { Strain of } \\
\text { Plasmodium } \\
\text { Tested }\end{array}$ & $\begin{array}{l}\text { Toxicity (value; } \\
\text { assay) }\end{array}$ \\
\hline \multirow[t]{4}{*}{ Lippia javanica } & Verbenaceae & [24] & Kenya & $\begin{array}{l}\text { Root } \\
\text { Barks }\end{array}$ & Methanol & Good & $5.9 \mu \mathrm{g} / \mathrm{ml} \mathrm{IC_{50 }}$ & $\begin{array}{l}\text { Plasmodium falcipa- } \\
\text { rum D6, W2 }\end{array}$ & $\mathrm{Nd}$ \\
\hline & & [104] & Kenya & Roots & $\begin{array}{l}\text { Dichlorometh- } \\
\text { ane/Ethyl } \\
\text { Acetate }\end{array}$ & Moderate & $\begin{array}{l}16.7- \\
19.2 \mu \mathrm{m} / \mathrm{ml} \\
\mathrm{IC}_{50}\end{array}$ & $\begin{array}{l}\text { Plasmodium falcipa- } \\
\text { rum K39, V1/S }\end{array}$ & $\mathrm{Nd}$ \\
\hline & & [22] & $\begin{array}{l}\text { South } \\
\text { Africa }\end{array}$ & Roots & Dichloromethane & Very Good & $3.8 \mu \mathrm{g} / \mathrm{ml} \mathrm{IC} 50$ & $\begin{array}{l}\text { Plasmodium falcipa- } \\
\text { rum D10 }\end{array}$ & $\mathrm{Nd}$ \\
\hline & & {$[25]$} & $\begin{array}{l}\text { South } \\
\text { Africa }\end{array}$ & Leaves & Acetone & Very Good & $\begin{array}{l}4.26 \mu \mathrm{g} / \mathrm{ml} \\
\mid \mathrm{C}_{50}\end{array}$ & $\begin{array}{l}\text { Plasmodium falcipa- } \\
\text { rum UP1 (CQ-R) }\end{array}$ & $\mathrm{Nd}$ \\
\hline Lippia multiflora & Verbenaceae & {$[57]$} & Ivory Coast & Leaves & Water & Very Good & $\begin{array}{l}1.18- \\
2.34 \mu \mathrm{g} / \mathrm{ml} \\
\mathrm{I}_{50}\end{array}$ & $\begin{array}{l}\text { Plasmodium falcipa- } \\
\text { rum Fcb1 \& F32 }\end{array}$ & $\mathrm{Nd}$ \\
\hline $\begin{array}{l}\text { Lophira lanceo- } \\
\text { lata }\end{array}$ & Ochnaceae & {$[52]$} & $\begin{array}{l}\text { Burkina } \\
\text { Faso }\end{array}$ & Leaves & Dichloromethane & Very Good & $4.7 \mu \mathrm{g} / \mathrm{ml} \mathrm{IC_{50 }}$ & $\begin{array}{l}\text { Plasmodium falci- } \\
\text { parum }\end{array}$ & $\mathrm{Nd}$ \\
\hline Ludwigia erecta & Onagraceae & [24] & Kenya & $\begin{array}{l}\text { Whole } \\
\text { plant }\end{array}$ & Methanol & Very Good & $\begin{array}{l}0.9-1.6 \mu \mathrm{g} / \mathrm{ml} \\
\mid \mathrm{C}_{50}\end{array}$ & $\begin{array}{l}\text { Plasmodium falcipa- } \\
\text { rum D6, W2 }\end{array}$ & $\mathrm{Nd}$ \\
\hline $\begin{array}{l}\text { Macrostylis } \\
\text { squarrosa }\end{array}$ & Rutaceae & [22] & $\begin{array}{l}\text { South } \\
\text { Africa }\end{array}$ & Stems & $\begin{array}{l}\text { Dichlorometh- } \\
\text { ane/Methanol }\end{array}$ & Moderate & $16 \mu \mathrm{g} / \mathrm{ml} \mathrm{IC}_{50}$ & $\begin{array}{l}\text { Plasmodium falcipa- } \\
\text { rum D10 }\end{array}$ & $\mathrm{Nd}$ \\
\hline $\begin{array}{l}\text { Maesa lanceo- } \\
\text { lata }\end{array}$ & Primulaceae & [22] & $\begin{array}{l}\text { South } \\
\text { Africa }\end{array}$ & Twigs & $\begin{array}{l}\text { Dichlorometh- } \\
\text { ane/Methanol }\end{array}$ & Good & $5.9 \mu \mathrm{g} / \mathrm{ml} \mathrm{IC} C_{50}$ & $\begin{array}{l}\text { Plasmodium falcipa- } \\
\text { rum D10 }\end{array}$ & $\mathrm{Nd}$ \\
\hline Markhamia lutea & Bignognaceae & {$[76]$} & Uganda & Leaves & Ethyl Acetate & $\mathrm{Nd}$ & $\mathrm{Nd}$ & $\begin{array}{l}\text { Plasmodium falcipa- } \\
\text { rum Fcb6 }\end{array}$ & $\mathrm{Nd}$ \\
\hline $\begin{array}{l}\text { Maytenus hetero- } \\
\text { phylla }\end{array}$ & - Celastraceae & [24] & Kenya & $\begin{array}{l}\text { Root } \\
\text { barks }\end{array}$ & Methanol & Very Good & $\begin{array}{l}1.8-3.9 \mu \mathrm{g} / \mathrm{ml} \\
\mid \mathrm{C}_{50}\end{array}$ & $\begin{array}{l}\text { Plasmodium falcipa- } \\
\text { rum D6, W2 }\end{array}$ & $\mathrm{Nd}$ \\
\hline $\begin{array}{l}\text { Maytenus obtusi- } \\
\text { folia }\end{array}$ & Celastraceae & {$[24]$} & Kenya & $\begin{array}{l}\text { Root } \\
\text { barks }\end{array}$ & Methanol & Good & $\begin{array}{l}<1.9-5.8 \mu \mathrm{g} / \\
\quad \mathrm{ml} \mathrm{IC}_{50}\end{array}$ & $\begin{array}{l}\text { Plasmodium falcipa- } \\
\text { rum D6, W2 }\end{array}$ & $\mathrm{Nd}$ \\
\hline $\begin{array}{l}\text { Maytenus putter- } \\
\text { lickioides }\end{array}$ & Celastraceae & {$[26]$} & Kenya & $\begin{array}{l}\text { Root } \\
\text { Barks }\end{array}$ & Methanol & Good & 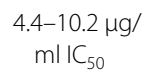 & $\begin{array}{l}\text { Plasmodium falcipa- } \\
\text { rum D6, W2 }\end{array}$ & $\mathrm{Nd}$ \\
\hline \multirow[t]{5}{*}{$\begin{array}{l}\text { Maytenus sen- } \\
\text { egalensis }\end{array}$} & Celastraceae & {$[58]$} & Sudan & $\begin{array}{l}\text { Stem } \\
\text { barks }\end{array}$ & Methanol & $\mathrm{Nd}$ & $\begin{array}{l}3.9-10 \mu \mathrm{g} / \mathrm{ml} \\
\mathrm{IC}_{50}\end{array}$ & $\begin{array}{l}\text { Plasmodium falcipa- } \\
\text { rum 3D7, Dd9 }\end{array}$ & $\mathrm{Nd}$ \\
\hline & & {$[26]$} & Kenya & $\begin{array}{l}\text { Root } \\
\text { barks }\end{array}$ & Methanol & Good & $\begin{array}{l}4.7-9.8 \mu \mathrm{g} / \mathrm{ml} \\
\mathrm{IC}_{50}\end{array}$ & $\begin{array}{l}\text { Plasmodium falcipa- } \\
\text { rum D6, W2 }\end{array}$ & $\mathrm{Nd}$ \\
\hline & & [22] & $\begin{array}{l}\text { South } \\
\text { Africa }\end{array}$ & Roots & Dichloromethane & Moderate & $\begin{array}{l}15.5 \mu \mathrm{g} / \mathrm{ml} \\
\mid \mathrm{C}_{50}\end{array}$ & $\begin{array}{l}\text { Plasmodium falcipa- } \\
\text { rum D10 }\end{array}$ & $\mathrm{Nd}$ \\
\hline & & [20] & Tanzania & $\begin{array}{l}\text { Stem } \\
\text { barks }\end{array}$ & Ethyl Acetate & Very Good & $\begin{array}{l}0.16 \mu \mathrm{g} / \mathrm{ml} \\
\mid \mathrm{C}_{50}\end{array}$ & $\begin{array}{l}\text { Plasmodium falcipa- } \\
\text { rum K1 }\end{array}$ & $\mathrm{Nd}$ \\
\hline & & [31] & Tanzania & Roots & Ethanol & Very Good & $\begin{array}{l}2.05 \mu \mathrm{g} / \mathrm{ml} \\
\mathrm{IC}_{50}\end{array}$ & $\begin{array}{l}\text { Plasmodium falcipa- } \\
\text { rum K1 }\end{array}$ & No \\
\hline $\begin{array}{r}\text { Maytenus } \\
\text { undata }\end{array}$ & Celastraceae & {$[26]$} & Kenya & Leaves & Water & Very Good & 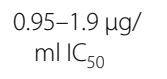 & $\begin{array}{l}\text { Plasmodium falcipa- } \\
\text { rum D6, W2 }\end{array}$ & $\mathrm{Nd}$ \\
\hline Melia azedarach & Meliaceae & {$[46]$} & D.R. Congo & Leaves & Dichloromethane & Moderate & $\begin{array}{l}19.14 \mu \mathrm{g} / \mathrm{ml} \\
\mathrm{IC}_{50}\end{array}$ & $\begin{array}{l}\text { Plasmodium } \\
\text { falciparum 3D7, } \\
\text { W2, Plasmodium } \\
\text { berghei berghei }\end{array}$ & $\mathrm{Nd}$ \\
\hline $\begin{array}{l}\text { Microdesmis } \\
\text { keayana }\end{array}$ & Pandaceae & {$[51]$} & Ivory Coast & Leaves & $\begin{array}{l}\text { Methylene } \\
\text { Chloride }\end{array}$ & Moderate & $\begin{array}{l}12.2 \mu \mathrm{g} / \mathrm{ml} \\
\mid \mathrm{C}_{50}\end{array}$ & $\begin{array}{l}\text { Plasmodium falcipa- } \\
\text { rum K1 }\end{array}$ & No \\
\hline \multirow[t]{3}{*}{$\begin{array}{c}\text { Microglossa } \\
\text { pyrifolia }\end{array}$} & Asteraceae & {$[24]$} & Kenya & Leaves & Methanol & Moderate & $\begin{array}{l}10.4 \mu \mathrm{g} / \mathrm{ml} \\
\mid \mathrm{C}_{50}\end{array}$ & $\begin{array}{l}\text { Plasmodium falcipa- } \\
\text { rum D6, W2 }\end{array}$ & $\mathrm{Nd}$ \\
\hline & & {$[77]$} & Uganda & Leaves & Ethyl Acetate & Very Good & 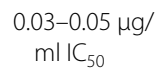 & $\begin{array}{l}\text { Plasmodium falcipa- } \\
\text { rum NF54 \& FCR3 }\end{array}$ & $\mathrm{Nd}$ \\
\hline & & [92] & Rwanda & Leaves & Dichloromethane & Very Good & $\begin{array}{l}1.5-2.4 \mu \mathrm{g} / \mathrm{ml} \\
\mathrm{IC}_{50}\end{array}$ & $\begin{array}{l}\text { Plasmodium falcipa- } \\
\text { rum 3D7, W2 }\end{array}$ & $\begin{array}{l}\text { Yes (SI=3.2; } \\
\text { human normal } \\
\text { foetal lungfibro- } \\
\text { blast [WI-38]) }\end{array}$ \\
\hline Mikania cordata & Compositae & [20] & Tanzania & Leaves & Ethyl Acetate & Moderate & $14 \mu \mathrm{g} / \mathrm{ml} \mathrm{IC}_{50}$ & $\begin{array}{l}\text { Plasmodium falcipa- } \\
\text { rum K1 }\end{array}$ & $\mathrm{Nd}$ \\
\hline
\end{tabular}


Table 1 (continued)

\begin{tabular}{|c|c|c|c|c|c|c|c|c|c|}
\hline Plant species & Plant family & Source & $\begin{array}{l}\text { Country } \\
\text { of study }\end{array}$ & $\begin{array}{l}\text { Part of } \\
\text { plant } \\
\text { used }\end{array}$ & $\begin{array}{l}\text { Extraction } \\
\text { solvent }\end{array}$ & $\begin{array}{l}\text { Antiplas- } \\
\text { modial } \\
\text { Activity }\end{array}$ & $\begin{array}{l}\mathrm{IC}_{50} \text { or } \mathrm{ED}_{50} \\
\text { or } \mathrm{LD}_{50}\end{array}$ & $\begin{array}{l}\text { Strain of } \\
\text { Plasmodium } \\
\text { Tested }\end{array}$ & $\begin{array}{l}\text { Toxicity (value; } \\
\text { assay) }\end{array}$ \\
\hline \multirow{2}{*}{\multicolumn{2}{|c|}{ Millettia zechiana Fabaceae }} & [28] & Ivory Coast & $\begin{array}{l}\text { Stem } \\
\text { Barks }\end{array}$ & Ethanol & Moderate & $\begin{array}{l}16.1 \mu \mathrm{g} / \mathrm{ml} \\
\mid \mathrm{C}_{50}\end{array}$ & $\begin{array}{l}\text { Plasmodium } \\
\text { falciparum Fcb1/ } \\
\text { Colombia Strain }\end{array}$ & $\mathrm{Nd}$ \\
\hline & & [43] & Ivory Coast & $\begin{array}{l}\text { Stem } \\
\text { Barks }\end{array}$ & Ethanol & Moderate & $\begin{array}{l}14.1 \mu \mathrm{g} / \mathrm{ml} \\
\mid \mathrm{C}_{50}\end{array}$ & $\begin{array}{l}\text { Plasmodium falcipa- } \\
\text { rum FCB1 }\end{array}$ & $\mathrm{Nd}$ \\
\hline \multirow[t]{2}{*}{$\begin{array}{l}\text { Momordica } \\
\text { balsamina }\end{array}$} & Cucurbitaceae & [22] & $\begin{array}{l}\text { South } \\
\text { Africa }\end{array}$ & Stems & $\begin{array}{l}\text { Dichlorometh- } \\
\text { ane/Methanol }\end{array}$ & Good & $5.3 \mu \mathrm{g} / \mathrm{ml} \mathrm{IC} C_{50}$ & $\begin{array}{l}\text { Plasmodium falcipa- } \\
\text { rum D10 }\end{array}$ & $\mathrm{Nd}$ \\
\hline & & [68] & $\begin{array}{l}\text { Mozam- } \\
\text { bique }\end{array}$ & $\begin{array}{l}\text { Aerial } \\
\text { Parts }\end{array}$ & Ns & $\begin{array}{l}\text { Very } \\
\text { Good }^{\mathrm{a}}\end{array}$ & $1 \mu \mathrm{M}$ & $\begin{array}{l}\text { Plasmodium berghei, } \\
\text { Plasmodium } \\
\text { falciparum }\end{array}$ & $\mathrm{Nd}$ \\
\hline $\begin{array}{l}\text { Momordica } \\
\text { charantia }\end{array}$ & Cucurbitaceae & [88] & Nigeria & Leaves & Methanol & Very Good & $12.5 \mathrm{nM}$ & $\begin{array}{l}\text { Plasmodium falci- } \\
\text { parum }\end{array}$ & $\mathrm{Nd}$ \\
\hline $\begin{array}{l}\text { Momordica } \\
\text { foetida }\end{array}$ & Cucurbitaceae & [77] & Uganda & Leaves & Water & Good & $\begin{array}{l}0.35-6.16 \mu \mathrm{g} / \\
\mathrm{ml} / \mathrm{I}_{50}\end{array}$ & $\begin{array}{l}\text { Plasmodium falcipa- } \\
\text { rum NF54 \& FCR3 }\end{array}$ & $\mathrm{Nd}$ \\
\hline \multirow[t]{2}{*}{$\begin{array}{l}\text { Monodora } \\
\text { myristica }\end{array}$} & Annonaceae & [33] & Gabon & Stem & Methanol & Good & $\begin{array}{l}5.5-6.1 \mu \mathrm{g} / \mathrm{ml} \\
\mathrm{IC}_{50}\end{array}$ & $\begin{array}{l}\text { Plasmodium falcipa- } \\
\text { rum Fcbm W2 }\end{array}$ & No \\
\hline & & [49] & Cameroon & Leaves & Methanol & Good & $\begin{array}{l}9.03 \mu \mathrm{g} / \mathrm{ml} \\
\mid \mathrm{C}_{50}\end{array}$ & $\begin{array}{l}\text { Plasmodium falcipa- } \\
\text { rum W2 }\end{array}$ & $\mathrm{Nd}$ \\
\hline \multirow[t]{3}{*}{ Morinda lucida } & Rubiaceae & [74] & $\begin{array}{l}\text { S. Tome' } \\
\text { And Prı } \\
\text { 'Ncipe }\end{array}$ & Barks & Ethanol & Good & $\begin{array}{l}<10 \mu \mathrm{g} / \mathrm{ml} \\
\mid \mathrm{C}_{50}\end{array}$ & $\begin{array}{l}\text { Plasmodium falcipa- } \\
\text { rum 3D7 and Dd2 }\end{array}$ & $\mathrm{Nd}$ \\
\hline & & [88] & Nigeria & Leaves & Methanol & Very Good & $25 \mathrm{nM}$ & $\begin{array}{l}\text { Plasmodium falci- } \\
\text { parum }\end{array}$ & $\mathrm{Nd}$ \\
\hline & & [53] & Nigeria & Roots & Dichloromethane & Moderate & $\begin{array}{l}13.37 \mu \mathrm{g} / \mathrm{ml} \\
\mid \mathrm{C}_{50}\end{array}$ & $\begin{array}{l}\text { Plasmodium falcipa- } \\
\text { rum D10 }\end{array}$ & $\mathrm{Nd}$ \\
\hline \multirow[t]{2}{*}{$\begin{array}{l}\text { Morinda morin- } \\
\text { doides }\end{array}$} & Rubiaceae & [43] & Ivory Coast & Leaves & Ethanol & Good & $9.8 \mu \mathrm{g} / \mathrm{ml} \mathrm{IC_{50 }}$ & $\begin{array}{l}\text { Plasmodium falcipa- } \\
\text { rum FCB1 }\end{array}$ & $\mathrm{Nd}$ \\
\hline & & [28] & Ivory Coast & Leaves & Ethanol & Moderate & $\begin{array}{l}11.6 \mu \mathrm{g} / \mathrm{ml} \\
\mid \mathrm{C}_{50}\end{array}$ & $\begin{array}{l}\text { Plasmodium } \\
\text { falciparum Fcb1/ } \\
\text { Colombia Strain }\end{array}$ & $\mathrm{Nd}$ \\
\hline Moringa oleifera & Moringaceae & [26] & Kenya & Leaves & Methanol & Moderate & $9.8 \mu \mathrm{g} / \mathrm{ml} \mathrm{I} C_{50}$ & $\begin{array}{l}\text { Plasmodium falcipa- } \\
\text { rum D6, W2 }\end{array}$ & $\mathrm{Nd}$ \\
\hline $\begin{array}{l}\text { Motandra } \\
\text { guineensis }\end{array}$ & Apocynaceae & [43] & Ivory Coast & Leaves & Ethanol & Moderate & $\begin{array}{l}16.3 \mu \mathrm{g} / \mathrm{ml} \\
\mid \mathrm{C}_{50}\end{array}$ & $\begin{array}{l}\text { Plasmodium falcipa- } \\
\text { rum FCB1 }\end{array}$ & $\mathrm{Nd}$ \\
\hline Mundulea sericea & Fabaceae & {$[86]$} & Namibia & $\begin{array}{l}\text { Leaves, } \\
\text { Shoots }\end{array}$ & Methanol & Very Good & $\begin{array}{l}3.279- \\
3.352 \mu \mathrm{g} / \mathrm{ml} \\
\mathrm{IC}_{50}\end{array}$ & $\begin{array}{l}\text { Plasmodium falcipa- } \\
\text { rum 3D7 }\end{array}$ & $\mathrm{Nd}$ \\
\hline $\begin{array}{l}\text { Mitragyna } \\
\text { inermis }\end{array}$ & Rubiaceae & [93] & Mali & Leaves & Chloroform & Very Good & 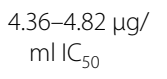 & $\begin{array}{l}\text { Plasmodium falcipa- } \\
\text { rum W2 \& 3D7 }\end{array}$ & No \\
\hline \multirow[t]{4}{*}{ Nauclea latifolia } & Rubiaceae & [93] & Mali & Barks & Chloroform & Good & $\begin{array}{l}5.36-6.2 \mu \mathrm{g} / \\
\mathrm{ml} \mathrm{IC}\end{array}$ & $\begin{array}{l}\text { Plasmodium falcipa- } \\
\text { rum W2 \& 3D7 }\end{array}$ & $\begin{array}{l}\text { Yes }\left({ }^{\prime} C_{50}=50 \mu \mathrm{g} /\right. \\
\text { ml; BALB/C } \\
\text { mouse })\end{array}$ \\
\hline & & [28] & Ivory Coast & Barks & Ethanol & Good & $8.9 \mu \mathrm{g} / \mathrm{ml} \mathrm{IC_{50 }}$ & $\begin{array}{l}\text { Plasmodium } \\
\text { falciparum Fcb1/ } \\
\text { Colombia Strain }\end{array}$ & No \\
\hline & & [106] & Ivory Coast & $\begin{array}{l}\text { Roots, } \\
\text { Stem }\end{array}$ & Water & Good & $\begin{array}{l}0.6-7.5 \mu \mathrm{g} / \mathrm{ml} \\
\mid \mathrm{C}_{50}\end{array}$ & $\begin{array}{l}\text { Plasmodium falcipa- } \\
\text { rum Fcb1-Colom- } \\
\text { bian And Nigerian } \\
\text { Strains }\end{array}$ & $\mathrm{Nd}$ \\
\hline & & [43] & Ivory Coast & $\begin{array}{l}\text { Root } \\
\text { Barks }\end{array}$ & Ethanol & Good & $7.3 \mu \mathrm{g} / \mathrm{ml} \mathrm{IC_{50 }}$ & $\begin{array}{l}\text { Plasmodium falcipa- } \\
\text { rum FCB1 }\end{array}$ & $\mathrm{Nd}$ \\
\hline $\begin{array}{l}\text { Nauclea pobe- } \\
\text { guinii }\end{array}$ & Rubiaceae & [107] & D.R.Congo & $\begin{array}{l}\text { Stem } \\
\text { Barks }\end{array}$ & Ethanol & In Active & $32 \mu \mathrm{g} / \mathrm{ml} \mathrm{I} C_{50}$ & $\begin{array}{l}\text { Plasmodium falcipa- } \\
\text { rum, Plasmodium } \\
\text { yeolii, Plasmodium } \\
\text { berghei }\end{array}$ & No \\
\hline
\end{tabular}


Table 1 (continued)

\begin{tabular}{|c|c|c|c|c|c|c|c|c|c|}
\hline Plant species & Plant family & Source & $\begin{array}{l}\text { Country } \\
\text { of study }\end{array}$ & $\begin{array}{l}\text { Part of } \\
\text { plant } \\
\text { used }\end{array}$ & $\begin{array}{l}\text { Extraction } \\
\text { solvent }\end{array}$ & $\begin{array}{l}\text { Antiplas- } \\
\text { modial } \\
\text { Activity }\end{array}$ & $\begin{array}{l}I C_{50} \text { or } E D_{50} \\
\text { or } L_{50}\end{array}$ & $\begin{array}{l}\text { Strain of } \\
\text { Plasmodium } \\
\text { Tested }\end{array}$ & $\begin{array}{l}\text { Toxicity (value; } \\
\text { assay) }\end{array}$ \\
\hline $\begin{array}{l}\text { Neoboutonia } \\
\text { glabrescens }\end{array}$ & Euphorbiaceae & {$[55]$} & Cameroon & Leaves & $\begin{array}{l}\text { Ethanol, Water, } \\
\text { Dichlorometh- } \\
\text { ane, Methanol, } \\
\text { Hexane }\end{array}$ & Good & $\begin{array}{l}7.56 \mu \mathrm{g} / \mathrm{ml} \\
\mid C_{50}\end{array}$ & $\begin{array}{l}\text { Plasmodium falcipa- } \\
\text { rum W2 }\end{array}$ & $\mathrm{Nd}$ \\
\hline $\begin{array}{l}\text { Neorautanenia } \\
\text { mitis }\end{array}$ & Fabaceae & {$[31]$} & Tanzania & Tubers & Ethanol & Very Good & $\begin{array}{l}1.58 \mu \mathrm{g} / \mathrm{ml} \\
\mathrm{IC}_{50}\end{array}$ & $\begin{array}{l}\text { Plasmodium falcipa- } \\
\text { rum K1 }\end{array}$ & No \\
\hline \multirow[t]{3}{*}{$\begin{array}{l}\text { Newbouldia } \\
\text { laevis }\end{array}$} & \multirow[t]{3}{*}{ Bignognaceae } & {$[108]$} & Togo & Leaves & Ethanol & Moderate & $\begin{array}{l}12.6 \mu \mathrm{g} / \mathrm{ml} \\
\mid \mathrm{C}_{50}\end{array}$ & $\begin{array}{l}\text { Plasmodium falci- } \\
\text { parum }\end{array}$ & $\mathrm{Nd}$ \\
\hline & & [109] & Nigeria & Leaves & Water & Moderate & $\begin{array}{l}19.5 \mu \mathrm{g} / \mathrm{ml} \\
\mid \mathrm{C}_{50}\end{array}$ & $\begin{array}{l}\text { Plasmodium falci- } \\
\text { parum }\end{array}$ & $\mathrm{Nd}$ \\
\hline & & {$[53]$} & Nigeria & Roots & Dichloromethane & Good & $\begin{array}{l}5.00 \mu \mathrm{g} / \mathrm{ml} \\
\mid \mathrm{C}_{50}\end{array}$ & $\begin{array}{l}\text { Plasmodium falcipa- } \\
\text { rum D10 }\end{array}$ & $\mathrm{Nd}$ \\
\hline \multirow[t]{2}{*}{$\begin{array}{l}\text { Ocimum ameri- } \\
\text { cana }\end{array}$} & \multirow[t]{2}{*}{ Lamiaceae } & {$[24]$} & Kenya & $\begin{array}{l}\text { Whole } \\
\text { Plant }\end{array}$ & Methanol & Moderate & $\begin{array}{c}8.9-12.1 \mu \mathrm{g} / \\
\mathrm{ml} \mathrm{IC}_{50}\end{array}$ & $\begin{array}{l}\text { Plasmodium falcipa- } \\
\text { rum D6, W2 }\end{array}$ & $\mathrm{Nd}$ \\
\hline & & {$[22]$} & $\begin{array}{l}\text { South } \\
\text { Africa }\end{array}$ & $\begin{array}{l}\text { Whole } \\
\text { Plant }\end{array}$ & $\begin{array}{l}\text { Dichlorometh- } \\
\text { ane/Methanol }\end{array}$ & Very Good & $4.2 \mu \mathrm{g} / \mathrm{ml} \mathrm{IC} \mathrm{C}_{50}$ & $\begin{array}{l}\text { Plasmodium falcipa- } \\
\text { rum D10 }\end{array}$ & $\mathrm{Nd}$ \\
\hline \multirow[t]{2}{*}{$\begin{array}{l}\text { Ocimum basili- } \\
\text { cum }\end{array}$} & \multirow[t]{2}{*}{ Lamiaceae } & [159] & D.R. Congo & Leaves & $\begin{array}{l}\text { Ethanol, Metha- } \\
\text { nol, Petroleum } \\
\text { Ether, Chloro- } \\
\text { form }\end{array}$ & Good & $\begin{array}{l}<0.35-18 \mu \mathrm{g} / \\
\quad \mathrm{ml} \mathrm{IC}_{50}\end{array}$ & $\begin{array}{l}\text { Plasmodium falci- } \\
\text { parum }\end{array}$ & $\mathrm{Nd}$ \\
\hline & & {$[26]$} & Kenya & Leaves & Methanol & Moderate & $\begin{array}{l}16.4 \mu \mathrm{g} / \mathrm{ml} \\
\mathrm{IC}_{50}\end{array}$ & $\begin{array}{l}\text { Plasmodium falcipa- } \\
\text { rum D6, W2 }\end{array}$ & $\mathrm{Nd}$ \\
\hline \multirow[t]{3}{*}{$\begin{array}{l}\text { Ocimum gratis- } \\
\text { simum }\end{array}$} & \multirow[t]{3}{*}{ Lamiaceae } & {$[30]$} & Kenya & $\begin{array}{l}\text { Leaves, } \\
\text { Twigs }\end{array}$ & Dichloromethane & Good & $\begin{array}{l}8.616 \mu \mathrm{g} / \mathrm{ml} \\
I_{50}\end{array}$ & $\begin{array}{l}\text { Plasmodium falcipa- } \\
\text { rum W2, D6 }\end{array}$ & $\mathrm{Nd}$ \\
\hline & & {$[40]$} & DR Congo & Leaves & Water & Good & $\begin{array}{l}7.25 \mu \mathrm{g} / \mathrm{ml} \\
\mathrm{IC}_{50}\end{array}$ & $\begin{array}{l}\text { Plasmodium falcipa- } \\
\text { rum K1 }\end{array}$ & No \\
\hline & & {$[26]$} & Kenya & Leaves & Methanol & Good & $5.9 \mu \mathrm{g} / \mathrm{ml} \mathrm{IC} 5$ & $\begin{array}{l}\text { Plasmodium falcipa- } \\
\text { rum D6, W2 }\end{array}$ & $\mathrm{Nd}$ \\
\hline $\begin{array}{l}\text { Ocimum } \\
\text { kilimandschari- } \\
\text { cum }\end{array}$ & Lamiaceae & {$[30]$} & Kenya & $\begin{array}{l}\text { Leaves, } \\
\text { Twigs }\end{array}$ & Dichloromethane & Very Good & $\begin{array}{l}0.843- \\
1.547 \mu \mathrm{g} / \mathrm{ml} \\
\mid \mathrm{C}_{50}\end{array}$ & $\begin{array}{l}\text { Plasmodium falcipa- } \\
\text { rum W2, D6 }\end{array}$ & $\mathrm{Nd}$ \\
\hline Olax gambecola & Olacaceae & {$[43]$} & Ivory Coast & $\begin{array}{l}\text { Whole } \\
\text { Plant }\end{array}$ & Ethanol & Good & $5.2 \mu \mathrm{g} / \mathrm{ml} \mathrm{IC} C_{50}$ & $\begin{array}{l}\text { Plasmodium falcipa- } \\
\text { rum FCB1 }\end{array}$ & $\mathrm{Nd}$ \\
\hline \multirow[t]{3}{*}{ Olea europaea } & \multirow[t]{3}{*}{ Oleaceae } & {$[24]$} & Kenya & $\begin{array}{l}\text { Stem } \\
\text { Barks }\end{array}$ & Methanol & Moderate & $\begin{array}{l}17.3 \mu \mathrm{g} / \mathrm{ml} \\
\mid \mathrm{C}_{50}\end{array}$ & $\begin{array}{l}\text { Plasmodium falcipa- } \\
\text { rum D6, W2 }\end{array}$ & $\mathrm{Nd}$ \\
\hline & & {$[21]$} & Kenya & $\begin{array}{l}\text { Inner } \\
\text { Barks }\end{array}$ & Methanol & Good & $\begin{array}{l}9.48 \mu \mathrm{g} / \mathrm{ml} \\
\mid \mathrm{C}_{50}\end{array}$ & $\begin{array}{l}\text { Plasmodium falcipa- } \\
\text { rum D6 }\end{array}$ & No \\
\hline & & {$[22]$} & $\begin{array}{l}\text { South } \\
\text { Africa }\end{array}$ & Leaves & $\begin{array}{l}\text { Dichlorometh- } \\
\text { ane/Methanol }\end{array}$ & Moderate & $12 \mu \mathrm{g} / \mathrm{ml} \mathrm{I} \mathrm{C}_{50}$ & $\begin{array}{l}\text { Plasmodium falcipa- } \\
\text { rum D10 }\end{array}$ & $\mathrm{Nd}$ \\
\hline Opilia celtidifolia & Opiliaceae & {$[52]$} & $\begin{array}{l}\text { Burkina } \\
\text { Faso }\end{array}$ & Leaves & Dichloromethane & Very Good & $2.8 \mu \mathrm{g} / \mathrm{ml} \mathrm{IC} C_{50}$ & $\begin{array}{l}\text { Plasmodium falci- } \\
\text { parum }\end{array}$ & $\begin{array}{l}\text { Yes }(\mathrm{SI}=0.4 ; \text { HepG2 } \\
\text { cells) }\end{array}$ \\
\hline $\begin{array}{l}\text { Ormocarpum } \\
\text { trachycarpum }\end{array}$ & Fabaceae & {$[77]$} & Kenya & $\begin{array}{l}\text { Stem } \\
\text { Barks }\end{array}$ & $\begin{array}{l}\text { Dichlorometh- } \\
\text { ane/Ethyl } \\
\text { Acetate }\end{array}$ & Moderate & $\begin{array}{l}17.5- \\
19.6 \mu \mathrm{g} / \mathrm{ml} \\
{ }_{\mid} C_{50}\end{array}$ & $\begin{array}{l}\text { Plasmodium falcipa- } \\
\text { rum K39, V1/S }\end{array}$ & $\mathrm{Nd}$ \\
\hline $\begin{array}{l}\text { Osteospermum } \\
\text { imbricatum }\end{array}$ & Asteraceae & {$[22]$} & $\begin{array}{l}\text { South } \\
\text { Africa }\end{array}$ & Stems & $\begin{array}{l}\text { Dichlorometh- } \\
\text { ane/Methanol }\end{array}$ & Good & $7.3 \mu \mathrm{g} / \mathrm{ml} \mathrm{IC} 5$ & $\begin{array}{l}\text { Plasmodium falcipa- } \\
\text { rum D10 }\end{array}$ & $\mathrm{Nd}$ \\
\hline $\begin{array}{c}\text { Phyllanthus } \\
\text { amarus }\end{array}$ & Phyllanthaceae & [53] & Nigeria & Leaves & Petroleum Ether & Very Good & $\begin{array}{l}4.99 \mu \mathrm{g} / \mathrm{ml} \\
I_{50}\end{array}$ & $\begin{array}{l}\text { Plasmodium falcipa- } \\
\text { rum D10 }\end{array}$ & $\mathrm{Nd}$ \\
\hline $\begin{array}{l}\text { Pachypodan- } \\
\text { thium confine }\end{array}$ & Annonaceae & {$[98]$} & Cameroon & $\begin{array}{l}\text { Stem } \\
\text { Barks }\end{array}$ & Water & Moderate $^{a}$ & $\begin{array}{l}16.6 \mu \mathrm{g} / \mathrm{ml} \\
\mathrm{IC}_{50}\end{array}$ & $\begin{array}{l}\text { Plasmodium falcipa- } \\
\text { rum W3 }\end{array}$ & $\mathrm{Nd}$ \\
\hline $\begin{array}{c}\text { Pappea capensis } \\
\text { Eckl.\&Zeyh }\end{array}$ & Sapindaceae & {$[37]$} & $\begin{array}{l}\text { South } \\
\text { Africa }\end{array}$ & Twigs & Dichloromethane & Good & $\begin{array}{l}5.47 \mu \mathrm{g} / \mathrm{ml} \\
\quad \mathrm{C}_{50}\end{array}$ & $\begin{array}{l}\text { Plasmodium falcipa- } \\
\text { rum NF54 }\end{array}$ & $\mathrm{Nd}$ \\
\hline
\end{tabular}


Table 1 (continued)

\begin{tabular}{|c|c|c|c|c|c|c|c|c|c|}
\hline Plant species & Plant family & Source & $\begin{array}{l}\text { Country } \\
\text { of study }\end{array}$ & $\begin{array}{l}\text { Part of } \\
\text { plant } \\
\text { used }\end{array}$ & $\begin{array}{l}\text { Extraction } \\
\text { solvent }\end{array}$ & $\begin{array}{l}\text { Antiplas- } \\
\text { modial } \\
\text { Activity }\end{array}$ & $\begin{array}{l}\mathrm{IC}_{50} \text { or } \mathrm{ED}_{50} \\
\text { or } \mathrm{LD}_{50}\end{array}$ & $\begin{array}{l}\text { Strain of } \\
\text { Plasmodium } \\
\text { Tested }\end{array}$ & $\begin{array}{l}\text { Toxicity (value; } \\
\text { assay) }\end{array}$ \\
\hline \multirow[t]{3}{*}{$\begin{array}{l}\text { Parinari curatel- } \\
\text { lifolia }\end{array}$} & $\begin{array}{l}\text { Chrysobalan- } \\
\text { aceae }\end{array}$ & [22] & $\begin{array}{l}\text { South } \\
\text { Africa }\end{array}$ & Roots & Dichloromethane & Good & $5.3 \mu \mathrm{g} / \mathrm{ml} / \mathrm{C}_{50}$ & $\begin{array}{l}\text { Plasmodium falcipa- } \\
\text { rum D10 }\end{array}$ & $\mathrm{Nd}$ \\
\hline & & [24] & Kenya & $\begin{array}{l}\text { Root } \\
\text { Barks }\end{array}$ & Methanol & Good & $\begin{array}{l}3.9-7.9 \mu \mathrm{g} / \mathrm{ml} \\
\mathrm{IC}_{50}\end{array}$ & $\begin{array}{l}\text { Plasmodium falcipa- } \\
\text { rum D6, W2 }\end{array}$ & $\mathrm{Nd}$ \\
\hline & & {$[37]$} & $\begin{array}{l}\text { South } \\
\text { Africa }\end{array}$ & $\begin{array}{l}\text { Stem } \\
\text { Barks }\end{array}$ & Dichloromethane & Good & $\begin{array}{l}6.99 \mu \mathrm{g} / \mathrm{ml} \\
\mathrm{IC}_{50}\end{array}$ & $\begin{array}{l}\text { Plasmodium falcipa- } \\
\text { rum NF54 }\end{array}$ & $\mathrm{Nd}$ \\
\hline \multirow[t]{2}{*}{ Parinari excelsa } & $\begin{array}{l}\text { Chrysobalan- } \\
\text { aceae }\end{array}$ & [20] & Tanzania & $\begin{array}{l}\text { Stem } \\
\text { Barks }\end{array}$ & Ethyl Acetate & Moderate & $10 \mu \mathrm{g} / \mathrm{ml} / \mathrm{C}_{50}$ & $\begin{array}{l}\text { Plasmodium falcipa- } \\
\text { rum K1 }\end{array}$ & $\mathrm{Nd}$ \\
\hline & & [75] & Uganda & Barks & Ethyl Acetate & $\mathrm{Nd}$ & $\mathrm{Nd}$ & $\begin{array}{l}\text { Plasmodium falcipa- } \\
\text { rum Fcb7 }\end{array}$ & $\mathrm{Nd}$ \\
\hline $\begin{array}{c}\text { Parkinsonia } \\
\text { aculeata }\end{array}$ & Fabaceae & [22] & $\begin{array}{l}\text { South } \\
\text { Africa }\end{array}$ & Twigs & $\begin{array}{l}\text { Dichlorometh- } \\
\text { ane/Methanol }\end{array}$ & Good & $9 \mu \mathrm{g} / \mathrm{ml} \mathrm{IC} C_{50}$ & $\begin{array}{l}\text { Plasmodium falcipa- } \\
\text { rum D10 }\end{array}$ & $\mathrm{Nd}$ \\
\hline \multirow[t]{3}{*}{$\begin{array}{l}\text { Pavetta corym- } \\
\text { bosa }\end{array}$} & Rubiaceae & [65] & Benin & $\begin{array}{l}\text { Aerial } \\
\text { parts }\end{array}$ & Methanol & Moderate & $\begin{array}{l}5.54-20 \mu \mathrm{m} / \mathrm{ml} \\
\mid \mathrm{C}_{50}\end{array}$ & $\begin{array}{l}\text { Plasmodium falcipa- } \\
\text { rum 3D7 \& K1 }\end{array}$ & $\mathrm{Nd}$ \\
\hline & & [110] & Togo & $\begin{array}{l}\text { Aerial } \\
\text { parts }\end{array}$ & Methanol & Very Good & $\begin{array}{l}2.042 \mu \mathrm{g} / \mathrm{ml} \\
\mathrm{IC}_{50}\end{array}$ & $\begin{array}{l}\text { Plasmodium falci- } \\
\text { parum }\end{array}$ & $\mathrm{Nd}$ \\
\hline & & [110] & Togo & $\begin{array}{r}\text { Aerial } \\
\text { part }\end{array}$ & Methanol & Very Good & $\begin{array}{l}2.042 \mu \mathrm{g} / \mathrm{ml} \\
\mathrm{IC}_{50}\end{array}$ & $\begin{array}{l}\text { Plasmodium falci- } \\
\text { parum }\end{array}$ & $\mathrm{Nd}$ \\
\hline \multirow[t]{2}{*}{ Pavetta crassipes } & Rubiaceae & [27] & $\begin{array}{l}\text { Burkina } \\
\text { Faso }\end{array}$ & Leaves & Crude Alkaloid & Very Good & $<4 \mu \mathrm{g} / \mathrm{ml} \mathrm{I} C_{50}$ & $\begin{array}{l}\text { Plasmodium falcipa- } \\
\text { rum W2 }\end{array}$ & $\mathrm{Nd}$ \\
\hline & & [71] & Togo & $\begin{array}{l}\text { Aerial } \\
\text { parts }\end{array}$ & Water & Good & $<7 \mu \mathrm{g} / \mathrm{ml} \mathrm{I} \mathrm{C}_{50}$ & $\begin{array}{l}\text { Plasmodium falci- } \\
\text { parum }\end{array}$ & $\mathrm{Nd}$ \\
\hline $\begin{array}{l}\text { Pelargonium } \\
\text { alchemilloides }\end{array}$ & Geraniaceae & [22] & $\begin{array}{l}\text { South } \\
\text { Africa }\end{array}$ & $\begin{array}{l}\text { Whole } \\
\text { plant }\end{array}$ & $\begin{array}{l}\text { Dichlorometh- } \\
\text { ane/Methanol }\end{array}$ & Moderate & $15 \mu \mathrm{g} / \mathrm{ml} / \mathrm{I}_{50}$ & $\begin{array}{l}\text { Plasmodium falcipa- } \\
\text { rum D10 }\end{array}$ & $\mathrm{Nd}$ \\
\hline $\begin{array}{l}\text { Pentaslanceo- } \\
\text { lata }\end{array}$ & Rubiaceae & [21] & Kenya & $\begin{array}{l}\text { Root } \\
\text { barks }\end{array}$ & Methanol & Good & $\begin{array}{l}5.15 \mu \mathrm{g} / \mathrm{ml} \\
\mathrm{IC}_{50}\end{array}$ & $\begin{array}{l}\text { Plasmodium falcipa- } \\
\text { rum D6 }\end{array}$ & No \\
\hline Pentas longiflora & Rubiaceae & {$[26]$} & Kenya & $\begin{array}{l}\text { Root } \\
\text { barks }\end{array}$ & Methanol & Moderate & $\begin{array}{l}13.3 \mu \mathrm{g} / \mathrm{ml} \\
\mathrm{IC} 50\end{array}$ & $\begin{array}{l}\text { Plasmodium falcipa- } \\
\text { rum D6, W2 }\end{array}$ & $\mathrm{Nd}$ \\
\hline Pentzia globosa & Asteraceae & [22] & $\begin{array}{l}\text { South } \\
\text { Africa }\end{array}$ & Roots & Dichloromethane & Good & $8 \mu \mathrm{g} / \mathrm{ml} \mathrm{IC50}$ & $\begin{array}{l}\text { Plasmodium falcipa- } \\
\text { rum D10 }\end{array}$ & $\mathrm{Nd}$ \\
\hline $\begin{array}{l}\text { Phyllanthus } \\
\text { amarus }\end{array}$ & Phyllanthaceae & [111] & Ghana & $\begin{array}{l}\text { Whole } \\
\text { Plant }\end{array}$ & Ethanol & Moderate & $\begin{array}{l}11.7 \mu \mathrm{g} / \mathrm{ml} \\
\mathrm{I}_{50}\end{array}$ & $\begin{array}{l}\text { Plasmodium falcipa- } \\
\text { rum Dd2 }\end{array}$ & No \\
\hline $\begin{array}{l}\text { Phyllanthus } \\
\text { fraternus }\end{array}$ & Phyllanthaceae & [112] & Ghana & $\begin{array}{l}\text { Whole } \\
\text { plant }\end{array}$ & Methanol & Very Good & $\begin{array}{l}0.44 \mu \mathrm{g} / \mathrm{ml} \\
\mathrm{IC}_{50}\end{array}$ & $\begin{array}{l}\text { Plasmodium falcipa- } \\
\text { rum 3D7, W2 }\end{array}$ & No \\
\hline \multirow[t]{2}{*}{$\begin{array}{l}\text { Phyllanthus } \\
\text { muellerianus }\end{array}$} & Phyllanthaceae & [28] & Ivory Coast & Leaves & Ethanol & Good & $9.4 \mu \mathrm{g} / \mathrm{ml} \mathrm{I} \mathrm{C}_{50}$ & $\begin{array}{l}\text { Plasmodium } \\
\text { falciparum Fcb1/ } \\
\text { Colombia Strain }\end{array}$ & No \\
\hline & & [43] & Ivory Coast & Leaves & Ethanol & Moderate & $\begin{array}{l}10.3 \mu \mathrm{g} / \mathrm{ml} \\
\mathrm{I}_{50}\end{array}$ & $\begin{array}{l}\text { Plasmodium falcipa- } \\
\text { rum FCB1 }\end{array}$ & $\mathrm{Nd}$ \\
\hline Phyllanthus niruri & i Phyllanthaceae & {$[69]$} & D.R.Congo & $\begin{array}{l}\text { Whole } \\
\text { Plant }\end{array}$ & Petroleum Ether & Very Good & $1.3 \mu \mathrm{g} / \mathrm{ml} \mathrm{IC_{50 }}$ & $\begin{array}{l}\text { Plasmodium falci- } \\
\text { parum }\end{array}$ & $\mathrm{Nd}$ \\
\hline $\begin{array}{l}\text { Phyllanthus } \\
\text { urinaria }\end{array}$ & Phyllanthaceae & {$[45]$} & Cambodia & $\begin{array}{l}\text { Whole } \\
\text { Plant }\end{array}$ & Water & Very Good & $2.4 \mu \mathrm{g} / \mathrm{ml} \mathrm{I} \mathrm{C}_{50}$ & $\begin{array}{l}\text { Plasmodium falcipa- } \\
\text { rum W2 }\end{array}$ & $\mathrm{Nd}$ \\
\hline \multirow[t]{3}{*}{ Physalis angulata } & Solanaceae & [28] & Ivory Coast & $\begin{array}{l}\text { Whole } \\
\text { Plant }\end{array}$ & Ethanol & Good & $7.9 \mu \mathrm{g} / \mathrm{ml} \mathrm{I} C_{50}$ & $\begin{array}{l}\text { Plasmodium } \\
\text { falciparum Fcb1/ } \\
\text { Colombia Strain }\end{array}$ & $\mathrm{Nd}$ \\
\hline & & [43] & Ivory Coast & $\begin{array}{l}\text { Whole } \\
\text { Plant }\end{array}$ & Ethanol & Good & $7.9 \mu \mathrm{g} / \mathrm{ml} \mathrm{I} \mathrm{C}_{50}$ & $\begin{array}{l}\text { Plasmodium falcipa- } \\
\text { rum FCB1 }\end{array}$ & $\mathrm{Nd}$ \\
\hline & & [44] & D.R. Congo & Leaves & $\begin{array}{l}\text { Methanolic and } \\
\text { dichlorometh- } \\
\text { ane }\end{array}$ & Very good & $\begin{array}{l}1.27 \mu \mathrm{g} / \mathrm{ml} \\
\mid \mathrm{C}_{50}\end{array}$ & $\begin{array}{l}\text { Plasmodium } \\
\text { falciparum 3D7, } \\
\text { W2, Plasmodium } \\
\text { berghei berghei }\end{array}$ & No \\
\hline
\end{tabular}


Table 1 (continued)

\begin{tabular}{|c|c|c|c|c|c|c|c|c|c|}
\hline Plant species & Plant family & Source & $\begin{array}{l}\text { Country } \\
\text { of study }\end{array}$ & $\begin{array}{l}\text { Part of } \\
\text { plant } \\
\text { used }\end{array}$ & $\begin{array}{l}\text { Extraction } \\
\text { solvent }\end{array}$ & $\begin{array}{l}\text { Antiplas- } \\
\text { modial } \\
\text { Activity }\end{array}$ & $\begin{array}{l}\mathrm{IC}_{50} \text { or } \mathrm{ED}_{50} \\
\text { or } \mathrm{LD}_{50}\end{array}$ & $\begin{array}{l}\text { Strain of } \\
\text { Plasmodium } \\
\text { Tested }\end{array}$ & $\begin{array}{l}\text { Toxicity (value; } \\
\text { assay) }\end{array}$ \\
\hline \multirow[t]{4}{*}{ Picralima nitida } & Apocynaceae & {$[53]$} & Nigeria & Roots & Ethanol & Good & $\begin{array}{l}6.29 \mu \mathrm{g} / \mathrm{ml} \\
\mid \mathrm{C}_{50}\end{array}$ & $\begin{array}{l}\text { Plasmodium falcipa- } \\
\text { rum D10 }\end{array}$ & $\mathrm{Nd}$ \\
\hline & & [113] & Nigeria & Stems & Methanol & Good & $\begin{array}{l}6.0-6.3 \mu \mathrm{g} / \mathrm{ml} \\
\mid \mathrm{C}_{50}\end{array}$ & $\begin{array}{l}\text { Plasmodium falcipa- } \\
\text { rum D6, W2 }\end{array}$ & No \\
\hline & & {$[89]$} & Cameroon & Seeds & Methanol & Moderate & $\begin{array}{l}10.9 \mu \mathrm{g} / \mathrm{ml} \\
\mid \mathrm{C}_{50}\end{array}$ & $\begin{array}{l}\text { Plasmodium falcipa- } \\
\text { rum W2 }\end{array}$ & $\mathrm{Nd}$ \\
\hline & & {$[114]$} & Ivory Coast & $\begin{array}{l}\text { Root, } \\
\text { Stem } \\
\text { Barks } \\
\text { Ans } \\
\text { Fruit } \\
\text { Rins }\end{array}$ & Ns & Very Good & $\begin{array}{l}0.188- \\
\quad 1.581 \mu \mathrm{g} / \mathrm{ml} \\
\mid \mathrm{C}_{50}\end{array}$ & $\begin{array}{l}\text { Plasmodium falci- } \\
\text { parum }\end{array}$ & $\mathrm{Nd}$ \\
\hline Piper capense & Piperaceae & {$[91]$} & Comoros & Ns & Dichloromethane & Good & $7 \mu \mathrm{g} / \mathrm{ml} \mathrm{I} C_{50}$ & $\begin{array}{l}\text { Plasmodium falcipa- } \\
\text { rum W2 }\end{array}$ & No \\
\hline \multirow[t]{2}{*}{$\begin{array}{l}\text { Piptadeniastrum } \\
\text { africanum }\end{array}$} & Leguminosae & {$[40]$} & D.R. Congo & $\begin{array}{l}\text { Stem } \\
\text { Barks }\end{array}$ & Water & Good & $\begin{array}{l}6.11 \mu \mathrm{g} / \mathrm{ml} \\
\mathrm{IC}_{50}\end{array}$ & $\begin{array}{l}\text { Plasmodium falcipa- } \\
\text { rum K1 }\end{array}$ & $\begin{array}{l}\text { Yes (SI=1.4-1.5; } \\
\text { human embry- } \\
\text { onic lung cells } \\
\text { [MRC-5]) }\end{array}$ \\
\hline & & {$[40]$} & D.R.Congo & $\begin{array}{l}\text { Stem } \\
\text { Barks }\end{array}$ & Water & Good & $\begin{array}{l}6.11 \mu \mathrm{g} / \mathrm{ml} \\
\mid \mathrm{C}_{50}\end{array}$ & $\begin{array}{l}\text { Plasmodium falcipa- } \\
\text { rum K1 }\end{array}$ & No \\
\hline $\begin{array}{l}\text { Piptostigma } \\
\text { calophyllum }\end{array}$ & Annonaceae & {$[49]$} & Cameroon & Leaves & Methanol & Good & $\begin{array}{l}6.72 \mu \mathrm{g} / \mathrm{ml} \\
\mid \mathrm{C}_{50}\end{array}$ & $\begin{array}{l}\text { Plasmodium falcipa- } \\
\text { rum W2 }\end{array}$ & $\mathrm{Nd}$ \\
\hline \multirow[t]{2}{*}{$\begin{array}{l}\text { Pittosporum } \\
\quad \text { viridiflorum }\end{array}$} & Pittosporaceae & {$[24]$} & Kenya & Leaves & Methanol & Moderate & $\begin{array}{l}17.6-18.9 \mu \mathrm{g} / \\
\mathrm{ml} \mathrm{iC}_{50}\end{array}$ & $\begin{array}{l}\text { Plasmodium falcipa- } \\
\text { rum D6, W2 }\end{array}$ & $\mathrm{Nd}$ \\
\hline & & {$[22]$} & $\begin{array}{l}\text { South } \\
\text { Africa }\end{array}$ & $\begin{array}{l}\text { Whole } \\
\text { Plant }\end{array}$ & Dichloromethane & Very Good & $3 \mu \mathrm{g} / \mathrm{ml} \mathrm{I} C_{50}$ & $\begin{array}{l}\text { Plasmodium falcipa- } \\
\text { rum D10 }\end{array}$ & $\mathrm{Nd}$ \\
\hline $\begin{array}{l}\text { Plumbago } \\
\text { zeylanica }\end{array}$ & $\begin{array}{c}\text { Plumbagi- } \\
\text { naceae }\end{array}$ & {$[22]$} & $\begin{array}{l}\text { South } \\
\text { Africa }\end{array}$ & Leaves & Dichloromethane & Very Good & $3 \mu \mathrm{g} / \mathrm{ml} \mathrm{IC_{50 }}$ & $\begin{array}{l}\text { Plasmodium falcipa- } \\
\text { rum D10 }\end{array}$ & $\mathrm{Nd}$ \\
\hline $\begin{array}{c}\text { Podocarpus } \\
\text { latifolius }\end{array}$ & Podocarpaceae & {$[21]$} & Kenya & $\begin{array}{l}\text { Root } \\
\text { Barks }\end{array}$ & Methanol & Good & $\begin{array}{l}6.43 \mu \mathrm{g} / \mathrm{ml} \\
\mid \mathrm{C}_{50}\end{array}$ & $\begin{array}{l}\text { Plasmodium falcipa- } \\
\text { rum D6 }\end{array}$ & No \\
\hline $\begin{array}{l}\text { Pollichia camp- } \\
\text { estris }\end{array}$ & $\begin{array}{l}\text { Caryophyl- } \\
\text { laceae }\end{array}$ & {$[22]$} & $\begin{array}{l}\text { South } \\
\text { Africa }\end{array}$ & Twigs & $\begin{array}{l}\text { Dichlorometh- } \\
\text { ane/Methanol }\end{array}$ & Good & $6.8 \mu \mathrm{g} / \mathrm{ml} \mathrm{IC} \mathrm{C}_{50}$ & $\begin{array}{l}\text { Plasmodium falcipa- } \\
\text { rum D10 }\end{array}$ & $\mathrm{Nd}$ \\
\hline \multirow[t]{2}{*}{$\begin{array}{l}\text { Polyalthia } \\
\text { longifolia }\end{array}$} & Annonaceae & {$[115]$} & Ghana & $\begin{array}{l}\text { Stem } \\
\text { Barks }\end{array}$ & $\begin{array}{l}\text { Ethanol, } \\
\text { N-Hexane, } \\
\text { Dichlo- } \\
\text { romethane, } \\
\text { Ethyl Acetate, } \\
\text { Methanol-Ethyl } \\
\text { Acetate }\end{array}$ & Good $^{\mathrm{a}}$ & $3-6 \mu \mathrm{g} / \mathrm{ml} \mathrm{IC}_{50}$ & $\begin{array}{l}\text { Plasmodium falcipa- } \\
\text { rum K1 }\end{array}$ & No \\
\hline & & {$[116]$} & Ghana & $\begin{array}{l}\text { Stem } \\
\text { Barks }\end{array}$ & $\begin{array}{l}\text { Methanol, } \\
\text { Chloroform, } \\
\text { Cyclohexane, } \\
\text { Ethyl Acetate }\end{array}$ & Good $^{a}$ & $\begin{array}{l}4.53-10.17 \mu M \\
I_{50}\end{array}$ & $\begin{array}{l}\text { Plasmodium falcipa- } \\
\text { rum 3D8 }\end{array}$ & $\mathrm{Nd}$ \\
\hline \multirow[t]{2}{*}{ Polyalthia oliveri } & Annonaceae & {$[55]$} & Cameroon & $\begin{array}{l}\text { Stem } \\
\text { Barks }\end{array}$ & $\begin{array}{l}\text { Ethanol, Water, } \\
\text { Dichlorometh- } \\
\text { ane, Methanol, } \\
\text { Hexane }\end{array}$ & Very Good & $\begin{array}{l}4.30 \mu \mathrm{g} / \mathrm{ml} \\
\mid \mathrm{C}_{50}\end{array}$ & $\begin{array}{l}\text { Plasmodium falcipa- } \\
\text { rum W2 }\end{array}$ & $\mathrm{Nd}$ \\
\hline & & [49] & Cameroon & $\begin{array}{l}\text { Stem } \\
\text { Barks }\end{array}$ & Methanol & Very Good & $\begin{array}{l}3.43 \mu \mathrm{g} / \mathrm{ml} \\
\mid \mathrm{C}_{50}\end{array}$ & $\begin{array}{l}\text { Plasmodium falcipa- } \\
\text { rum W2 }\end{array}$ & $\mathrm{Nd}$ \\
\hline $\begin{array}{l}\text { Polyalthia sua- } \\
\text { veolens }\end{array}$ & Annonaceae & [49] & Cameroon & Twigs & Methanol & Very Good & $\begin{array}{l}3.23 \mu \mathrm{g} / \mathrm{ml} \\
\mid \mathrm{C}_{50}\end{array}$ & $\begin{array}{l}\text { Plasmodium falcipa- } \\
\text { rum W2 }\end{array}$ & $\mathrm{Nd}$ \\
\hline $\begin{array}{l}\text { Polygonatum } \\
\text { verticillatum }\end{array}$ & Asparagaceae & [117] & Kenya & Rhizome & $\begin{array}{l}\text { N-Hexane, Chlo- } \\
\text { roform }\end{array}$ & Very Good & $\begin{array}{l}2.33- \\
4.62 \mu \mathrm{g} / \mathrm{ml} \\
\mid \mathrm{C}_{50}\end{array}$ & $\begin{array}{l}\text { Plasmodium } \\
\text { falciparum }\end{array}$ & No \\
\hline $\begin{array}{l}\text { Premna chryso- } \\
\text { clada }\end{array}$ & Lamiaceae & {$[26]$} & Kenya & Leaves & Methanol & Moderate & $\begin{array}{l}11.1 \mu \mathrm{g} / \mathrm{ml} \\
\mid \mathrm{C}_{50}\end{array}$ & $\begin{array}{l}\text { Plasmodium falcipa- } \\
\text { rum D6, W2 }\end{array}$ & $\mathrm{Nd}$ \\
\hline Prosopis africana & Fabaceae & {$[50]$} & Nigeria & Ns & $\begin{array}{l}\text { Methanol, Water, } \\
\text { Butanol, Ethyl } \\
\text { Acetate }\end{array}$ & Moderate & $\begin{array}{l}14.97- \\
15.28 \mu \mathrm{g} / \mathrm{ml} \\
\mid C_{50}\end{array}$ & $\begin{array}{l}\text { Plasmodium falcipa- } \\
\text { rum 3D7, K1 }\end{array}$ & $\begin{array}{c}\text { Yes }(\mathrm{SI} \geq 99 ; \text { mouse } \\
\text { heart-derived } \\
\text { cells }[\mathrm{NBMH}])\end{array}$ \\
\hline
\end{tabular}


Table 1 (continued)

\begin{tabular}{|c|c|c|c|c|c|c|c|c|c|}
\hline Plant species & Plant family & Source & $\begin{array}{l}\text { Country } \\
\text { of study }\end{array}$ & $\begin{array}{l}\text { Part of } \\
\text { plant } \\
\text { used }\end{array}$ & $\begin{array}{l}\text { Extraction } \\
\text { solvent }\end{array}$ & $\begin{array}{l}\text { Antiplas- } \\
\text { modial } \\
\text { Activity }\end{array}$ & $\begin{array}{l}I C_{50} \text { or } E D_{50} \\
\text { or } L_{50}\end{array}$ & $\begin{array}{l}\text { Strain of } \\
\text { Plasmodium } \\
\text { Tested }\end{array}$ & $\begin{array}{l}\text { Toxicity (value; } \\
\text { assay) }\end{array}$ \\
\hline Prunus africana & Rosaceae & {$[24]$} & Kenya & $\begin{array}{l}\text { Stem } \\
\text { Barks }\end{array}$ & Methanol & Moderate & $\begin{array}{l}17.3 \mu \mathrm{g} / \mathrm{ml} \\
\mid \mathrm{C}_{50}\end{array}$ & $\begin{array}{l}\text { Plasmodium falcipa- } \\
\text { rum D6, W2 }\end{array}$ & $\mathrm{Nd}$ \\
\hline $\begin{array}{l}\text { Pseudospondias } \\
\text { microcarpa }\end{array}$ & Anacardiaceae & {$[31]$} & Tanzania & Roots & Ethanol & Very Good & $\begin{array}{l}1.13 \mu \mathrm{g} / \mathrm{ml} \\
\mathrm{IC}_{50}\end{array}$ & $\begin{array}{l}\text { Plasmodium falcipa- } \\
\text { rum K1 }\end{array}$ & No \\
\hline $\begin{array}{l}\text { Psiadia punctu- } \\
\text { lata }\end{array}$ & Asteraceae & {$[22]$} & $\begin{array}{l}\text { South } \\
\text { Africa }\end{array}$ & Twigs & Dichloromethane & Good & $9 \mu \mathrm{g} / \mathrm{ml} \mathrm{IC} 50$ & $\begin{array}{l}\text { Plasmodium falcipa- } \\
\text { rum D10 }\end{array}$ & $\mathrm{Nd}$ \\
\hline \multirow[t]{2}{*}{ Psidium guajava } & Myrtaceae & {$[40]$} & DR Congo & Leaves & Water & Good & $\begin{array}{l}5.46 \mu \mathrm{g} / \mathrm{ml} \\
\mid \mathrm{C}_{50}\end{array}$ & $\begin{array}{l}\text { Plasmodium falcipa- } \\
\text { rum K1 }\end{array}$ & No \\
\hline & & {$[20]$} & Tanzania & Leaves & Ethyl Acetate & Moderate & $10 \mu \mathrm{g} / \mathrm{ml} \mathrm{IC}_{50}$ & $\begin{array}{l}\text { Plasmodium falcipa- } \\
\text { rum K1 }\end{array}$ & $\mathrm{Nd}$ \\
\hline $\begin{array}{c}\text { Psorospermum } \\
\text { senegalense }\end{array}$ & Hypericaceae & {$[63]$} & $\begin{array}{l}\text { Burkina } \\
\text { Faso }\end{array}$ & Leaves & Dichloromethane & Moderate & $\begin{array}{l}10.03 \mu \mathrm{g} / \mathrm{ml} \\
\mid \mathrm{C}_{50}\end{array}$ & $\begin{array}{l}\text { Plasmodium falcipa- } \\
\text { rum 3D7 \&W2 }\end{array}$ & No \\
\hline $\begin{array}{r}\text { Ptaeroxylon } \\
\text { obliquum }\end{array}$ & Rutaceae & {$[22]$} & $\begin{array}{l}\text { South } \\
\text { Africa }\end{array}$ & Stems & $\begin{array}{l}\text { Dichlorometh- } \\
\text { ane/Methanol }\end{array}$ & Good & $5.5 \mu \mathrm{g} / \mathrm{ml} \mathrm{I} \mathrm{C}_{50}$ & $\begin{array}{l}\text { Plasmodium falcipa- } \\
\text { rum D10 }\end{array}$ & $\mathrm{Nd}$ \\
\hline $\begin{array}{l}\text { Pterocarpus } \\
\text { angolensis }\end{array}$ & Fabaceae & {$[22]$} & $\begin{array}{l}\text { South } \\
\text { Africa }\end{array}$ & Roots & Dichloromethane & Moderate & $\begin{array}{l}10.6 \mu \mathrm{g} / \mathrm{ml} \\
\mathrm{IC}_{50}\end{array}$ & $\begin{array}{l}\text { Plasmodium falcipa- } \\
\text { rum D10 }\end{array}$ & $\mathrm{Nd}$ \\
\hline $\begin{array}{l}\text { Pterocarpus } \\
\text { erinaceus }\end{array}$ & Fabaceae & {$[118]$} & $\begin{array}{l}\text { Burkina } \\
\text { Faso }\end{array}$ & $\begin{array}{l}\text { Leaves } \\
\text { Ans } \\
\text { Barks }\end{array}$ & $\begin{array}{l}\text { Ethanol, Chloro- } \\
\text { form }\end{array}$ & Very Good & $\begin{array}{l}1.93 \mu \mathrm{g} / \mathrm{ml} \\
\mathrm{IC}_{50}\end{array}$ & $\begin{array}{l}\text { Plasmodium falcipa- } \\
\text { rum 3D7 And Dd2 }\end{array}$ & $\mathrm{Nd}$ \\
\hline Pulicaria crispa & Asteraceae & {$[34]$} & Sudan & $\begin{array}{l}\text { Whole } \\
\text { Plant }\end{array}$ & $\begin{array}{l}\text { Petroleum Ether/ } \\
\text { Chloroform }\end{array}$ & Very Good & $<5 \mu \mathrm{g} / \mathrm{ml} \mathrm{IC} C_{50}$ & $\begin{array}{l}\text { Plasmodium falci- } \\
\text { parum }\end{array}$ & $\mathrm{Nd}$ \\
\hline \multirow[t]{2}{*}{$\begin{array}{l}\text { Pycnanthus } \\
\text { angolensis }\end{array}$} & Myristicaceae & {$[28]$} & Ivory Coast & $\begin{array}{l}\text { Stem } \\
\text { Barks }\end{array}$ & Ethanol & Moderate & $\begin{array}{l}18.2 \mu \mathrm{g} / \mathrm{ml} \\
\mathrm{IC}_{50}\end{array}$ & $\begin{array}{l}\text { Plasmodium } \\
\text { falciparum Fcb1/ } \\
\text { Colombia Strain }\end{array}$ & $\mathrm{Nd}$ \\
\hline & & {$[74]$} & $\begin{array}{l}\text { S. Tome' } \\
\text { And Prı } \\
\text { 'Ncipe }\end{array}$ & Barks & Ethanol & Very Good & $<5 \mu \mathrm{g} / \mathrm{ml} \mathrm{I} \mathrm{C}_{50}$ & $\begin{array}{l}\text { Plasmodium falcipa- } \\
\text { rum 3D7 And Dd2 }\end{array}$ & $\mathrm{Nd}$ \\
\hline $\begin{array}{l}\text { Pyrenacantha } \\
\text { grandiflora } \\
\text { Baill }\end{array}$ & Icacinaceae & {$[37]$} & $\begin{array}{l}\text { South } \\
\text { Africa }\end{array}$ & Roots & Dichloromethane & Good & $\begin{array}{l}5.82 \mu \mathrm{g} / \mathrm{ml} \\
\mid \mathrm{C}_{50}\end{array}$ & $\begin{array}{l}\text { Plasmodium falcipa- } \\
\text { rum NF54 }\end{array}$ & $\mathrm{Nd}$ \\
\hline \multirow[t]{2}{*}{ Quassia africana } & Simaroubaceae & {$[103]$} & $\begin{array}{l}\text { Congo } \\
\text { Brazza- } \\
\text { ville }\end{array}$ & Leaves & $\begin{array}{l}\text { Water, Ethanol, } \\
\text { Dichlorometh- } \\
\text { ane }\end{array}$ & Very Good & $\begin{array}{l}0.1-2.2 \mu \mathrm{g} / \mathrm{ml} \\
\mid \mathrm{C}_{50}\end{array}$ & $\begin{array}{l}\text { Plasmodium falcipa- } \\
\text { rum Fcm29- } \\
\text { Cameroon }\end{array}$ & $\begin{array}{c}\text { Yes }\left(\mathrm{IC}_{50}=6.7 \mu \mathrm{g} /\right. \\
\mathrm{ml} ; \mathrm{KB} \text { cells })\end{array}$ \\
\hline & & {$[40]$} & D.R. Congo & $\begin{array}{l}\text { Root } \\
\text { Barks }\end{array}$ & Water & Very Good & $\begin{array}{l}0.46 \mu \mathrm{g} / \mathrm{ml} \\
\mid C_{50}\end{array}$ & $\begin{array}{l}\text { Plasmodium falcipa- } \\
\text { rum K1 }\end{array}$ & No \\
\hline $\begin{array}{l}\text { Ranunculus } \\
\text { multifidus }\end{array}$ & Ranunculaceae & {$[22]$} & $\begin{array}{l}\text { South } \\
\text { Africa }\end{array}$ & $\begin{array}{l}\text { Whole } \\
\text { Plant }\end{array}$ & $\begin{array}{l}\text { Dichlorometh- } \\
\text { ane/Methanol }\end{array}$ & Very Good & $2.3 \mu \mathrm{g} / \mathrm{ml} \mathrm{IC}_{50}$ & $\begin{array}{l}\text { Plasmodium falcipa- } \\
\text { rum D10 }\end{array}$ & $\mathrm{Nd}$ \\
\hline $\begin{array}{l}\text { Rauvolfia caffra } \\
\text { Sond }\end{array}$ & Apocynaceae & {$[37]$} & $\begin{array}{l}\text { South } \\
\text { Africa }\end{array}$ & Roots & Dichloromethane & Very Good & $\begin{array}{l}2.13 \mu \mathrm{g} / \mathrm{ml} \\
\mid \mathrm{C}_{50}\end{array}$ & $\begin{array}{l}\text { Plasmodium falcipa- } \\
\text { rum NF54 }\end{array}$ & $\mathrm{Nd}$ \\
\hline $\begin{array}{l}\text { Rauvolfia nom- } \\
\text { basiana }\end{array}$ & Apocynaceae & {$[26]$} & Kenya & $\begin{array}{l}\text { Root } \\
\text { Barks }\end{array}$ & Methanol & Good & $9.1 \mu \mathrm{g} / \mathrm{ml} / \mathrm{C}_{50}$ & $\begin{array}{l}\text { Plasmodium falcipa- } \\
\text { rum D6, W2 }\end{array}$ & $\mathrm{Nd}$ \\
\hline \multirow[t]{3}{*}{$\begin{array}{l}\text { Rauvolfia vomi- } \\
\text { toria }\end{array}$} & Apocynaceae & {$[53]$} & Nigeria & Roots & Dichloromethane & Very Good & $\begin{array}{l}4.78 \mu \mathrm{g} / \mathrm{ml} \\
\mid \mathrm{C}_{50}\end{array}$ & $\begin{array}{l}\text { Plasmodium falcipa- } \\
\text { rum D10 }\end{array}$ & $\mathrm{Nd}$ \\
\hline & & {$[28]$} & Ivory Coast & Barks & Ethanol & Very Good & $2.5 \mu \mathrm{g} / \mathrm{ml} \mathrm{IC}_{50}$ & $\begin{array}{l}\text { Plasmodium } \\
\text { falciparum Fcb1/ } \\
\text { Colombia Strain }\end{array}$ & No \\
\hline & & {$[43]$} & Ivory Coast & $\begin{array}{l}\text { Root } \\
\text { Barks }\end{array}$ & Ethanol & Very Good & $2.5 \mu \mathrm{g} / \mathrm{ml} \mathrm{IC}_{50}$ & $\begin{array}{l}\text { Plasmodium falcipa- } \\
\text { rum FCB1 }\end{array}$ & $\mathrm{Nd}$ \\
\hline \multirow[t]{2}{*}{$\begin{array}{l}\text { Rhamnus } \\
\text { prinoides }\end{array}$} & Rhamnaceae & {$[77]$} & Kenya & Roots & Methanol & Moderate & $\begin{array}{l}15.1 \mu \mathrm{g} / \mathrm{ml} \\
\mid \mathrm{C}_{50}\end{array}$ & $\begin{array}{l}\text { Plasmodium falcipa- } \\
\text { rum K39 (CQ-S), } \\
\text { ENT30, NF54, V1/S }\end{array}$ & $\mathrm{Nd}$ \\
\hline & & {$[21]$} & Kenya & $\begin{array}{l}\text { Root } \\
\text { Barks }\end{array}$ & Methanol & Very Good & $\begin{array}{l}3.53 \mu \mathrm{g} / \mathrm{ml} \\
\mid \mathrm{C}_{50}\end{array}$ & $\begin{array}{l}\text { Plasmodium falcipa- } \\
\text { rum D6 }\end{array}$ & No \\
\hline $\begin{array}{l}\text { Rhizophora } \\
\text { mucronata }\end{array}$ & Rhizophoraceae & {$[22]$} & $\begin{array}{l}\text { South } \\
\text { Africa }\end{array}$ & Twigs & $\begin{array}{l}\text { Dichlorometh- } \\
\text { ane/Methanol }\end{array}$ & Good & $5.6 \mu \mathrm{g} / \mathrm{ml} \mathrm{IC} 50$ & $\begin{array}{l}\text { Plasmodium falcipa- } \\
\text { rum D10 }\end{array}$ & $\mathrm{Nd}$ \\
\hline
\end{tabular}


Table 1 (continued)

\begin{tabular}{|c|c|c|c|c|c|c|c|c|c|}
\hline Plant species & Plant family & Source & $\begin{array}{l}\text { Country } \\
\text { of study }\end{array}$ & $\begin{array}{l}\text { Part of } \\
\text { plant } \\
\text { used }\end{array}$ & $\begin{array}{l}\text { Extraction } \\
\text { solvent }\end{array}$ & $\begin{array}{l}\text { Antiplas- } \\
\text { modial } \\
\text { Activity }\end{array}$ & $\begin{array}{l}I C_{50} \text { or } E D_{50} \\
\text { or } L D_{50}\end{array}$ & $\begin{array}{l}\text { Strain of } \\
\text { Plasmodium } \\
\text { Tested }\end{array}$ & $\begin{array}{l}\text { Toxicity (value; } \\
\text { assay) }\end{array}$ \\
\hline $\begin{array}{c}\text { Ricinus com- } \\
\text { munis var. } \\
\text { communis }\end{array}$ & Euphorbiaceae & {$[22]$} & $\begin{array}{l}\text { South } \\
\text { Africa }\end{array}$ & Stems & Water & Good & $8.0 \mu \mathrm{g} / \mathrm{ml} / \mathrm{C}_{50}$ & $\begin{array}{l}\text { Plasmodium falcipa- } \\
\text { rum D10 }\end{array}$ & $\mathrm{Nd}$ \\
\hline \multirow[t]{2}{*}{ Rubia cordifolia } & Rubiaceae & {$[95]$} & Kenya & $\begin{array}{l}\text { Leaves/ } \\
\text { Seeds/ } \\
\text { Stems }\end{array}$ & Methanol & Very Good & $\begin{array}{l}1.20 \mu \mathrm{g} / \mathrm{ml} \\
\mid \mathrm{C}_{50}\end{array}$ & $\begin{array}{l}\text { Plasmodium } \\
\text { Knowlesi }\end{array}$ & $\mathrm{Nd}$ \\
\hline & & {$[24]$} & Kenya & $\begin{array}{l}\text { Whole } \\
\text { Plant }\end{array}$ & Methanol & Very Good & $<5 \mu \mathrm{g} / \mathrm{ml} \mathrm{IC} C_{50}$ & $\begin{array}{l}\text { Plasmodium falcipa- } \\
\text { rum D6, W2 }\end{array}$ & $\mathrm{Nd}$ \\
\hline $\begin{array}{l}\text { Rumex abys- } \\
\text { sinicus }\end{array}$ & Polygonaceae & {$[92]$} & Rwanda & Roots & Water & Very Good & $\begin{array}{l}3.1-4.3 \mu \mathrm{g} / \mathrm{ml} \\
\mid \mathrm{C}_{50}\end{array}$ & $\begin{array}{l}\text { Plasmodium falcipa- } \\
\text { rum 3D7, W2 }\end{array}$ & $\begin{array}{l}\text { Yes }(\mathrm{SI}=3.1 \text {; } \\
\text { human normal } \\
\text { foetal lung fibro- } \\
\text { blast [WI-38]) }\end{array}$ \\
\hline Rumex crispus & Polygonaceae & {$[22]$} & $\begin{array}{l}\text { South } \\
\text { Africa }\end{array}$ & Roots & Dichloromethane & Moderate & $14 \mu \mathrm{g} / \mathrm{ml} \mathrm{IC} C_{50}$ & $\begin{array}{l}\text { Plasmodium falcipa- } \\
\text { rum D10 }\end{array}$ & $\mathrm{Nd}$ \\
\hline $\begin{array}{l}\text { Salacia mada- } \\
\text { gascariensis }\end{array}$ & Celastraceae & {$[20]$} & Tanzania & Roots & Petroleum Ether & Very Good & $0.8 \mu \mathrm{g} / \mathrm{ml} \mathrm{I} \mathrm{C}_{50}$ & $\begin{array}{l}\text { Plasmodium falcipa- } \\
\text { rum K1 }\end{array}$ & $\mathrm{Nd}$ \\
\hline $\begin{array}{l}\text { Salvia africana- } \\
\quad \text { lutea }\end{array}$ & Lamiaceae & {$[120]$} & $\begin{array}{l}\text { South } \\
\text { Africa }\end{array}$ & $\begin{array}{l}\text { Aerial } \\
\text { Parts }\end{array}$ & $\begin{array}{l}\text { Methanol/Chlo- } \\
\text { roform }\end{array}$ & Moderate & $\begin{array}{l}15.863 \mu \mathrm{g} / \mathrm{ml} \\
\mathrm{IC}_{50}\end{array}$ & $\begin{array}{l}\text { Plasmodium falcipa- } \\
\text { rum FCR-3 }\end{array}$ & $\mathrm{Nd}$ \\
\hline Salvia albicaulis & Lamiaceae & {$[120]$} & $\begin{array}{l}\text { South } \\
\text { Africa }\end{array}$ & $\begin{array}{l}\text { Aerial } \\
\text { Parts }\end{array}$ & $\begin{array}{l}\text { Methanol/Chlo- } \\
\text { roform }\end{array}$ & Moderate & $\begin{array}{l}15.833 \mu \mathrm{g} / \mathrm{ml} \\
\mathrm{IC}_{50}\end{array}$ & $\begin{array}{l}\text { Plasmodium falcipa- } \\
\text { rum FCR-3 }\end{array}$ & $\mathrm{Nd}$ \\
\hline Salvia aurita & Lamiaceae & {$[120]$} & $\begin{array}{l}\text { South } \\
\text { Africa }\end{array}$ & $\begin{array}{l}\text { Aerial } \\
\text { Parts }\end{array}$ & $\begin{array}{l}\text { Methanol/Chlo- } \\
\text { roform }\end{array}$ & Good & $\begin{array}{l}8.923 \mu \mathrm{g} / \mathrm{ml} \\
\quad \mathrm{IC}_{50}\end{array}$ & $\begin{array}{l}\text { Plasmodium falcipa- } \\
\text { rum FCR-3 }\end{array}$ & $\mathrm{Nd}$ \\
\hline $\begin{array}{l}\text { Salvia chamelae- } \\
\text { agnea }\end{array}$ & Lamiaceae & [120] & $\begin{array}{l}\text { South } \\
\text { Africa }\end{array}$ & $\begin{array}{l}\text { Aerial } \\
\text { Parts }\end{array}$ & $\begin{array}{l}\text { Methanol/Chlo- } \\
\text { roform }\end{array}$ & Good & $\begin{array}{l}8.713 \mu \mathrm{g} / \mathrm{ml} \\
\quad \mathrm{IC}_{50}\end{array}$ & $\begin{array}{l}\text { Plasmodium falcipa- } \\
\text { rum FCR-3 }\end{array}$ & $\mathrm{Nd}$ \\
\hline Salvia dolomitica & Lamiaceae & [120] & $\begin{array}{l}\text { South } \\
\text { Africa }\end{array}$ & $\begin{array}{l}\text { Aerial } \\
\text { Parts }\end{array}$ & $\begin{array}{l}\text { Methanol/Chlo- } \\
\text { roform }\end{array}$ & Good & $\begin{array}{l}7.623 \mu \mathrm{g} / \mathrm{ml} \\
\mathrm{IC}_{50}\end{array}$ & $\begin{array}{l}\text { Plasmodium falcipa- } \\
\text { rum FCR-3 }\end{array}$ & $\mathrm{Nd}$ \\
\hline Salvia garipensis & Lamiaceae & {$[120]$} & $\begin{array}{l}\text { South } \\
\text { Africa }\end{array}$ & $\begin{array}{l}\text { Aerial } \\
\text { Parts }\end{array}$ & $\begin{array}{l}\text { Methanol/Chlo- } \\
\text { roform }\end{array}$ & Moderate & $\begin{array}{l}13.953 \mu \mathrm{g} / \mathrm{ml} \\
\mathrm{IC}_{50}\end{array}$ & $\begin{array}{l}\text { Plasmodium falcipa- } \\
\text { rum FCR-3 }\end{array}$ & $\mathrm{Nd}$ \\
\hline Salvia muirii & Lamiaceae & {$[120]$} & $\begin{array}{l}\text { South } \\
\text { Africa }\end{array}$ & $\begin{array}{l}\text { Aerial } \\
\text { Parts }\end{array}$ & $\begin{array}{l}\text { Methanol/Chlo- } \\
\text { roform }\end{array}$ & Moderate & $\begin{array}{l}11.873 \mu \mathrm{g} / \mathrm{ml} \\
\mathrm{IC}_{50}\end{array}$ & $\begin{array}{l}\text { Plasmodium falcipa- } \\
\text { rum FCR-3 }\end{array}$ & $\mathrm{Nd}$ \\
\hline Salvia radula & Lamiaceae & {$[120]$} & $\begin{array}{l}\text { South } \\
\text { Africa }\end{array}$ & $\begin{array}{l}\text { Aerial } \\
\text { Parts }\end{array}$ & $\begin{array}{l}\text { Methanol/Chlo- } \\
\text { roform }\end{array}$ & Very Good & $\begin{array}{l}3.913 \mu \mathrm{g} / \mathrm{ml} \\
\mid \mathrm{C}_{50}\end{array}$ & $\begin{array}{l}\text { Plasmodium falcipa- } \\
\text { rum FCR-3 }\end{array}$ & $\begin{array}{l}\text { Yes } \\
\qquad\left(\mathrm{IC}_{50}=20.12 \mu \mathrm{g} /\right. \\
\text { ml; Kidney cells })\end{array}$ \\
\hline \multirow[t]{2}{*}{ Salvia repens } & Lamiaceae & [120] & $\begin{array}{l}\text { South } \\
\text { Africa }\end{array}$ & $\begin{array}{l}\text { Aerial } \\
\text { Parts }\end{array}$ & $\begin{array}{l}\text { Methanol/Chlo- } \\
\text { roform }\end{array}$ & Good & $\begin{array}{l}8.253 \mu \mathrm{g} / \mathrm{ml} \\
\mid \mathrm{C}_{50}\end{array}$ & $\begin{array}{l}\text { Plasmodium falcipa- } \\
\text { rum FCR-3 }\end{array}$ & $\mathrm{Nd}$ \\
\hline & & {$[22]$} & $\begin{array}{l}\text { South } \\
\text { Africa }\end{array}$ & $\begin{array}{l}\text { Whole } \\
\text { Plant }\end{array}$ & $\begin{array}{l}\text { Dichlorometh- } \\
\text { ane/Methanol }\end{array}$ & Moderate & $\begin{array}{l}10.8 \mu \mathrm{g} / \mathrm{m} \mid \\
\mid \mathrm{C}_{50}\end{array}$ & $\begin{array}{l}\text { Plasmodium falcipa- } \\
\text { rum D10 }\end{array}$ & $\mathrm{Nd}$ \\
\hline Salvia runcinata & Lamiaceae & [120] & $\begin{array}{l}\text { South } \\
\text { Africa }\end{array}$ & $\begin{array}{l}\text { Aerial } \\
\text { Parts }\end{array}$ & $\begin{array}{l}\text { Methanol/Chlo- } \\
\text { roform }\end{array}$ & Moderate & $\begin{array}{l}16.613 \mu \mathrm{g} / \mathrm{ml} \\
\mathrm{IC}_{50}\end{array}$ & $\begin{array}{l}\text { Plasmodium falcipa- } \\
\text { rum FCR-3 }\end{array}$ & $\mathrm{Nd}$ \\
\hline Salvia schlechteri & Lamiaceae & {$[120]$} & $\begin{array}{l}\text { South } \\
\text { Africa }\end{array}$ & $\begin{array}{l}\text { Aerial } \\
\text { Parts }\end{array}$ & $\begin{array}{l}\text { Methanol/Chlo- } \\
\text { roform }\end{array}$ & Moderate & $\begin{array}{l}17.513 \mu \mathrm{g} / \mathrm{ml} \\
\mathrm{IC}_{50}\end{array}$ & $\begin{array}{l}\text { Plasmodium falcipa- } \\
\text { rum FCR-3 }\end{array}$ & $\mathrm{Nd}$ \\
\hline $\begin{array}{l}\text { Salvia steno- } \\
\text { phylla }\end{array}$ & Lamiaceae & {$[120]$} & $\begin{array}{l}\text { South } \\
\text { Africa }\end{array}$ & $\begin{array}{l}\text { Aerial } \\
\text { Parts }\end{array}$ & $\begin{array}{l}\text { Methanol/Chlo- } \\
\text { roform }\end{array}$ & Good & $\begin{array}{l}6.53 \mu \mathrm{g} / \mathrm{ml} \\
\mid \mathrm{C}_{50}\end{array}$ & $\begin{array}{l}\text { Plasmodium falcipa- } \\
\text { rum FCR-3 }\end{array}$ & $\begin{array}{l}\text { Yes } \\
\qquad\left(\mathrm{IC}_{50}=12.12 \mu \mathrm{g} /\right. \\
\mathrm{ml} \text {; Kidney cells })\end{array}$ \\
\hline $\begin{array}{l}\text { Sonchus sch- } \\
\text { weinfurthi }\end{array}$ & Compositae & {$[95]$} & Kenya & $\begin{array}{l}\text { Barks/ } \\
\text { Roots }\end{array}$ & Methanol & Very Good & $\begin{array}{l}2.10 \mu \mathrm{g} / \mathrm{ml} \\
\mid \mathrm{C}_{50}\end{array}$ & $\begin{array}{l}\text { Plasmodium } \\
\text { Knowlesi }\end{array}$ & $\mathrm{Nd}$ \\
\hline Scaevola plumieri & i Goodeniaceae & {$[22]$} & $\begin{array}{l}\text { South } \\
\text { Africa }\end{array}$ & Twigs & Dichloromethane & Moderate & $11 \mu \mathrm{g} / \mathrm{ml} \mathrm{IC} 50$ & $\begin{array}{l}\text { Plasmodium falcipa- } \\
\text { rum D10 }\end{array}$ & $\mathrm{Nd}$ \\
\hline $\begin{array}{l}\text { Schefflera umbel- } \\
\text { lifera }\end{array}$ & Araliaceae & {$[22]$} & $\begin{array}{l}\text { South } \\
\text { Africa }\end{array}$ & Leaves & $\begin{array}{l}\text { Dichlorometh- } \\
\text { ane/Methanol }\end{array}$ & Very Good & $3.7 \mu \mathrm{g} / \mathrm{ml} \mathrm{IC} 50$ & $\begin{array}{l}\text { Plasmodium falcipa- } \\
\text { rum D10 }\end{array}$ & $\mathrm{Nd}$ \\
\hline $\begin{array}{l}\text { Schizozygia cof- } \\
\text { faeoides }\end{array}$ & Apocynaceae & {$[26]$} & Kenya & Leaves & Methanol & Moderate & $\begin{array}{l}10.5 \mu \mathrm{g} / \mathrm{ml} \\
\mid C_{50}\end{array}$ & $\begin{array}{l}\text { Plasmodium falcipa- } \\
\text { rum D6, W2 }\end{array}$ & $\mathrm{Nd}$ \\
\hline $\begin{array}{l}\text { Schkuhria pin- } \\
\text { nata }\end{array}$ & Compositae & {$[24]$} & Kenya & $\begin{array}{l}\text { Whole } \\
\text { Plant }\end{array}$ & Methanol & Good & $\begin{array}{l}1.3-6.8 \mu \mathrm{g} / \mathrm{ml} \\
\mid \mathrm{C}_{50}\end{array}$ & $\begin{array}{l}\text { Plasmodium falcipa- } \\
\text { rumD6, W2 }\end{array}$ & $\mathrm{Nd}$ \\
\hline $\begin{array}{l}\text { Schrankia lepto- } \\
\text { carpa }\end{array}$ & Fabaceae & {$[65]$} & Benin & $\begin{array}{l}\text { Aerial } \\
\text { Parts }\end{array}$ & Methanol & Moderate & $\begin{array}{l}3.38->20 \mu \mathrm{g} / \\
\mathrm{ml} \mathrm{IC}_{50}\end{array}$ & $\begin{array}{l}\text { Plasmodium falcipa- } \\
\quad \text { rum 3D7 \& K1 }\end{array}$ & $\mathrm{Nd}$ \\
\hline
\end{tabular}


Table 1 (continued)

\begin{tabular}{|c|c|c|c|c|c|c|c|c|c|}
\hline Plant species & Plant family & Source & $\begin{array}{l}\text { Country } \\
\text { of study }\end{array}$ & $\begin{array}{l}\text { Part of } \\
\text { plant } \\
\text { used }\end{array}$ & $\begin{array}{l}\text { Extraction } \\
\text { solvent }\end{array}$ & $\begin{array}{l}\text { Antiplas- } \\
\text { modial } \\
\text { Activity }\end{array}$ & $\begin{array}{l}\mathrm{IC}_{50} \text { or } \mathrm{ED}_{50} \\
\text { or } \mathrm{LD}_{50}\end{array}$ & $\begin{array}{l}\text { Strain of } \\
\text { Plasmodium } \\
\text { Tested }\end{array}$ & $\begin{array}{l}\text { Toxicity (value; } \\
\text { assay) }\end{array}$ \\
\hline $\begin{array}{l}\text { Sclerocarya } \\
\text { birrea }\end{array}$ & Anacardiaceae & [24] & Kenya & $\begin{array}{l}\text { Stem } \\
\text { Barks }\end{array}$ & Methanol & Moderate & 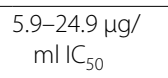 & $\begin{array}{l}\text { Plasmodium falcipa- } \\
\text { rum D6, W2 }\end{array}$ & $\mathrm{Nd}$ \\
\hline Secamone afzelii & Apocynaceae & {$[65]$} & Benin & $\begin{array}{l}\text { Aerial } \\
\text { Parts }\end{array}$ & Methanol & Moderate & $\begin{array}{l}6.48->20 \mu \mathrm{g} / \\
\mathrm{ml} \mathrm{IC}_{50}\end{array}$ & $\begin{array}{l}\text { Plasmodium falcipa- } \\
\text { rum 3D7 \& K1 }\end{array}$ & $\mathrm{Nd}$ \\
\hline $\begin{array}{l}\text { Securidaca lon- } \\
\text { gipedunculata }\end{array}$ & Polygalaceae & [121] & Mali & Leaves & Dichloromethane & Good & $6.9 \mu \mathrm{g} / \mathrm{ml} \mathrm{I} \mathrm{C}_{50}$ & $\begin{array}{l}\text { Plasmodium falcipa- } \\
\text { rum 3D7 }\end{array}$ & $\mathrm{Nd}$ \\
\hline Securinega virosa & Phyllanthaceae & [52] & $\begin{array}{l}\text { Burkina } \\
\text { Faso }\end{array}$ & Leaves & Dichloromethane & Good & $7.1 \mu \mathrm{g} / \mathrm{ml} \mathrm{I} \mathrm{C}_{50}$ & $\begin{array}{l}\text { Plasmodium falci- } \\
\text { parum }\end{array}$ & $\mathrm{Nd}$ \\
\hline $\begin{array}{l}\text { Senecio oxyrii- } \\
\text { folius }\end{array}$ & Asteraceae & {$[22]$} & $\begin{array}{l}\text { South } \\
\text { Africa }\end{array}$ & $\begin{array}{l}\text { Whole } \\
\text { plant }\end{array}$ & $\begin{array}{l}\text { Dichlorometh- } \\
\text { ane/Methanol }\end{array}$ & Moderate & $13 \mu \mathrm{g} / \mathrm{ml} \mid \mathrm{C}_{50}$ & $\begin{array}{l}\text { Plasmodium falcipa- } \\
\text { rum D10 }\end{array}$ & $\mathrm{Nd}$ \\
\hline $\begin{array}{l}\text { Senecio stuhl- } \\
\text { mannii }\end{array}$ & Asteraceae & {$[56]$} & Uganda & Shoots & Ethyl Acetate & Moderate & $\begin{array}{l}14.0-15.2 \mu \mathrm{g} / \\
\mathrm{ml} \mathrm{IC}\end{array}$ & $\begin{array}{l}\text { Plasmodium falcipa- } \\
\text { rum D10, K1 }\end{array}$ & $\mathrm{Nd}$ \\
\hline $\begin{array}{l}\text { Senna didymo- } \\
\text { botrya }\end{array}$ & Fabaceae & {$[22]$} & $\begin{array}{l}\text { South } \\
\text { Africa }\end{array}$ & Twigs & $\begin{array}{l}\text { Dichlorometh- } \\
\text { ane/Methanol }\end{array}$ & Good & $9.5 \mu \mathrm{g} / \mathrm{ml} \mathrm{IC_{50 }}$ & $\begin{array}{l}\text { Plasmodium falcipa- } \\
\text { rum D10 }\end{array}$ & $\mathrm{Nd}$ \\
\hline \multirow[t]{2}{*}{ Senna petersiana } & Fabaceae & [22] & $\begin{array}{l}\text { South } \\
\text { Africa }\end{array}$ & Twigs & $\begin{array}{l}\text { Dichlorometh- } \\
\text { ane/Methanol }\end{array}$ & Moderate & $13 \mu \mathrm{g} / \mathrm{ml} / \mathrm{C}_{50}$ & $\begin{array}{l}\text { Plasmodium falcipa- } \\
\text { rum D10 }\end{array}$ & $\mathrm{Nd}$ \\
\hline & & [59] & Malawi & Leaves & Methanol & Very Good & $\begin{array}{l}2.67 \mu \mathrm{g} / \mathrm{ml} \\
\mathrm{I}_{50}\end{array}$ & $\begin{array}{l}\text { Plasmodium falcipa- } \\
\text { rum VI/S }\end{array}$ & $\mathrm{Nd}$ \\
\hline $\begin{array}{l}\text { Sericocomopsis } \\
\text { hildebrandtii }\end{array}$ & Amaranthaceae & [21] & Kenya & $\begin{array}{l}\text { Root } \\
\text { Barks }\end{array}$ & Methanol & Very Good & $\begin{array}{l}3.78 \mu \mathrm{g} / \mathrm{ml} \\
\mid \mathrm{C}_{50}\end{array}$ & $\begin{array}{l}\text { Plasmodium falcipa- } \\
\text { rum D6 }\end{array}$ & No \\
\hline $\begin{array}{l}\text { Setaria mega- } \\
\text { phylla }\end{array}$ & Poaceae & [22] & $\begin{array}{l}\text { South } \\
\text { Africa }\end{array}$ & $\begin{array}{l}\text { Whole } \\
\text { plant }\end{array}$ & $\begin{array}{l}\text { Dichlorometh- } \\
\text { ane/Methanol }\end{array}$ & Very Good & $4.5 \mu \mathrm{g} / \mathrm{ml} \mathrm{IC} C_{50}$ & $\begin{array}{l}\text { Plasmodium falcipa- } \\
\text { rum D10 }\end{array}$ & $\mathrm{Nd}$ \\
\hline \multirow[t]{2}{*}{ Sida acuta } & Malvaceae & [118] & $\begin{array}{l}\text { Burkina } \\
\text { Faso }\end{array}$ & $\begin{array}{l}\text { Whole } \\
\text { Plant }\end{array}$ & $\begin{array}{l}\text { Ethanol, Chloro- } \\
\text { form, Water }\end{array}$ & Very Good & $\begin{array}{l}0.87-0.92 \mu \mathrm{g} / \\
\mathrm{ml} \mathrm{IC}_{50}\end{array}$ & $\begin{array}{l}\text { Plasmodium falcipa- } \\
\text { rum 3D7 And Dd2 }\end{array}$ & $\mathrm{Nd}$ \\
\hline & & [38] & Ivory Coast & Ns & Ethanol & Good & $\begin{array}{l}3.9-5.4 \mu \mathrm{g} / \mathrm{ml} \\
\mathrm{IC}_{50}\end{array}$ & $\begin{array}{l}\text { Plasmodium falci- } \\
\text { parum }\end{array}$ & No \\
\hline $\begin{array}{l}\text { Solanum pandu- } \\
\text { riforme }\end{array}$ & Solanaceae & [25] & $\begin{array}{l}\text { South } \\
\text { Africa }\end{array}$ & Leaves & Acetone & Very Good & $\begin{array}{l}3.62 \mu \mathrm{g} / \mathrm{ml} \\
\mid \mathrm{C}_{50}\end{array}$ & $\begin{array}{l}\text { Plasmodium falcipa- } \\
\text { rum UP1 (CQ-R) }\end{array}$ & $\mathrm{Nd}$ \\
\hline Solanecio mannii & i Asteraceae & [92] & Rwanda & Leaves & Dichloromethane & Moderate & $\begin{array}{l}12.7-18.2 \mu \mathrm{g} / \\
\mathrm{ml} \mathrm{IC}_{50}\end{array}$ & $\begin{array}{l}\text { Plasmodium falcipa- } \\
\text { rum 3D7, W2 }\end{array}$ & No \\
\hline $\begin{array}{l}\text { Spilanthes mauri- } \\
\text { tiana }\end{array}$ & - Asteraceae & {$[22]$} & $\begin{array}{l}\text { South } \\
\text { Africa }\end{array}$ & Stems & $\begin{array}{l}\text { Dichlorometh- } \\
\text { ane/Methanol }\end{array}$ & Good & $5.3 \mu \mathrm{g} / \mathrm{ml} \mathrm{I} \mathrm{C}_{50}$ & $\begin{array}{l}\text { Plasmodium falcipa- } \\
\text { rum D10 }\end{array}$ & $\mathrm{Nd}$ \\
\hline $\begin{array}{l}\text { Staudtia gabon- } \\
\text { ensis }\end{array}$ & Myristicaceae & [33] & Gabon & Stems & Methanol & Very Good & $0.8 \mu \mathrm{g} / \mathrm{ml} \mathrm{I} C_{50}$ & $\begin{array}{l}\text { Plasmodium falcipa- } \\
\text { rum Fcbm W2 }\end{array}$ & No \\
\hline $\begin{array}{l}\text { Stephania abys- } \\
\text { sinica }\end{array}$ & $\begin{array}{l}\text { Menisper- } \\
\text { maceae }\end{array}$ & [24] & Kenya & $\begin{array}{l}\text { Root } \\
\text { Barks }\end{array}$ & Methanol & Good & $\begin{array}{l}4.7-6.1 \mu \mathrm{g} / \mathrm{ml} \\
\mid \mathrm{C}_{50}\end{array}$ & $\begin{array}{l}\text { Plasmodium falcipa- } \\
\text { rum D6, W2 }\end{array}$ & $\mathrm{Nd}$ \\
\hline $\begin{array}{l}\text { Stephania } \\
\text { rotunda }\end{array}$ & $\begin{array}{l}\text { Menisper- } \\
\text { maceae }\end{array}$ & {$[45]$} & Cambodia & Tubers & Dichloromethane & Very Good & $1.0 \mu \mathrm{g} / \mathrm{ml} \mathrm{I} \mathrm{C}_{50}$ & $\begin{array}{l}\text { Plasmodium falcipa- } \\
\text { rum W2 }\end{array}$ & $\mathrm{Nd}$ \\
\hline $\begin{array}{l}\text { Struchium spar- } \\
\text { ganophorum }\end{array}$ & Asteraceae & [73] & $\begin{array}{l}\text { S. Tome' } \\
\text { And Prı } \\
\text { 'Ncipe }\end{array}$ & Leaves & Petroleum Ether & Good & $\begin{array}{l}<10 \mu \mathrm{g} / \mathrm{ml} \\
\mid \mathrm{C}_{50}\end{array}$ & $\begin{array}{l}\text { Plasmodium falcipa- } \\
\text { rum 3D7 And Dd2 }\end{array}$ & $\mathrm{Nd}$ \\
\hline $\begin{array}{l}\text { Strychnopsis } \\
\text { thouarsii }\end{array}$ & $\begin{array}{r}\text { Menisper- } \\
\text { maceae }\end{array}$ & [122] & $\begin{array}{l}\text { Madagas- } \\
\text { car }\end{array}$ & $\begin{array}{l}\text { Stem } \\
\text { Barks }\end{array}$ & Methanol & $\begin{array}{l}\text { Very } \\
\text { Good }^{\mathrm{a}}\end{array}$ & $3.1-4.2 \mu \mathrm{M}$ & $\begin{array}{l}\text { Plasmodium } \\
\text { falciparum NF54, } \\
\text { Plasmodium yoelli } \\
265 \text { BY }\end{array}$ & No \\
\hline $\begin{array}{l}\text { Strychnos hen- } \\
\text { ningsii }\end{array}$ & Loganiaceae & {$[72]$} & Kenya & Twigs & Methanol & Moderate & $\begin{array}{l}14.6-17.9 \mu \mathrm{g} / \\
\mathrm{ml} \mathrm{IC}_{50}\end{array}$ & $\begin{array}{l}\text { Plasmodium falcipa- } \\
\text { rum K1, NF54 }\end{array}$ & $\mathrm{Nd}$ \\
\hline $\begin{array}{l}\text { Strychnos } \\
\text { pungens }\end{array}$ & Loganiaceae & [22] & $\begin{array}{l}\text { South } \\
\text { Africa }\end{array}$ & Leaves & Dichloromethane & Moderate & $\begin{array}{l}12.6 \mu \mathrm{mg} / \mathrm{ml} \\
\mathrm{IC}_{50}\end{array}$ & $\begin{array}{l}\text { Plasmodium falcipa- } \\
\text { rum D10 }\end{array}$ & $\mathrm{Nd}$ \\
\hline $\begin{array}{l}\text { Strychnos } \\
\text { spinosa }\end{array}$ & Loganiaceae & [123] & Senegal & $\begin{array}{l}\text { Leaves, } \\
\text { Stem }\end{array}$ & Methanol, Water & Moderate & $15 \mu \mathrm{g} / \mathrm{ml} \mathrm{IC_{50 }}$ & $\begin{array}{l}\text { Plasmodiumfalci- } \\
\text { parum }\end{array}$ & $\mathrm{Nd}$ \\
\hline Strychnos icaja & Loganiaceae & {$[46]$} & D.R. congo & $\begin{array}{l}\text { Root } \\
\text { barks }\end{array}$ & $\begin{array}{l}\text { Methanolic and } \\
\text { dichlorometh- } \\
\text { ane }\end{array}$ & Very good & $\begin{array}{l}0.69 \mu \mathrm{mg} / \mathrm{ml} \\
\mathrm{IC}_{50}\end{array}$ & $\begin{array}{l}\text { Plasmodium } \\
\text { falciparum 3D7, } \\
\text { W2, Plasmodium } \\
\text { berghei berghei }\end{array}$ & $\mathrm{Nd}$ \\
\hline
\end{tabular}


Table 1 (continued)

\begin{tabular}{|c|c|c|c|c|c|c|c|c|c|}
\hline Plant species & Plant family & Source & $\begin{array}{l}\text { Country } \\
\text { of study }\end{array}$ & $\begin{array}{l}\text { Part of } \\
\text { plant } \\
\text { used }\end{array}$ & $\begin{array}{l}\text { Extraction } \\
\text { solvent }\end{array}$ & $\begin{array}{l}\text { Antiplas- } \\
\text { modial } \\
\text { Activity }\end{array}$ & $\begin{array}{l}\mathrm{IC}_{50} \text { or } \mathrm{ED}_{50} \\
\text { or } \mathrm{LD}_{50}\end{array}$ & $\begin{array}{l}\text { Strain of } \\
\text { Plasmodium } \\
\text { Tested }\end{array}$ & $\begin{array}{l}\text { Toxicity (value; } \\
\text { assay) }\end{array}$ \\
\hline \multirow[t]{3}{*}{$\begin{array}{l}\text { Suregada zanzi- } \\
\text { bariensis }\end{array}$} & Euphorbiaceae & {$[26]$} & Kenya & Leaves & Methanol & Good & $\begin{array}{l}5.8-6.7 \mu \mathrm{g} / \mathrm{ml} \\
\mid \mathrm{C}_{50}\end{array}$ & $\begin{array}{l}\text { Plasmodium falcipa- } \\
\text { rum D6, W2 }\end{array}$ & $\mathrm{Nd}$ \\
\hline & & [124] & Kenya & Leaves & Methanol & Very Good & 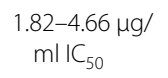 & $\begin{array}{l}\text { Plasmodium falcipa- } \\
\text { rum D6\&W2 }\end{array}$ & $\mathrm{Nd}$ \\
\hline & & [124] & Kenya & Leaves & Methanol & Very Good & $\begin{array}{l}1.82-4.66 \mu \mathrm{g} / \\
\mathrm{ml} \mathrm{IC}\end{array}$ & $\begin{array}{l}\text { Plasmodium falcipa- } \\
\text { rum D6, W2 }\end{array}$ & No \\
\hline \multirow{2}{*}{$\begin{array}{l}\text { Syzygium cor- } \\
\text { datum subsp. } \\
\text { cordatum }\end{array}$} & Myrtaceae & [22] & $\begin{array}{l}\text { South } \\
\text { Africa }\end{array}$ & Twigs & $\begin{array}{l}\text { Dichlorometh- } \\
\text { ane/Methanol }\end{array}$ & Moderate & $\begin{array}{l}14.7 \mu \mathrm{g} / \mathrm{ml} \\
\mathrm{IC}_{50}\end{array}$ & $\begin{array}{l}\text { Plasmodium falcipa- } \\
\text { rum D10 }\end{array}$ & $\mathrm{Nd}$ \\
\hline & & {$[37]$} & $\begin{array}{l}\text { South } \\
\text { Africa }\end{array}$ & Leaves & Dichloromethane & Good & $\begin{array}{l}6.15 \mu \mathrm{g} / \mathrm{ml} \\
\mathrm{IC}_{50}\end{array}$ & $\begin{array}{l}\text { Plasmodium falcipa- } \\
\text { rum NF54 }\end{array}$ & $\mathrm{Nd}$ \\
\hline $\begin{array}{c}\text { Tabernaemon- } \\
\text { tana elegans }\end{array}$ & Apocynaceae & {$[37]$} & $\begin{array}{l}\text { South } \\
\text { Africa }\end{array}$ & Roots & Dichloromethane & Very Good & $\begin{array}{l}0.33 \mu \mathrm{g} / \mathrm{ml} \\
\mathrm{IC}_{50}\end{array}$ & $\begin{array}{l}\text { Plasmodium falcipa- } \\
\text { rum NF54 }\end{array}$ & $\mathrm{Nd}$ \\
\hline $\begin{array}{l}\text { Tabernaemon- } \\
\text { tana pachysi- } \\
\text { phon }\end{array}$ & Apocynaceae & [26] & Kenya & Flower & Methanol & Very Good & $\begin{array}{l}4.4-4.8 \mu \mathrm{g} / \mathrm{ml} \\
\quad \mathrm{IC}_{50}\end{array}$ & $\begin{array}{l}\text { Plasmodium falcipa- } \\
\text { rum D6, W2 }\end{array}$ & $\mathrm{Nd}$ \\
\hline Tagetes minuta & Asteraceae & [75] & Uganda & Leaves & Ethyl Acetate & $\mathrm{Nd}$ & $\mathrm{Nd}$ & $\begin{array}{l}\text { Plasmodium falcipa- } \\
\text { rum Fcb8 }\end{array}$ & $\mathrm{Nd}$ \\
\hline \multirow[t]{2}{*}{$\begin{array}{l}\text { Tamarindus } \\
\text { indica }\end{array}$} & Fabaceae & [23] & Sudan & $\begin{array}{l}\text { Stem } \\
\text { Barks }\end{array}$ & Methanol & Moderate & $10 \mu \mathrm{g} / \mathrm{ml} / \mathrm{C}_{50}$ & $\begin{array}{l}\text { Plasmodium falcipa- } \\
\text { rum 3D7, Dd2 }\end{array}$ & No \\
\hline & & [110] & Togo & Fruits & Water & Very Good & $\begin{array}{l}4.786 \mu \mathrm{g} / \mathrm{ml} \\
\mid \mathrm{C}_{50}\end{array}$ & $\begin{array}{l}\text { Plasmodium falci- } \\
\text { parum }\end{array}$ & $\mathrm{Nd}$ \\
\hline $\begin{array}{l}\text { Tapinanthus } \\
\text { dodoneifolius }\end{array}$ & Loranthaceae & {$[52]$} & $\begin{array}{l}\text { Burkina } \\
\text { Faso }\end{array}$ & Leaves & Methanol & Good & $5.2 \mu \mathrm{g} / \mathrm{ml} \mathrm{I} \mathrm{C}_{50}$ & $\begin{array}{l}\text { Plasmodium falci- } \\
\text { parum }\end{array}$ & $\mathrm{Nd}$ \\
\hline $\begin{array}{c}\text { Tarchonanthus } \\
\text { camphoratus }\end{array}$ & Asteraceae & [22] & $\begin{array}{l}\text { South } \\
\text { Africa }\end{array}$ & $\begin{array}{l}\text { Whole } \\
\text { Plant }\end{array}$ & $\begin{array}{l}\text { Dichlorometh- } \\
\text { ane/Methanol }\end{array}$ & Good & $6 \mu \mathrm{g} / \mathrm{ml} \mathrm{I} \mathrm{C}_{50}$ & $\begin{array}{l}\text { Plasmodium falcipa- } \\
\text { rum D10 }\end{array}$ & $\mathrm{Nd}$ \\
\hline \multirow[t]{2}{*}{ Teclea nobilis } & Rutaceae & [24] & Kenya & $\begin{array}{l}\text { Stem } \\
\text { Barks }\end{array}$ & Methanol & Moderate & 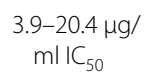 & $\begin{array}{l}\text { Plasmodium falcipa- } \\
\text { rum D6, W2 }\end{array}$ & $\mathrm{Nd}$ \\
\hline & & [75] & Uganda & Barks & Ethyl Acetate & $\mathrm{Nd}$ & $\mathrm{Nd}$ & $\begin{array}{l}\text { Plasmodium falcipa- } \\
\text { rum Fcb9 }\end{array}$ & $\mathrm{Nd}$ \\
\hline Tecoma capensis & Bignoniaceae & [22] & $\begin{array}{l}\text { South } \\
\text { Africa }\end{array}$ & Twigs & $\begin{array}{l}\text { Dichlorometh- } \\
\text { ane/Methanol }\end{array}$ & Moderate & $\begin{array}{l}10.2 \mu \mathrm{gg} / \mathrm{ml} \\
\mathrm{IC}_{50}\end{array}$ & $\begin{array}{l}\text { Plasmodium falcipa- } \\
\text { rum D10 }\end{array}$ & $\mathrm{Nd}$ \\
\hline Tectona grandis & Lamiaceae & [112] & Ghana & Leaves & Methanol & Very Good & $\begin{array}{l}0.92 \mu \mathrm{g} / \mathrm{ml} \\
\mid \mathrm{C}_{50}\end{array}$ & $\begin{array}{l}\text { Plasmodium falcipa- } \\
\text { rum 3D7, W2 }\end{array}$ & No \\
\hline \multirow[t]{2}{*}{$\begin{array}{l}\text { Terminalia avi- } \\
\text { cennioides }\end{array}$} & Combretaceae & [50] & Nigeria & Ns & $\begin{array}{l}\text { Methanol, Water, } \\
\text { Butanol, Ethyl } \\
\text { Acetate }\end{array}$ & Moderate & $\begin{array}{l}12.28- \\
14.09 \mu \mathrm{g} / \mathrm{ml} \\
\mid \mathrm{C}_{50}\end{array}$ & $\begin{array}{l}\text { Plasmodium falcipa- } \\
\text { rum 3D7, K1 }\end{array}$ & $\begin{array}{l}\text { Yes }(\mathrm{SI} \geq 114 ; \\
\text { mouse heart- } \\
\text { derived cells } \\
[\mathrm{NBMH}])\end{array}$ \\
\hline & & [52] & $\begin{array}{l}\text { Burkina } \\
\text { Faso }\end{array}$ & Leaves & Methanol & Very Good & $1.9 \mu \mathrm{g} / \mathrm{ml} \mathrm{IC}_{50}$ & $\begin{array}{l}\text { Plasmodium falci- } \\
\text { parum }\end{array}$ & $\mathrm{Nd}$ \\
\hline $\begin{array}{l}\text { Terminalia } \\
\text { glaucescens }\end{array}$ & Combretaceae & [39] & Ivory Coast & $\begin{array}{l}\text { Stem, } \\
\text { Leave }\end{array}$ & $\begin{array}{l}\text { Water, Ethanol, } \\
\text { Pentane }\end{array}$ & Very Good & $\begin{array}{l}2.34-4.83 \mu \mathrm{g} / \\
\mathrm{ml} \mathrm{IC}_{50}\end{array}$ & $\begin{array}{l}\text { Plasmodium falcipa- } \\
\text { rum Fcm29, Fcb1, } \\
\text { CQ-S (Nigerian) }\end{array}$ & No \\
\hline \multirow[t]{2}{*}{$\begin{array}{r}\text { Terminalia } \\
\text { ivorensis }\end{array}$} & Combretaceae & {$[32]$} & Ghana & $\begin{array}{l}\text { Stem } \\
\text { Barks }\end{array}$ & Ethanol & Good & $\begin{array}{l}6.949 \mu \mathrm{g} / \mathrm{ml} \\
\mathrm{IC}_{50}\end{array}$ & $\begin{array}{l}\text { Plasmodium falcipa- } \\
\text { rum 3D7 }\end{array}$ & $\mathrm{Nd}$ \\
\hline & & [112] & Ghana & Leaves & Methanol & Good & $\begin{array}{l}5.70 \mu \mathrm{g} / \mathrm{ml} \\
\mathrm{IC}_{50}\end{array}$ & $\begin{array}{l}\text { Plasmodium falcipa- } \\
\text { rum 3D7, W2 }\end{array}$ & No \\
\hline $\begin{array}{l}\text { Terminalia } \\
\text { macroptera }\end{array}$ & Combretaceae & [27] & $\begin{array}{l}\text { Burkina } \\
\text { Faso }\end{array}$ & $\begin{array}{l}\text { Root } \\
\text { Barks }\end{array}$ & Water & Very Good & $1 \mu \mathrm{g} / \mathrm{ml} \mathrm{IC} C_{50}$ & $\begin{array}{l}\text { Plasmodium falcipa- } \\
\text { rum W2 }\end{array}$ & $\mathrm{Nd}$ \\
\hline Terminalia mollis & Combretaceae & [92] & Rwanda & $\begin{array}{l}\text { Root } \\
\text { Barks }\end{array}$ & Methanol & Moderate & $\begin{array}{l}11.7-26.3 \mu \mathrm{g} / \\
\mathrm{ml} \mathrm{IC} C_{50}\end{array}$ & $\begin{array}{l}\text { Plasmodium falcipa- } \\
\text { rum 3D7, W2 }\end{array}$ & No \\
\hline $\begin{array}{l}\text { Terminalia } \\
\text { spinosa }\end{array}$ & Combretaceae & {$[26]$} & Kenya & $\begin{array}{l}\text { Stem } \\
\text { Barks }\end{array}$ & Methanol & Good & $7.9 \mu \mathrm{g} / \mathrm{ml} \mathrm{IC} 50$ & $\begin{array}{l}\text { Plasmodium falcipa- } \\
\text { rum D6, W2 }\end{array}$ & $\mathrm{Nd}$ \\
\hline $\begin{array}{l}\text { Tetracera poggei } \\
\text { Gilg }\end{array}$ & Dilleniaceae & {$[69]$} & DR Congo & Leaves & Petroleum Ether & Very Good & $1.7 \mu \mathrm{g} / \mathrm{ml} \mathrm{I} \mathrm{C}_{50}$ & $\begin{array}{l}\text { Plasmodium falci- } \\
\text { parum }\end{array}$ & $\mathrm{Nd}$ \\
\hline $\begin{array}{l}\text { Tetrapleura } \\
\text { tetraptera }\end{array}$ & Fabaceae & [33] & Gabon & Leaves & Dichloromethane & Moderate & $\begin{array}{l}10.1-13.0 \mu \mathrm{g} / \\
\mathrm{ml} \mathrm{IC}_{50}\end{array}$ & $\begin{array}{l}\text { Plasmodium falcipa- } \\
\text { rum FCB, 3D7 }\end{array}$ & No \\
\hline
\end{tabular}


Table 1 (continued)

\begin{tabular}{|c|c|c|c|c|c|c|c|c|c|}
\hline Plant species & Plant family & Source & $\begin{array}{l}\text { Country } \\
\text { of study }\end{array}$ & $\begin{array}{l}\text { Part of } \\
\text { plant } \\
\text { used }\end{array}$ & $\begin{array}{l}\text { Extraction } \\
\text { solvent }\end{array}$ & $\begin{array}{l}\text { Antiplas- } \\
\text { modial } \\
\text { Activity }\end{array}$ & $\begin{array}{l}\mathrm{IC}_{50} \text { or } \mathrm{ED}_{50} \\
\text { or } \mathrm{LD}_{50}\end{array}$ & $\begin{array}{l}\text { Strain of } \\
\text { Plasmodium } \\
\text { Tested }\end{array}$ & $\begin{array}{l}\text { Toxicity (value; } \\
\text { assay) }\end{array}$ \\
\hline Thalia geniculata & Marantaceae & {$[65]$} & Benin & Roots & Methanol & Moderate & $\begin{array}{l}2.83->20 \mu \mathrm{g} / \\
\mathrm{ml} \mathrm{IC}_{50}\end{array}$ & $\begin{array}{l}\text { Plasmodium falcipa- } \\
\text { rum 3D7 \& K1 }\end{array}$ & $\mathrm{Nd}$ \\
\hline Tinospora bakis & $\begin{array}{l}\text { Menisper- } \\
\text { maceae }\end{array}$ & [34] & Sudan & $\begin{array}{l}\text { Whole } \\
\text { Plant }\end{array}$ & $\begin{array}{l}\text { Petroleum Ether/ } \\
\text { Chloroform }\end{array}$ & Very Good & $<5 \mu \mathrm{g} / \mathrm{ml} \mathrm{IC_{50 }}$ & $\begin{array}{l}\text { Plasmodium falci- } \\
\text { parum }\end{array}$ & $\mathrm{Nd}$ \\
\hline \multirow[t]{2}{*}{$\begin{array}{l}\text { Tithonia diver- } \\
\text { sifolia }\end{array}$} & Asteraceae & [73] & $\begin{array}{l}\text { S. Tome' } \\
\text { And Prı } \\
\text { 'Ncipe }\end{array}$ & $\begin{array}{l}\text { Aerial } \\
\text { Parts }\end{array}$ & $\begin{array}{l}\text { Petroleum Ether, } \\
\text { Dichlorometh- } \\
\text { ane }\end{array}$ & Good & $\begin{array}{l}<10 \mu \mathrm{g} / \mathrm{ml} \\
\mid \mathrm{C}_{50}\end{array}$ & $\begin{array}{l}\text { Plasmodium falcipa- } \\
\text { rum 3D7 And Dd2 }\end{array}$ & $\mathrm{Nd}$ \\
\hline & & [92] & Rwanda & Flowers & Dichloromethane & Very Good & $\begin{array}{l}1.0-1.1 \mu \mathrm{g} / \mathrm{ml} \\
\mathrm{IC}_{50}\end{array}$ & $\begin{array}{l}\text { Plasmodium falcipa- } \\
\text { rum 3D7, W2 }\end{array}$ & No \\
\hline \multirow[t]{2}{*}{ Toddalia asiatica } & Rutaceae & [26] & Kenya & $\begin{array}{l}\text { Root } \\
\text { Barks }\end{array}$ & Methanol & Good & $\begin{array}{l}6.82-13.9 \mu \mathrm{g} / \\
\mathrm{ml} \mathrm{IC}_{50}\end{array}$ & $\begin{array}{l}\text { Plasmodium falcipa- } \\
\text { rum D6, W2 }\end{array}$ & $\mathrm{Nd}$ \\
\hline & & [125] & Kenya & $\begin{array}{l}\text { Root } \\
\text { Barks }\end{array}$ & $\begin{array}{l}\text { Dichlorometh- } \\
\text { ane + Metha- } \\
\text { nol }\end{array}$ & $\begin{array}{l}\text { Very } \\
\text { Good }^{\mathrm{a}}\end{array}$ & $\begin{array}{l}9-100 \mathrm{ng} / \mathrm{ml} \\
\mid \mathrm{CC}_{50}\end{array}$ & $\begin{array}{l}\text { Plasmodium falci- } \\
\text { parum }\end{array}$ & $\mathrm{Nd}$ \\
\hline \multirow[t]{5}{*}{ Trichilia emetica } & Meliaceae & [121] & Mali & Leaves & Dichloromethane & Moderate & $\begin{array}{l}11.9 \mu \mathrm{g} / \mathrm{ml} \\
\mathrm{IC}_{50}\end{array}$ & $\begin{array}{l}\text { Plasmodium falcipa- } \\
\text { rum 3D7 }\end{array}$ & $\mathrm{Nd}$ \\
\hline & & [58] & Sudan & Leaves & Methanol & Good & 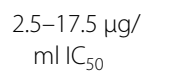 & $\begin{array}{l}\text { Plasmodium falcipa- } \\
\text { rum 3D7, Dd6 }\end{array}$ & $\mathrm{Nd}$ \\
\hline & & [24] & Kenya & $\begin{array}{l}\text { Stem } \\
\text { Barks }\end{array}$ & Methanol & Moderate & $13.3 \mu \mathrm{g} / \mathrm{ml} \mathrm{C}_{50}$ & $\begin{array}{l}\text { Plasmodium falcipa- } \\
\text { rum D6, W2 }\end{array}$ & $\mathrm{Nd}$ \\
\hline & & [25] & $\begin{array}{l}\text { South } \\
\text { Africa }\end{array}$ & $\begin{array}{l}\text { Stem } \\
\text { Barks }\end{array}$ & Acetone & Very Good & $\begin{array}{l}3.29 \mu \mathrm{g} / \mathrm{ml} \\
\mathrm{IC}_{50}\end{array}$ & $\begin{array}{l}\text { Plasmodium falcipa- } \\
\text { rum UP1 (CQ-R) }\end{array}$ & $\mathrm{Nd}$ \\
\hline & & [22] & $\begin{array}{l}\text { South } \\
\text { Africa }\end{array}$ & $\begin{array}{l}\text { Leaves, } \\
\text { Twigs }\end{array}$ & $\begin{array}{l}\text { Dichlorometh- } \\
\text { ane/Methanol }\end{array}$ & Very Good & $3.5 \mu \mathrm{g} / \mathrm{ml} \mathrm{I} \mathrm{C}_{50}$ & $\begin{array}{l}\text { Plasmodium falcipa- } \\
\text { rum D10 }\end{array}$ & $\mathrm{Nd}$ \\
\hline $\begin{array}{l}\text { Triclisia dictyo- } \\
\text { phylla }\end{array}$ & $\begin{array}{l}\text { Menisper- } \\
\text { maceae }\end{array}$ & {$[40]$} & D.R. Congo & Leaves & Water & Good & $\begin{array}{l}5.13 \mu \mathrm{g} / \mathrm{ml} \\
\mid \mathrm{C}_{50}\end{array}$ & $\begin{array}{l}\text { Plasmodium falcipa- } \\
\text { rum K1 }\end{array}$ & No \\
\hline \multirow[t]{2}{*}{$\begin{array}{l}\text { Tridax procum- } \\
\text { bens }\end{array}$} & Asteraceae & [22] & $\begin{array}{l}\text { South } \\
\text { Africa }\end{array}$ & $\begin{array}{l}\text { Whole } \\
\text { Plant }\end{array}$ & $\begin{array}{l}\text { Dichlorometh- } \\
\text { ane/Methanol }\end{array}$ & Moderate & $17 \mu \mathrm{g} / \mathrm{ml} / \mathrm{IC}_{50}$ & $\begin{array}{l}\text { Plasmodium falcipa- } \\
\text { rum D10 }\end{array}$ & $\mathrm{Nd}$ \\
\hline & & [26] & Kenya & $\begin{array}{l}\text { Whole } \\
\text { Plant }\end{array}$ & Methanol & Moderate & $\begin{array}{l}15.4 \mu \mathrm{g} / \mathrm{ml} \\
\mathrm{IC}_{50}\end{array}$ & $\begin{array}{l}\text { Plasmodium falcipa- } \\
\text { rum D6, W2 }\end{array}$ & $\mathrm{Nd}$ \\
\hline $\begin{array}{l}\text { Triumfetta } \\
\text { welwitschii var. } \\
\text { hirsuta }\end{array}$ & Malvaceae & [22] & $\begin{array}{l}\text { South } \\
\text { Africa }\end{array}$ & Leaves & $\begin{array}{l}\text { Dichlorometh- } \\
\text { ane/Methanol }\end{array}$ & Very Good & $3.6 \mu \mathrm{g} / \mathrm{ml} \mathrm{I} C_{50}$ & $\begin{array}{l}\text { Plasmodium falcipa- } \\
\text { rum D10 }\end{array}$ & $\mathrm{Nd}$ \\
\hline \multirow[t]{2}{*}{$\begin{array}{l}\text { Turraea flori- } \\
\text { bunda }\end{array}$} & Meliaceae & [22] & $\begin{array}{l}\text { South } \\
\text { Africa }\end{array}$ & Leaves & $\begin{array}{l}\text { Dichlorometh- } \\
\text { ane/Methanol }\end{array}$ & Good & $8.8 \mu \mathrm{g} / \mathrm{ml} \mathrm{IC}_{50}$ & $\begin{array}{l}\text { Plasmodium falcipa- } \\
\text { rum D10 }\end{array}$ & $\mathrm{Nd}$ \\
\hline & & [26] & Kenya & $\begin{array}{l}\text { Stem } \\
\text { Barks }\end{array}$ & Methanol & Good & $5.5 \mu \mathrm{g} / \mathrm{ml} \mathrm{I} \mathrm{C}_{50}$ & $\begin{array}{l}\text { Plasmodium falcipa- } \\
\text { rum D6, W2 }\end{array}$ & $\mathrm{Nd}$ \\
\hline \multirow[t]{2}{*}{ Turraea robusta } & Meliaceae & {$[72]$} & Kenya & $\begin{array}{l}\text { Root } \\
\text { Barks }\end{array}$ & Methanol & Very Good & $\begin{array}{l}2.4-3.5 \mu \mathrm{g} / \mathrm{ml} \\
\mathrm{IC}_{50}\end{array}$ & $\begin{array}{l}\text { Plasmodium falcipa- } \\
\text { rum K1, NF54 }\end{array}$ & $\mathrm{Nd}$ \\
\hline & & [24] & Kenya & $\begin{array}{l}\text { Stem } \\
\text { Barks }\end{array}$ & Methanol & Good & $\begin{array}{l}2.1-10.3 \mu \mathrm{g} / \\
\mathrm{ml} / \mathrm{C}_{50}\end{array}$ & $\begin{array}{l}\text { Plasmodium falcipa- } \\
\text { rum D6, W2 }\end{array}$ & $\mathrm{Nd}$ \\
\hline $\begin{array}{l}\text { Tylosema fas- } \\
\text { soglensis }\end{array}$ & Fabaceae & [30] & Kenya & Tubers & Dichloromethane & Very Good & $\begin{array}{l}0.77-0.896 \mu \mathrm{g} / \\
\mathrm{ml} / \mathrm{I}_{50}\end{array}$ & $\begin{array}{l}\text { Plasmodium falcipa- } \\
\text { rum W2, D6 }\end{array}$ & $\mathrm{Nd}$ \\
\hline $\begin{array}{l}\text { Uapaca palu- } \\
\text { dosa }\end{array}$ & Phyllanthaceae & [103] & $\begin{array}{l}\text { Congo } \\
\text { Brazza- } \\
\text { ville }\end{array}$ & Barks & Dichloromethane & Good & $8 \mu \mathrm{g} / \mathrm{ml} \mathrm{I} C_{50}$ & $\begin{array}{l}\text { Plasmodium falcipa- } \\
\text { rum Fcm29- } \\
\text { Cameroon }\end{array}$ & $\mathrm{Nd}$ \\
\hline $\begin{array}{l}\text { Uvaria acumi- } \\
\text { nata }\end{array}$ & Annonaceae & [26] & Kenya & $\begin{array}{l}\text { Root } \\
\text { Barks }\end{array}$ & Methanol & Good & $\begin{array}{l}6.9-8.9 \mu \mathrm{g} / \mathrm{ml} \\
\mid \mathrm{C}_{50}\end{array}$ & $\begin{array}{l}\text { Plasmodium falcipa- } \\
\text { rum D6, W2 }\end{array}$ & $\mathrm{Nd}$ \\
\hline Uvaria scheffleri & Annonaceae & {$[26]$} & Kenya & Leaves & Methanol & Good & $6.8 \mu \mathrm{g} / \mathrm{ml} \mathrm{I} \mathrm{C}_{50}$ & $\begin{array}{l}\text { Plasmodium falcipa- } \\
\text { rum D6, W2 }\end{array}$ & $\mathrm{Nd}$ \\
\hline Uvaria afzelii & Annonaceae & [48] & Ivory Coast & Roots & Pentane & Moderate & $\begin{array}{l}9-22 \mu \mathrm{g} / \mathrm{ml} \\
\quad \mathrm{C}_{50}\end{array}$ & $\begin{array}{l}\text { Plasmodium falcipa- } \\
\text { rum FCM29, CQ-S } \\
\text { (Nigerian) }\end{array}$ & No \\
\hline $\begin{array}{l}\text { Uvariastrum } \\
\text { zenkeri }\end{array}$ & Annonaceae & [49] & Cameroon & Twigs & Ethanol & Very Good & $\begin{array}{l}1.89 \mu \mathrm{g} / \mathrm{ml} \\
\mathrm{I}_{50}\end{array}$ & $\begin{array}{l}\text { Plasmodium falcipa- } \\
\text { rum W2 }\end{array}$ & $\mathrm{Nd}$ \\
\hline $\begin{array}{c}\text { Uvariodendron } \\
\text { molundense }\end{array}$ & Annonaceae & [49] & Cameroon & Twigs & Methanol & Very Good & $\begin{array}{l}4.79 \mu \mathrm{gg} / \mathrm{ml} \\
\mid \mathrm{C}_{50}\end{array}$ & $\begin{array}{l}\text { Plasmodium falcipa- } \\
\text { rum W2 }\end{array}$ & $\mathrm{Nd}$ \\
\hline
\end{tabular}


Table 1 (continued)

\begin{tabular}{|c|c|c|c|c|c|c|c|c|c|}
\hline Plant species & Plant family & Source & $\begin{array}{l}\text { Country } \\
\text { of study }\end{array}$ & $\begin{array}{l}\text { Part of } \\
\text { plant } \\
\text { used }\end{array}$ & $\begin{array}{l}\text { Extraction } \\
\text { solvent }\end{array}$ & $\begin{array}{l}\text { Antiplas- } \\
\text { modial } \\
\text { Activity }\end{array}$ & $\begin{array}{l}\mathrm{IC}_{50} \text { or } \mathrm{ED}_{50} \\
\text { or } \mathrm{LD}_{50}\end{array}$ & $\begin{array}{l}\text { Strain of } \\
\text { Plasmodium } \\
\text { Tested }\end{array}$ & $\begin{array}{l}\text { Toxicity (value; } \\
\text { assay) }\end{array}$ \\
\hline $\begin{array}{l}\text { Uvariopsis } \\
\text { congolana }\end{array}$ & Annonaceae & [55] & Cameroon & Stems & $\begin{array}{l}\text { Ethanol, Water, } \\
\text { Dichlorometh- } \\
\text { ane, Methanol, } \\
\text { Hexane }\end{array}$ & Very Good & $\begin{array}{l}4.47 \mu \mathrm{g} / \mathrm{ml} \\
\mid \mathrm{C}_{50}\end{array}$ & $\begin{array}{l}\text { Plasmodium falcipa- } \\
\text { rum W2 }\end{array}$ & $\mathrm{Nd}$ \\
\hline $\begin{array}{l}\text { Vangueria } \\
\text { infausta Burch. } \\
\text { subsp. Infausta }\end{array}$ & Rubiaceae & [37] & $\begin{array}{l}\text { South } \\
\text { Africa }\end{array}$ & Roots & Dichloromethane & Very Good & $\begin{array}{l}1.84 \mu \mathrm{g} / \mathrm{ml} \\
\mid \mathrm{C}_{50}\end{array}$ & $\begin{array}{l}\text { Plasmodium falcipa- } \\
\text { rum NF54 }\end{array}$ & $\mathrm{Nd}$ \\
\hline Vepris lanceolata & Rutaceae & [20] & Kenya & $\begin{array}{l}\text { Root } \\
\text { Barks }\end{array}$ & Ethyl Acetate & Good & $7.0 \mu \mathrm{g} / \mathrm{ml} \mathrm{IC_{50 }}$ & $\begin{array}{l}\text { Plasmodium falcipa- } \\
\text { rum K1 }\end{array}$ & $\mathrm{Nd}$ \\
\hline \multirow[t]{6}{*}{$\begin{array}{l}\text { Vernonia amyg- } \\
\text { dalina }\end{array}$} & Asteraceae & [74] & $\begin{array}{l}\text { S. Tome' } \\
\text { And Prı } \\
\text { 'Ncipe }\end{array}$ & Leaves & Ethyl Acetate & Moderate & $10 \mu \mathrm{g} / \mathrm{ml} / \mathrm{C}_{50}$ & $\begin{array}{l}\text { Plasmodium falcipa- } \\
\text { rum 3D7 And Dd2 }\end{array}$ & $\mathrm{Nd}$ \\
\hline & & {$[80]$} & Cameroon & Leaves & Dichloromethane & Moderate & 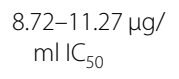 & $\begin{array}{l}\text { Plasmodium falcipa- } \\
\text { rum 3D7, DD2 }\end{array}$ & No \\
\hline & & [126] & Nigeria & Leaves & Ethanol & Good & $\begin{array}{l}9.83 \mu \mathrm{g} / \mathrm{ml} \\
\mid \mathrm{C}_{50}\end{array}$ & $\begin{array}{l}\text { Plasmodium falcipa- } \\
\text { rum 3D7, NF-54 }\end{array}$ & $\begin{array}{l}\text { Yes }(S I=6.14 ; \\
\text { C-1008 kidney } \\
\text { fibroblast }\end{array}$ \\
\hline & & {$[26]$} & Kenya & Leaves & Methanol & Good & $\begin{array}{l}4.9-7.2 \mu \mathrm{g} / \mathrm{ml} \\
\mid \mathrm{C}_{50}\end{array}$ & $\begin{array}{l}\text { Plasmodium falcipa- } \\
\text { rum D6, W2 }\end{array}$ & $\mathrm{Nd}$ \\
\hline & & {$[127]$} & Nigeria & Leaves & Ethanol & Moderate & $\begin{array}{l}11.2 \mu \mathrm{g} / \mathrm{ml} \\
\mid \mathrm{C}_{50}\end{array}$ & $\begin{array}{l}\text { Plasmodium falci- } \\
\text { parum }\end{array}$ & $\begin{array}{l}\text { Yes } \\
\left(\mathrm{LD}_{50}=1950 \mathrm{mg} /\right. \\
\mathrm{kg} \text {; rat })\end{array}$ \\
\hline & & {$[69]$} & D.R. Congo & Leaves & Petroleum Ether & Very Good & $2.5 \mu \mathrm{g} / \mathrm{ml} \mathrm{I} \mathrm{C}_{50}$ & $\begin{array}{l}\text { Plasmodium falci- } \\
\text { parum }\end{array}$ & $\mathrm{Nd}$ \\
\hline $\begin{array}{l}\text { Vernonia brachy- } \\
\text { calyx }\end{array}$ & Asteraceae & [104] & Kenya & Leaves & $\begin{array}{l}\text { Dichlorometh- } \\
\text { ane/Ethyl } \\
\text { Acetate }\end{array}$ & Good & $\begin{array}{l}6.6-8.4 \mu \mathrm{g} / \\
\mathrm{ml} \mathrm{IC_{50 }}\end{array}$ & $\begin{array}{l}\text { Plasmodium falcipa- } \\
\text { rum K39, V1/S }\end{array}$ & $\mathrm{Nd}$ \\
\hline Vernonia cinerea & Asteraceae & {$[45]$} & Cambodia & $\begin{array}{l}\text { Whole } \\
\text { Plant }\end{array}$ & Dichloromethane & Moderate & $\begin{array}{l}18.3 \mu \mathrm{gg} / \mathrm{ml} \\
\mathrm{IC}_{50}\end{array}$ & $\begin{array}{l}\text { Plasmodium falcipa- } \\
\text { rum W2 }\end{array}$ & $\mathrm{Nd}$ \\
\hline \multirow[t]{4}{*}{$\begin{array}{l}\text { Vernonia col- } \\
\text { orata }\end{array}$} & Asteraceae & {$[57]$} & Ivory Coast & $\begin{array}{l}\text { Stems, } \\
\text { Leaves }\end{array}$ & Water & Good & 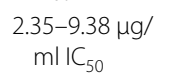 & $\begin{array}{l}\text { Plasmodium falcipa- } \\
\text { rum Fcb1 \& F32 }\end{array}$ & $\mathrm{Nd}$ \\
\hline & & [54] & Zimbabwe & Leaves & $\begin{array}{l}\text { Petrolether/Ethyl- } \\
\text { acetate }\end{array}$ & Moderate & $\begin{array}{l}12.1-17.8 \mu \mathrm{g} / \\
\mathrm{ml} \mathrm{IC}_{50}\end{array}$ & $\begin{array}{l}\text { Plasmodium falcipa- } \\
\text { rum Pow, Dd2 }\end{array}$ & $\mathrm{Nd}$ \\
\hline & & [91] & Comoros & Roots & Dichloromethane & Very Good & $3 \mu \mathrm{g} / \mathrm{ml} \mathrm{IC} C_{50}$ & $\begin{array}{l}\text { Plasmodium falcipa- } \\
\text { rum W2 }\end{array}$ & No \\
\hline & & {$[22]$} & $\begin{array}{l}\text { South } \\
\text { Africa }\end{array}$ & Leaves & $\begin{array}{l}\text { Dichlorometh- } \\
\text { ane/Methanol }\end{array}$ & Very Good & $4.7 \mu \mathrm{g} / \mathrm{ml} \mathrm{IC_{50 }}$ & $\begin{array}{l}\text { Plasmodium falcipa- } \\
\text { rum D10 }\end{array}$ & $\mathrm{Nd}$ \\
\hline $\begin{array}{l}\text { Vernonia fastigi- } \\
\text { ata }\end{array}$ & Asteraceae & {$[22]$} & $\begin{array}{l}\text { South } \\
\text { Africa }\end{array}$ & Leaves & $\begin{array}{l}\text { Dichlorometh- } \\
\text { ane/Methanol }\end{array}$ & Moderate & $10 \mu \mathrm{g} / \mathrm{ml} / \mathrm{C}_{50}$ & $\begin{array}{l}\text { Plasmodium falcipa- } \\
\text { rum D10 }\end{array}$ & $\mathrm{Nd}$ \\
\hline $\begin{array}{l}\text { Vernonia } \\
\text { guineensis }\end{array}$ & Asteraceae & [128] & Cameroon & Leaves & Dichloromethane & Very Good & $\begin{array}{l}1.635- \\
1.823 \mu \mathrm{g} / \mathrm{ml} \\
\mathrm{IC}_{50}\end{array}$ & $\begin{array}{l}\text { Plasmodium falci- } \\
\text { parum }\end{array}$ & No \\
\hline \multirow[t]{2}{*}{ Vernonia lasiopus } & s Compositae & {$[12]$} & Kenya & Leaves & $\begin{array}{l}\text { Chloroform, } \\
\text { Ethylacetate, } \\
\text { Methanol }\end{array}$ & Very Good & $\begin{array}{l}1.0-3.2 \mu \mathrm{g} / \mathrm{ml} \\
\mid \mathrm{C}_{50}\end{array}$ & $\begin{array}{l}\text { Plasmodium falcipa- } \\
\text { rum K39 (CQ-S), } \\
\text { ENT30, NF54, V1/S }\end{array}$ & $\mathrm{Nd}$ \\
\hline & & [73] & Kenya & $\begin{array}{l}\text { Root } \\
\text { Barks }\end{array}$ & Dichloromethane & Very Good & $\begin{array}{l}4.7-4.9 \mu \mathrm{g} / \mathrm{ml} \\
\mid \mathrm{C}_{50}\end{array}$ & $\begin{array}{l}\text { Plasmodium falcipa- } \\
\text { rum K1, NF54 }\end{array}$ & $\mathrm{Nd}$ \\
\hline $\begin{array}{l}\text { Vernonia myri- } \\
\text { antha }\end{array}$ & Asteraceae & {$[22]$} & $\begin{array}{l}\text { South } \\
\text { Africa }\end{array}$ & Leaves & $\begin{array}{l}\text { Dichlorometh- } \\
\text { ane/Methanol }\end{array}$ & Very Good & $3 \mu \mathrm{g} / \mathrm{ml} \mathrm{IC_{50 }}$ & $\begin{array}{l}\text { Plasmodium falcipa- } \\
\text { rum D10 }\end{array}$ & $\mathrm{Nd}$ \\
\hline $\begin{array}{l}\text { Vernonia oligo- } \\
\text { cephala }\end{array}$ & Asteraceae & {$[22]$} & $\begin{array}{l}\text { South } \\
\text { Africa }\end{array}$ & Leaves & $\begin{array}{l}\text { Dichlorometh- } \\
\text { ane/Methanol }\end{array}$ & Very Good & $3.5 \mu \mathrm{g} / \mathrm{ml} \mathrm{IC_{50 }}$ & $\begin{array}{l}\text { Plasmodium falcipa- } \\
\text { rum D10 }\end{array}$ & $\mathrm{Nd}$ \\
\hline Vismia guineensis & s Hypericaceae & {$[48]$} & Ivory Coast & Leaves & Pentane & Moderate & $\begin{array}{l}15-20 \mu \mathrm{g} / \mathrm{ml} \\
\mid \mathrm{C}_{50}\end{array}$ & $\begin{array}{l}\text { Plasmodium falcipa- } \\
\text { rum FCM29, CQ-S } \\
\text { (Nigerian) }\end{array}$ & $\mathrm{Nd}$ \\
\hline \multirow[t]{2}{*}{$\begin{array}{l}\text { Warburgia } \\
\text { ugandensis }\end{array}$} & Canellaceae & [72] & Kenya & $\begin{array}{l}\text { Stem } \\
\text { Barks }\end{array}$ & Dichloromethane & Very Good & $\begin{array}{l}1.4-2.2 \mu \mathrm{g} / \mathrm{ml} \\
\mid \mathrm{C}_{50}\end{array}$ & $\begin{array}{l}\text { Plasmodium falcipa- } \\
\text { rum K1, NF54 }\end{array}$ & $\mathrm{Nd}$ \\
\hline & & [24] & Kenya & $\begin{array}{l}\text { Root } \\
\text { Barks }\end{array}$ & Methanol & Good & $\begin{array}{l}4.1-6.1 \mu \mathrm{g} / \mathrm{ml} \\
\mid \mathrm{C}_{50}\end{array}$ & $\begin{array}{l}\text { Plasmodium falcipa- } \\
\text { rum D6, W2 }\end{array}$ & $\mathrm{Nd}$ \\
\hline
\end{tabular}


Table 1 (continued)

\begin{tabular}{|c|c|c|c|c|c|c|c|c|c|}
\hline Plant species & Plant family & Source & $\begin{array}{l}\text { Country } \\
\text { of study }\end{array}$ & $\begin{array}{l}\text { Part of } \\
\text { plant } \\
\text { used }\end{array}$ & $\begin{array}{l}\text { Extraction } \\
\text { solvent }\end{array}$ & $\begin{array}{l}\text { Antiplas- } \\
\text { modial } \\
\text { Activity }\end{array}$ & $\begin{array}{l}\mathrm{IC}_{50} \text { or } \mathrm{ED}_{50} \\
\text { or } \mathrm{LD}_{50}\end{array}$ & $\begin{array}{l}\text { Strain of } \\
\text { Plasmodium } \\
\text { Tested }\end{array}$ & $\begin{array}{l}\text { Toxicity (value; } \\
\text { assay) }\end{array}$ \\
\hline $\begin{array}{l}\text { Warburgia } \\
\text { stuhlmannii }\end{array}$ & Canellaceae & [26] & Kenya & $\begin{array}{l}\text { Stem } \\
\text { Barks }\end{array}$ & Methanol & Very Good & $\begin{array}{l}1.8-2.3 \mu \mathrm{g} / \mathrm{ml} \\
\mid \mathrm{C}_{50}\end{array}$ & $\begin{array}{l}\text { Plasmodium falcipa- } \\
\text { rum D6, W2 }\end{array}$ & $\mathrm{Nd}$ \\
\hline $\begin{array}{l}\text { Ximenia ameri- } \\
\text { cana }\end{array}$ & Olacaceae & [57] & Ivory Coast & $\begin{array}{l}\text { Stem, } \\
\text { Leave }\end{array}$ & Water & Very Good & $\begin{array}{l}0.6-2.6 \mu \mathrm{g} / \mathrm{ml} \\
\mid \mathrm{C}_{50}\end{array}$ & $\begin{array}{l}\text { Plasmodium falcipa- } \\
\text { rum Fcb1 \& F32 }\end{array}$ & $\mathrm{Nd}$ \\
\hline \multirow[t]{2}{*}{$\begin{array}{l}\text { Xylopia aethi- } \\
\text { opica }\end{array}$} & \multirow[t]{2}{*}{ Annonaceae } & [98] & Cameroon & $\begin{array}{l}\text { Stem } \\
\text { Barks }\end{array}$ & Water & Moderate $^{a}$ & $\begin{array}{l}17.8 \mu \mathrm{gg} / \mathrm{ml} \\
\mathrm{IC}_{50}\end{array}$ & $\begin{array}{l}\text { Plasmodium falcipa- } \\
\text { rum W5 }\end{array}$ & $\mathrm{Nd}$ \\
\hline & & [49] & Cameroon & Leaves & Methanol & Very Good & $\begin{array}{l}3.75 \mu \mathrm{g} / \mathrm{ml} \\
\mathrm{IC}_{50}\end{array}$ & $\begin{array}{l}\text { Plasmodium falcipa- } \\
\text { rum W2 }\end{array}$ & $\mathrm{Nd}$ \\
\hline Xylopia africana & Annonaceae & [49] & Cameroon & $\begin{array}{l}\text { Stem } \\
\text { Barks }\end{array}$ & Methanol & Very Good & $\begin{array}{l}1.07 \mu \mathrm{g} / \mathrm{ml} \\
\mathrm{IC}_{50}\end{array}$ & $\begin{array}{l}\text { Plasmodium falcipa- } \\
\text { rum W2 }\end{array}$ & $\mathrm{Nd}$ \\
\hline \multirow{2}{*}{$\begin{array}{l}\text { Xylopia parviflora } \\
\text { (A.Rich.)Benth. } \\
\text { Oliv }\end{array}$} & \multirow{2}{*}{ Annonaceae } & [37] & $\begin{array}{l}\text { South } \\
\text { Africa }\end{array}$ & Roots & Dichloromethane & Very Good & $\begin{array}{l}2.19 \mu \mathrm{g} / \mathrm{ml} \\
\mid \mathrm{C}_{50}\end{array}$ & $\begin{array}{l}\text { Plasmodium falcipa- } \\
\text { rum NF54 }\end{array}$ & $\mathrm{Nd}$ \\
\hline & & [49] & Cameroon & Leaves & Methanol & Very Good & $\begin{array}{l}3.44 \mu \mathrm{g} / \mathrm{ml} \\
\mid \mathrm{C}_{50}\end{array}$ & $\begin{array}{l}\text { Plasmodium falcipa- } \\
\text { rum W2 }\end{array}$ & $\mathrm{Nd}$ \\
\hline $\begin{array}{l}\text { Xylopia phloi- } \\
\text { odora }\end{array}$ & Annonaceae & [98] & Cameroon & $\begin{array}{l}\text { Stem } \\
\text { Barks }\end{array}$ & Water & Moderate $^{a}$ & $\begin{array}{l}17.9 \mu \mathrm{g} / \mathrm{ml} \\
\mathrm{IC}_{50}\end{array}$ & $\begin{array}{l}\text { Plasmodium falcipa- } \\
\text { rum W2 }\end{array}$ & $\mathrm{Nd}$ \\
\hline $\begin{array}{l}\text { Xysmalobium } \\
\text { undulatum }\end{array}$ & Apocynaceae & [22] & $\begin{array}{l}\text { South } \\
\text { Africa }\end{array}$ & $\begin{array}{l}\text { Whole } \\
\text { Plant }\end{array}$ & $\begin{array}{l}\text { Dichlorometh- } \\
\text { ane/Methanol }\end{array}$ & Good & $6 \mu \mathrm{g} / \mathrm{ml} \mathrm{I} C_{50}$ & $\begin{array}{l}\text { Plasmodium falcipa- } \\
\text { rum D10 }\end{array}$ & $\mathrm{Nd}$ \\
\hline \multirow[t]{5}{*}{$\begin{array}{l}\text { Zanthoxylum } \\
\text { chalybeum }\end{array}$} & \multirow[t]{5}{*}{ Rutaceae } & [137] & Kenya & $\begin{array}{l}\text { Root } \\
\text { Barks }\end{array}$ & Water & Good & $\begin{array}{l}2.32-5.52 \mu \mathrm{g} / \\
\quad \mathrm{ml} \mathrm{IC}_{50}\end{array}$ & $\begin{array}{l}\text { Plasmodium falcipa- } \\
\text { rum NF54, ENT30 }\end{array}$ & $\mathrm{Nd}$ \\
\hline & & [77] & Uganda & $\begin{array}{l}\text { Stem } \\
\text { Barks }\end{array}$ & Ethyl Acetate & Very Good & $\begin{array}{l}0.57-3.21 \mu \mathrm{g} / \\
\quad \mathrm{ml} \mathrm{IC}_{50}\end{array}$ & $\begin{array}{l}\text { Plasmodium falcipa- } \\
\text { rum NF54 \& FCR3 }\end{array}$ & $\mathrm{Nd}$ \\
\hline & & [92] & Rwanda & $\begin{array}{l}\text { Root } \\
\text { Barks }\end{array}$ & Methanol & Very Good & $\begin{array}{l}1.9-4.2 \mu \mathrm{g} / \mathrm{ml} \\
\mid \mathrm{C}_{50}\end{array}$ & $\begin{array}{l}\text { Plasmodium falcipa- } \\
\text { rum 3D7, W2 }\end{array}$ & No \\
\hline & & [20] & Tanzania & $\begin{array}{l}\text { Root } \\
\text { Barks }\end{array}$ & Ethyl Acetate & Very Good & $4.2 \mu \mathrm{g} / \mathrm{ml} \mathrm{IC} \mathrm{C}_{50}$ & $\begin{array}{l}\text { Plasmodium falcipa- } \\
\text { rum K1 }\end{array}$ & $\mathrm{Nd}$ \\
\hline & & {$[26]$} & Kenya & $\begin{array}{l}\text { Root } \\
\text { Barks }\end{array}$ & Methanol & Very Good & $\begin{array}{l}2.9-3.7 \mu \mathrm{g} / \mathrm{ml} \\
\mid \mathrm{C}_{50}\end{array}$ & $\begin{array}{l}\text { Plasmodium falcipa- } \\
\text { rum D6, W2 }\end{array}$ & $\mathrm{Nd}$ \\
\hline $\begin{array}{l}\text { Zanthoxylum } \\
\text { gilletii }\end{array}$ & Rutaceae & [43] & Ivory Coast & $\begin{array}{l}\text { Stem } \\
\text { Barks }\end{array}$ & Ethanol & Very Good & $2.8 \mu \mathrm{g} / \mathrm{ml} \mathrm{IC_{50 }}$ & $\begin{array}{l}\text { Plasmodium falcipa- } \\
\text { rum FCB1 }\end{array}$ & $\mathrm{Nd}$ \\
\hline $\begin{array}{l}\text { Zanthoxylum } \\
\text { heitzii }\end{array}$ & Rutaceae & [129] & $\begin{array}{l}\text { Republic } \\
\text { Of } \\
\text { Congo }\end{array}$ & Barkss & Hexane & $\begin{array}{l}\text { Very } \\
\text { Good }^{\mathrm{a}}\end{array}$ & $\begin{array}{l}0.0089 \mu \mathrm{g} / \mathrm{ml} \\
\mathrm{IC}_{50}\end{array}$ & $\begin{array}{l}\text { Plasmodium falcipa- } \\
\text { rum, Plasmodium } \\
\text { berghei }\end{array}$ & $\mathrm{Nd}$ \\
\hline $\begin{array}{l}\text { Zanthoxylum } \\
\text { tsihanimposa }\end{array}$ & Rutaceae & [130] & $\begin{array}{l}\text { Madagas- } \\
\text { car }\end{array}$ & $\begin{array}{l}\text { Stem } \\
\text { Barks }\end{array}$ & $\begin{array}{l}\text { Dichlorometh- } \\
\text { ane + Metha- } \\
\text { nol }\end{array}$ & $\begin{array}{l}\text { Very } \\
\text { Good }^{\mathrm{a}}\end{array}$ & $98.4 \mu \mathrm{M} I C_{50}$ & $\begin{array}{l}\text { Plasmodium falcipa- } \\
\text { rum FCM29 }\end{array}$ & $\mathrm{Nd}$ \\
\hline $\begin{array}{l}\text { Zanthoxylum } \\
\text { usambarense }\end{array}$ & Rutaceae & [24] & Kenya & $\begin{array}{l}\text { Root } \\
\text { Barks }\end{array}$ & Methanol & Good & $\begin{array}{l}3.2-5.5 \mu \mathrm{g} / \mathrm{ml} \\
\mathrm{IC}_{50}\end{array}$ & $\begin{array}{l}\text { Plasmodium falcipa- } \\
\text { rum D6, W2 }\end{array}$ & $\mathrm{Nd}$ \\
\hline Zea mays & Poaceae & [131] & Nigeria & Leaves & $\begin{array}{l}\text { Ethanol, ethyl } \\
\text { acetate }\end{array}$ & Good & $\begin{array}{l}3.69- \\
9.31 \mu \mathrm{g} / \mathrm{ml} \\
\mid \mathrm{C}_{50}\end{array}$ & $\begin{array}{l}\text { Plasmodium falcipa- } \\
\text { rum 3D7, INDO, } \\
\text { Plasmodium } \\
\text { berghei }\end{array}$ & $\mathrm{Nd}$ \\
\hline \multirow[t]{2}{*}{ Zehreria scabra } & \multirow[t]{2}{*}{ Cucurbitaceae } & {$[22]$} & $\begin{array}{l}\text { South } \\
\text { Africa }\end{array}$ & $\begin{array}{l}\text { Whole } \\
\text { Plant }\end{array}$ & $\begin{array}{l}\text { Dichlorometh- } \\
\text { ane/Methanol }\end{array}$ & Good & $5.6 \mu \mathrm{g} / \mathrm{ml} \mathrm{IC_{50 }}$ & $\begin{array}{l}\text { Plasmodium falcipa- } \\
\text { rum D10 }\end{array}$ & $\mathrm{Nd}$ \\
\hline & & [26] & Kenya & $\begin{array}{l}\text { Whole } \\
\text { Plant }\end{array}$ & Methanol & Good & $9.8 \mu \mathrm{g} / \mathrm{ml} \mathrm{IC_{50 }}$ & $\begin{array}{l}\text { Plasmodium falcipa- } \\
\text { rum D6, W2 }\end{array}$ & $\mathrm{Nd}$ \\
\hline Ziziphus abyssica & Rhamnaceae & [24] & Kenya & Leaves & Methanol & Moderate & $\begin{array}{l}17.5 \mu \mathrm{g} / \mathrm{ml} \\
\mid \mathrm{C}_{50}\end{array}$ & $\begin{array}{l}\text { Plasmodium falcipa- } \\
\text { rum D6, W2 }\end{array}$ & $\mathrm{Nd}$ \\
\hline \multirow[t]{2}{*}{$\begin{array}{l}\text { Ziziphus mucro- } \\
\text { nata }\end{array}$} & \multirow[t]{2}{*}{ Rhamnaceae } & [22] & $\begin{array}{l}\text { South } \\
\text { Africa }\end{array}$ & Leaves & Dichloromethane & Moderate & $12 \mu \mathrm{g} / \mathrm{ml} / \mathrm{C}_{50}$ & $\begin{array}{l}\text { Plasmodium falcipa- } \\
\text { rum D10 }\end{array}$ & $\mathrm{Nd}$ \\
\hline & & [25] & $\begin{array}{l}\text { South } \\
\text { Africa }\end{array}$ & $\begin{array}{l}\text { Stem } \\
\text { Barks }\end{array}$ & Acetone & Very Good & $\begin{array}{l}4.13 \mu \mathrm{g} / \mathrm{ml} \\
\mathrm{IC}_{50}\end{array}$ & $\begin{array}{l}\text { Plasmodium falcipa- } \\
\text { rum UP1 (CQ-R) }\end{array}$ & $\mathrm{Nd}$ \\
\hline $\begin{array}{l}\text { Ziziphus cambo- } \\
\text { diana }\end{array}$ & Rhamnaceae & {$[45]$} & Cambodia & Stems & Dichloromethane & Moderate & $\begin{array}{l}19.0 \mu \mathrm{g} / \mathrm{ml} \\
\mid \mathrm{C}_{50}\end{array}$ & $\begin{array}{l}\text { Plasmodium falcipa- } \\
\text { rum W2 }\end{array}$ & $\mathrm{Nd}$ \\
\hline
\end{tabular}

Nd Not done, Ns Not specified, S/ Selectivity index

${ }^{a}$ Activity determined using pure compounds isolated from plant 
Table 2 In vivo antimalarial activity of African medicinal plants

\begin{tabular}{|c|c|c|c|c|c|c|c|c|c|}
\hline Plant species & Plant family & Source & $\begin{array}{l}\text { Country of } \\
\text { study }\end{array}$ & $\begin{array}{l}\text { Part of } \\
\text { plant used }\end{array}$ & $\begin{array}{l}\text { Extraction } \\
\text { solvent }\end{array}$ & $\begin{array}{l}\text { Antima- } \\
\text { larial } \\
\text { activity }\end{array}$ & $\begin{array}{l}\text { Parasite } \\
\text { suppression } \\
\text { rate }\end{array}$ & $\begin{array}{l}\text { Strain of } \\
\text { Plasmodium } \\
\text { tested }\end{array}$ & $\begin{array}{l}\text { Toxicity (value; } \\
\text { assay) }\end{array}$ \\
\hline \multirow[t]{2}{*}{ Acacia nilotica } & Fabaceae & [132] & Nigeria & Roots & Water & Moderate & $\begin{array}{l}79.5 \% \text { at } \\
400 \mathrm{mg} / \mathrm{kg} / \\
\text { day }\end{array}$ & $\begin{array}{l}\text { Plasmodium } \\
\text { berghei } \\
\text { NK65 }\end{array}$ & No \\
\hline & & [133] & Nigeria & Roots & Methanol & Very good & $\begin{array}{l}62.59 \% \text { at } \\
150 \mathrm{mg} / \mathrm{kg} / \\
\text { day }\end{array}$ & $\begin{array}{l}\text { Plasmodium } \\
\text { berghei } \\
\text { NK65 }\end{array}$ & No \\
\hline \multirow[t]{3}{*}{$\begin{array}{c}\text { Adansonia } \\
\text { digitata }\end{array}$} & Malvaceae & [134] & Nigeria & Stem barks & Methanol & $\begin{array}{l}\text { Moder } \\
\text { ate }^{\mathrm{a}}\end{array}$ & $\begin{array}{l}90.18 \% \text { at } \\
400 \mathrm{mg} / \mathrm{kg} / \\
\text { day }\end{array}$ & $\begin{array}{l}\text { Plasmodium } \\
\text { berghei }\end{array}$ & $\mathrm{Nd}$ \\
\hline & & [135] & Kenya & Stem barks & Ethanol & Very good & $\begin{array}{l}>60 \% \text { at } \\
100 \mathrm{mg} / \mathrm{kg} / \\
\text { day }\end{array}$ & $\begin{array}{l}\text { Plasmodium } \\
\text { berghei }\end{array}$ & No \\
\hline & & [135] & Kenya & Stem barks & Water & Very good & $\begin{array}{l}60.47 \% \text { at } \\
100 \mathrm{mg} / \mathrm{kg} / \\
\text { day }\end{array}$ & $\begin{array}{l}\text { Plasmodium } \\
\text { berghei }\end{array}$ & No \\
\hline $\begin{array}{l}\text { Ageratum } \\
\text { conyzoides }\end{array}$ & Asteraceae & [136] & Nigeria & Leaves & Water & Moderate & $\begin{array}{l}89.87 \% \text { at } \\
400 \mathrm{mg} / \mathrm{kg} / \\
\text { day }\end{array}$ & $\begin{array}{l}\text { Plasmodium } \\
\text { berghei } \\
\text { NK65 }\end{array}$ & $\mathrm{Nd}$ \\
\hline $\begin{array}{l}\text { Albizia gum- } \\
\text { mifera }\end{array}$ & Fabaceae & [137] & Kenya & Root barks & Methanol & Very good ${ }^{\mathrm{a}}$ & $\begin{array}{l}72.9 \% \text { at } \\
20 \mathrm{mg} / \\
\text { kg.day }\end{array}$ & $\begin{array}{l}\text { Plasmodium } \\
\text { falciparum } \\
\text { NF54 and } \\
\text { ENT36 }\end{array}$ & $\mathrm{Nd}$ \\
\hline $\begin{array}{l}\text { Allophylus } \\
\text { africanus }\end{array}$ & Sapindaceae & [138] & Nigeria & $\begin{array}{l}\text { Stems, } \\
\text { roots }\end{array}$ & Ns & Very good & $\begin{array}{l}92.82-97.81 \\
\text { at } 50 \mathrm{mg} / \\
\mathrm{kg} / \mathrm{day}\end{array}$ & $\begin{array}{l}\text { Plasmodium } \\
\text { berghei } \\
\text { NK-65 }\end{array}$ & $\mathrm{Nd}$ \\
\hline $\begin{array}{l}\text { Aloe pulcher- } \\
\text { rima }\end{array}$ & $\begin{array}{l}\text { Xanthor- } \\
\text { rhoeaceae }\end{array}$ & [139] & Ethiopia & Leaves & Methanol & Good $^{\mathrm{a}}$ & $\begin{array}{l}56.2 \text { at } \\
200 \mathrm{mg} / \mathrm{kg} / \\
\text { day }\end{array}$ & $\begin{array}{l}\text { Plasmodium } \\
\text { berghei }\end{array}$ & No \\
\hline \multirow[t]{2}{*}{$\begin{array}{l}\text { Anthocleista } \\
\text { djalonensis }\end{array}$} & $\begin{array}{c}\text { Gentian- } \\
\text { aceae }\end{array}$ & [140] & Nigeria & Roots & $\begin{array}{l}\text { Chloroform, } \\
\text { ethyl } \\
\text { acetate, } \\
\text { methanol }\end{array}$ & Moderate & $\begin{array}{l}64.81-87.66 \% \\
\text { at } 500 \mathrm{mg} / \\
\mathrm{kg} / \text { day }\end{array}$ & $\begin{array}{l}\text { Plasmodium } \\
\text { beghei } \\
\text { ANKA }\end{array}$ & No \\
\hline & & {$[140]$} & Nigeria & Roots & $\begin{array}{l}\text { Ethanol, } \\
\text { chloro- } \\
\text { form, ethyl } \\
\text { acetate, } \\
\text { methanol }\end{array}$ & Moderate & $\begin{array}{l}67.92 \% \text { at } \\
500 \mathrm{mg} / \mathrm{kg} / \\
\text { day }\end{array}$ & $\begin{array}{l}\text { Plasmodium } \\
\text { berghei } \\
\text { ANKA }\end{array}$ & No \\
\hline $\begin{array}{l}\text { Artemisia } \\
\text { macivarae }\end{array}$ & Asteraceae & [141] & Nigeria & $\begin{array}{l}\text { Whole } \\
\text { plant }\end{array}$ & Chloroform & Very good & $\begin{array}{l}80 \% \text { at } \\
100 \mathrm{mg} / \mathrm{kg}\end{array}$ & $\begin{array}{l}\text { Plasmodium } \\
\text { berghei }\end{array}$ & $\mathrm{Nd}$ \\
\hline Aspilia africana & Asteraceae & [142] & Nigeria & Leaves & Ethanol & Moderate & $\begin{array}{l}92.23 \% \text { at } \\
400 \mathrm{mg} / \mathrm{kg} / \\
\text { day }\end{array}$ & $\begin{array}{l}\text { Plasmodium } \\
\text { berhhei } \\
\text { NK65 }\end{array}$ & No \\
\hline \multirow[t]{3}{*}{$\begin{array}{l}\text { Azadirachta } \\
\text { indica }\end{array}$} & Meliaceae & [143] & Kenya & Leaves & Methanol & Good & $\begin{array}{l}83.48 \% \text { at } \\
250 \mathrm{mg} / \mathrm{kg} / \\
\text { day }\end{array}$ & $\begin{array}{l}\text { Plasmodium } \\
\text { falciparum } \\
\text { D6 and W2 }\end{array}$ & No \\
\hline & & [144] & Cameroon & Leaves & Ethanol & Moderate & $\begin{array}{l}69.28 \% \text { at } \\
300 \mathrm{mg} / \mathrm{kg} / \\
\text { day }\end{array}$ & $\begin{array}{l}\text { Plasmodium } \\
\text { berghei } \\
\text { NK65 }\end{array}$ & No \\
\hline & & [145] & Nigeria & Leaves & Methanol & Very good & $\begin{array}{l}56-87 \% \text { at } \\
50 \mathrm{mg} / \mathrm{kg} / \\
\text { day }\end{array}$ & $\begin{array}{l}\text { Plasmodium } \\
\text { berghei } \\
\text { ANKA }\end{array}$ & No \\
\hline $\begin{array}{l}\text { Balanites } \\
\text { rotundifolia }\end{array}$ & $\begin{array}{l}\text { Zygophyl- } \\
\text { laceae }\end{array}$ & [146] & Ethiopia & Leaves & Methanol & Moderate & $\begin{array}{l}67 \% \text { at } \\
400 \mathrm{mg} / \mathrm{dl}\end{array}$ & $\begin{array}{l}\text { Plasmodium } \\
\text { berghei }\end{array}$ & No \\
\hline Blighia sapida & Sapindaceae & [147] & Nigeria & Leaves & Ethanol & Good & $\begin{array}{l}57 \% \text { at } \\
200 \mathrm{mg} / \mathrm{kg} / \\
\text { day }\end{array}$ & $\begin{array}{l}\text { Plasmodium } \\
\text { berghei } \\
\text { ANKA }\end{array}$ & No \\
\hline
\end{tabular}


Table 2 (continued)

\begin{tabular}{|c|c|c|c|c|c|c|c|c|c|}
\hline Plant species & Plant family & Source & $\begin{array}{l}\text { Country of } \\
\text { study }\end{array}$ & $\begin{array}{l}\text { Part of } \\
\text { plant used }\end{array}$ & $\begin{array}{l}\text { Extraction } \\
\text { solvent }\end{array}$ & $\begin{array}{l}\text { Antima- } \\
\text { larial } \\
\text { activity }\end{array}$ & $\begin{array}{l}\text { Parasite } \\
\text { suppression } \\
\text { rate }\end{array}$ & $\begin{array}{l}\text { Strain of } \\
\text { Plasmodium } \\
\text { tested }\end{array}$ & $\begin{array}{l}\text { Toxicity (value; } \\
\text { assay) }\end{array}$ \\
\hline $\begin{array}{c}\text { Bombax buo- } \\
\text { nopozense }\end{array}$ & Malvaceae & [148] & Nigeria & Root barks & Water & Good & $\begin{array}{l}93 \% \text { at } \\
200 \mathrm{mg} / \mathrm{kg} / \\
\text { day }\end{array}$ & $\begin{array}{l}\text { Plasmodium } \\
\text { berghei } \\
\text { NK65 }\end{array}$ & $\mathrm{Nd}$ \\
\hline Brassica nigra & Brassicaceae & [149] & Ethiopia & Seeds & Methanol & Moderate & $\begin{array}{l}53.13 \% \text { at } \\
400 \mathrm{mg} / \mathrm{kg} / \\
\text { day }\end{array}$ & $\begin{array}{l}\text { Plasmodium } \\
\text { berghei } \\
\text { ANKA }\end{array}$ & $\mathrm{Nd}$ \\
\hline $\begin{array}{l}\text { Calpurnia } \\
\text { aurea }\end{array}$ & Fabaceae & [150] & Ethiopia & Leaves & $\begin{array}{l}\text { Hydroalco- } \\
\text { hol }\end{array}$ & Very good & $\begin{array}{l}51.15 \% \text { at } \\
60 \mathrm{mg} / \mathrm{kg}\end{array}$ & $\begin{array}{l}\text { Plasmodium } \\
\text { berghei }\end{array}$ & No \\
\hline Carica papaya & Caricaceae & [151] & Nigeria & Leaves & Ethanol & Good & $\begin{array}{l}59.29 \% \text { at } \\
200 \mathrm{mg} / \mathrm{kg}\end{array}$ & $\begin{array}{l}\text { Plasmodim } \\
\text { berghei } \\
\text { NK65 }\end{array}$ & $\mathrm{Nd}$ \\
\hline $\begin{array}{l}\text { Senna occiden- } \\
\text { talis }\end{array}$ & Fabaceae & [152] & D.R. Congo & Root barks & Ethanol & Good & $\begin{array}{l}68 \% \text { at } \\
200 \mathrm{mg} / \mathrm{kg}\end{array}$ & $\begin{array}{l}\text { Plasmodium } \\
\text { berghei } \\
\text { ANKA }\end{array}$ & No \\
\hline $\begin{array}{l}\text { Cassia siebe- } \\
\text { riana }\end{array}$ & Fabaceae & [153] & Nigeria & Stems & Ethanol & Good & $\begin{array}{l}63.9 \% \text { at } \\
300 \mathrm{~g} / \mathrm{kg} / \\
\text { day }\end{array}$ & $\begin{array}{l}\text { Plasmodium } \\
\text { berghei } \\
\text { NK65 }\end{array}$ & No \\
\hline $\begin{array}{l}\text { Cassia } \\
\text { singueana }\end{array}$ & Fabaceae & [154] & Nigeria & Root barks & Methanol & Good & $\begin{array}{l}79.06 \% \text { at } \\
200 \mathrm{mg} / \mathrm{kg} / \\
\text { day }\end{array}$ & $\begin{array}{l}\text { Plasmodium } \\
\text { berghei }\end{array}$ & $\begin{array}{l}\text { Yes }\left(L_{50}=\right. \\
\quad 847 \mathrm{mg} / \mathrm{kg} ; \text { mice })\end{array}$ \\
\hline $\begin{array}{l}\text { Chrozophora } \\
\text { senegalensis }\end{array}$ & $\begin{array}{l}\text { Euphorbi- } \\
\text { aceae }\end{array}$ & [155] & Nigeria & $\begin{array}{l}\text { Whole } \\
\text { plant }\end{array}$ & Methanol & Very good & $\begin{array}{l}51.8 \% \text { at } \\
75 \mathrm{mg} / \mathrm{kg} / \\
\text { day }\end{array}$ & $\begin{array}{l}\text { Plasmodium } \\
\text { berghei }\end{array}$ & $\mathrm{Nd}$ \\
\hline $\begin{array}{l}\text { Chrysophyllum } \\
\text { albidum }\end{array}$ & Sapotaceae & [156] & Nigeria & $\begin{array}{l}\text { Seeds, pulp } \\
\text { juice }\end{array}$ & Ethanol & Moderate & $\begin{array}{l}72.97 \% \text { at } \\
500 \mathrm{mg} / \mathrm{kg}\end{array}$ & $\begin{array}{l}\text { Plasmodium } \\
\text { berghei }\end{array}$ & No \\
\hline $\begin{array}{l}\text { Clausena } \\
\text { anisota }\end{array}$ & Rutaceae & [157] & Nigeria & Leaves & Ethanol & Very good & $\begin{array}{l}82.02 \% \text { at } \\
78 \mathrm{mg} / \mathrm{kg} / \\
\text { day }\end{array}$ & $\begin{array}{l}\text { Plasmodium } \\
\text { berghei }\end{array}$ & $\begin{array}{l}\text { Yes }\left(L D_{50}=\right. \\
393.7 \mathrm{mg} / \mathrm{kg} ; \\
\text { albino mice) }\end{array}$ \\
\hline $\begin{array}{l}\text { Combretum } \\
\text { molle }\end{array}$ & $\begin{array}{l}\text { Combreta- } \\
\text { ceae }\end{array}$ & [158] & Ethiopia & Seeds & Methanol & Good & $\begin{array}{l}63.5 \% \text { at } \\
250 \mathrm{mg} / \mathrm{kg} / \\
\text { day }\end{array}$ & $\begin{array}{l}\text { Plasmodium } \\
\text { berghei } \\
\text { ANKA }\end{array}$ & $\mathrm{Nd}$ \\
\hline $\begin{array}{l}\text { Commiphora } \\
\text { africana }\end{array}$ & Burseraceae & [159] & Tanzania & Stem barks & $\begin{array}{l}\text { Dichlo- } \\
\text { romethane }\end{array}$ & Moderate & $\begin{array}{l}64.24 \% \text { at } \\
400 \mathrm{mg} / \mathrm{kg} / \\
\text { day }\end{array}$ & $\begin{array}{l}\text { Plasmodium } \\
\text { falciparum } \\
\text { (D6, Dd2), } \\
\text { Plasmodium } \\
\text { berghei }\end{array}$ & No \\
\hline $\begin{array}{l}\text { Crossopteryx } \\
\text { febrifuga }\end{array}$ & Rubiaceae & [160] & Nigeria & Stem barks & Ethanol & Good & $\begin{array}{l}63.65 \% \text { at } \\
200 \mathrm{mg} / \mathrm{kg} / \\
\text { day }\end{array}$ & $\begin{array}{l}\text { Plasmodium } \\
\text { berghei var. } \\
\text { ANKA }\end{array}$ & $\mathrm{Nd}$ \\
\hline $\begin{array}{l}\text { Croton macros- } \\
\text { tachyus }\end{array}$ & $\begin{array}{l}\text { Euphorbi- } \\
\text { aceae }\end{array}$ & [161] & Kenya & Stem barks & Ethyl acetate & Moderate & $\begin{array}{l}82 \% \text { at } \\
500 \mathrm{mg} / \mathrm{kg} / \\
\text { day }\end{array}$ & $\begin{array}{l}\text { Plasmodium } \\
\text { berghei } \\
\text { ANKA }\end{array}$ & $\mathrm{Nd}$ \\
\hline \multirow[t]{2}{*}{$\begin{array}{l}\text { Cryptolepis } \\
\text { sanguino- } \\
\text { lenta }\end{array}$} & Apocynaceae & [162] & Congo & Root barks & Ethanol & Moderate & $\begin{array}{l}75.07 \% \text { at } \\
400 \mathrm{mg} / \mathrm{kg} / \\
\text { day }\end{array}$ & $\begin{array}{l}\text { Plasmodium } \\
\text { falciparum, } \\
\text { Plasmodium } \\
\text { berghei } \\
\text { berghei }\end{array}$ & $\mathrm{Nd}$ \\
\hline & & {$[84]$} & Ghana & Roots & $\begin{array}{l}\text { Hexane, } \\
\text { ethanol, } \\
\text { dichlo- } \\
\text { romethane }\end{array}$ & Very good* & $\begin{array}{l}>80 \% \text { at } \\
2.5 \mathrm{mg} / \mathrm{kg} / \\
\text { day }\end{array}$ & $\begin{array}{l}\text { Plasmodium } \\
\text { vinckei } \\
\text { petteri, } \\
\text { Plasmodium } \\
\text { berghei } \\
\text { ANKA }\end{array}$ & $\mathrm{Nd}$ \\
\hline $\begin{array}{l}\text { Cucumis metu- } \\
\text { liferus }\end{array}$ & $\begin{array}{l}\text { Cucurbita- } \\
\text { ceae }\end{array}$ & [163] & Tanzania & Leaves & Chloroform & Moderate & $\begin{array}{l}70.69 \% \text { at } \\
600 \mathrm{mg} / \mathrm{kg} / \\
\text { day }\end{array}$ & $\begin{array}{l}\text { Plasmodium } \\
\text { berghei } \\
\text { ANKA }\end{array}$ & $\mathrm{Nd}$ \\
\hline
\end{tabular}


Table 2 (continued)

\begin{tabular}{|c|c|c|c|c|c|c|c|c|c|}
\hline Plant species & Plant family & Source & $\begin{array}{l}\text { Country of } \\
\text { study }\end{array}$ & $\begin{array}{l}\text { Part of } \\
\text { plant used }\end{array}$ & $\begin{array}{l}\text { Extraction } \\
\text { solvent }\end{array}$ & $\begin{array}{l}\text { Antima- } \\
\text { larial } \\
\text { activity }\end{array}$ & $\begin{array}{l}\text { Parasite } \\
\text { suppression } \\
\text { rate }\end{array}$ & $\begin{array}{l}\text { Strain of } \\
\text { Plasmodium } \\
\text { tested }\end{array}$ & $\begin{array}{l}\text { Toxicity (value; } \\
\text { assay) }\end{array}$ \\
\hline $\begin{array}{l}\text { Dichrostachys } \\
\text { cinerea }\end{array}$ & Fabaceae & [159] & Tanzania & Stem barks & Methanol & Moderate & $\begin{array}{l}53.12 \% \text { at } \\
400 \mathrm{mg} / \mathrm{kg} / \\
\text { day }\end{array}$ & $\begin{array}{l}\text { Plasmodium } \\
\text { falciparum } \\
\text { (D6, Dd2), } \\
\text { Plasmodium } \\
\text { berghei }\end{array}$ & No \\
\hline $\begin{array}{l}\text { Dodonaea } \\
\text { angustifolia }\end{array}$ & Sapindaceae & [164] & Ethiopia & Roots & N-butanol & Moderate & $\begin{array}{l}55.8 \% \text { at } \\
400 \mathrm{mg} / \mathrm{kg} / \\
\text { day }\end{array}$ & $\begin{array}{l}\text { Plasmodium } \\
\text { berghei }\end{array}$ & $\mathrm{Nd}$ \\
\hline $\begin{array}{c}\text { Enantia chlor- } \\
\text { antha Oliv }\end{array}$ & Annonaceae & [165] & Nigeria & Stem barks & Ethanol & Moderate & $\begin{array}{l}75.23 \% \text { at } \\
500 \mathrm{mg} / \mathrm{kg}\end{array}$ & $\begin{array}{l}\text { Plasmodium } \\
\text { berghei } \\
\text { NK-65 }\end{array}$ & $\mathrm{Nd}$ \\
\hline $\begin{array}{l}\text { Erigeron flori- } \\
\text { bundus }\end{array}$ & Asteraceae & [144] & Cameroon & $\begin{array}{l}\text { Whole } \\
\text { plant }\end{array}$ & Ethanol & Good & $\begin{array}{l}62.4 \% \text { at } \\
240 \mathrm{mg} / \mathrm{kg} / \\
\text { day }\end{array}$ & $\begin{array}{l}\text { Plasmodium } \\
\text { berghei } \\
\text { NK65 }\end{array}$ & No \\
\hline $\begin{array}{l}\text { Euphorbia } \\
\text { cordifolia }\end{array}$ & $\begin{array}{l}\text { Euphorbi- } \\
\text { aceae }\end{array}$ & [166] & Cameroon & $\begin{array}{l}\text { Whole } \\
\text { plant }\end{array}$ & Aqueous & Very good & $\begin{array}{l}94.70 \% \text { at } \\
200 \mathrm{mg} / \mathrm{kg} / \\
\text { day }\end{array}$ & $\begin{array}{l}\text { Plasmodium } \\
\text { berghei }\end{array}$ & No \\
\hline $\begin{array}{l}\text { Euphorbia } \\
\text { hirta L }\end{array}$ & $\begin{array}{l}\text { Euphorbi- } \\
\text { aceae }\end{array}$ & [162] & Congo & $\begin{array}{l}\text { Whole } \\
\text { plant }\end{array}$ & Ethanol & Moderate & $\begin{array}{l}69.44 \% \text { at } \\
400 \mathrm{mg} / \mathrm{kg} / \\
\text { day }\end{array}$ & $\begin{array}{l}\text { Plasmodium } \\
\text { falciparum, } \\
\text { Plasmodium } \\
\text { berghei } \\
\text { berghei }\end{array}$ & $\mathrm{Nd}$ \\
\hline $\begin{array}{l}\text { Faidherbia } \\
\text { albida }\end{array}$ & Fabaceae & {$[167]$} & Nigeria & Stem barks & Ethanol & Moderate & $\begin{array}{l}89.5 \text { at } \\
400 \mathrm{mg} / \mathrm{kg} / \\
\text { day }\end{array}$ & $\begin{array}{l}\text { Plasmodium } \\
\text { berghei } \\
\text { NK65 }\end{array}$ & $\mathrm{Nd}$ \\
\hline $\begin{array}{l}\text { Grewia plagio- } \\
\text { phylla }\end{array}$ & Malvaceae & [143] & Kenya & Leaves & Methanol & Moderate & $\begin{array}{l}77.9 \text { at } \\
250 \mathrm{mg} / \mathrm{kg} / \\
\text { day }\end{array}$ & $\begin{array}{l}\text { Plasmodium } \\
\text { falciparum } \\
\text { D6 and W2 }\end{array}$ & $\mathrm{Nd}$ \\
\hline $\begin{array}{l}\text { Grewia } \\
\text { trichocarpa }\end{array}$ & Malvaceae & [168] & Kenya & Root & Water & Good & $\begin{array}{l}35.8 \% \text { at } \\
10 \mathrm{mg} / \mathrm{kg} / \\
\text { day }\end{array}$ & $\begin{array}{l}\text { Plasmodium } \\
\text { berghei }\end{array}$ & $\begin{array}{l}\text { Yes }\left(\mathrm{LD}_{50}=\right. \\
545.8 \mu \mathrm{g} / \mathrm{ml} \text {; brine } \\
\text { shrimp) }\end{array}$ \\
\hline Garcinia kola & Clusiaceae & [169] & Nigeria & Seeds & $\begin{array}{l}\text { Petroleum } \\
\text { ether }\end{array}$ & Very good* & $\begin{array}{l}93 \% \text { at } \\
200 \mathrm{mg} / \mathrm{kg} / \\
\text { day }\end{array}$ & $\begin{array}{l}\text { Plasmodium } \\
\text { berghei }\end{array}$ & $\mathrm{Nd}$ \\
\hline $\begin{array}{l}\text { Hippocratea } \\
\text { africana }\end{array}$ & Celastraceae & [170] & Nigeria & $\mathrm{Nd}$ & Ethanol & Moderate & $\begin{array}{l}90.9 \% \text { at } \\
600 \mathrm{mg} / \mathrm{kg} / \\
\text { day }\end{array}$ & $\begin{array}{l}\text { Plasmodium } \\
\text { berghei } \\
\text { berghei }\end{array}$ & $\begin{array}{l}\text { Yes }\left(L D_{50}=\right. \\
2449 \mathrm{mg} / \mathrm{kg} ; \text { mice })\end{array}$ \\
\hline $\begin{array}{l}\text { Hoslundia } \\
\text { opposita }\end{array}$ & Lamiaceae & [143] & Kenya & Leaves & Methanol & Moderate & $\begin{array}{l}79.67 \% \text { at } \\
250 \mathrm{mg} / \mathrm{kg} / \\
\text { day }\end{array}$ & $\begin{array}{l}\text { Plasmodium } \\
\text { falciparum } \\
\text { D6 and W2 }\end{array}$ & $\begin{array}{l}\text { Yes }\left(\mathrm{CC}_{50}=\right. \\
37 \mu \mathrm{g} / \mathrm{ml} \text {; Vero E6 } \\
\text { cells) }\end{array}$ \\
\hline $\begin{array}{l}\text { Icacina senega- } \\
\text { lensis }\end{array}$ & Icacinaceae & [171] & Nigeria & Leaves & Methanol & Very good & $\begin{array}{l}80 \% \text { at } \\
100 \mathrm{mg} / \mathrm{kg} / \\
\text { day }\end{array}$ & $\begin{array}{l}\text { Plasmodium } \\
\text { berghei }\end{array}$ & $\begin{array}{l}\text { Yes }\left(\mathrm{LD}_{50}>2000 \mathrm{mg} /\right. \\
\mathrm{kg} ; \text {; mice })\end{array}$ \\
\hline $\begin{array}{l}\text { Indigofera } \\
\text { spicata }\end{array}$ & Fabaceae & [172] & Ethiopia & Roots & Methanol & Moderate & $\begin{array}{l}53.42 \% \text { at } \\
600 \mathrm{mg} / \mathrm{kg} / \\
\text { day }\end{array}$ & $\begin{array}{l}\text { Plasmodium } \\
\text { berghei } \\
\text { ANKA }\end{array}$ & $\mathrm{Nd}$ \\
\hline $\begin{array}{l}\text { Lannea sch- } \\
\text { weinfurthii }\end{array}$ & $\begin{array}{l}\text { Anacardi- } \\
\text { aceae }\end{array}$ & [143] & Kenya & Leaves & Methanol & Moderate & $\begin{array}{l}83.48 \% \text { at } \\
250 \mathrm{mg} / \mathrm{kg} / \\
\text { day }\end{array}$ & $\begin{array}{l}\text { Plasmodium } \\
\text { falciparum } \\
\text { D6 and W2 }\end{array}$ & $\begin{array}{l}\text { Yes }\left(\mathrm{CC}_{50}=\right. \\
76 \mu \mathrm{g} / \mathrm{ml} \text {; Vero E6 } \\
\text { cells) }\end{array}$ \\
\hline $\begin{array}{l}\text { Lippia kitu- } \\
\text { iensis }\end{array}$ & Verbenaceae & [163] & Tanzania & Leaves & Ethyl acetate & Moderate & $\begin{array}{l}70.14 \% \text { at } \\
600 \mathrm{mg} / \mathrm{kg} / \\
\text { day }\end{array}$ & $\begin{array}{l}\text { Plasmodium } \\
\text { berghei } \\
\text { ANKA }\end{array}$ & $\mathrm{Nd}$ \\
\hline $\begin{array}{l}\text { Lophira lanceo- } \\
\text { lata }\end{array}$ & Ochnaceae & [173] & Nigeria & Leaves & Methanol & Moderate & $\begin{array}{l}80 \% \text { at } \\
400 \mathrm{mg} / \mathrm{kg} / \\
\text { day }\end{array}$ & $\begin{array}{l}\text { Plasmodium } \\
\text { berghei }\end{array}$ & No \\
\hline $\begin{array}{l}\text { Maerua cras- } \\
\text { sifolia }\end{array}$ & Capparaceae & [174] & Nigeria & Leaves & Methanol & Moderate & $\begin{array}{l}86 \% \text { at } \\
400 \mathrm{mg} / \mathrm{kg} / \\
\text { day }\end{array}$ & $\begin{array}{l}\text { Plasmodium } \\
\text { berghei } \\
\text { NK65 }\end{array}$ & No \\
\hline
\end{tabular}


Table 2 (continued)

\begin{tabular}{|c|c|c|c|c|c|c|c|c|c|}
\hline Plant species & Plant family & Source & $\begin{array}{l}\text { Country of } \\
\text { study }\end{array}$ & $\begin{array}{l}\text { Part of } \\
\text { plant used }\end{array}$ & $\begin{array}{l}\text { Extraction } \\
\text { solvent }\end{array}$ & $\begin{array}{l}\text { Antima- } \\
\text { larial } \\
\text { activity }\end{array}$ & $\begin{array}{l}\text { Parasite } \\
\text { suppression } \\
\text { rate }\end{array}$ & $\begin{array}{l}\text { Strain of } \\
\text { Plasmodium } \\
\text { tested }\end{array}$ & $\begin{array}{l}\text { Toxicity (value; } \\
\text { assay) }\end{array}$ \\
\hline $\begin{array}{l}\text { Maytenus sen- } \\
\text { egalensis }\end{array}$ & Celastraceae & {$[175]$} & Tanzania & Root barks & Ethanol & Very good & $\begin{array}{l}98.1 \% \text { at } \\
100 \mathrm{mg} / \mathrm{kg} / \\
\text { day }\end{array}$ & $\begin{array}{l}\text { Plasmodium } \\
\text { berghei }\end{array}$ & No \\
\hline $\begin{array}{l}\text { Morinda } \\
\text { morindoides }\end{array}$ & Rubiaceae & [152] & D.R. Congo & Leaves & $\begin{array}{l}\text { Dichlo- } \\
\text { romethane }\end{array}$ & Good & $\begin{array}{l}74 \% \text { at } \\
200 \mathrm{mg} / \mathrm{kg} / \\
\text { day }\end{array}$ & $\begin{array}{l}\text { Plasmodium } \\
\text { berghei } \\
\text { ANKA }\end{array}$ & No \\
\hline $\begin{array}{l}\text { Mucuna } \\
\text { pruriens }\end{array}$ & Fabaceae & [176] & Nigeria & Leaves & Water & Good & $\begin{array}{l}71.75 \% \text { at } \\
270 \mathrm{mg} / \mathrm{kg} / \\
\text { day }\end{array}$ & $\begin{array}{l}\text { Plasmodium } \\
\text { berghei } \\
\text { NK65 }\end{array}$ & No \\
\hline \multirow[t]{2}{*}{$\begin{array}{l}\text { Nauclea } \\
\text { latifolia }\end{array}$} & Rubiaceae & [177] & Nigeria & Leaves & Ethanol & Moderate & $\begin{array}{l}60.63 \% \text { at } \\
500 \mathrm{mg} / \mathrm{kg} / \\
\text { day }\end{array}$ & $\begin{array}{l}\text { Plasmodium } \\
\text { berghei }\end{array}$ & No \\
\hline & & {$[165]$} & Nigeria & Roots & Ethanol & Moderate & $\begin{array}{l}71.15 \% \text { at } \\
500 \mathrm{mg} / \mathrm{kg} / \\
\text { day }\end{array}$ & $\begin{array}{l}\text { Plasmodium } \\
\text { berghei } \\
\text { NK-65 }\end{array}$ & $\mathrm{Nd}$ \\
\hline $\begin{array}{l}\text { Oldenlandia } \\
\text { affinis }\end{array}$ & Rubiaceae & [178] & Nigeria & Aerial parts & $\begin{array}{l}\text { Methanol, } \\
\text { water, } \\
\text { dichlo- } \\
\text { romethane }\end{array}$ & Moderate & $\begin{array}{l}75 \% \text { at } \\
400 \mathrm{mg} / \mathrm{kg} / \\
\text { day }\end{array}$ & $\begin{array}{l}\text { Plasmodium } \\
\text { berghei }\end{array}$ & No \\
\hline $\begin{array}{l}\text { Peschiera fuch- } \\
\text { siaefolia }\end{array}$ & Apocynaceae & [179] & $\begin{array}{l}\text { Madagas- } \\
\text { car }\end{array}$ & Stem barks & Ns & Good* $^{*}$ & $\begin{array}{l}43.4 \% \text { at } \\
10 \mathrm{mg} / \mathrm{kg} / \\
\text { day }\end{array}$ & $\begin{array}{l}\text { Plasmodium } \\
\text { yoelii N67, } \\
\text { Plasmodium } \\
\text { falciparum } \\
\text { FMC29 }\end{array}$ & $\mathrm{Nd}$ \\
\hline $\begin{array}{c}\text { Phyllanthus } \\
\text { amarus }\end{array}$ & $\begin{array}{l}\text { Phyllan- } \\
\text { thaceae }\end{array}$ & [180] & Nigeria & $\begin{array}{l}\text { Whole } \\
\text { plant }\end{array}$ & $\begin{array}{l}\text { Water and } \\
\text { ethanol }\end{array}$ & Good & $\begin{array}{l}79 \% \text { at } \\
1600 \mathrm{mg} / \\
\mathrm{kg} / \text { day }\end{array}$ & $\begin{array}{l}\text { Plasmodium } \\
\text { yoelii }\end{array}$ & $\mathrm{Nd}$ \\
\hline \multirow[t]{2}{*}{$\begin{array}{l}\text { Phyllanthus } \\
\text { niruri }\end{array}$} & $\begin{array}{l}\text { Phyllan- } \\
\text { thaceae }\end{array}$ & [152] & D.R. Congo & $\begin{array}{l}\text { Whole } \\
\text { plant }\end{array}$ & Ethanol & Good & $\begin{array}{l}73 \% \text { at } \\
200 \mathrm{mg} / \mathrm{kg} / \\
\text { day }\end{array}$ & $\begin{array}{l}\text { Plasmodium } \\
\text { berghei } \\
\text { ANKA }\end{array}$ & No \\
\hline & & [181] & Nigeria & Aerial parts & $\begin{array}{l}\text { Methanol/ } \\
\text { chloroform }\end{array}$ & Very good & $\begin{array}{l}90.48 \% \text { at } \\
100 \mathrm{mg} / \mathrm{kg} / \\
\text { day }\end{array}$ & $\begin{array}{l}\text { Plasmodium } \\
\text { berghei } \\
\text { berghei } \\
\text { NK65 }\end{array}$ & $\mathrm{Nd}$ \\
\hline $\begin{array}{l}\text { Phytolacca } \\
\text { dodecandra }\end{array}$ & $\begin{array}{c}\text { Phytolac- } \\
\text { caceae }\end{array}$ & [182] & Ethiopia & Leaves & Methanol & Moderate & $\begin{array}{l}55.24 \% \text { at } \\
400 \mathrm{mg} / \mathrm{kg} / \\
\text { day }\end{array}$ & $\begin{array}{l}\text { Plasmodium } \\
\text { berghei }\end{array}$ & $\mathrm{Nd}$ \\
\hline $\begin{array}{l}\text { Picralima } \\
\text { nitida }\end{array}$ & Apocynaceae & [183] & Nigeria & Seeds & Ethanol & Good & $\begin{array}{l}73 \% \text { at } \\
115 \mathrm{mg} / \mathrm{kg} / \\
\text { day }\end{array}$ & $\begin{array}{l}\text { Plasmodium } \\
\text { berghei } \\
\text { berghei }\end{array}$ & $\begin{array}{l}\text { Yes }\left(\mathrm{LD}_{50}=\right. \\
87.29 \mu \mathrm{g} / \mathrm{ml} ; \\
\text { albino mice })\end{array}$ \\
\hline $\begin{array}{l}\text { Piliostigma } \\
\text { thonningii }\end{array}$ & Fabaceae & [184] & Nigeria & Leaves & Ethanol & Moderate & $\begin{array}{l}91 \% \text { at } \\
400 \mathrm{mg} / \mathrm{kg} / \\
\text { day }\end{array}$ & $\begin{array}{l}\text { Plasmodium } \\
\text { berghei } \\
\text { NK65 }\end{array}$ & No \\
\hline $\begin{array}{l}\text { Premna chryso- } \\
\text { clada }\end{array}$ & Lamiaceae & [143] & Kenya & Leaves & Methanol & Good & $\begin{array}{l}65.08 \% \text { at } \\
250 \mathrm{mg} / \mathrm{kg} / \\
\text { day }\end{array}$ & $\begin{array}{l}\text { Plasmodium } \\
\text { falciparum } \\
\text { D6 and W2 }\end{array}$ & $\mathrm{Nd}$ \\
\hline $\begin{array}{l}\text { Pseudocedrela } \\
\text { kotschyi }\end{array}$ & Meliaceae & [185] & Nigeria & Leaves & Ethanol & Moderate & $\begin{array}{l}90 \% \text { at } \\
400 \mathrm{mg} / \mathrm{kg} / \\
\text { day }\end{array}$ & $\begin{array}{l}\text { Plasmodium } \\
\text { berghei } \\
\text { (NK65 }\end{array}$ & No, \\
\hline Rhus natalensis & $\begin{array}{c}\text { Anacardi- } \\
\text { aceae }\end{array}$ & [143] & Kenya & Leaves & Methanol & Moderate & $\begin{array}{l}82.7 \% \text { at } \\
250 \mathrm{mg} / \mathrm{kg} / \\
\text { day }\end{array}$ & $\begin{array}{l}\text { Plasmodium } \\
\text { falciparum } \\
\text { D6 and W2 }\end{array}$ & $\mathrm{Nd}$ \\
\hline Salacia nitida & Celastraceae & [165] & Nigeria & Roots & Ethanol & Moderate & $\begin{array}{l}71.15 \% \text { at } \\
250 \mathrm{mg} / \mathrm{kg} / \\
\text { day }\end{array}$ & $\begin{array}{l}\text { Plasmodium } \\
\text { berghei } \\
\text { NK-65 }\end{array}$ & $\mathrm{Nd}$ \\
\hline $\begin{array}{c}\text { Stachytarpheta } \\
\text { cayennensis }\end{array}$ & Verbenaceae & [186] & Nigeria & Leaves & Ethanol & Good & $\begin{array}{l}78.2 \% \text { at } \\
270 \mathrm{mg} / \mathrm{kg} / \\
\text { day }\end{array}$ & $\begin{array}{c}\text { Plasmodium } \\
\text { berghei } \\
\text { berghei }\end{array}$ & $\begin{array}{l}\text { Yes }\left(\mathrm{LD}_{50}=\right. \\
938.08 \mathrm{mg} / \mathrm{kg} \text {; } \\
\text { albino mice })\end{array}$ \\
\hline
\end{tabular}


Table 2 (continued)

\begin{tabular}{|c|c|c|c|c|c|c|c|c|c|}
\hline Plant species & Plant family & Source & $\begin{array}{l}\text { Country of } \\
\text { study }\end{array}$ & $\begin{array}{l}\text { Part of } \\
\text { plant used }\end{array}$ & $\begin{array}{l}\text { Extraction } \\
\text { solvent }\end{array}$ & $\begin{array}{l}\text { Antima- } \\
\text { larial } \\
\text { activity }\end{array}$ & $\begin{array}{l}\text { Parasite } \\
\text { suppression } \\
\text { rate }\end{array}$ & $\begin{array}{l}\text { Strain of } \\
\text { Plasmodium } \\
\text { tested }\end{array}$ & $\begin{array}{l}\text { Toxicity (value; } \\
\text { assay) }\end{array}$ \\
\hline $\begin{array}{l}\text { Telfairia occi- } \\
\text { dentalis }\end{array}$ & $\begin{array}{l}\text { Cucurbita- } \\
\text { ceae }\end{array}$ & [187] & Nigeria & Leaves & Water & Good & $\begin{array}{l}72.17 \% \text { at } \\
200 \mathrm{mg} / \mathrm{kg} / \\
\text { day }\end{array}$ & $\begin{array}{l}\text { Plasmodium } \\
\text { berghei } \\
\text { ANKA }\end{array}$ & No \\
\hline $\begin{array}{l}\text { Tithonia diver- } \\
\text { sifolia }\end{array}$ & Asteraceae & [160] & Nigeria & Aerial parts & Ethanol & Good & $\begin{array}{l}74.97 \% \text { at } \\
200 \mathrm{mg} / \mathrm{kg} / \\
\text { day }\end{array}$ & $\begin{array}{l}\text { Plasmodium } \\
\text { berghei var. } \\
\text { ANKA I }\end{array}$ & $\mathrm{Nd}$ \\
\hline $\begin{array}{l}\text { Toddalia } \\
\text { asiatica }\end{array}$ & Rutaceae & [188] & Kenya & Root barks & Methanol & Moderate & $\begin{array}{l}59.3 \% \text { at } \\
500 \mathrm{mg} / \mathrm{kg} / \\
\text { day }\end{array}$ & $\begin{array}{l}\text { Plasmodium } \\
\text { berghei } \\
\text { NK66 }\end{array}$ & $\mathrm{Nd}$ \\
\hline $\begin{array}{l}\text { Trema orien- } \\
\text { talis }\end{array}$ & $\begin{array}{l}\text { Canna- } \\
\text { baceae }\end{array}$ & [189] & Nigeria & Stem barks & Methanol & Good & $\begin{array}{l}70 \% \text { at } \\
200 \mathrm{mg} / \mathrm{kg} / \\
\text { day }\end{array}$ & $\begin{array}{l}\text { Plasmodium } \\
\text { berghei }\end{array}$ & $\mathrm{Nd}$ \\
\hline $\begin{array}{l}\text { Trichilia megal- } \\
\text { antha }\end{array}$ & Meliaceae & [190] & Nigeria & Stem barks & $\begin{array}{l}\text { Methanol, } \\
\text { chloroform }\end{array}$ & Good & $\begin{array}{l}89.1-100 \% \text { at } \\
200 \mathrm{mg} / \mathrm{kg} / \\
\text { day }\end{array}$ & $\begin{array}{l}\text { Plasmodium } \\
\text { berghei } \\
\text { berghei } \\
\text { ANKA }\end{array}$ & $\mathrm{Nd}$ \\
\hline $\begin{array}{l}\text { Triphyophyllum } \\
\text { peltatum }\end{array}$ & $\begin{array}{l}\text { Dioncophyl- } \\
\text { laceae }\end{array}$ & [191] & Ivory Coast & $\begin{array}{l}\text { Roots, stem } \\
\text { barks }\end{array}$ & $\begin{array}{l}\text { Dichlo- } \\
\text { romethane }\end{array}$ & Very good* & $\begin{array}{l}99 \% \text { at } \\
50 \mathrm{mg} / \mathrm{kg} / \\
\text { day }\end{array}$ & $\begin{array}{l}\text { Plasmodium } \\
\text { berghei } \\
\text { ANKA CRS }\end{array}$ & $\mathrm{Nd}$ \\
\hline $\begin{array}{l}\text { Uvaria acumi- } \\
\text { nata }\end{array}$ & Annonaceae & [143] & Kenya & Roots & Methanol & Good & $\begin{array}{l}27.0 \% \text { at } \\
250 \mathrm{mg} / \mathrm{kg} / \\
\text { day }\end{array}$ & $\begin{array}{l}\text { Plasmodium } \\
\text { falciparum } \\
\text { D6 and W2 }\end{array}$ & $\mathrm{Nd}$ \\
\hline $\begin{array}{l}\text { Uvaria } \\
\text { ChamaeP. } \\
\text { Beaur }\end{array}$ & Annonaceae & [170] & Nigeria & $\mathrm{Nd}$ & Ethanol & Moderate & $\begin{array}{l}72.2 \% \text { at } \\
600 \mathrm{mg} / \mathrm{kg} / \\
\text { day }\end{array}$ & $\begin{array}{l}\text { Plasmodium } \\
\text { berghei } \\
\text { berghei }\end{array}$ & $\begin{array}{l}\text { Yes }\left(\mathrm{LD}_{50}=\right. \\
3464 \mathrm{mg} / \mathrm{kg} ; \text { mice })\end{array}$ \\
\hline $\begin{array}{l}\text { Verbena } \\
\text { hastata }\end{array}$ & Verbenaceae & [192] & Nigeria & Leaves & Ethanol & Moderate & $\begin{array}{l}70 \% \text { at } \\
400 \mathrm{mg} / \mathrm{kg} / \\
\text { day }\end{array}$ & $\begin{array}{l}\text { Plasmodium } \\
\text { berghei }\end{array}$ & No \\
\hline \multirow[t]{3}{*}{$\begin{array}{l}\text { Vernonia } \\
\text { amygdalina }\end{array}$} & Asteraceae & [193] & Uganda & Leaves & Water & Good & $\begin{array}{l}73 \% \text { at } \\
200 \mathrm{mg} / \mathrm{kg} / \\
\text { day }\end{array}$ & $\begin{array}{l}\text { Plasmodium } \\
\text { berghei }\end{array}$ & No \\
\hline & & [194] & Nigeria & Leaves & Water & Good & $\begin{array}{l}50.78- \\
62.66 \% \text { at } \\
125 \mathrm{mg} / \mathrm{kg} / \\
\text { day }\end{array}$ & $\begin{array}{l}\text { Plasmodium } \\
\text { berghei } \\
\text { ANKA }\end{array}$ & $\mathrm{Nd}$ \\
\hline & & [195] & Botswana & $\begin{array}{l}\text { Leaves } \\
\text { and root } \\
\text { barks }\end{array}$ & Ethanol & Moderate & $\begin{array}{l}67 \% \text { at } \\
500 \mathrm{mg} / \mathrm{kg} / \\
\text { day }\end{array}$ & $\begin{array}{l}\text { Plasmodium } \\
\text { berghei }\end{array}$ & $\mathrm{Nd}$ \\
\hline $\begin{array}{l}\text { Vernonia } \\
\text { lasiopus }\end{array}$ & Asteraceae & [188] & Kenya & Root barks & Methanol & Moderate & $\begin{array}{l}59.3 \% \text { at } \\
500 \mathrm{mg} / \mathrm{kg} / \\
\text { day }\end{array}$ & $\begin{array}{l}\text { Plasmodium } \\
\text { berghei } \\
\text { NK67 }\end{array}$ & $\mathrm{Nd}$ \\
\hline $\begin{array}{l}\text { Withania } \\
\text { somnifera }\end{array}$ & Solanaceae & [196] & Ethiopia & Leaves & Methanol & Moderate & $\begin{array}{l}57 \% \text { at } \\
300 \mathrm{mg} / \mathrm{kg} / \\
\text { day }\end{array}$ & $\begin{array}{l}\text { Plasmodium } \\
\text { berghei } \\
\text { ANKA }\end{array}$ & $\mathrm{Nd}$ \\
\hline $\begin{array}{l}\text { Xylopia aethi- } \\
\text { opica }\end{array}$ & Annonaceae & [141] & Nigeria & Fruits & Chloroform & Very good & $\begin{array}{l}60 \% \text { at } \\
100 \mathrm{mg} / \mathrm{kg} / \\
\text { day }\end{array}$ & $\begin{array}{l}\text { Plasmodium } \\
\text { berghei }\end{array}$ & $\mathrm{Nd}$ \\
\hline $\begin{array}{l}\text { Artemisia abys- } \\
\text { sinica }\end{array}$ & Asteraceae & [197] & Ethiopia & Aerial parts & $\begin{array}{l}\text { Hydroalco- } \\
\text { hol }\end{array}$ & Good & $\begin{array}{l}64.7 \% \text { at } \\
200 \mathrm{mg} / \mathrm{kg} / \\
\text { day }\end{array}$ & $\begin{array}{l}\text { Plasmodium } \\
\text { berghei }\end{array}$ & $\mathrm{Nd}$ \\
\hline $\begin{array}{l}\text { Rotheca myri- } \\
\text { coides }\end{array}$ & Lamiaceae & [198] & Ethiopia & Leaves & Methanol & Good & $\begin{array}{l}54.14 \% \text { at } \\
200 \mathrm{mg} / \mathrm{kg} / \\
\text { day }\end{array}$ & $\begin{array}{l}\text { Plasmodium } \\
\text { berghei }\end{array}$ & No \\
\hline $\begin{array}{l}\text { Dodonaea } \\
\text { angustifolia }\end{array}$ & Sapindaceae & [198] & Ethiopia & Roots & Methanol & Good & $\begin{array}{l}57.74 \% \text { at } \\
200 \mathrm{mg} / \mathrm{kg} / \\
\text { day }\end{array}$ & $\begin{array}{l}\text { Plasmodium } \\
\text { berghei }\end{array}$ & No \\
\hline
\end{tabular}


Table 2 (continued)

\begin{tabular}{|c|c|c|c|c|c|c|c|c|c|}
\hline Plant species & Plant family & Source & $\begin{array}{l}\text { Country of } \\
\text { study }\end{array}$ & $\begin{array}{l}\text { Part of } \\
\text { plant used }\end{array}$ & $\begin{array}{l}\text { Extraction } \\
\text { solvent }\end{array}$ & $\begin{array}{l}\text { Antima- } \\
\text { larial } \\
\text { activity }\end{array}$ & $\begin{array}{l}\text { Parasite } \\
\text { suppression } \\
\text { rate }\end{array}$ & $\begin{array}{l}\text { Strain of } \\
\text { Plasmodium } \\
\text { tested }\end{array}$ & $\begin{array}{l}\text { Toxicity (value; } \\
\text { assay) }\end{array}$ \\
\hline $\begin{array}{l}\text { Clutia abys- } \\
\text { sinica }\end{array}$ & Peraceae & [199] & Kenya & Leaves & Methanol & Moderate & $\begin{array}{l}40.45 \% \text { at } \\
100 \mathrm{mg} / \mathrm{kg} / \\
\text { day }\end{array}$ & $\begin{array}{l}\text { Plasmodium } \\
\text { falciparum, } \\
\text { Plasmodium } \\
\text { berghei } \\
\text { ANKA }\end{array}$ & No \\
\hline $\begin{array}{l}\text { Pittosporum } \\
\text { viridiflorum }\end{array}$ & $\begin{array}{l}\text { Pitto- } \\
\text { sporaceae }\end{array}$ & [199] & Kenya & Leaves & Methanol & Moderate & $\begin{array}{l}54.77 \% \text { at } \\
100 \mathrm{mg} / \mathrm{kg} / \\
\text { day }\end{array}$ & $\begin{array}{l}\text { Plasmodium } \\
\text { falciparum } \\
\text { D6 \&W2, } \\
\text { Plasmodium } \\
\text { berghei } \\
\text { ANKA }\end{array}$ & $\begin{array}{l}\text { Yes ( } \mathrm{SI}=2.51 \text {; Vero } \\
\text { E6 cells) }\end{array}$ \\
\hline
\end{tabular}

Nd Not done, Ns Not specified, S/ Selectivity index

${ }^{\text {a } A c t i v i t y ~ d e t e r m i n e d ~ u s i n g ~ p u r e ~ c o m p o u n d s ~ i s o l a t e d ~ f r o m ~ p l a n t ~}$

Africa is slothful. Despite a considerable number of plant species that have demonstrated significant antiplasmodial activity in vitro, fewer plants have been evaluated in vivo and only one clinical trial with Cochlospermum planchonii (Bixaceae) has been conducted so far. This reinforces the need for basic and clinical research in the region. Van Wyk [213] had also arrived at the same conclusion.

This review revealed research articles from 31 African countries. Most of the articles were from Nigeria. This is suggestive that Nigeria is leading the podium in research on anti-malarial drug discovery and development, deservedly so, because she is probably the most affected country in the world. It is noteworthy that South Africa which is generally more technologically advanced than Nigeria had very few (8) articles. The African region is the most affected in the world recording the greatest number of cases and malaria attributed deaths. However, the distribution of malaria in Africa is not even, with sub-Saharan Africa harboring disproportionately the greatest number of cases. This is suggestive that research to identify new anti-malarial drugs may be related to the burden of the disease, thus the government policy to control the disease. There is, therefore, the need for policy-driven research into new anti-malarial all across the African region. In this review, $\mathrm{IC}_{50}$ values of $<20 \mu \mathrm{g} / \mathrm{ml}$ were considered as the cutoff of significant anti-malarial activity. This cutoff is considered the minimum to qualify as a first-pass "hit" in anti-malarial drugs screening [214]. Five hundred and two (502) plant species from 169 families were observed to have moderate to very good anti-malarial activity. The most investigated plant families were Euphorbiaceae, Fabaceae, Rubiaceae, and Annonaceae. However, the plant families containing the most active plants were Apocynaceae, Celestraceae, and Rutaceae. This finding suggests that more emphasis should be given to plants in these families for anti-malarial drug discovery. Besides, the most investigated plant species were Azadirachta indica, Nauclea latifolia, Picralima nitida, and Zanthoxylum chalybeum. Alchornea cordifolia, Flueggea virosa, Crytolepis sanguinolenta, and Zanthoxylum chalybeum were the only plant species with consistently very good antiplasmodial and anti-malarial activities between studies. This is very surprising that no clinical trial using any of these plants has been conducted. Further studies on these plant species should be performed.

This study revealed that overall, a majority of the plants investigated had very good antiplasmodial activity in vitro. That activity decreases as you move to in vivo in most studies, with a majority of plants demonstrating only moderate activity. For example, Gathirwa et al. [146] showed that the activity of Uvaria acuminate decreased from good activity in vitro to inactive in vivo. However, a few studies show that plant activity could also increase from in vitro to in vivo. For example, Ngbolua et al. [211] showed that the activity of Vernonia ambigua increased from in vitro to in vivo analysis. Other examples include studies by Muthaura et al. [20] using Boscia angustifolia, Kweyamba et al. [162] using Commiphora Africana, and Ajaiyeoba et al. [204] using Annona senegalensis. This suggests that plants could still have significant antimalarial activity in vivo although they failed to in vitro. Most investigators usually progress to in vivo studies only when they observe significant antiplasmodial activity in vitro. This may explain the findings of a smaller number of in vivo studies in the current study. The investigation of the anti-malarial activities of plants should continue in vivo despite the dismal performance of the plants in vitro. 


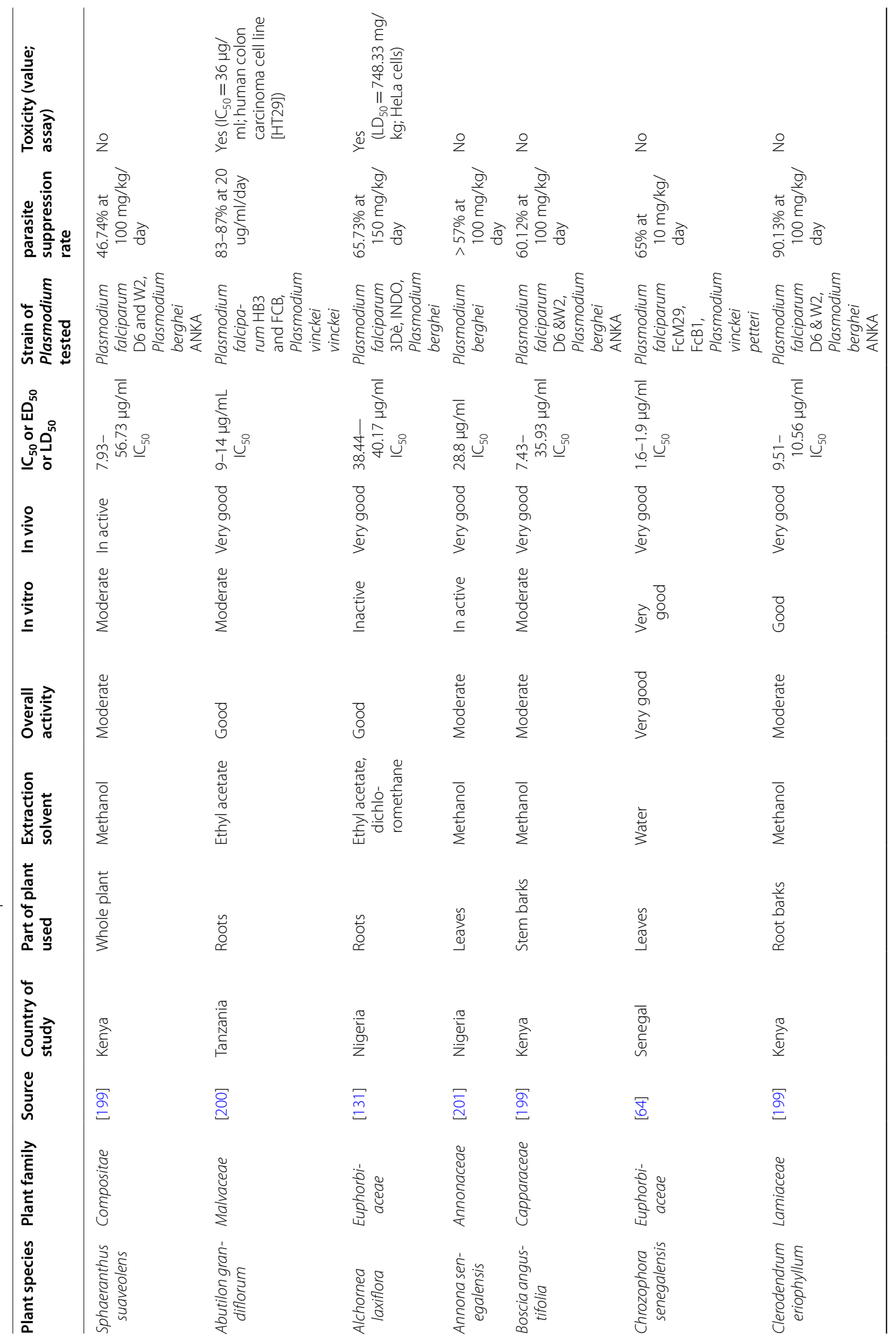




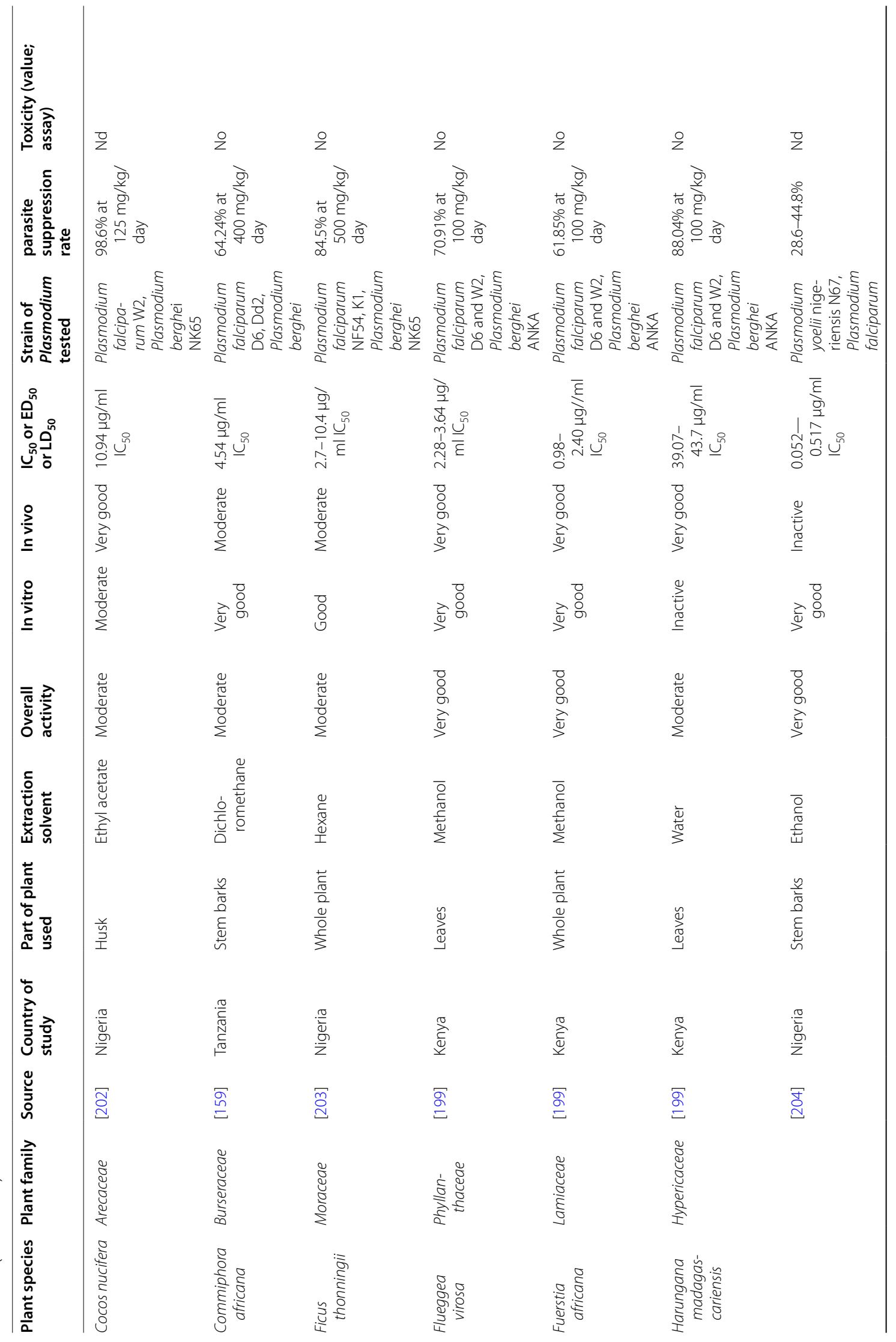




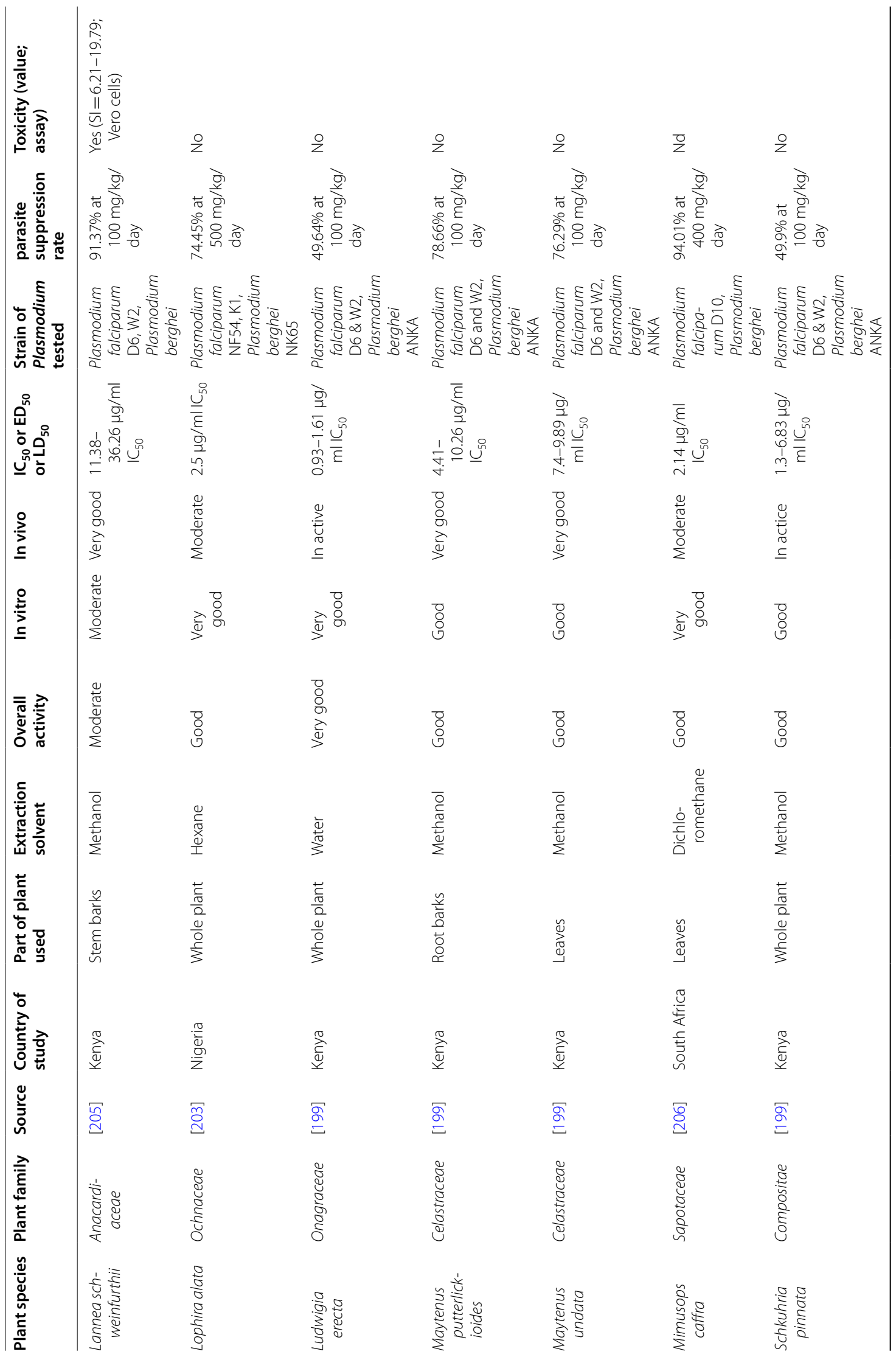


Tajbakhsh et al. Malar J (2021) 20:349

Page 39 of 50

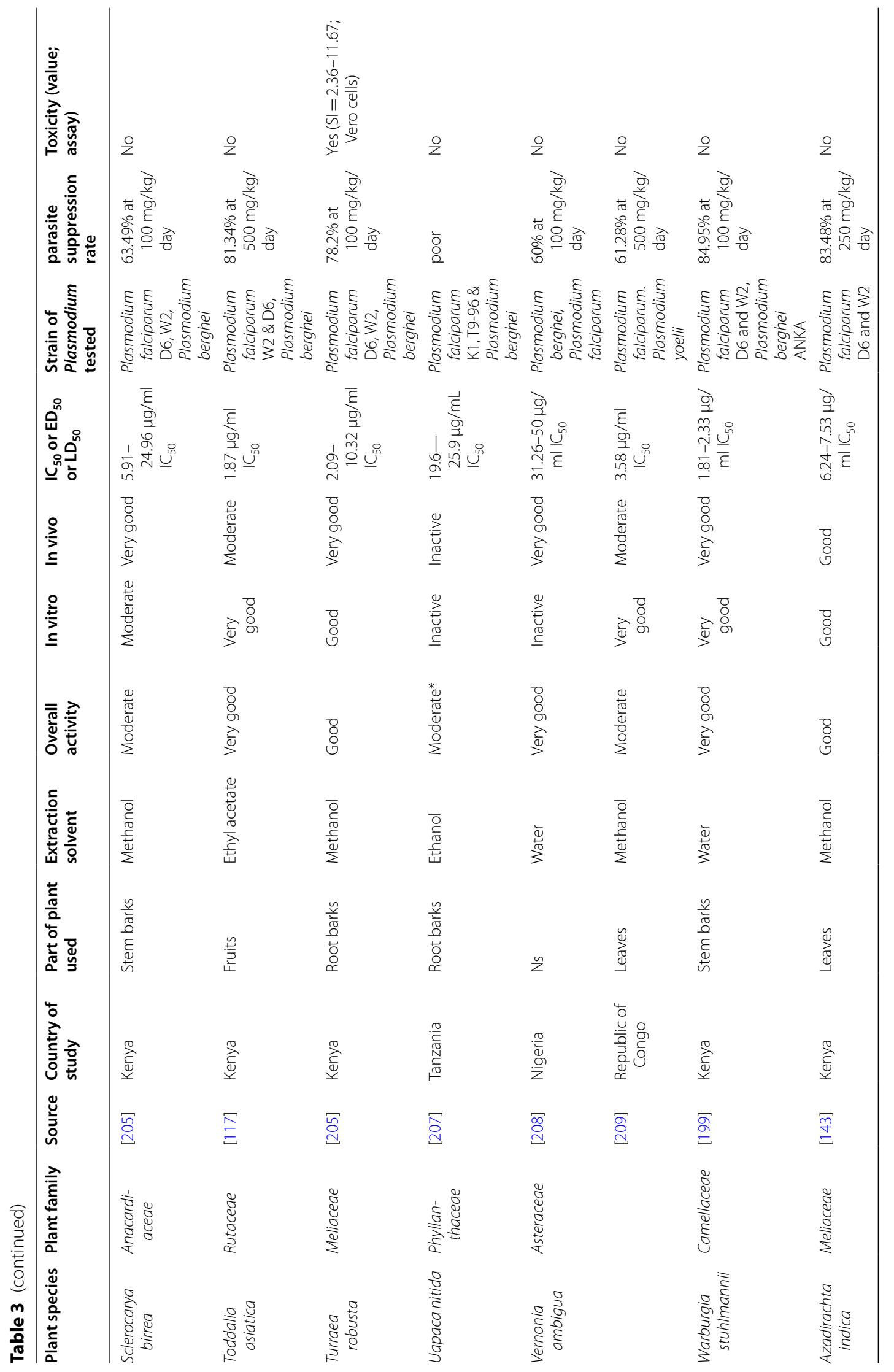




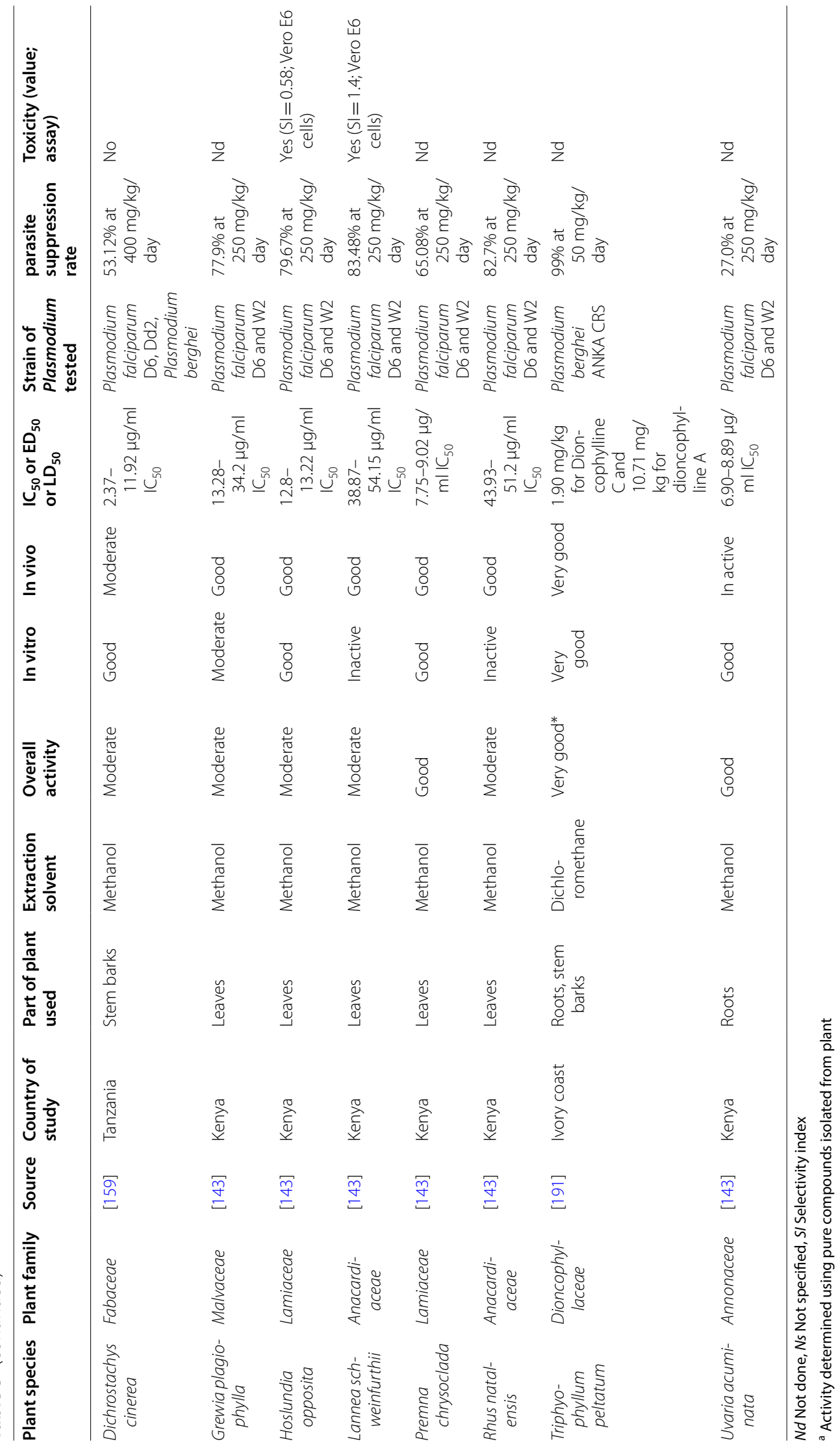




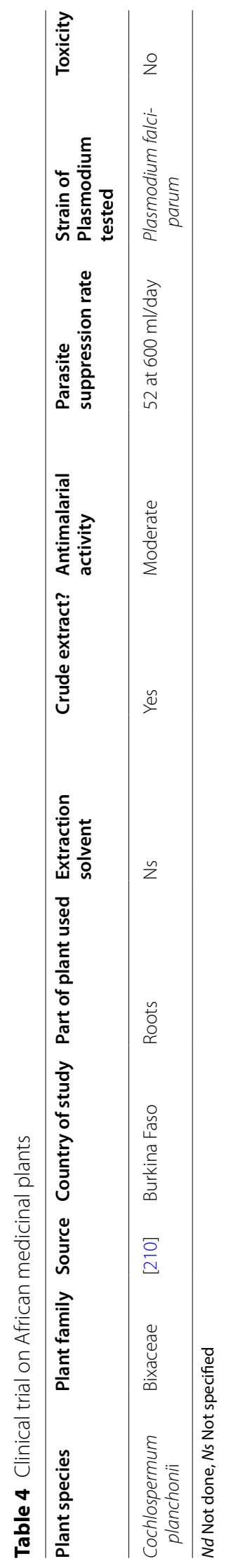




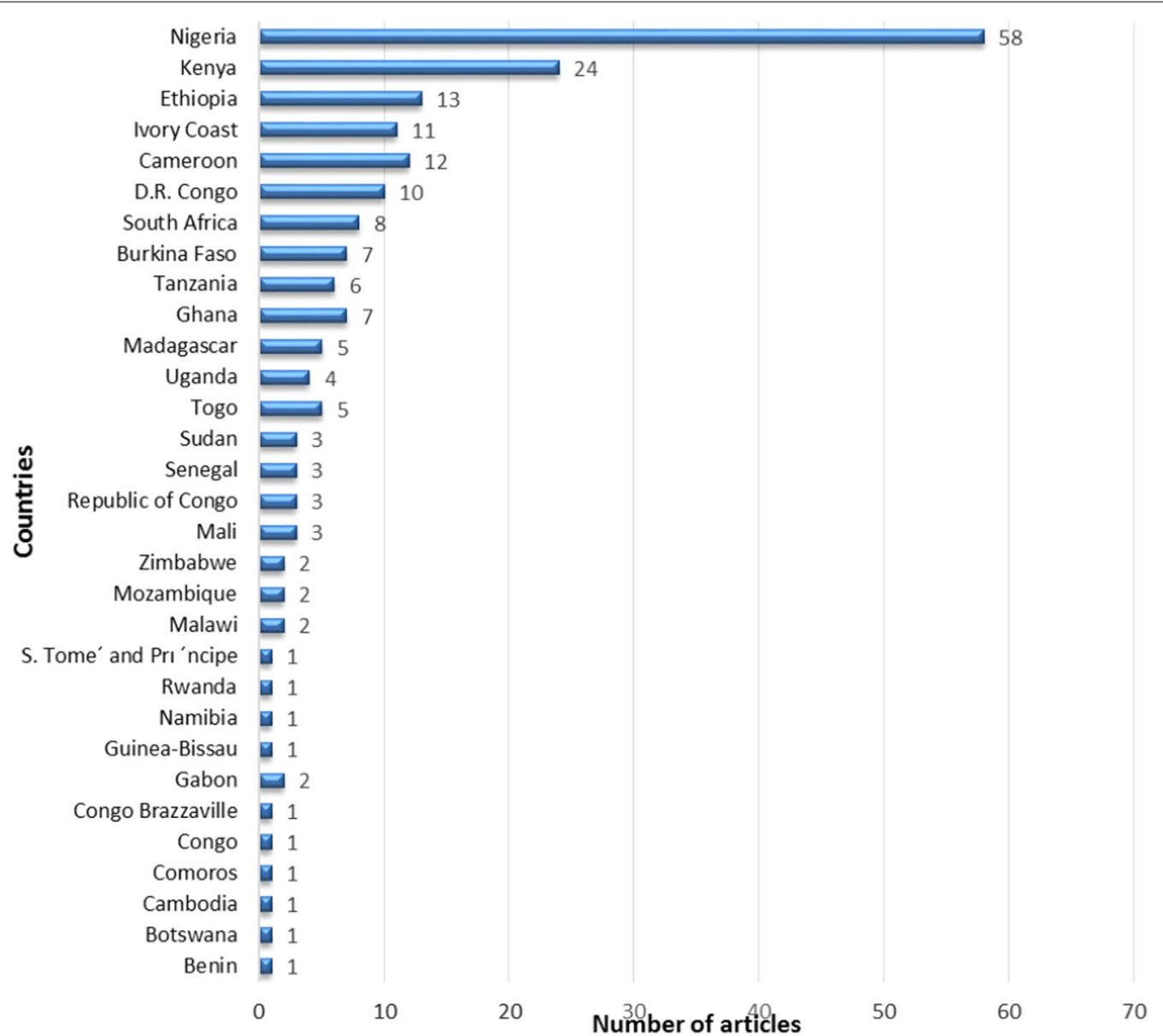

Fig. 2 Distribution of the research articles on the antiplasmodial activity of indigenous plants according to African countries

The current study revealed substantial inter-study variation in the antiplasmodial activity of several plant species. For example, considerable variation in the antiplasmodial activity was observed for Senna occidentalis, Adansonia digitata, Acanthospermum hispidum, Rotheca myricoides, Anogeissus leocarpus, Annona muricata, Ageratum conyzoides, Albizia coriaria, Ekebergia capensis, Flueggea virosa, Lippia javanica, Maytenus senegalensis, Morinda lucida, Picralima nitida, Trichilia emetica, Vernonia amydalina, and Vernonia colorata. The factors that could have accounted for these differences may include differences in the extraction solvent thus the extraction yield and extracted metabolite. With dichloromethane, mainly the apolar metabolites are extracted. In contrast, with methanol, from polar to moderate apolar metabolites are extracted.

Most (95.7\%) of the studies used crude extract for their investigation and rarely the pure compounds (Additional file 1: Table S2 presents a summary of active compounds that have been identified from some of the plants). The finding of a majority of studies in Africa using only the crude extract of plants may be attributed to the absence of the necessary infrastructure to process the plant materials to get the pure compounds. Furthermore, there may be geographical differences in the areas where the plants were collected and this may also affect the activity of the same plant species. For example, despite using the same extraction solvent, the antiplasmodial activity of Acacia nilotica was moderate in South Africa and very good in Sudan. There was also variation between the different assay types. For example, the activities of Vernonia ambigua [211] and Annona senegalensis [204] have been reported to increase from inactive in vitro to very good in vivo. However, a few plant species including Alchornea cordifolia, and Zanthoxylum chalybeum, were observed to be consistently very good between studies. These plant species should be exploited further for their antiplasmodial activity. The activities of the plants were equally observed to increase with the isolation of the active compounds thus reinforcing the need for research into identifying the active compounds of African medicinal plants. The marked difference in the antiplasmodial activity of 
the crude extract of Artemisia annua and the pure compounds points out the issue that even the compounds which show only low potency and may be discarded from the initial screen for further development may still have active components with therapeutic potential [215]. The strain of the Plasmodium used may also be another factor accounting for the inter-study variation observed; studies using chloroquine-sensitive strains of the parasite like $P$. falciparum 3D7, D6, NF54 tend to report higher antiplasmodial activity compared to studies using chloroquineresistant strains like P. falciparum W2, Dd5, K1 or D10.

This study revealed that only a few $(26.3 \%)$ of the plants demonstrated some degree of toxicity. The families hosting the most toxic plant species were Lamiaceae, Anacardiaceae, Moraceae, and Meliaceae. The most toxic plants were Azadirachta indica and Vernonia amygdalina. The former [168] is one of the few plant species that demonstrated very good antiplasmodial activity in some studies. Other plants with high toxicity but very good antiplasmodial/anti-malarial activities include Arenga engleri [25], Celtis integrifolia [52], Ficus platyhylla [50], Gutenbergia cordifolia [21], Helchrysum cymosum [97], Microglossa pyrifolia [92], Opilia celtidifolia [52], Quassia Africana [103], Rumex abyssinicus [92], Clausena anisota [157], Icacina senegalensis [171], Abutilon grandiflorum [200], and Lannea schweinfurthii [205]. The isolation of the active compounds, which has to be done, could eliminate the toxicity, if not all, to a certain degree. For example, Salvia radula crude extract (of aerial parts) has been shown to demonstrate some degree of toxicity, but betulafolientriol oxide isolated from the plant was very active with little or no toxicity against human kidney epithelial cells [120]. There was also considerable variation in the toxicity between the assay types (in vitro or in vivo). As many as $32.8 \%$ of the plants demonstrated some level of toxicity in vitro meanwhile $26.7 \%$ were toxic in vivo. Since it is customary to evaluate toxicity at the in vitro level and toxic plants are discarded before in vivo evaluation, that may explain while fewer plants were toxic in vivo. Toxicity varied within the same plant species from study to study and could be attributed to differences in the study design as well as differences in the parts of the plants used for testing. From this study, the most toxicity was observed with the leaves. Also, a relationship could be established between toxicity and antiplasmodial activity; as the activity of the plant increases, the toxicity, on the other hand, was observed to decrease. Furthermore, albino mice and Vero E6 cells were the most commonly used assays in the evaluation of toxicity. Unfortunately, the authors could nt make a meaningful relationship between the type of assay and toxicity because of the fewer studies assessing the toxicity of the medicinal plants.
This study, however, is limited in that the analyses may have been compounded by the substantial interstudy variation in the methodologies used by different independent studies for the extraction of plant material, the overall extraction yield, the diversity of extracted metabolites as well as the geographical variations in the different sites used in the plant collection. However, the study has provided important baseline data that may be exploited by researchers in the field for the discovery and development of new anti-malarial drugs.

\section{Conclusion}

This study has revealed the slothful progress in the discovery and development of new anti-malarial drugs from African medicinal plants. Despite the encouraging activities demonstrated by the plants in vitro, fewer plants have been evaluated in vivo and just one clinical trial has been conducted so far with Cochlospermum planchonii (Bixaceae). The study also revealed considerable inter-study variation in the antiplasmodial activities of the plants, however, the activity of some plants including Alchornea cordifolia, Azadirachta indica, and Zanthoxylum chalybeum was consistently very good. The study demonstrates a relationship between antiplasmodial activity and toxicity whereby the toxicity of the plants decreases as the antiplasmodial activity increases. Besides, the active compounds were identified in just a handful of the plants. Therefore, there is a need for a policy-driven approach in the discovery and development of new anti-malarial drugs to subvert the rising resistance to the frontline anti-malarial drugs in the world.

\section{Abbreviations}

PRISMA: Preferred Reporting Items for Systematic Reviews and Meta-analysis; $\mathrm{Nd}$ : Not done; Ns: Not specified; SI: Selectivity Index; LD 50 : Median lethal dose; $\mathrm{IC}_{50}$ : Half-maximal inhibitory concentration; $\mathrm{CC}_{50}$ : 50\% Cytotoxic concentration; $L_{50}$ : Lethal concentration.

\section{Supplementary Information}

The online version contains supplementary material available at https://doi. org/10.1186/s12936-021-03866-0.

Additional file 1: Table S1. In vitro and in vivo studies reporting inactive antiplasmodial or antimalarial activity. Table S2. List of active compounds identified from plants.

\section{Acknowledgements \\ I would like to express my special appreciation and thanks to Professor Dr. Wanderley de Souza for his helpful comments.}

Authors' contributions

All authors contributed equally to the study. All authors read and approved the manuscript. 


\section{Funding}

N/A.

\section{Availability of data and materials}

Not applicable.

\section{Declarations}

\section{Ethics approval and consent to participate}

Not applicable.

\section{Consent for publication}

Not applicable.

\section{Competing interests}

The authors declare that they have no competing interests.

\section{Author details}

'Department of Microbiology, Shahrekord Branch, Islamic Azad University, Shahrekord, Iran. ${ }^{2}$ Department of Biomedical Science, Faculty of Health Sciences, Regional Hospital Buea, Buea, Cameroon. ${ }^{3}$ Department of Public Health and Hygiene, Faculty of Health Sciences, University of Buea, Yaoundé, Cameroon. ${ }^{4}$ Department of Medical Laboratory Sciences, Faculty of Health Sciences, University of Buea, Yaoundé, Cameroon. ${ }^{5}$ Young Researchers and Elite Club, Shahrekord Branch, Islamic Azad University, Shahrekord, Iran. ${ }^{6}$ Department of Biomedical Sciences and Pathobiology, Center for One Health Research, Virginia Maryland College of Veterinary Medicine, Virginia Tech, 1410 Prices Fork Road, Blacksburg, VA 24061-0342, USA. ${ }^{7}$ Shahrekord Branch, Islamic Azad University, Shahrekord, Iran. ${ }^{8}$ Shahid Beheshti University of Medical Sciences, Tehran, Iran.

Received: 16 February 2021 Accepted: 27 July 2021

Published online: 25 August 2021

\section{References}

1. WHO. World malaria report 2019. Geneva: World Health Organization; 2019. Accessed on 28/06/2021 at https://www.who.int/publicationsdetail/world-malaria-report-2019.

2. Kwenti ET. Malaria and HIV coinfection in sub-Saharan Africa: prevalence, impact, and treatment strategies. Res Rep Trop Med. 2018;9:123-36.

3. Kwenti ET, Kukwah TA, Kwenti TDB, Nyassa BR, Dilonga MH, Enow-Orock $\mathrm{G}$, et al. Comparative analysis of IgG and IgG subclasses against Plasmodium falciparum MSP- $1_{19}$ in children from five contrasting bioecological zones of Cameroon. Malar J. 2019;18:16.

4. Dondorp AM, Nosten F, Yi P, Das D, Phyo AP, Tarning J, et al. Artemisinin resistance in Plasmodium falciparum malaria. N Engl J Med. 2009:361:455-67.

5. Murray CJ, Rosenfeld LC, Lim SS, Andrews KG, Foreman KJ, Haring D, et al. Global malaria mortality between 1980 and 2010: a systematic analysis. Lancet. 2012;379:413-31.

6. Nagendrappa PB, Annamalai P, Naik M, Mahajan V, Mathur A, Susanta G, et al. A prospective comparative field study to evaluate the efficacy of a traditional plant-based malaria prophylaxis. J Intercult Ethnopharmacol. 2017:6:36-41.

7. Newman DJ, Cragg GM. Natural products as sources of new drugs over the 30 years from 1981 to 2010. J Nat Prod. 2012;75:311-35.

8. Cragg GM, Grothaus PG, Newman DJ. Impact of natural products on developing new anti-cancer agents. Chem Rev. 2009;109:3012-43.

9. Willcox ML. A clinical trial of "AM", a Ugandan herbal remedy for malaria. J Public Health Med. 1999;21:318-24.

10. Suswardany DL, Sibbritt DW, Supardi S, Pardosi JF, Chang S, Adams J. A cross-sectional analysis of traditional medicine use for malaria alongside free antimalarial drugs treatment amongst adults in high-risk malaria endemic provinces of Indonesia. PLoS One. 2017;12:e0173522.

11. Ibrahima HA, Imama IA, Bellob AM, Umara U, Muhammada S, Abdullahia SA. The potential of Nigerian medicinal plants as antimalarial agent: a review. Int J Sci Technol. 2012;2:600-5.
12. Zofou D, Kuete V, Titanji VPK. Antimalarial and other antiprotozoal products from African Medicinal plants. In: Medicinal plant research in Africa: pharmacology and chemistry. Kuete V, Ed. Chapt. 17. Amsterdam, Elsevier, 2013;661-709.

13. Lawal B, Shittu OK, Kabiru AY, Jigam AA, Umar MB, Berinyuy EB, et al. Potential antimalarials from African natural products: a review. J Intercult Ethnopharmacol. 2015:4:318-43.

14. Van Wyk BE. A review of commercially important African medicinal plants. J Ethnopharmacol. 2015;176:118-34.

15. Kaur R, Kaur H. Plant derived antimalarial agents. J Med Plants Studies. 2017:5:346-63.

16. Lemma MT, Ahmed AM, Elhady MT, Ngo HT, Vu TL, Sang TK, et al. Medicinal plants for in vitro antiplasmodial activities: a systematic review of literature. Parasitol Int. 2017:66:713-20.

17. Moher D, Liberati A, Tetzlaff J, Altman DG. Preferred Reporting Items for Systematic Reviews and Meta-Analyses: the PRISMA statement. PLoS Med. 2009;6:1000097.

18. Deharo E, Bourdy G, Quenevo C, Munoz V, Ruiz G, Sauvain M. A search for natural bioactive compounds in Bolivia through multidisciplinary approach. Part V. Evaluation of the antimalarial activity of plants used by the Tacana Indians. J Ethnopharmacol. 2001;77:91-8.

19. Becker JVW, van der Merwe MM, van Brummelen AC, Pillay P, Crampton BG, Mmutlane EM, et al. In vitro anti-plasmodial activity of Dicoma anomala subsp gerrardii (Asteraceae): identification of its main active constituent, structure-activity relationship studies, and gene expression profiling. Malar J. 2011;10:295.

20. Gessler MC, Nkunya MH, Mwasumbi LB, Heinrich M, Tanner M. Screening Tanzanian medicinal plants for antimalarial activity. Acta Trop. 1994:56:65-77.

21. Koch A, Tamez P, Pezzuto J, Soejarto D. Evaluation of plants used for antimalarial treatment by the Maasai of Kenya. J Ethnopharmacol. 2005;101:95-9.

22. Clarkson C, Maharaj VJ, Crouch NR, Grace OM, Pillay P, Matsabisa MG, et al. In vitro antiplasmodial activity of medicinal plants native to or naturalised in South Africa. J Ethnopharmacol. 2004;92:177-91.

23. El Tahir A, Satti GM, Khalid SA. Antiplasmodial activity of selected Sudanese medicinal plants with emphasis on Maytenus senegalensis (Lam.) Exell. J Ethnopharmacol. 1999:64:227-33.

24. Muthaura CN, Keriko JM, Mutai C, Yenesew A, Gathirwa JW, Irungu BN, et al. Antiplasmodial potential of traditional phytotherapy of some remedies used in treatment of malaria in Meru-Tharaka Nithi County of Kenya. J Ethnopharmacol. 2015;175:315-23.

25. Prozesky EA, Meyer JJ, Louw Al. In vitro antiplasmodial activity and cytotoxicity of ethnobotanically selected South African plants. J Ethnopharmacol. 2001;76:239-45

26. Muthaura CN, Keriko JM, Mutai C, Yenesew A, Gathirwa JW, Irungu BN, et al. Antiplasmodial potential of traditional antimalarial phytotherapy remedies used by the Kwale community of the Kenyan Coast. J Ethnopharmacol. 2015;170:148-57.

27. Sanon S, Ollivier E, Azas N, Mahiou V, Gasquet M, Ouattara CT, et al. Ethnobotanical survey and in vitro antiplasmodial activity of plants used in traditional medicine in Burkina Faso. J Ethnopharmacol. 2003;86:143-7.

28. Zirihi-Guédé N, Mambu L, Guédé-Guina F, Bodo B, Grellier P. In vitro antiplasmodial activity and cytotoxicity of 33 West African plants used for treatment of malaria. J Ethnopharmacol. 2005:98:281-5.

29. Koukouikila-Koussounda F, Abena AA, Nzoungani A, Mombouli JV, Ouamba JM, Kun J, et al. In vitro evaluation of antiplasmodial activity of extracts of Acanthospermum hispidum DC (Asteraceae) and Ficus thonningii Blume (Moraceae), two plants used in traditional medicine in the Republic of Congo. Afr J Tradit Complement Altern Med. 2012;10:270-6.

30. Owuor BO, Ochanda JO, Kokwaro JO, Cheruiyot AC, Yeda RA, Okudo CA et al. In vitro antiplasmodial activity of selected Luo and Kuria medicinal plants. J Ethnopharmacol. 2012;144:779-81.

31. Malebo HM, Tanja W, Cal M, Swaleh SAM, Omolo MO, Hassanali A, et al. Antiplasmodial, anti-trypanosomal, anti-leishmanial and cytotoxicity activity of selected Tanzanian medicinal plants. Tanzan J Health Res. 2009;11:226-34.

32. Annan K, Sarpong K, Asare C, Dickson R, Amponsah Kl, Gyan B, et al. In vitro anti-plasmodial activity of three herbal remedies for malaria in 
Ghana: Adenia cissampeloides (Planch.) Harms., Termina liaivorensis A. Chev, and Elaeis guineensis Jacq. Pharmacognosy Res. 2012;4:225-9.

33. Lekana-Douki JB, Liabagui SLO, Bongui JB, Zatra R, Lebibi J, ToureNdouo FS. In vitro antiplasmodial activity of crude extracts of Tetrapleura tetraptera and Copaifera religiosa. BMC Res Notes. 2011:4:506.

34. Ahmed EHM, Nour BYM, Mohammed YG, Khalid HS. Antiplasmodial activity of some medicinal plants used in Sudanese fFolk-medicine. Environ Health Insights. 2010;4:1-6.

35. Kuria KA, Chepkwony H, Govaerts C, Roets E, Busson R, De Witte P, et al. The antiplasmodial activity of isolates from Ajuga remota. J Nat Prod. 2002;65:789-93.

36. Lasisi AA, Olayiwola MA, Balogun SA, Akinloye OA, Ojo DA. Phytochemical composition, cytotoxicity and in vitro antiplasmodial activity of fractions from Alafia barteri olive (Hook F. Icon)-Apocynaceae. J Saudi Chem Soc. 2016;20:2-6.

37. Bapela MJ, Meyer JJ, Kaiser M. In vitro antiplasmodial screening of ethnopharmacologically selected South African plant species used for the treatment of malaria. J Ethnopharmacol. 2014;156:370-3.

38. Banzouzi JT, Prado R, Menan H, Valentin A, Roumestan C, Mallie M, et al. In vitro antiplasmodial activity of extracts of Alchornea cordifolia and identification of an active constituent: ellagic acid. J Ethnopharmacol. 2002;81:399-401.

39. Mustofa, Valentin A, Benoit-Vical F, Pélissier Y, Koné-Bamba D, Mallié M. Antiplasmodial activity of plant extracts used in West African traditional medicine. J Ethnopharmacol. 2000;73:145-51.

40. Musuyu Muganza D, Fruth BI, Nzunzu Lami J, Mesia GK, Kambu $\mathrm{OK}$, Tona GL, et al. In vitro antiprotozoal and cytotoxic activity of 33 ethonopharmacologically selected medicinal plants from Democratic Republic of Congo. J Ethnopharmacol. 2012;141:301-8.

41. Abdissa D, Geleta G, Bacha K, Abdissa N. Phytochemical investigation of Aloe pulcherrima roots and evaluation for its antibacterial and antiplasmodial activities. PLoS ONE. 2017;12:e0173882.

42. Iyiola OA, Tijani AY, Lateef KM. Antimalarial activity of ethanolic stem barks extract of Alstonia boonei in mice. Asian J Biol Sci. 2011;4:235-43.

43. Zirihi-Guédé N, N'guessan K, Etien Dibié T, Grellier P. Ethnopharmacological study of plants used to treat malaria, in traditional medicine, by Bete populations of Issia (Côte d'Ivoire). J Pharm Sci Res. 2010;2:216-27.

44. Lumpu SL, Kikueta CM, Tshodi ME, Mbenza AP, Kambu OK, Mbamu BM, et al. Antiprotozoal screening and cytotoxicity of extracts and fractions from the leaves, stem barks and root barks of Alstonia congensis. J Ethnopharmacol. 2013;148:724-7.

45. Hout S, Chea A, Bun SS, Elias R, Gasquet M, Timon-David P, et al. Screening of selected indigenous plants of Cambodia for antiplasmodial activity. J Ethnopharmacol. 2006;107:12-8.

46. Lusakibanza M, Mesia G, Tona G, Karemere S, Lukuka A, Tits M, et al. In vitro and in vivo antimalarial and cytotoxic activity of five plants used in Congolese traditional medicine. J Ethnopharmacol. 2010;129:398-402.

47. Yamthe LRT, Fokou PVT, Mbouna CDJ, Keumoe R, Ndjakou BL, Djouonzo $\mathrm{PT}$, et al. Extracts from Annona muricata $\mathrm{L}$. and Annona reticulata $\mathrm{L}$. (Annonaceae) potently and selectively inhibit Plasmodium falciparum. Medicines (Basel). 2015:2:55-66.

48. Ménan H, Banzouzi J-T, Hocquette A, Pélissier Y, Blache Y, Koné M, et al. Antiplasmodial activity and cytotoxicity of plants used in West African traditional medicine for the treatment of malaria. J Ethnopharmacol. 2006:105:131-6.

49. Boyom FF, Fokou PV, Yamthe LR, Mfopa AN, Kemgne EM, Mbacham WF, et al. Potent antiplasmodial extracts from Cameroonian Annonaceae. J Ethnopharmacol. 2011;134:717-24.

50. Shuaibu MN, Wuyep PA, Yanagi T, Hirayama K, Tanaka T, Kouno I. The use of microfluorometric method for activity-guided isolation of antiplasmodial compound from plant extracts. Parasitol Res. 2008;102:1119-27.

51. Vonthron-Sénécheau C, Weniger B, Ouattara M, Bi FT, Kamenan A, Lobstein $A$, et al. In vitro antiplasmodial activity and cytotoxicity of ethnobotanically selected Ivorian plants. J Ethnopharmacol. 2003;87:221-5.

52. Sanon S, Gansane A, Ouattara LP, Traore A, OueDRaogo IN, Tiono A, et al. In vitro antiplasmodial and cytotoxic properties of some medicinal plants from western Burkina Faso. Afr J Lab Med. 2013;2:81.
53. Chukwujekwu JC, van Staden J, Smith P, Meyer JJM. Antibacterial, antiinflammatory, and antimalarial activities of some Nigerian medicinal plants. S Afr J Bot. 2005;71:316-25.

54. Kraft C, Jenett-Siems K, Siems K, Jakupovic J, Mavi S, Bienzle U, et al. In vitro antiplasmodial evaluation of medicinal plants from Zimbabwe. Phytother Res. 2003;17:123-8.

55. Boyom FF, Kemgne EM, Tepongning R, Ngouana V, Mbacham WF, Tsamo E, et al. Antiplasmodial activity of extracts from seven medicinal plants used in malaria treatment in Cameroon. J Ethnopharmacol. 2009;123:483-8.

56. Waako PJ, Katuura E, Smith P, Folb P. East African medicinal plants as a source of lead compounds for the development of new antimalarial drugs. Afr J Ecol. 2007:45:102-6.

57. Benoit F, Valentin A, Pelissier Y, Diafouka F, Marion C, Kone-Bamba D, et al. In vitro antimalarial activity of vegetal extracts used in West African traditional medicine. Am J Trop Med Hyg. 1996;54:67-71.

58. El-Tahir A, Satti GM, Khalid SA. Antiplasmodial activity of selected Sudanese medicinal plants with emphasis on Acacia nilotica. Phytother Res. 1999;13:474-8.

59. MacKinnon S1, Durst T, Arnason JT, Angerhofer C, Pezzuto J, SanchezVindas PE, et al. Antimalarial activity of tropical Meliaceae extracts and Gedunin derivatives. J Nat Prod. 1997;60:336-41.

60. Connelly MP, Fabiano E, Patel IH, Kinyanjui SM, Mberu EK, Watkins WM. Antimalarial activity in crude extracts of Malawian medicinal plants. Ann Trop Med Parasitol. 1996;90:597-602.

61. Ngwira KJ, Maharaj VJ, Mgani QA. In vitro antiplasmodial and HIV-1 neutralization activities of root and leaf extracts from Berberis holstii. J Herb Med. 2015;5:30-5.

62. Jansen O, Angenot L, Tits M, Nicolas JP, De Mol P, Nikiéma JB, et al. Evaluation of 13 selected medicinal plants from Burkina Faso for their antiplasmodial properties. J Ethnopharmacol. 2010;130:143-50.

63. Benoit-Vical F, Soh PN, Saléry M, Harguem L, Poupat C, Nongonierma R. Evaluation of Senegalese plants used in malaria treatment: focus on Chrozophora senegalensis. J Ethnopharmacol. 2008;116:43-8.

64. Ogunlanaa OO, Kimb H-S, Watayab Y, Olagunjuc JO, Akindahunsid AA, Tan NH. Antiplasmodial flavonoid from young twigs and leaves of Caesalpinia bonduc (Linn) Roxb. J Chem Pharm Res. 2015;7:931-7.

65. Weniger B, Lagnika L, Vonthron-Sénécheau C, Adjobimey T, Gbenou J, Moudachirou $\mathrm{M}$, et al. Evaluation of ethnobotanically selected Benin medicinal plants for their in vitro antiplasmodial activity. J Ethnopharmacol. 2004;90:279-84.

66. Melariri P, Campbell W, Etusim P, Smith P. Antiplasmodial properties and bioassay-guided fractionation of ethyl acetate extracts from Carica papaya leaves. J Parasitol Res. 2011;2011:104954.

67. Kayembe JS, Taba KM, Ntumba K, Tshiongo MTC, Kazadi TK. In vitro antimalarial activity of 20 quinones isolated from four plants used by traditional healers in the Democratic Republic of Congo. J Med Plant Res. 2010;4:991-4.

68. Ramalhete C, Lopes D, Mulhovo S, Rosário VE, Ferreira MJU. Antimalarial activity of some plants traditionally used in Mozambique. Workshop Plantas Medicinais e Fitoterapêuticas nos Trópicos.IICT /CCCM, 29, 30 e 31 de Outubro de 2008.

69. Tona L, Cimanga RK, Mesia K, Musuamba CT, De Bruyne T, Apers S, et al. In vitro antiplasmodial activity of extracts and fractions from seven medicinal plants used in the Democratic Republic of Congo. J Ethnopharmacol. 2004;93:27-32.

70. Gbeassor M, Kossou Y, Amegbo K, de Souza C, Koumaglo K, Denke A. Antimalarial effects of eight African medicinal plants. J Ethnopharmacol. 1989;25:115-8.

71. Afoulous S, Ferhout H, Raoelison EG, Valentin A, Moukarzel B, Couderc F, et al. Chemical composition and anticancer, antiinflammatory, antioxidant and antimalarial activities of leaf essential oil of Cedrelopsis grevei. Food Chem Toxicol. 2013;56:352-62.

72. Irungu BN, Rukunga GM, Mungai GM, Muthaura CN. In vitro antiplasmodial and cytotoxicity activities of 14 medicinal plants from Kenya. S Afr J Bot. 2007:73:204-7.

73. do Céu de Madureira M, Paula Martins A, Gomes M, Paiva J, Proença da Cunha A, do Rosário V. Antimalarial activity of medicinal plants used in 
traditional medicine in S. Tomé and Príncipe islands. J Ethnopharmacol. 2002;81:23-9.

74. Rukunga GM, Gathirwa JW, Omar SA, Muregi FW, Muthaura CN, Kirira PG, et al. Anti-plasmodial activity of the extracts of some Kenyan medicinal plants. J Ethnopharmacol. 2009;121:282-5.

75. Lacroix D, Prado S, Kamoga D, Kasenene J, Namukobe J, Krief S, et al. Antiplasmodial and cytotoxic activities of medicinal plants traditionally used in the village of Kiohima Uganda. J Ethnopharmacol. 2011;133:850-5.

76. Muregi FW, Chhabra SC, Njagi EN, Lang'at-Thoruwa CC, Njue WM, Orago AS, et al. Anti-plasmodial activity of some Kenyan medicinal plant extracts singly and in combination with chloroquine. Phytother Res. 2004;18:379-84

77. Adia MM, Emami SN, Byamukama R, Faye I, Borg-Karlson AK. Antiplasmodial activity and phytochemical analysis of extracts from selected Ugandan medicinal plants. J Ethnopharmacol. 2016;186:14-9.

78. Lamien-Meda A, Kiendrebeogo M, Compaoré M, Meda RN, Bacher M, Koenig K, et al. Quality assessment and antiplasmodial activity of West African Cochlospermum species. Phytochemistry. 2015;119:51-61.

79. Benoit F, Valentin A, Pélissier Y, Marion C, Dakuyo Z, Mallié M, et al. Antimalarial activity in vitro of Cochlospermum tinctorium tubercle extracts. Trans R Soc Trop Med Hyg. 1995;89:217-8.

80. Zofou D, Kengne ABO, Tene M. Ngemenya MN, Tane P, Titanji VP. In vitro antiplasmodial activity and cytotoxicity of crude extracts and compounds from the stem barks of Kigelia africana (Lam.) Benth (Bignoniaceae). Parasitol Res. 2011;108:1383-90.

81. Paulo A, Gomes ET, Houghton PJ. New alkaloids from Cryptolepis sanguinolenta. J Nat Prod. 1995;58:1485-91.

82. Kirby GC, Paine A, Warhurst DC, Noamese BK, Phillipson JD. In vitro and in vivo antimalarial activity of cryptolepine, a plant-derived indoloquinoline. Phytother Res. 1995;9:359-63.

83. Cimanga K, De Bruyne T, Pieters L, Vlietinck AJ, Turger CA. In vitro and in vivo antiplasmodial activity of cryptolepine and related alkaloids from Cryptolepis sanguinea. J Nat Prod. 1997;60:688-91.

84. Grellier P, Ramiaramanana L, Millerioux V, Deharo E, Schrével J, Frappier $F$, et al. Antimalarial activity of cryptolepine and isocryptolepine, alkaloids isolated from Cryptolepis sanguinolenta. Phytother Res. 1996:10:317-21.

85. Zofou D, Tematio EL, Ntie-Kang F, Tene M, Ngemenya MN, Tane P, et al. New antimalarial hits from Dacryodes edulis (Burseraceae) - Part l: Isolation, in vitro activity, in silico "drug-likeness" and pharmacokinetic profiles. PLoS ONE. 2013;8:e79544.

86. Nafuka SN, Mumbengegwi DR. Phytochemical analysis and in vitro anti-plasmodial activity of selected ethnomedicinal plants used to treat malaria associated symptoms in Northern Namibia. Int Sci Technol J Namibia. 2013;2:78-93.

87. Jansen O, Tits M, Nicolas ALJP, De Mol P, Nikiema J-B, Frédérich M. Antiplasmodial activity of Dicoma tomentosa (Asteraceae) and identification of urospermal A-15-O-acetate as the main active compound. Malar J. 2012;11:289.

88. Olasehinde $\mathrm{Gl}$, Ojurongbe $\mathrm{O}$, Adeyeba $\mathrm{AO}$, Fagade $\mathrm{OE}$, Valecha $\mathrm{N}$, Ayanda IO, et al. In vitro studies on the sensitivity pattern of Plasmodium falciparum to antimalarial drugs and local herbal extracts. Malar J. 2014;13:63.

89. Bickii J, Tchouya GRF, Tchouankeu JC, Tsamo E. Antimalarial activity in crude extracts of some Cameroonian medicinal plants. Afr J Tradit Complement Altern Med. 2007:4:107-11.

90. Liu Y, Murakami N, Ji H, Abreu P, Zhang S. Antimalarial flavonol glycosides from Euphorbiahirta. Pharm Biol. 2007;45:278-81.

91. Kaou AM, Mahiou-Leddet V, Hutter S, Aïnouddine S, Hassani S, Yahaya I, et al. Antimalarial activity of crude extracts from nine African medicinal plants. J Ethnopharmacol. 2008;116:74-83.

92. Muganga R, Angenot L, Tits M, Frédérich M. Antiplasmodial and cytotoxic activities of Rwandan medicinal plants used in the treatment of malaria. J Ethnopharmacol. 2010;128:52-7.

93. Traore-Keita F, Gasquet M, Di Giorgio C, Ollivier E, Delmas F, Keita A, et al. Antimalarial activity of four plants used in traditional medicine in Mali. Phytother Res. 2000;14:45-7.

94. Ancolio C, Azas N, Mahiou V, Ollivier E, Di Giorgio C, Keita A, et al. Antimalarial activity of extracts and alkaloids isolated from six plants used in traditional medicine in Mali and Sao Tome. Phytother Res. 2002;16:646-9.

95. Nyambati GK, Lagat ZO, Maranga RO, Samuel M, Ozwara H. In vitro anti-plasmodial activity of Rubia cordifolia, Harrizonia abyssinica, Leucas calostachys Olive and Sanchus schweinfurthii medicinal plants. J Appl Pharm Sci. 2013;3:57-62.

96. Afoulous S, Ferhout H, Raoelison EG, Valentin A, Moukarzel B, Couderc F, et al. Helichrysum gymnocephalum essential oil: chemical composition and cytotoxic, antimalarial and antioxidant activities, attribution of the activity origin by correlations. Molecules. 2011;16:8273-91.

97. Van Vuuren SF, Viljoen AM, Van Zyl RL, Van Heerden FR, Baser KHC. The antimicrobial, antimalarial and toxicity profiles of helihumulone, Leaf essential oil and extracts of Helichrysum cymosum (L.) D. Don subsp. cymosum. S Afr J Bot. 2006;72:287-90.

98. Boyom FF. Composition and anti-plasmodial activities of essential oils from some Cameroonian medicinal plants. Phytochemistry. 2003;64:1269-75.

99. Fotie J, Bohle DS, Leimanis ML, Georges E, Rukunga G, Nkengfack AE. Lupeol long-chain fatty acid esters with antimalarial activity from Holarrhena floribunda. J Nat Prod. 2006:69:62-7.

100. Sarr SO, Perrotey S, Fall I, Ennahar S, Zhao M, Diop YM, et al. Icacina senegalensis (Icacinaceae), traditionally used for the treatment of malaria, inhibits in vitro Plasmodium falciparum growth without host cell toxicity. Malar J. 2011;10:85.

101. Bickii J, Njifutie N, Foyere JA, Basco LK, Ringwald P. In vitro antimalarial activity of limonoids from Khaya grandifoliola C.D.C. (Meliaceae). J Ethnopharmacol. 2000;69:27-33.

102. Wube AA, Bucar F, Asres K, Gibbons S, Rattray L, Croft SL. Antimalarial compounds from Kniphofia foliosa roots. Phytother Res. 2005;19:472-6.

103. Mbatchi SF, Mbatchi B, Banzouzi JT, Bansimba T, Nsonde Ntandou GF, Ouamba JM, et al. In vitro antiplasmodial activity of 18 plants used in Congo Brazzaville traditional medicine. J Ethnopharmacol. 2006;104:168-74.

104. Oketch-Rabah HA, Dossaji SF, Mberu EK. Antimalarial activity of some Kenyan medicinal plants. Pharm Biol. 1999:37:329-34.

105. Ramalhete $C$, da Cruz FP, Mulhovo S, Sousa IJ, Fernandes MX, Prudêncio $M$, et al. Dual-stage triterpenoids from an African medicinal plant targeting the malaria parasite. Bioorg Med Chem. 2014;22:3887-90.

106. BenoitVical F, Valentin A, Cournac V, Pélissier Y, Mallié M, Bastide JM. In vitro antiplasmodial activity of stem and root extracts of Nauclea latifolia S.M. (Rubiaceae). J Ethnopharmacol. 1998;61:173-8.

107. Mesia K, Cimanga RK, Dhooghe L, Cos P, Apers S, Totté J, et al. Antimalarial activity and toxicity evaluation of a quantified Nauclea pobeguinii extract. J Ethnopharmacol. 2010;131:6.

108. Gbeassor M, Kedjagni AY, Koumaglo K, de Soma C, Agbo K, Aklikokou K, et al. In vitro antimalarial activity of six medicinal plants. Phytother Res. 1990:4:115-7.

109. Karim T, Béourou S, Touré AO, Ouattara K, Meité S, Ako A, et al. Antioxidant activities and estimation of the phenols and flavonoids content in the extracts of medicinal plants used to treat malaria in Ivory Coast. Int J Curr Microbiol App Sci. 2015:4:862-74.

110. Koudouvo K, Karou SD, Ilboudo DP, Kokou K, Essien K, Aklikokou K, et al. In vitro antiplasmodial activity of crude extracts from Togolese medicinal plants. Asian Pac J Trop Med. 2011;4:129-32.

111. Appiah-Opong R, Nyarko AK, Dodoo D, Gyang FN, Koram KA, Ayisi NK Antiplasmodial activity of extracts of Tridax procumbens and Phyllanthus amarus in in vitro Plasmodium falciparum culture systems. Ghana Med J. 2011:45:143-50.

112. Komlaga G, Cojean S, Dickson RA, Mehdi A, Beniddir MA, SuyyaghAlbouz S, et al. Antiplasmodial activity of selected medicinal plants used to treat malaria in Ghana. Parasitol Res. 2016;115:3185-95.

113. Falodun A, Imieje V, Erharuyi O, Ahomafor J, Jacob MR, Khan SI, et al. Evaluation of three medicinal plant extracts against Plasmodium falciparum and selected microganisms. Afr J Tradit Complement Altern Med. 2014;11:142-6.

114. François G, Aké Assi L, Holenz J, Bringmann G. Constituents of Picralima nitida display pronounced inhibitory activities against asexual erythrocytic forms of Plasmodium falciparum in vitro. J Ethnopharmacol. 1996:54:113-7. 
115. Gbedema SY, Bayor MT, Annan K, Wright CW. Clerodane diterpenes from Polyalthia longifolia (sonn.) Thw. Var. Pendula: potential antimalarial agents for drug resistant Plasmodium falciparum infection. J Ethnopharmacol. 2015;169:176-82.

116. Annan K, Ekuadzi E, Asare C, Sarpong K, Pistorius D, Oberer L, et al. Antiplasmodial constituents from the stem barks of Polyalthia longifolia var pendula. Phytochem Lett. 2015;11:28-31.

117. Orwa JA, Ngeny L, Mwikwabe NM, Ondicho J, Jondiko IJ. Antimalarial and safety evaluation of extracts from Toddalia asiatica (L) Lam. (Rutaceae). J Ethnopharmacol. 2013;145:587-90.

118. Karou D, Dicko MH, Sanon S, Simpore J, Traore AS. Antimalarial activity of Sida acuta Burm. F. (Malvaceae) and Pterocarpus erinaceus Poir. (Fabaceae). J Ethnopharmacol. 2003;89:291-4.

119. Muregi FW, Chhabra SC, Njagi EN, Lang'at-Thoruwa CC, Njue WM, Orago AS, et al. In vitro antiplasmodial activity of some plants used in Kisii, Kenya against malaria and their chloroquine potentiation effects. J Ethnopharmacol. 2003;84:235-9.

120. Kamatou GPP, Van Zyl RL, Davids H, Van Heerden FR, Lourens ACU, Viljoen AM. Antimalarial and anticancer activities of selected South African Salvia species and isolated compounds from S. radula. S Afr J Bot. 2008;74:238-43.

121. Bah S, Jäger AK, Adsersen A, Diallo D, Paulsen BS. Antiplasmodial and GABA(A)-benzodiazepine receptor binding activities of five plants used in traditional medicine in Mali. West Africa J Ethnopharmacol. 2007;110:451-7.

122. Carraz M, Jossang A, Franetich J-F, Siau A, Ciceron L, Hannoun L, et al. A plant-derived morphinan as a novel lead compound active against malaria liver stages. PLoS Med. 2006;3:e513.

123. Niass O, Sarr SO, Dieye B, Diop A, Diop YM. In vitro assessment of the antiplasmodial activity of three extracts used in local traditional medicine in Saloum (Senegal). Eur Sci J. 2016;12:157-65.

124. Kigondu EV, Rukunga GM, Keriko JM, Tonui WK, Gathirwa JW, Kirira PG, et al. Anti-parasitic activity and cytotoxicity of selected medicinal plants from Kenya. J Ethnopharmacol. 2009;123:504-9.

125. Gakunju DM, Mberu EK, Dossaji SF, Gray Al, Waigh RD, Waterman PG, et al. Potent antimalarial activity of the alkaloid nitidine, isolated from a Kenyan herbal remedy. Antimicrob Agents Chemother. 1995;39:2606-9.

126. Omoregie ES, Pal A, Sisodia B. In vitro antimalarial and cytotoxic activities of leaf extracts of Vernonia amygdalina (Del.). Niger J Basic Appl Sci. 2011;19:121-6.

127. Shaa KK, Oguche S, Watila IM, Ikpa TF. In vitro antimalarial activity of the extracts of Vernonia amygdalina commonly used in traditional medicine in Nigeria. Sci World J. 2011;6:5-9.

128. Toyang NJ, Krause MA, Fairhurst RM, Tane P, Bryant J, Verpoorte R. Antiplasmodial activity of sesquiterpene lactones and a sucrose ester from Vernonia guineensis Benth (Asteraceae). J Ethnopharmacol. 2013;147:618-21.

129. Goodman CD, Austarheim I, Mollard V, Mikolo B, Malterud KE, McFadden Gl, et al. Natural products from Zanthoxylum heitzii with potent activity against the malaria parasite. Malar J. 2016;15:481.

130. Randrianarivelojosia M, Rasidimanana VT, Rabarison H, Cheplogoi PK, Ratsimbason M, Mulholland DA, et al. Plants traditionally prescribed to treat tazo (malaria) in the eastern region of Madagascar. Malar J. 2003;2:25.

131. Okokon JE, Augustine NB, Mohanakrishnan D. Antimalarial, antiplasmodial and analgesic activities of root extract of Alchornea laxiflora. Pharm Biol. 2017;55:1022-31.

132. Alli LA, Adesokan AA, Salawu OA, Akanji MA, Tijani AY. Anti-plasmodial activity of aqueous root extract of Acacia nilotica. Afr J Biochem Res. 2011;5:214-9.

133. Jigam AA, Akanya HO, Dauda BEN, Okogun JO. Polygalloyltannin isolated from the roots of Acacia nilotica Del. (Leguminoseae) is effective against Plasmodium berghei in mice. J Med Plant Res. 2010;4:1169-75.

134. Adeoye AO, Bewaji CO. Chemopreventive, and remediation effect of Adansonia digitata $\mathrm{L}$ Baobab (Bombacaceae) stem barks extracts in mouse model malaria. J Ethnopharmacol. 2018;210:31-8.

135. Musila MF, Dossaji SF, Nguta JM, Lukhoba CW, Munyao JM. In vivo antimalarial activity, toxicity and phytochemical screening of selected antimalarial plants. J Ethnopharmacol. 2013;146:557-61.

136. Ukwe VC, Epueke EA, Ekwunife Ol, Okoye TC, Akudor GC, Ubaka CM. Antimalarial activity of aqueous extract and fractions of leaves of
Ageratum conyzoides in mice infected with Plasmodium berghei. Int J Pharm Sci. 2010;2:33-8.

137. Rukunga GM, Muregi FW, Tolo FM, Omar SA, Mwitari P, Muthaura CN, et al. The antiplasmodial activity of spermine alkaloids isolated from Albizia gummifera. Fitoterapia. 2007;78:455-9.

138. Oladosu IA, Balogun SO, Ademowo GO. Phytochemical screening, antimalarial and histopathological studies of Allophylus africanus and Tragia benthamii. Chin J Nat Med. 2013;11:371-6.

139. Teka T, Bisrat D, Yeshak MY, Asres K. Antimalarial activity of the chemical constituents of the leaves latex of Aloe pulcherrima Gilbert and Sebsebe. Molecules. 2016;21:1415.

140. Akpan EJ, Okokon JE, Etuk IC. Antiplasmodial and antipyretic studies on root extracts of Anthocleista djalonensis against Plasmodium berghei. Asian Pac J Trop Dis. 2012:2:36-42.

141. Ene AC, Ameh DA, Kwanashie HO, Agomo PU, Atawodi SE. Preliminary in vivo antimalarial screening of petroleum ether, chloroform, and methanol extracts of fifteen plants grown in Nigeria. J Pharmacol Toxicol. 2008;3:254-60.

142. Christian AG, Mfon AG, Dick EA, David-Oku E, Akpan JL, Chukwuma EB. Antimalarial potency of the leaf extract of Aspilia africana (Pers.) C.D. Adams. Asian Pac J Trop Med. 2012;2:126-9.

143. Gathirwa JW, Rukunga GM, Mwitari PG, Mwikwabe NM, Kimani CW, Muthaura CN, et al. Traditional herbal antimalarial therapy in Kilifi district. Kenya J Ethnopharmacol. 2011;134:434-42.

144. Tepongning RN, Mbah JN, Avoulou FL, Jerme MM, Ndanga EKK, Fekam FB. Hydroethanolic extracts of Erigeron floribundus and Azadirachta indica reduced Plasmodium berghei parasitemia in Balb/c mice. Evid Based Complement Alternat Med. 2018;2018:5156710.

145. Akin-Osanaiye BC, Nok AJ, Ibrahim S, Inuwa HM, Onyike E, Amlabu E, et al. Antimalarial effect of neem leaves and neem stem barks extracts on Plasmodium berghei infected in the pathology and treatment of malaria. Int J Res Biochem Biophy. 2013;3:7-14.

146. Asrade $S$, Mengesha Y, Moges G, Gelayee DA. In vivo antiplasmodial activity evaluation of the leaves of Balanites rotundifolia (Van Tiegh) Blatter (Balanitaceae) against Plasmodium berghei. J Exp Pharmacol. 2017:9:59-66.

147. Otegbade OO, Ojo JA, Adefokun DI, Abiodun OO, Thomas BN, Ojurongbe $\mathrm{O}$. Ethanol extract of Blighia sapida stem barks show remarkable prophylactic activity in experimental Plasmodium berghei-infected mice. Drug Target Insights. 2017;11:1177392817728725.

148. Christian AG, Thecla EC, Dick EA, Chile AE, Chimsorom CK, Ckukwu ND, et al. In vivo antiplasmodial activity of Bombax buonopozense root barks aqueous extract in mice infected by Plasmodium berghei. J Tradit Chin Med. 2017;37:431-5.

149. Muluye AB, Melese E, Adinew GM. Antimalarial activity of $80 \%$ methanolic extract of Brassica nigra (L.) Koch. (Brassicaceae) seeds against Plasmodium berghei infection in mice. BMC Compl Alternative Med. 2015;15:367.

150. Eyasu M, Shibeshi W, Gida M. In vivo antimalarial activity of hydromethanolic leaf extract of Calpurnia aurea (Fabaceae) in mice infected with chloroquine-sensitive Plasmodium berghei. Int J Pharmacol. 2013;2:131-42.

151. Onaku LO, Attama AA, Okore VC, Tijani AY, Ngene AA, Esimone CO. Antagonistic antimalarial properties of pawpaw leaf aqueous extract in combination with artesunic acid in Plasmodium berghei-infected mice. J Vector Borne Dis. 2011;48:96-100

152. Tona L, Mesia K, Ngimbi NP, Chrimwami B, Okondahoka, Cimanga K, et al. In vivo antimalarial activity of Cassia Occidentalism, Morinda morindoides and Phyllanthus niruri. Ann Trop Med Parasit. 2001;95:47-57.

153. Abdulrazak N, Asiya UI, Usman NS, Unata IM, Farida A. Anti-plasmodial activity of ethanolic extract of root and stem bark of Cassia sieberiana DC on mice. J Intercult Ethnopharmacol. 2015:4:96-101.

154. Adzu B, Abbah J, Vongtau H, Gamaniel K. Studies on the use of Cassia singueana in malaria ethnopharmacy. J Ethnopharmacol. 2003;88:261-7

155. Jigam AA, Razaq UTA, Egbuta MN. In vivo antimalarial and toxicological evaluation of Chrozophora senegalensis A. Juss (Euphorbiaceae) extracts. J Appl Pharm Sci. 2011;1:90-4.

156. Ihekwereme CP, Okoye FK, Agu SC, Oli AN. Traditional consumption of the fruit pulp of Chrysophyllum albidum (Sapotaceae) in pregnancy may 
be serving as an intermittent preventive therapy against malaria infection. Anc Sci Life. 2017;36:191-5.

157. Okokon JE, Etebong EO, Udobang JA, Essien GE. Antiplasmodial and analgesic activities of Clausena anisate. Asian Pac J Trop Med. 2012:5:214-9.

158. Anato M, Ketema T. Anti-plasmodial activities of Combretum molle (Combretaceae) [Zwoo] seed extract in Swiss albino mice. BMC Res Notes. 2018;11:312.

159. Kweyamba PA, Zofou D, Efange N, Assob JN, Kitau J, Nyindo M. In vitro and in vivo studies on antimalarial activity of Commiphora africana and Dichrostachys cinerea used by the Maasai in Arusha region. Tanzania Malar J. 2019;18:119.

160. Elufioye TO, Agbedahunsi JM. Antimalarial activities of Tithonia diversifolia (Asteraceae) and Crossopteryx febrifuga (Rubiaceae) on mice in vivo. Ethnopharmacol. 2004;93:167-71.

161. Obey JK, Ngeiywa MM, Kiprono P, Omar S, vonWright A, Kauhanen J, et al. Antimalarial activity of Croton macrostachyus stem barks extracts against Plasmodium berghei in vivo. J Pathog. 2018;2018:393854.

162. Tona Ngimbi NP, Tsakala M, Mesia K, Cimanga K, Apers S, De Bruyne T, et al. Antimalarial activity of 20 crude extracts from nine African medicinal plants used in Kinshasa Congo. J Ethnopharmacol. 1999;68:193-203.

163. Mzena T, Swai H, Chacha M. Antimalarial activity of Cucumis metuliferus and Lippia kituiensis against Plasmodium berghei infection in mice. Res Rep Trop Med. 2018;9:81-8.

164. Amelo W, Nagpal P, Makonnen E. Antiplasmodial activity of solvent fractions of methanolic root extract of Dodonaea angustifolia in Plasmodium berghei infected mice. BMC Complement Altern Med. 2014;14:462.

165. Ogbonna DN, Sokari TG, Agomuoh AA. Antimalarial activities of some selected traditional herbs from South Eastern Nigeria against Plasmodium species. Res J Parasit. 2008;3:25-31.

166. Gounoue Kamkumo R, Tsakem Nangap JM, Tchokouaha Yamthe LR, Ngueguim Tsofack F, Tsouh Fokou PV, Tchatat Tali MB, et al. Antimalarial activity of the aqueous extract of Euphorbia cordifolia Elliot in Plasmodium berghei-infected mice. Asian Pac J Trop Med. 2020;13:176-84.

167. Oluwakanyinsola AS, Adeniyi YT, Babayi H, Angela CN, Anagbogu RA, Agbakwuru VA. Antimalarial activity of ethanolic stem barks extract of Faidherbia albida (Del) a Chev (Mimosoidae) in mice. Arch Appl Sci Res. 2010;2:261-8

168. Nguta JM, Mbaria JM. Brine shrimp toxicity and antimalarial activity of some plants traditionally used in treatment of malaria in Msambweni district of Kenya. J Ethnopharmacol. 2013;148:988-92.

169. Oluwatosin A, Tolulope A, Ayokulehin K, Okorie P, Aderemi K, Falade C, et al. Antimalarial potential of kolaviron, a biflavonoid from Garcinia kola seeds, against Plasmodium berghei infection in Swiss albino mice. Asian Pac J Trop Med. 2014;7:97-104

170. Okokon JE, Ita BN, Udokpoh AE. The in vivo antimalarial activities of Uvariae chamae and Hippocratea africana. Ann Trop Med Parasitol. 2006;100:585-90.

171. David-Oku E, Ifeoma OO, Christian AG, Dick EA. Evaluation of the antimalarial potential of Icacina senegalensis Juss (Icacinaceae). Asian Pac J Trop Med. 2014:7:S469-72.

172. Birru EM, Geta M, Gurmu AE. Antiplasmodial activity of Indigofera spicata root extract against Plasmodium berghei infection in mice. Malar J. 2017;16:198

173. Onyeto CA, Akah PA, Nworu CS, Okoye TC, Okorie NA, Mbaoji FN, et al. Anti-plasmodial and antioxidant activities of methanol extract of the fresh leaves of Lophira lanceolata (Ochnaceae). Afr J Biotechnol. 2014:13:1731-8.

174. Christian AG, Akanimo EG, Ahunna AG, Nwakaego EM, Chimsorom CK. Antimalarial potency of the methanol leaf extract of Maerua crassifolia Forssk (Capparaceae). Asian Pac J Trop Dis. 2014;4:35-9.

175. Malebo HM, Tanja W, Cal M, Swaleh SAM, Omolo MO, Hassanali A, et al. Antiplasmodial, anti-trypanosomal, anti-leishmanial and cytotoxicity activity of selected Tanzanian medicinal plants. Tanzan J Health Res. 2015:4:226-34.

176. Okafor Al, Nok AJ, Inuwa HM. Antiplasmodial activity of aqueous leaf extract of Mucuna Pruriens Linn in mice infected with Plasmodium berghei (NK-65 Strain). J Appl Pharm Sci. 2013;3(4 Suppl 1):S52-5.

177. Edagha IA, Peter Al, Aquaisua AN. Histopathological effect of Nauclea latifolia ethanolic leaf extract and artemether/lumefantrine on the hippocampus of P berghei-infected mice. Int J Brain Cognitive Sci. 2017;6:9-16.

178. Nworu CS, Ejikeme TI, Ezike AC, Ndu O, Akunne TC, Onyeto CA, et al. Anti-plasmodial and anti-inflammatory activities of cyclotide-rich extract and fraction of Oldenlandia affinis (R.\& S.) D.C. (Rubiaceae). Afri Health Sci. 2017;17:827-43.

179. Ramanitrahasimbola D, Rasoanaivo P, Ratsimamanga-Urverg S, Federici E, Palazzino G, Galeffi C, et al. Biological activities of the plant-derived bisindole voacamine with reference to malaria. Phytother Res. 2001;15:30-3

180. Ajala TO1, Igwilo Cl, Oreagba IA, Odeku OA. The antiplasmodial effect of the extracts and formulated capsules of Phyllanthus amarus on Plasmodium yoelii infection in mice. Asian Pac J Trop Med. 2011;4:283-7.

181. Ifeoma O, Samuel O, Itohan AM, Adeola SO. Isolation, fractionation and evaluation of the antiplasmodial properties of Phyllanthus niruri resident in its chloroform fraction. Asian Pac J Trop Med. 2013;6:169-75.

182. Adinew GM. Antimalarial activity of methanolic extract of Phytolacca dodecandra leaves against Plasmodium berghei infected Swiss albino mice. Int J Pharmacol Clin Sci. 2014;3:39-45.

183. Okokon JE, Antia BS, Igboasoiyi AC, Essien EE, Mbagwu HO. Evaluation of antiplasmodial activity of ethanolic seed extract of Picralima nitida.J Ethnopharmacol. 2007;111:464-7.

184. Madara AA, Ajayi JA, Salawu OA, Tijani AY. Antimalarial activity of ethanolic leaf extract of Piliostigma thonningii Schum (Caesalpiniacea) in mice infected with Plasmodium berghei berghei. Afr J Biotechnol. 2010;9:3475-80

185. Christian AG, Ahunna AG, Nwakaego EM, Chimsorom CK, Chile AE. Antimalarial potential of the ethanolic leaf extract of Pseudocedrala kotschyi. J Acute Dis. 2015:4:23-7.

186. Okokon JE, Ettebong E, Antia BS. In vivo antimalarial activity of ethanolic leaf extract of Stachytarpheta cavennensis. Indian J Pharmacol. 2008:40:111-3.

187. Adegbolagun OM, Emikpe BO, Woranola IO, Ogunremi Y. Synergistic effect of aqueous extract of Telfaria occidentalis on the biological activities of artesunate in Plasmodium berghei infected mice. Afr Health Sci. 2013;13:970-6

188. Muregi FW, Ishih A, Miyase T, Suzuki T, Kino H, Amano T, et al. Antimalarial activity of methanolic extracts from plants used in Kenyan ethnomedicine and their interactions with chloroquine (CQ) against a CQtolerant rodent parasite, in mice. J Ethnopharmacol 2007:111:190-5.

189. Olanlokun JO, Oluwole MD, Afolayan AJ. In vitro antiplasmodial activity and prophylactic potentials of extract and fractions of Trema orientalis (Linn.) stem barks. BMC Complement Altern Med. 2017;17:407.

190. Fadare DA, Abiodun OO, Ajaiyeoba EO. In vivo antimalarial activity of Trichilia megalantha harms extracts and fractions in animal models. Parasitol Res. 2013;112:2991-5.

191. François G, Steenackers T, Timperman G, Aké Assi L, Haller RD, Bär S, et al. Retarded development of exoerythrocytic stages of the rodent malaria parasite Plasmodium berghei in human hepatoma cells by extracts from dioncophyllaceae and ancistrocladaceae species. Int $J$ Parasitol. 1997:27:29-32

192. Akuodor GC, Idris-Usman M, Anyalewechi N, Odo E, Ugwu CT, Akpan $\mathrm{J}$, et al. In vivo antimalarial activity of ethanolic leaf extract of Verbena hastata against Plasmodium berghei in mice. J Herb Med Toxicol. 2010:4:17-23.

193. Njan AA, Adzu B, Agaba AG, Byarugaba D, Díaz-Llera S, Bangsberg DR. The analgesic and antiplasmodial activities and toxicology of Vernonia amygdalina. J Med Food. 2008;11:574-81.

194. Iwalokun BA. Enhanced antimalarial effects of chloroquine by aqueous Vernonia amygdalina leaf extract in mice infected with chloroquine resistant and sensitive Plasmodium berghei strains. Afr Health Sci. 2008:8:25-35

195. Abosi AO, Raseroka BH. In vivo antimalarial activity of Vernonia amygdalina. Br J Biomed Sci. 2003:60:89-91.

196. Dame ZT, Petros B, Mekonnen Y. Evaluation of anti-Plasmodium berghei activity of crude and column fractions of extracts from Withania somnifera. Turk J Biol. 2013;37:147-50.

197. Adugna M, Feyera T, Taddese W, Admasu P. In vivo antimalarial activity of crude extract of aerial part of Artemisia abyssinica against Plasmodium berghei in mice. Glob J Pharmacol. 2014;8:460-8. 
198. Deressa T, Mekonnen Y, Animut A. In vivo antimalarial activities of Clerodendrum myricoides, Dodonea angustifolia, and Aloe debrana against Plasmodium berghei. Ethiop J Health Dev. 2010;24:25-9.

199. Muthaura CN, Rukunga GM, Chhabra SC, Omar SA, Guantai AN, Gathirwa JW, et al. Antimalarial activity of some plants traditionally used in treatment of malaria in Kwale district of Kenya. J Ethnopharmacol. 2007;112:545-51.

200. Beha E, Jung A, Wiesner J, Rimpler H, Lanzer M, Heinrich M. Antimalarial activity of extracts of Abutilon grandiflorum G Don - a traditional Tanzanian medicinal plant. Phytother Res. 2004;18:236-40.

201. Ajaiyeoba EO, Abiodun OO, Falade MO, Ogbole NO, Ashidi JS, Happi CT, et al. In vitro cytotoxicity studies of 20 plants used in Nigerian antimalarial ethnomedicine. Phytomedicine. 2006;13:295-8.

202. Adebayo JO, Balogun EA, Malomo SO, Soladoye AO, Olatunji LA, Kolawole OM, et al. Antimalarial activity of Cocos nucifera Husk fibre: further studes. Evid Based Complement Altern Med. 2013:2013:742476.

203. Falade MO, Akinboye DO, Gbotosho GO, Ajaiyeoba EO, Happi TC, Abiodun $\mathrm{OO}$, et al. In vitro and in vivo antimalarial activity of Ficus thonningii Blume (Moraceae) and Lophira alata Banks (Ochnaceae), identified from the ethnomedicine of the Nigerian middle belt. J Parasit Res. 2014;2014:972853

204. Iwalewa EO, Omisore NO, Adewunmi CO, Gbolade AA, Ademowo OG, Nneji C, et al. Anti-protozoan activities of Harungana madagascariensis stem barks extract on trichomonads and malaria. J Ethnopharmacol. 2008;117:507-11.

205. Gathirwa JW, Rukunga GM, Njagi EN, Omar SA, Mwitari PG, Guantai $\mathrm{AN}$, et al. The in vitro anti-plasmodial and in vivo antimalarial efficacy of combinations of some medicinal plants used traditionally for treatment of malaria by the Meru community in Kenya. J Ethnopharmacol. 2008;115:223-31.

206. Simelane MBC, Shonhai A, Shode FO, Smith P, Singh M, Opoku AR. Anti-plasmodial activity of some Zulu medicinal plants and of some triterpenes isolated from them. Molecules. 2013;18:12313.

207. Steele JC, Warhurst DC, Kirby GC, Simmonds MSJ. In vitro and in vivo evaluation of betulinic acid as an antimalarial. Phytother Res. 1999:13:115-9.

208. Builders MI, Wannang NN, Ajoku GA, Builders PF, Orisadipe A, Aguiyi JC. Evaluation of the antimalarial potential of Vernonia ambigua Kotschy and Peyr (Asteraceae). Int J Pharmacol. 2011;7:238-47.

209. Ngbolua KN, Rakotoarimanana H, Rafatro H, Ratsimamanga US, Mudogo V, Mpiana PT, et al. Comparative antimalarial and cytotoxic activities of two Vernonia species: Vernonia amygdalina from the Democratic Republic of Congo and Vernonia cinerea subsp vialis endemic to Madagascar. Int J Biol Chem Sci. 2011;5:345-53.

210. Benoit-Vical F, Imbert C, Bonfils JP, Sauvaire Y. Antiplasmodial and antifungal activities of iridal, a plant triterpenoid. Phytochemistry. 2003:62:747-51.

211. Applequist WL, Ratsimbason M, Kuhlman A, Ratonandrasana S, Rasamison V, Kingston DG. Antimalarial use of Malagasy plants is poorly correlated with performance in antimalarial bioassays. Econ Bot. 2017;71:75-82.

212. Thiengsusuk A, Chaijaroenkul W, NaBangchang K. Antimalarial activities of medicinal plants and herbal formulations used in Thai traditional medicine. Parasitol Res. 2013;112:1475.

213. Udobang JA, Nwafor PA, Okokon JE. Analgesic and antimalarial activities of crude leaf extract and fractions of Acalypha wilkensiana. J Ethnopharmacol. 2010;127:373-8.

214. Mohammed T, Erko B, Giday M. Evaluation of antimalarial activity of leaves of Acokanthera schimperi and Croton macrostachyus against Plasmodium berghei in Swiss albino mice. Compl Altern Med. 2014;14:314.

215. Kuria KA, De Coster S, Muriuki G, Masengo W, Kibwage I, Hoogmartens $J$, et al. Antimalarial activity of Ajuga remota Benth (Labiatae) and Caesalpinia Volkensii Harms (Caesalpiniaceae): in vitro confirmation of ethnopharmacological use. J Ethnopharmacol. 2001;74:141-8.

216. Mesfin A, Giday M, Animut A, Teklehaymanot T. Ethnobotanical study of antimalarial plants in Shineile District, Somali Region, Ethiopia, and in vivo evaluation of selected ones against Plasmodium berghei. J Ethnopharmacol. 2012;139:221-7.

217. Hilou A, Nacoulma OG, Guiguemde TR. In vivo antimalarial activities of extracts from Amaranthus spinosus L. and Boerhaavia erecta L. in mice. J Ethnopharmacol. 2006:103:236-40.
218. Adebajo AC, Odediran SA, Aliyu FA, Nwafor PA, Nwoko NT, Umana US In vivo antiplasmodial potentials of the combinations of four Nigerian antimalarial plants. Molecules. 2014:19:13136-46.

219. Dikasso D, Mekonnen E, Debella A, Abebe D, Urga K, Menonnen W, et al. In vivo antimalarial activity of hydroalcoholic extracts from Asparagus africanus Lam in mice infected with Plasmodium berghei. Ethiop J Health Dev. 2006:20:112-8.

220. Yerbanga RS, Lucantoni L, Lupidi G, Dori GU, Tepongning NR, Nikiéma $\mathrm{JB}$, et al. Antimalarial plant remedies from Burkina Faso: their potential for prophylactic use. J Ethnopharmacol. 2012;140:255-60.

221. Karou SD, Tchacondo T, Ouattara L, Anani K, Savadogo A, Agbonon A, et al. Antimicrobial, antiplasmodial, haemolytic and antioxidant activities of crude extracts from three selected Togolese medicinal plants. Asian Pac J Trop Med. 2011;4:808-13.

222. Bonkian LN, Yerbanga RS, Koama B, Soma A, Cisse M, Valea I, et al. In vivo antiplasmodial activity of two Sahelian plant extracts on Plasmodium berghei ANKA infected NMRI mice. Evid Based Complement Alternat Med. 2018:24:6859632

223. Ajaiyeoba E, Ashidi J, Abiodun O, Okpako L, Ogbole O, Akinboye D, et al. Antimalarial ethnobotany: in vitro antiplasmodial activity of seven plants indentified in the Nigerian middle belt. Pharm Biol. 2005;42:588-91.

224. Kefe A, Giday M, Mamo H, Erko B. Antimalarial properties of crude extracts of seeds of Brucea antidysenterica and leaves of Ocimum lamiifolium. BMC Complement Altern Med. 2016;16:118.

225. Innocent E, Moshi MJ, Masimba PJ, Mbwambo ZH, Kapingu MC, Kamuhabwa A. Screening of traditionally used plants for in vivo antimalarial activity in mice. Afr J Tradit Complement Altern Med. 2009;6:163-7.

226. Mengiste B, Mekonnen E, Urga K. In vivo animalarial activity of Dodonaea angustifolia seed extracts against Plasmodium berghei in mice model. MEJS. 2012:4:147-63.

227. Biruksew A, Zeynudin A, Alemu Y, Golassa L, Yohannes M, Debella A, et al. Zingiber officinale Roscoe and Echinops kebericho Mesfin showed antiplasmodial activities against Plasmodium berghei in a dose-dependent manner in Ethiopia. Ethiop J Health Sci. 2018;28:655.

228. Agbaje EO, Onabanjo AO. The effects of extracts of Enantia chlorantha in malaria. Ann Trop Med Parasitol. 1991;85:585-90.

229. Ajayi EIO, Adelekeb MA, Adewumia TY, Adeyemia AA. Antiplasmodial activities of ethanol extracts of Euphorbia hirta whole plant and Vernonia amygdalina leaves in Plasmodium berghei-infected mice. J Taibah Univ Sci. 2017;11:831-5.

230. Omole AR, Malebo MH, Nondo SOR, Katani S, Mbugi H, Midiwo J, et al. In vivo anti-plasmodial activity of crude extracts of three medicinal plants used traditionally for malaria treatment in Kenya. Eur J Med Plants. 2018;24:1-7

231. Nureye D, Assefa S, Nedi T, Engidawork E. In vivo antimalarial activity of the $80 \%$ methanolic root barks extract and solvent fractions of Gardenia ternifolia Schumach \& Thonn (Rubiaceae) against Plasmodium berghei. Evid Based Complement Alternat Med. 2018;2018:9217835.

232. Beaufay C, Hérent MF, Quetin-Leclercq J, Bero J. In vivo antimalarial activity and toxicity studies of triterpenic esters isolated from Keetia leucantha and crude extracts. Malar J. 2017;16:406.

233. Bankole AE, Adekunle AA, Sowemimo AA, Umebese CE, Abiodun O, Gbotosho GO. Phytochemical screening and in vivo antimalarial activity of extracts from three medicinal plants used in malaria treatment in Nigeria. Parasitol Res. 2016;115:299-305.

234. Jansen O, Tchinda AT, Loua J, Esters V, Cieckiewicz E, Ledoux A. Antiplasmodial activity of Mezoneuron benthamianum leaves and identification of its active constituents. J Ethnopharmacol. 2017;203:20-6

235. Udobre AS, Udobang JA, Udoh AE, Anah VU, Akpan AE, Charles GE. Effect of methanol leaf extract of Nauclea latifolia on albino mice infected with Plasmodium berghei berghei. Afr J Pharmacol Ther. 2013;2:83-7.

236. Mesia K, Tona L, Mampunza MM, Ntamabyaliro N, Muanda T, Muyembe T, et al. Antimalarial efficacy of a quantified extract of Nauclea pobeguinii stem barks in human adult volunteers with diagnosed uncomplicated falciparum malaria .Part 2: a clinical phase IIB trial. Planta Med. 2012;78:853-60.

237. Okeola VO, Adaramoye OA, Nneji CM, Falade CO, Farombi EO, Ademowo OG. Antimalarial and antioxidant activities of methanolic extract 
of Nigella sativa seeds (black cumin) in mice infected with Plasmodium yoelii nigeriensis. Parasitol Res. 2011;108:1507-12.

238. Girma S, Giday M, Erko B, Mamo H. Effect of crude leaf extract of Osyris quadripartita on Plasmodium berghei in Swiss albino mice. BMC Complement Alternative Med. 2015;15:184.

239. Kabiru AY, Ibikunle GF, Innalegwu DA, Bola BM, Madaki FM. In vivo antiplasmodial and analgesic effect of crude ethanol extract of Piper guineense leaf extract in Albino Mice. Scientifica (Cairo). 2016: 8687313

240. Hiben MG, Sibhat GG, Fanta BS, Gebrezgi HD, Tesema SB. Evaluation of Senna singueana leaf extract as an alternative or adjuvant therapy for malaria. J Tradit Complement Med. 2015;6:112-7.

241. Tadesse SA, Wubneh ZB. Antimalarial activity of Syzygium guineense during early and established Plasmodium infection in rodent models. BMC Complement Alternative Med. 2017;17:21.

242. Adepiti AO, Iwalewa EO. Evaluation of the combination of Uvaria chamae (P Beauv) and amodiaquine in murine malaria. J Ethnopharmacol. 2016;193:30-5.
243. Masaba SC. The antimalarial activity of Vernonia amygdalina Del (Compositae). Trans R Soc Trop Med Hyg. 2000:94:694-5.

244. Omoregie ES, Pal A. Antiplasmodial, antioxidant and immunomodulatory activities of ethanol extract of Vernonia amygdalina del. leaves in Swiss mice. Avicenna J Phytomed. 2016;6:236-7.

245. Challand S, Willcox M. A Clinical trial of the traditional medicine Vernonia amygdalina in the treatment of uncomplicated Malaria. J Altern Complement Med. 2009;15:1231-7.

246. Ajayi BB, Ogunsola JO, Olatoye Ol, Antia RE, Agbedea S. Effects of pituitary extract, ovaprim, and bitter leaves (Vernonia amygdalina) on the histopathology of African catfish (Clarias gariepinus) Aquacult. Fish. 2018;3:232-7.

\section{Publisher's Note}

Springer Nature remains neutral with regard to jurisdictional claims in published maps and institutional affiliations.
Ready to submit your research? Choose BMC and benefit from:

- fast, convenient online submission

- thorough peer review by experienced researchers in your field

- rapid publication on acceptance

- support for research data, including large and complex data types

- gold Open Access which fosters wider collaboration and increased citations

- maximum visibility for your research: over $100 \mathrm{M}$ website views per year

At BMC, research is always in progress.

Learn more biomedcentral.com/submissions 